\title{
Funktionale Bedeutung der Protein-Protein Interaktion zwischen dem Tabak Ankyrin-Repeat Protein ANK1 und dem bZIP-Transkriptionsfaktor BZI-1 im Rahmen der pflanzlichen Auxin- und Pathogenantwort
}

\author{
Dissertation \\ zur Erlangung des Doktorgrades \\ der Mathematischen-Naturwissenschaftlichen Fakultät \\ der Georg-August-Universität zu Göttingen
}

vorgelegt von

Stefan Böttner

aus Eschwege

Göttingen, 2007 
D7

Referent:

PD Dr. W. Dröge-Laser

Korreferent:

Prof. Dr. C. Gatz

Tag der mündlichen Prüfung: $\quad$ 01. November 2007 
Die Wirklichkeit bleibt stets hinter dem Erträumten zurück.

Ralph Waldo Emerson 


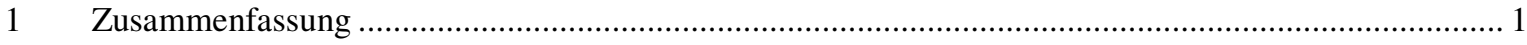

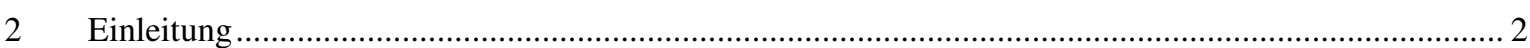

2.1 Der bZIP-Transkriptionsfaktor BZI-1 aus Nicotiana tabacum ............................................. 2

2.2 Die Auxin vermittelte transkriptionelle Kontrolle .............................................................. 5

2.3 Die BZI-1 Interaktionspartner BZI-2, BZI-3 und BZI-4 ................................................ 7

$2.4 \quad$ BZI-1 interagiert mit dem Ankyrin-Repeat Protein ANK1 ................................................. 9

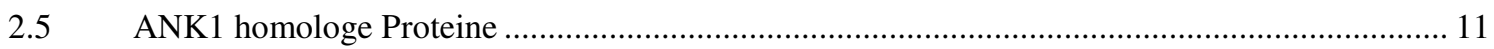

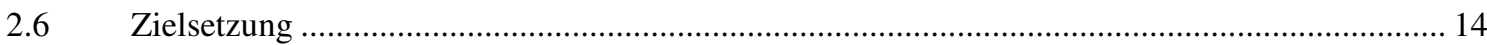

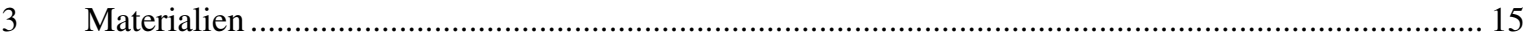

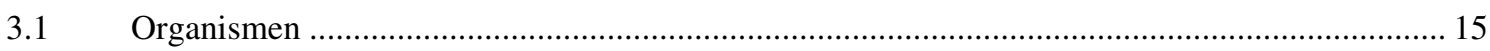

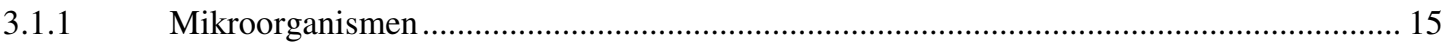

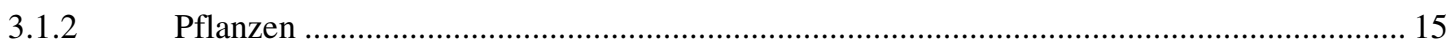

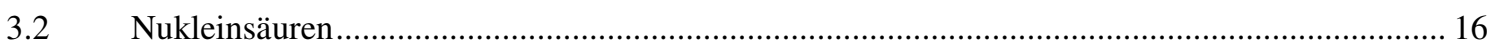

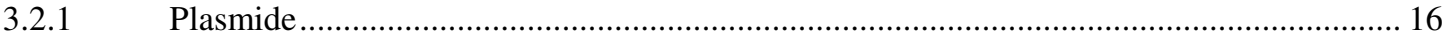

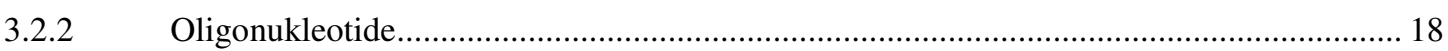

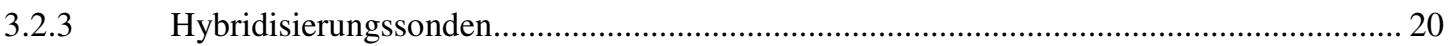

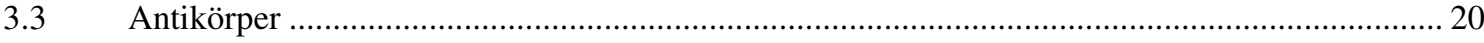

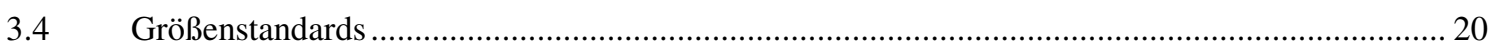

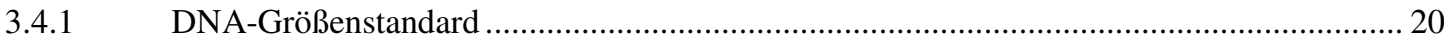

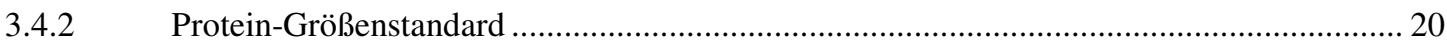

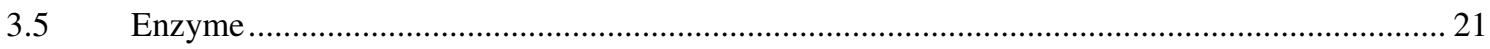

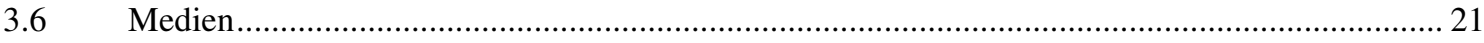

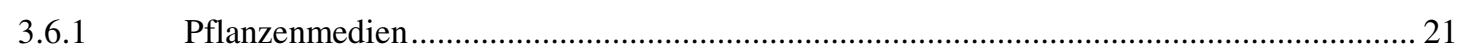

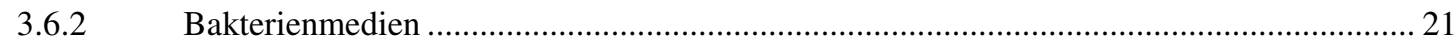

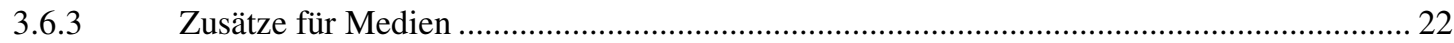

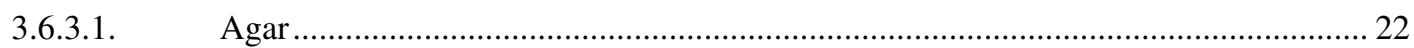

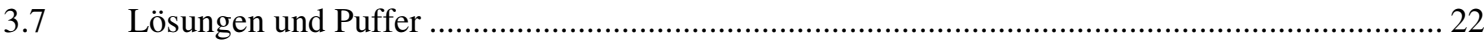

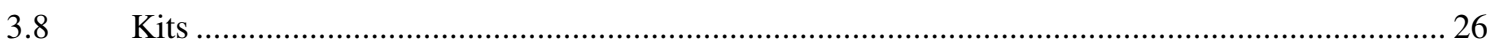

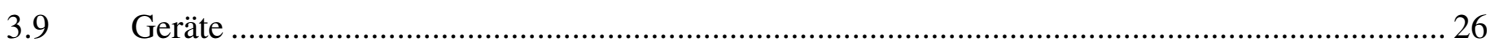

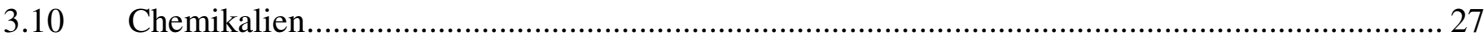

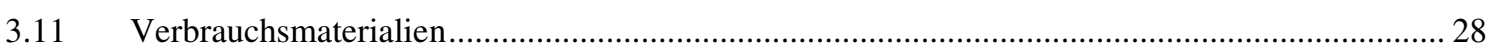

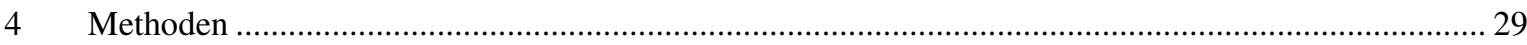

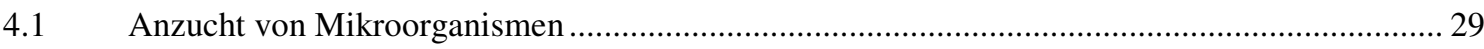

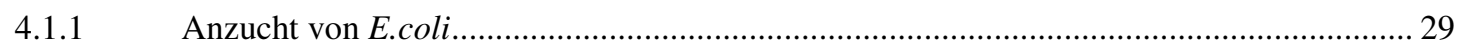

4.1.2 Anzucht von Agrobakterium tumefaciens ................................................................. 29

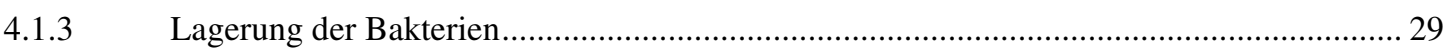

4.1.4 Anzucht des Tabak Mosaik Virus ................................................................................. 29

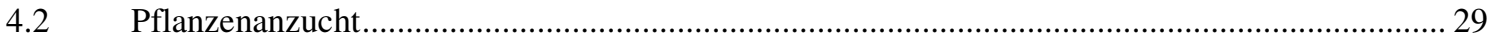

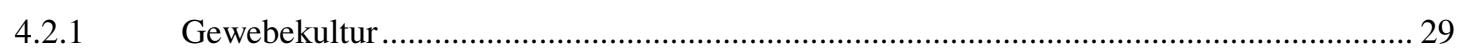

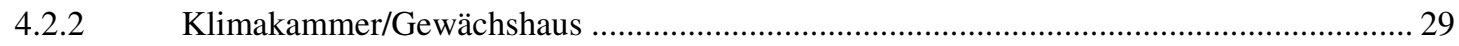

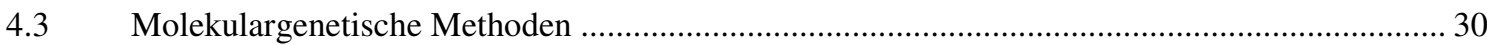




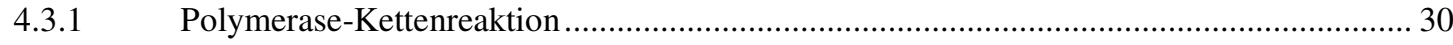

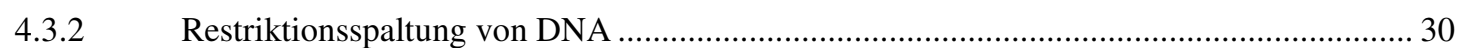

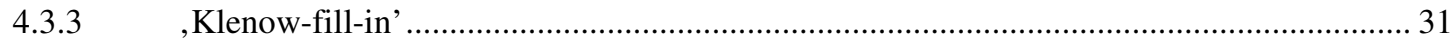

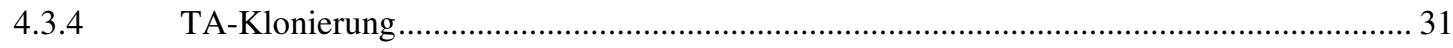

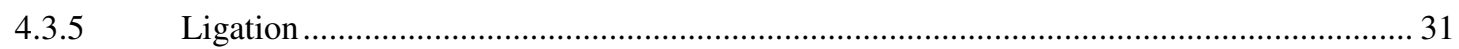

4.3.6 Konstruktion der verwendeten Vektoren ............................................................. 31

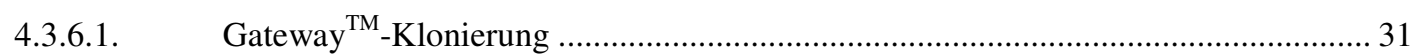

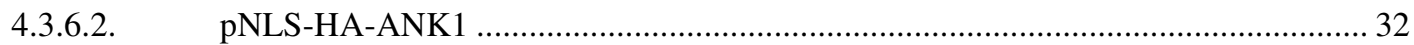

4.3.6.3. Einfügen von Punktmutationen ..................................................................... 32

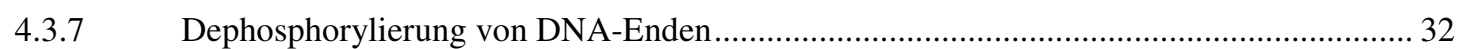

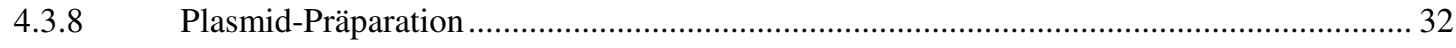

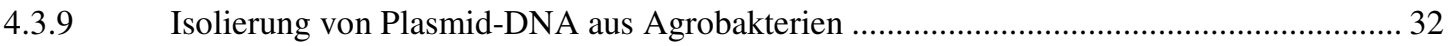

4.3.10 Konzentrations- und Reinheitbestimmung von Nukleinsäuren....................................... 32

4.3.11 Agarosegelelektrophorese von DNA-Molekülen .................................................... 33

4.3.12 DNA-Elution aus Agarosegelen................................................................................. 33

4.3.13 Ethanolfällung von DNA aus wässrigen Lösungen ................................................. 33

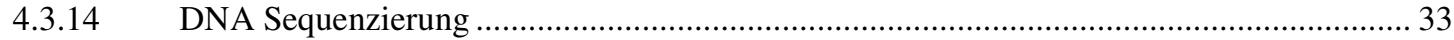

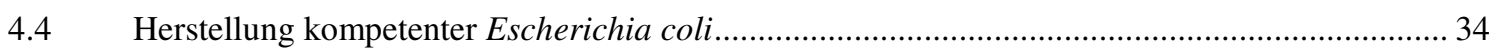

4.5 Herstellung kompetenter Agrobacterium tumefaciens........................................................ 34

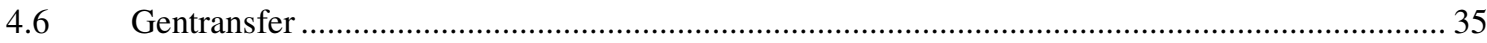

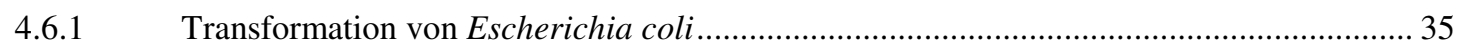

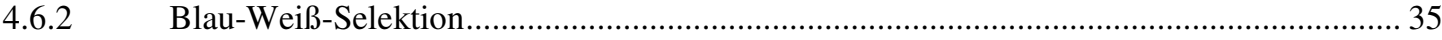

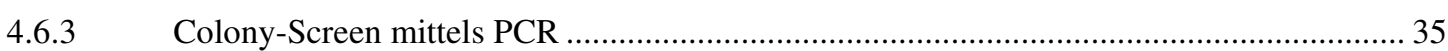

4.6.4 Transformation von Agrobacterium tumefaciens ......................................................... 35

4.6.5 Stabile Transformation von Nicotiana tabacum ............................................................. 35

4.6.6 Transiente Transfektion von Nicotiana tabacum Mesophyllprotoplasten ......................... 36

4.6.6.1. Protoplasten ,Two-Hybrid' (P2H) Analyse ....................................................... 37

4.6.6.2. Aktivierungsstudien in Tabak Mesophyllprotoplasten ........................................... 38

4.6.6.3. Messung der ß-Glukuronidase (GUS)- Aktivität..................................................... 38

4.6.6.4. Messung der Neuraminidase (NAN)- Aktivität..................................................... 38

4.6.7 Transiente Expression in Nicotiana benthamiana .......................................................... 39

4.6.7.1. ， Bimolecular Fluorescence Complementation’ (BiFC) ........................................... 39

4.6.7.2. Bestimmung der Lokalisation von YFP-Fusionsproteinen.................................... 39

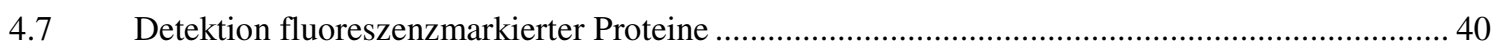

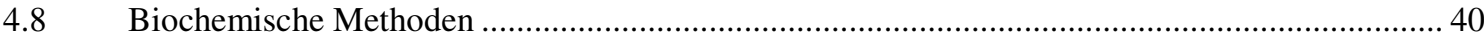

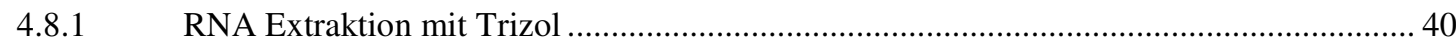

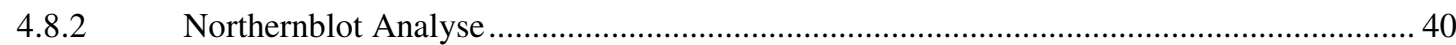

4.8.2.1. Auftrennung von RNA in denaturierenden Agarosegelen .................................. 40

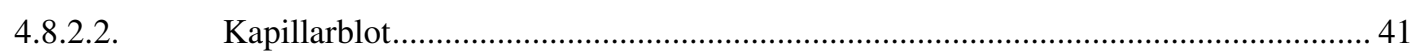

4.8.2.3. Herstellen einer radioaktiv markierten DNA-Sonde ........................................... 41 
4.8.2.4. Hybridisierung der Northern Blot Membran ................................................... 42

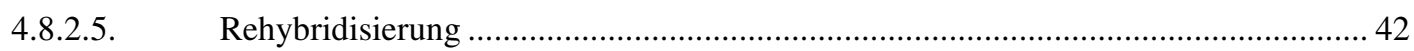

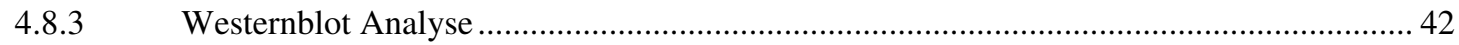

4.8.3.1. Präparation von pflanzlichen Gesamtprotein-Extrakten unter denaturierenden

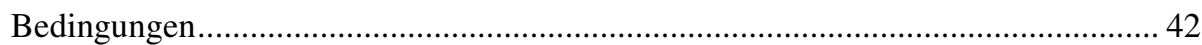

4.8.3.2. Diskontinuierliche SDS-Polyacrylamid-Gelelektrophorese ................................ 42

4.8.3.3. Transfer von Proteinen auf PVDF-Membranen..................................................... 43

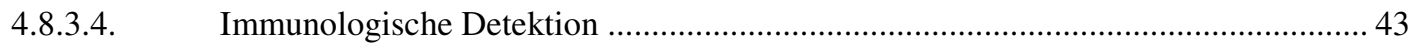

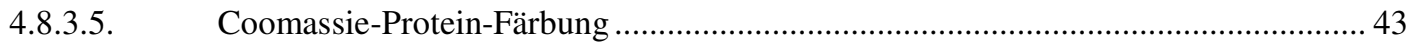

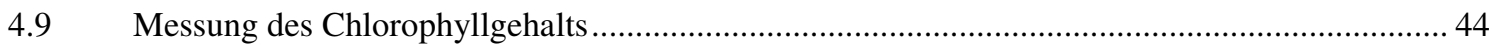

4.10 Trypan-Blue Anfärbung von abgestorbenen Zellen ....................................................... 44

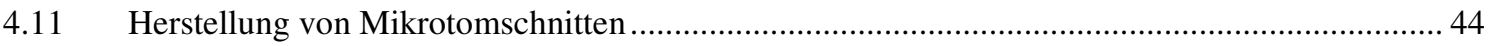

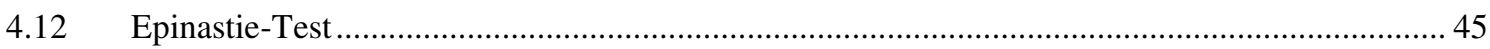

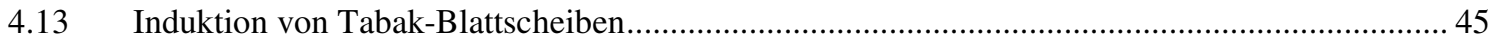

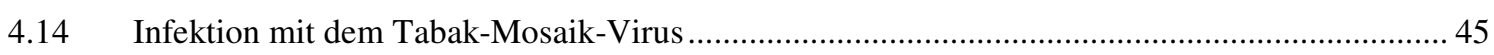

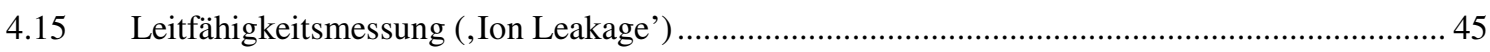

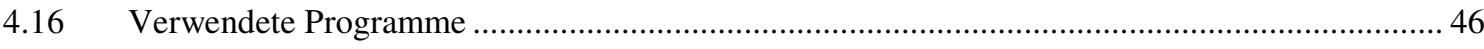

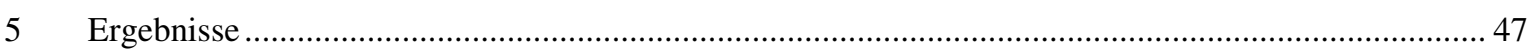

5.1 Analyse der in planta Interaktion von ANK1 und BZI-1 ................................................... 47

5.1.1 In planta Interaktion von ANK1 und BZI-1 im Protoplasten Two-Hybrid System............ 47

5.1.2 BZI-1 interagiert auch mit den bZIP-Transkriptionsfaktoren BZI-2, BZI-3 und BZI-4 ..... 50

5.1.3 ANK1 interagiert spezifisch mit BZI-1 und nicht mit den bZIP-Transkriptionsfaktoren BZI-

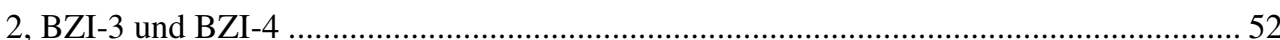

5.1.4 Durch Mutationen in den Ankyrin-Repeat Motiven II oder III wird die ANK1/BZI-1

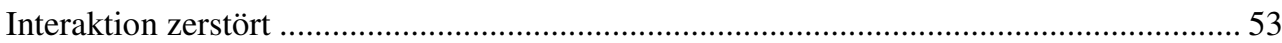

5.1.5 Nachweis der in planta Interaktion von ANK1 und BZI-1 mittels der ,Bimolecular Fluorescence Complementation' ................................................................................. 55

5.2 Untersuchung der zellulären Lokalisation von ANK1 in Abhängigkeit verschiedener Stimuli ... 57

5.2.1 ANK1 homodimerisiert im Cytosol ........................................................................ 58

5.2.2 ANK1 fungiert nicht als Retentionsfaktor von BZI-1 ............................................. 60

5.2.3 Durch BZI-1 Überexpression gelangt YFP-ANK1 in den Zellkern................................. 61

5.2.4 Nach der Inhibierung des Kernexports akkumuliert ANK1 im Kern.............................. 63

5.2.5 Nach Auxingabe akkumuliert ANK1 im Zellkern ........................................................6 66

5.2.6 Die Expression von ANK1 und BZI-1 ist nach Auxininduktion nicht verändert............... 68

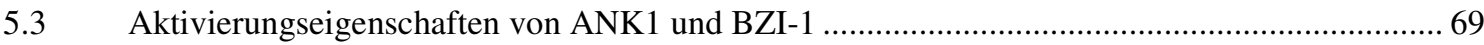

5.3.1 In Abhängigkeit von Auxin verstärkt ANK1 die BZI-1/BZI-2 vermittelte Genaktivierung69

5.3.2 Die Lokalisierung von ANK1 im Zellkern verstärkt die BZI-1 - BZI-2 vermittelte

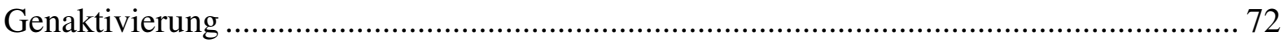

5.4 Herstellung und Charakterisierung transgener ANK1 und BZI-1 Pflanzen .............................. 74

5.4.1 Überexpression von ANK1 in Nicotiana tabacum ....................................................... 74 
5.4.1.1. Phänotypische Charakterisierung der ANK1-Überexpressionspflanzen .................. 76

5.4.2 Reduktion der ANK1 Expression in Nicotiana tabacum ................................................. 76

5.4.2.1. Phänotypische Charakterisierung der ANK1-RNAi Pflanzen .................................. 77

5.4.3 Reduktion der BZI-1 Expression in Nicotiana tabacum ............................................... 83

5.4.3.1. Vegetatives Wachstum der BZI-1-RNAi Pflanzen................................................ 84

5.4.3.2. Blütenmorphologie der BZI-1-RNAi Pflanzen................................................... 86

5.4.4 Analyse der Auxin Responsivität der transgenen Pflanzen............................................ 88

5.4.4.1. Hormoninduzierte Organogenese an Tabak Blattscheiben ...................................... 88

5.4.4.2. Auxin induzierte Epinastie von Tabak Blattstreifen ...........................................8 89

5.4.5 Untersuchung der Funktion von ANK1 und BZI-1 in der Pathogenabwehr ...................... 92

5.4.5.1. ANK1 und BZI-1 beeinflussen den TMV-induzierten Zelltod und nicht die Replikation des

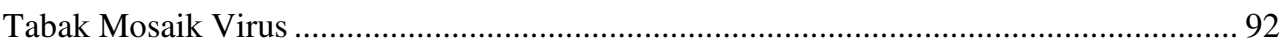

5.4.5.2. Die Expression von ANK1 bleibt nach TMV-Infektion unverändert....................... 95

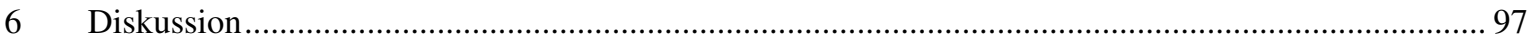

6.1 Das Ankyrin-Repeat Protein ANK1 interagiert spezifisch mit dem bZIP-Transkriptionsfaktor

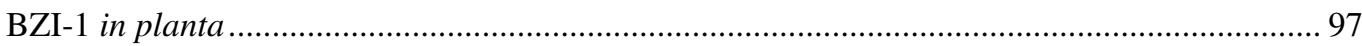

6.2 Auxin induziert die Akkumulation von ANK1 im Zellkern ................................................... 100

6.3 Die bZIP-Transkriptionsfaktoren BZI-1 und BZI-2 kooperieren mit ANK1 bei der Kontrolle der pflanzlichen Auxinantwort 104

6.4 ANK1 und BZI-1 wirken als negative Regulatoren des TMV-induzierten Hypersensitiven Zelltods..... 109

6.5 Modell der BZI-1/ANK1 vermittelten Zielgenexpression ............................................... 112

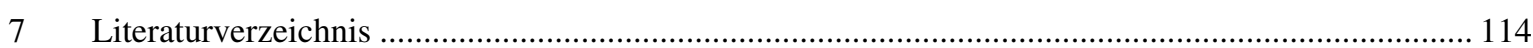

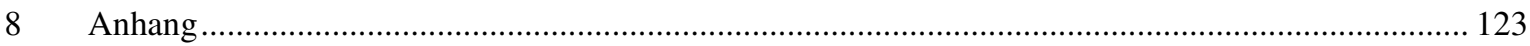

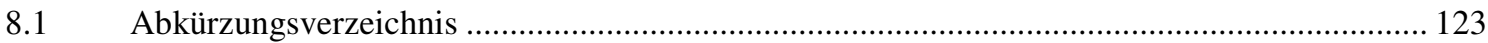

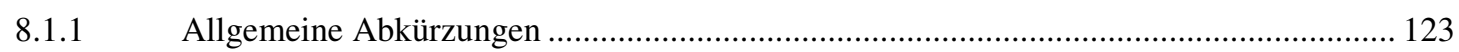

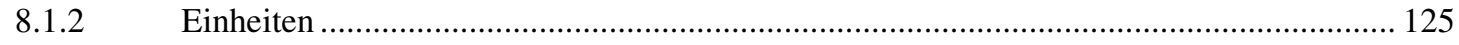

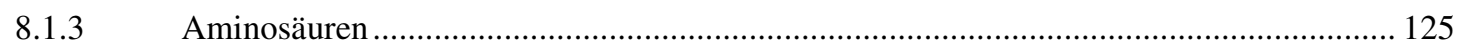

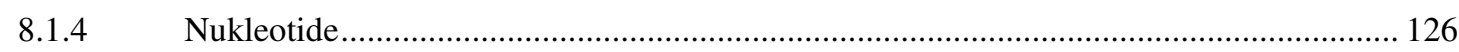

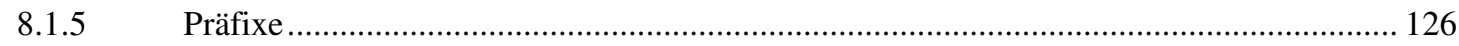




\section{$1 \quad$ Zusammenfassung}

Für den Tabak (Nicotiana tabacum) bZIP-Transkriptionsfaktor BZI-1 konnte eine Beteiligung an der Auxinantwort und am Tabak Mosaik Virus (TMV) induzierten hypersensitiven Zelltod gezeigt werden (Kuhlmann et al., 2003; Heinekamp et al., 2004). Eine Heterodimerisierung mit dem bZIP-Transkriptionsfaktor BZI-2 konnte mit Hilfe des Hefe ,Two-Hybrid' nachgewiesen werden (Strathmann et al., 2001).

Mittels Protoplasten ,Two-Hybrid' und ,Bimolecular Fluorescence Complementation' Analysen ließ sich eine spezifische in planta Interaktion zwischen BZI-1 und dem Ankyrin-Repeat Protein ANK1 nachweisen. Diese Interaktion wird auf der Seite von BZI1 durch die $\alpha$-helikale Domäne DI und auf der Seite von ANK1 durch die AnkyrinRepeats vermittelt. Ziel der Arbeit war die funktionellen Charakterisierung des Transkriptionsfaktors BZI-1 und des Ankyrin-Repeat Proteins ANK1.

Mit Hilfe der Expression von YFP-Fusionsproteinen konnte ANK1 im Cytosol und BZI-1 im Zellkern lokalisiert werden. Die Inhibierung des Kernexportes und Auxingabe führen zur Akkumulation von ANK1 im Zellkern von Tabak Mesophyllprotoplasten. Durch CoExpression von ANK1 zusätzlich zu BZI-1 und BZI-2, wird die BZI-1/BZI-2 vermittelte Auxin abhängige Transkription verstärkt. Damit fungiert ANK1 möglicherweise als ein Co-Aktivator von BZI-1.

Transgene Pflanzen in denen die Expression von ANK1, BZI-1 oder BZI-2 mittels eines ,RNA-Interferenz' Ansatzes (RNAi) reduziert ist, zeigen eine deutlich abgeschwächte Auxinantwort. Nach der Infektion mit dem Tabak Mosaik Virus ist der hypersensitive Zelltod in den ANK1- und BZI-1-RNAi Pflanzen verstärkt.

Da die ANK1- und BZI-1-RNAi Pflanzen vergleichbare Phänotypen zeigen, wird eine biologische Bedeutung der ANK1/BZI-1 Interaktion in der Regulation der pflanzlichen Auxinantwort und des TMV-induzierten hypersensitiven Zelltods postuliert. 


\section{$2 \quad$ Einleitung}

Pflanzen sind ständig sich verändernden endogenen und exogenen Einflüssen ausgesetzt, auf die sie spezifisch reagieren müssen. $\mathrm{Zu}$ diesen Einflüssen gehören neben den pflanzlichen Entwicklungsprozessen auch abiotische und biotische Faktoren wie Temperatur, Licht oder Pathogene. Auf zellulärer Ebene wird diese Anpassung durch eine differenzielle Genexpression erreicht. Dabei binden Transkriptionsfaktoren an cisElemente von Promotoren und regulieren die Transkription ihrer Zielgene, indem sie diese reprimieren oder aktivieren (zur Übersicht: Casal, 2002).

Transkriptionsfaktoren sind modular aufgebaute Proteine, die durch funktionelle Proteindomänen gekennzeichnet sind (Ptashne, 1988; Ptashne, 1989; Frankel und Kim, 1991). Dies können unter anderem Protein-Protein Interaktionsdomänen oder Aktivierungsdomänen sein. Allen Transkriptionsfaktoren gemeinsam ist eine DNABindedomäne (Keegan et al., 1986; Frankel und Kim, 1991). Aufgrund ihrer konservierten Domänen werden die Transkriptionsfaktoren in unterschiedliche Familien eingeteilt. Dazu zählen die Zink-Finger Proteine, MYB Transkriptionsfaktoren, MADS-Box Proteine, Helix-turn-Helix Proteine, Homöobox Proteine und bZIP Proteine (Riechmann et al., 2000; Riechmann und Ratcliff, 2000).

\subsection{Der bZIP-Transkriptionsfaktor BZI-1 aus Nicotiana tabacum}

Die bZIP-Transkriptionsfaktoren (,basische Leucin-Zipper') sind eine Familie von Transkriptionsfaktoren, die ausschließlich in Eukaryonten vorkommenden (Landschulz et $a l .$, 1988). Die Familie der bZIP-Transkriptionsfaktoren ist charakterisiert durch eine basische DNA-Bindedomäne, die die Bindung des Proteins an spezifische DNA-cisElemente vermittelt, und einen angrenzenden Leucin-Zipper.

Ein Leucin-Zipper besteht aus der heptameren Wiederholung von Leucinen oder anderen hydrophoben Aminosäuren (LxxxxxLxxxxxxL) und hat eine $\alpha$-helikale Konformation. Leucin-Zipper ermöglichen die Dimerisierung zweier bZIP-Proteine, durch die Bildung einer ,coiled-coil' Konformation (O'Shea et al., 1989). Durch diese Dimerisierung werden die basischen Domänen so zueinander ausgerichtet, dass sie an die große Furche der DNADoppelhelix binden können (Vinson et al., 1989). Die basischen Domänen bilden nach der 
Dimerisierung der Transkriptionsfaktoren ebenfalls eine ,coiled-coil' Struktur aus, durch die die Bindung an die DNA noch verstärkt werden kann (Krylov et al., 1995).

Pflanzliche bZIP-Transkriptionsfaktoren binden dabei bevorzugt an DNA mit einem ACGT-Kernmotiv. Die dieses Kernmotiv flankierenden Sequenzen bestimmen dabei die Spezifität der Bindung (Izawa et al., 1993). Die Bindung an palindromische Sequenzen wird bevorzugt, wie die der A-Box (TACGTA), C-Box (GACGTC) und G-Box (CACGTG) (Izawa et al., 1993), aber von einer Bindung der bZIP-Transkriptionsfaktoren an nicht palindromische Boxen wurde auch berichtet (Choi et al., 2000; Fukazawa et al., 2000).

Der Transkriptionsfaktor BZI-1 wird der Klasse der basischen Leucin-Zipper zugeordnet. Er weist neben der basischen Domäne und dem Leucin-Zipper noch die zu anderen bZIPTranskriptionsfaktoren konservierten Domänen N, DI, DII und DIV auf (Heinekamp et al., 2002; Kuhlmann et al., 2003).

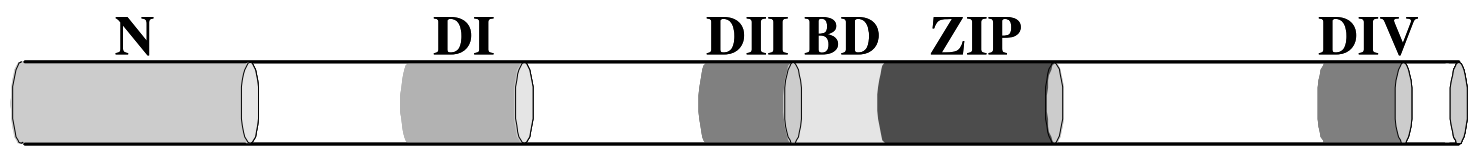

\begin{abstract}
Abbildung 2.1 Schematische Darstellung der Domänenstruktur von NtBZI-1. Die Domänenstruktur basiert auf dem Vergleich zu anderen homologen bZIP-Transkriptionsfaktoren (DrögeLaser et al., 1997). N: N-terminale Domäne; DI: Domäne I; DII: Domäne II; BD: basische Domäne; ZIP: Leucin-Zipper; DIV: Domäne IV (abgewandelt nach Kuhlmann, 2003).
\end{abstract}

Für die aminoterminale Domäne $\mathrm{N}$ konnten in Hefe und in planta aktivierende Eigenschaften gezeigt werden (Heinekamp et al., 2002). Für die Domäne DI wird eine $\alpha$ helikale Struktur aufgrund der Peptidsequenz postuliert. Diese Domäne könnte eine Protein-Protein Interaktion vermitteln. Für BZI-1 konnte eine Interaktion mit dem Ankyrin-Repeat Protein ANK1 im Bereich der erweiterten DI Domäne (Aminosäuren 73222) gezeigt werden (Kuhlmann et al., 2003). Den Domänen DII und DIV konnte bisher noch keine eindeutige Funktion zugewiesen werden. Die Domäne DII zeichnet sich durch eine relativ saure Region aus. Beide Domänen weisen eine putative Phosphorylierungsstelle auf.

In Anlehnung an die Einteilung für die bZIP-Transkriptionsfaktoren aus Arabidopsis thaliana lässt sich BZI-1 in die Gruppe C der bZIP-Transkriptionsfaktoren einteilen (Jakoby et al., 2002). Die Gruppe C ist charakterisiert durch die bis zu neunfache heptameren Wiederholung des Leucin-Zipper Motivs und durch eine N-terminale Domäne 
mit einer hydrophoben oder sauren Signatur, die Aktivierungseigenschaften besitzen könnte.

Es konnten verschiedene BZI-1 homologe Proteine identifiziert werden. Dazu gehören unter anderem CPRF2 (,common plant regulatory factor 2'; Weisshaar et al., 1991) aus Petroselinum crispum, dem eine Rolle in der lichtabhängigen Genregulation zugeschrieben wird (Rügner et al., 2001). In Arabidopsis thaliana weist BZI-1 die größte Sequenzidentität zu den Transkriptionsfaktoren bZIP63 und bZIP10 auf (Jakoby et al., 2002). Die Funktion von bZIP63 ist noch weitgehend ungeklärt, aber für bZIP10 konnte eine Funktion in der positiven Regulation der Hypersensitiven Reaktion gezeigt werden (Kaminaka et al., 2006). Weitere BZI-1 homologe Proteine sind OHP1 (,O2heterodimerizing protein 1') und OHP2 (,O2-heterodimerizing protein 2') aus Zea mays (Pysh et al., 1993). Vincentz et al., 2003 ordnet BZI-1 in die O2 (,opaque 2') Familie der bZIP-Transkriptionsfaktoren ein, geht allerdings davon aus, dass die bZIPTranskriptionsfaktoren aus monokotylen Pflanzen dieser Gruppe, zu denen auch OHP1 und OHP2 gehören, eine funktionelle Spezialisierung besitzen, die nur in monokotylen Pflanzen vorkommt.

Zur Aufklärung der Funktion von BZI-1 wurden transgene Pflanzen hergestellt, in denen eine trunkierte Version von BZI-1 (BZI-1 $\Delta \mathrm{N})$ überexprimiert wird. Die BZI-1 Domäne N ist eine Aktivierungsdomäne. In Hefe und in planta Analysen konnte gezeigt werden, dass ein exprimiertes BZI-1 $\Delta \mathrm{N}$ Derivat keine Aktivierungseigenschaften mehr besitzt (Heinekamp et al., 2002), aber in EMSA Studien weiterhin an ein ACGT enthaltendes cisElement binden kann (Kuhlmann et al., 2003). Die Expression des BZI-1 $\Delta$ N Derivats wirkt dadurch wahrscheinlich dominant-negativ auf die Expression der Zielgene von BZI1. Bindet BZI-1 $\Delta \mathrm{N}$ als Homo- oder Heterodimer mit einem anderen bZIPTranskriptionsfaktor an ein Promotorelement, kommt es durch die deletierte Aktivierungsdomäne $\mathrm{N}$ nicht mehr zu einer entsprechenden Zielgenaktivierung.

Die BZI-1 $\Delta \mathrm{N}$ Pflanzen wurden auf ihre Auxinantwort und auf ihre Reaktion nach Pathogeninfektion hin untersucht. Für BZI-1 konnte bereits eine serinspezifische Phosphorylierung nach Pathogeninfektion in vitro und in vivo gezeigt werden (DrögeLaser et al., 1997; Kuhlmann et al., 2003). Nach TMV-Infektion (Tabak Mosaik Virus) zeigen Wildtyp Pflanzen eine N-Gen vermittelte Hypersensitive Reaktion (HR), durch die die für die TMV-Infektion typische nekrotische Läsionen entstehen. In den BZI-1 $\Delta \mathrm{N}$ Pflanzen bilden sich zwar anfänglich Läsionen ähnlich wie im Wildtyp aus, doch sind die 
Läsionen nicht lokal begrenzt. Sie breiten sich aus bis das ganze Blatt nekrotisch ist (Kuhlmann et al., 2003).

In Arabidopsis thaliana konnte für die $l s d l$ Mutante ein ähnlicher Phänotyp beschrieben werden (Dietrich et al., 1997). LSD1 ist ein Zink-Finger Protein, das cytosolisch lokalisiert ist und als negativer Regulator des induzierten Zelltods fungiert. Durch die Interaktion von LSD1 mit bZIP10, einem Gruppe C bZIP-Transkriptionsfaktor, kommt es zur Retention von bZIP10 im Cytosol (Kaminaka et al., 2006).

Der Phänotyp der BZI-1 $\Delta$ N Pflanzen ist pleiotrop. Die Blätter sind dunkelgrün und gewellt und die Pflanzen zeigen eine verringerte Apikaldominanz (Heinekamp, et al., 2004). Versuche zur Auxin induzierten Organogenese an Blattscheiben und der Bestimmung der Auxin bedingten epinastischen Krümmung von Blattstreifen zeigten, dass BZI-1 $\Delta \mathrm{N}$ Pflanzen eine verringerte Auxinantwort haben (Heinekamp et al., 2004). Da eine Untersuchung des Auxingehalts in den transgenen Pflanzen jedoch keinen Unterschied zum Wildtyp zeigte, kann davon ausgegangen werden, dass BZI-1 an der Auxinantwort beteiligt ist.

\subsection{Die Auxin vermittelte transkriptionelle Kontrolle}

Die BZI-1 $1 \Delta \mathrm{N}$ Pflanzen zeigen außerdem eine reduzierte Transkription des Auxin induzierbaren GH3 Gens (Roux und Perrot-Rechenmann, 1997; Heinekamp et al., 2004). Der Promotor des GH3 Gens aus Soja (Glycine max) ist gut charakterisiert (Hagen und Guilfoyle, 2002) und der Promotor des GH3 Gens aus Tabak weist starke Übereinstimmungen zum Promotor des Soja GH3 Gens auf (Heinekamp et al., 2004). Im GmGH3 Promotor konnten drei Auxin responsive Elemente identifiziert werden, von denen das D1- und D4-Element konservierte AuxREs (,auxin responsive element') beinhalten (Ulmasov et al., 1995).

Auxin war das erste Pflanzenhormon das entdeckt wurde (Went, 1926). Es gibt verschiedene Auxine in Pflanzen, wobei IAA (Indol-3-Essigsäure) das am häufigsten vorkommende ist (Teale et al., 2006). Auxin reguliert viele Aspekte der pflanzlichen Entwicklung wie die embryonale und post-embryonale Entwicklung, den Gravi- und Phototropismus, die Zellteilung, Zellstreckung und Differenzierung. Es ist unter anderem beteiligt an der Apikaldominanz, der Wurzelbildung und Seneszenz (zur Übersicht: Woodward und Bartel, 2005; Teale et al., 2006). 
Auxininduzierbare Gene werden in verschiedene Familien aufgeteilt. Dies sind die ACS(Aminocyclopropan-Carboxylat Synthase), GST- (Glutathion-S-Transferase), SAUR(,small auxin up RNA'), GH3- (Gretchenhagen-3) und die Aux/IAA-Genfamilie. Eine besondere Rolle spielt dabei die Genfamilie der Aux/IAAs, deren Transkription zum einen durch Auxin induziert wird (Abel et al., 1994), aber auch an der Regulation Auxin induzierbaren Gene beteiligt ist.

Ihre Rolle in der Auxin abhängigen transkriptionellen Kontrolle ist in Abbildung 2.2 dargestellt. Für Aux/IAA Proteine konnte ein negativer Einfluss auf die Zielgenexpression gezeigt werden (Ulmasov et al., 1997). In der Abwesenheit von Auxin interagieren Aux/IAA Proteine mit den ARF-Transkriptionsfaktoren (,auxin responsive factor') über eine carboxyterminale Domäne, die homolog zu der carboxyterminalen Domäne der ARFTranskriptionsfaktoren ist und für die eine Funktion in der Protein-Protein-Interaktion angenommen wird. Diese Interaktion inhibiert die Funktion der ARFTranskriptionsfaktoren. ARF-Transkriptionsfaktoren binden an die AuxRE cis-Elemente mit der Consensus-Sequenz TGTCTC in den Promotorbereichen von Auxin induzierbaren Genen (Ulmasov et al., 1995) als Homo- oder Heterodimere und aktivieren oder reprimieren diese (Okushima et al., 2005; Tiwari et al., 2003). Reguliert wird die Menge an Aux/IAA Proteinen durch Auxin, wobei der SCF ${ }^{\mathrm{TIR} 1}$ Ubiquitin-Ligase Komplex eine entscheidende Rolle spielt. Ubiqitin-Ligase Komplexe steuern den Proteinabbau. Dabei werden Proteine spezifisch durch den Ubiqitin-Ligase Komplex ubiquitiniert, die dann durch das 26S-Proteasom abgebaut werden. Für die Spezifität sorgen die dem Komplex zugehörigen F-box Proteine. Der Auxin Rezeptor TIR1 (,transport inhibitor response 1') ist ein F-box Protein. Auxin bindet an den Auxin Rezeptor TIR1, der die Ubiquitinvermittelte Degradation der Aux/IAA Proteine bewirkt (Dharmasiri et al., 2005). Dadurch können die ARF-Transkriptionsfaktoren wieder die Genexpression von Auxin induzierten Genen aktivieren (zur Übersicht: Teale et al., 2006).

Im GH3 Promotor aus Tabak konnte neben dem AuxRE-Element eine G-Box in der D1Domäne und ein G-Box ähnliches Element in der E1-Domäne identifiziert werden. Für das BZI-1 Protein konnte eine Bindung an die E1- und D1-Domäne in vitro gezeigt werden. Die E1-Domäne kann eine Auxinresponsivität auf einen Minimalpromotor übertragen (Liu et al., 1994; Liu et al., 1997). Zusätzlich konnte in ChIP Experimenten (,Chromatin Immunoprecipitation') die in vivo Bindung des BZI-1 Proteins an den GH3 Promotor bestätigt werden (Heinekamp et al., 2004). Da aber in den GH3 Promotoren aus Nicotiana 
tabacum und Glycine max G-Boxen und AuxRE-Elemente, an die eine Bindung von ARFTranskriptionsfaktoren gezeigt werde konnte (Guilfoyle et al., 1998), vorhanden sind, ist davon auszugehen, dass die Auxinantwort durch verschiedene Faktoren moduliert werden kann. Heinekamp et al., 2004 postuliert, dass GH3 ein direktes Zielgen von BZI-1 ist, und das die Menge des GH3 Transkripts quantitativ durch BZI-1 reguliert wird. Dabei könnten weitere mit BZI-1 interagierende Proteine eine Rolle spielen.

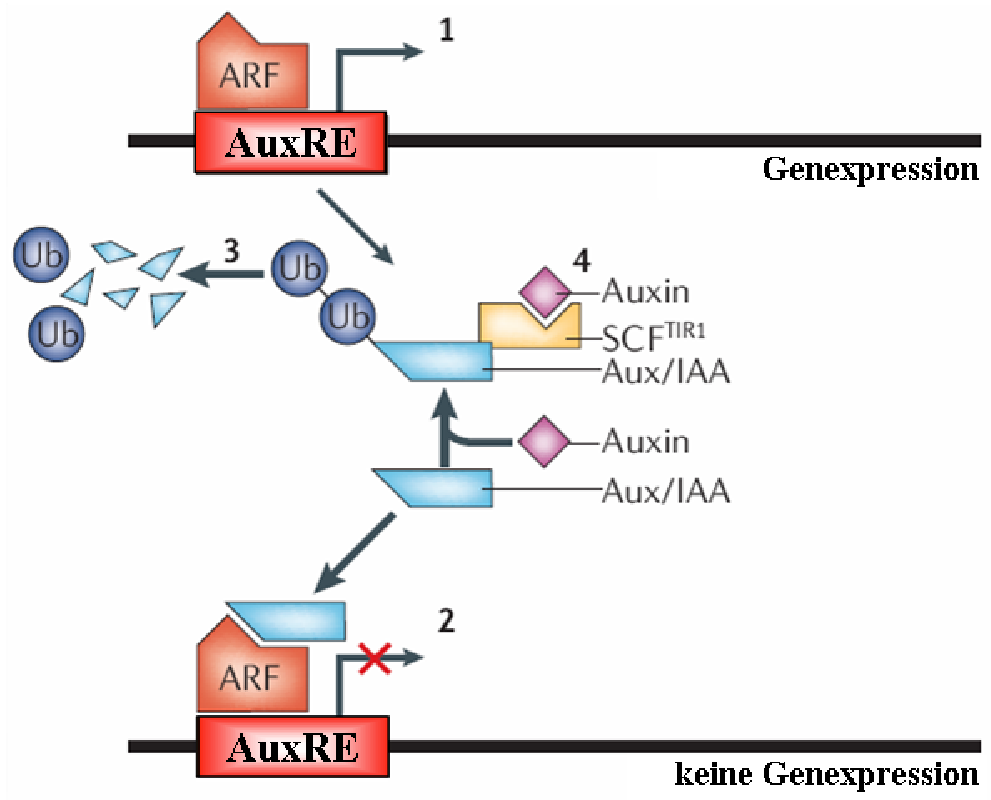

Abbildung 2.2: Modell der Auxin vermittelten Aktivierung der Genexpression. (1) ARF (,auxin responsive factor') Transkriptionsfaktoren binden an die AuxREs (,auxin responsive elements') in den Promotorbereichen von Auxin induzierbaren Genen und aktivieren diese. (2) Die Aux/IAAs sind frühe Auxin responsive Proteine, die an die ARFs binden und diese inhibieren. (4) Auxin bindet an das F-box Protein TIR1 (,transport inhibitor response 1'), das zum SCF-TIR1 Komplex gehört. Die SCF E1 Ligase erkennt Aux/IAA Proteine und ubiquitiniert diese. (3) Die ubiquitinierten Proteine werden durch das 26SProteasom abgebaut (verändert nach Teale et al., 2006).

\subsection{Die BZI-1 Interaktionspartner BZI-2, BZI-3 und BZI-4}

Um Interaktionspartner von BZI-1 zu finden, wurde im Vorfeld dieser Arbeit eine HefeInteraktionsstudie (,Yeast Two-Hybird'; Y2H) durchgeführt. Es wurde ein C-terminales Fragment von BZI-1, das den Leucin-Zipper beinhaltet und aus den Aminosäuren 238 bis 450 besteht, als Köder benutzt. Als Interaktionspartner von BZI-1 konnten in diesem Screen BZI-2, BZI-3 und BZI-4 gefunden werden. Die Interaktion konnte in vitro in einem ,Far Western' Ansatz bestätigt werden (Strathmann et al., 2001). Auch in anderen Pflanzenarten wurden heterodimerisierende bZIP-Transkriptionsfaktoren identifiziert. So 
konnte dies in Petersilie für die Gruppe der CPRF-Transkriptionsfaktoren (Rügner et al., 2001) und in Arabidopsis thaliana für die bZIP-Transkriptionsfaktoren der Gruppen C und S (Jakoby et al., 2002) gezeigt werden.

Die Transkriptionsfaktoren BZI-2, BZI-3 und BZI-4 werden in Analogie an die Einteilung der bZIP-Transkriptionsfaktoren in Arabidopsis thaliana in die Gruppe S eingeordnet. Diese Gruppe ist charakterisiert durch eine zentrale basische DNA-Bindedomäne und einen angrenzenden Leucin-Zipper, der aus einer acht- bis neunfachen heptameren Wiederholung des Leucin-Zipper Motivs besteht. Amino- und Carboxyterminale Bereiche sind in dieser Gruppe relativ kurz und weisen auf genomischer Ebene keine Introns auf (Jakoby et al., 2002, Strathmann, 2003).

Transgene BZI-2 Pflanzen, in denen die Expression von BZI-2 durch einen RNA Interference Ansatz reduziert ist, sind kleiner im Wuchs, haben kleinere Blätter und Blüten (Iven, 2004). Der Blütenphänotyp ist bei den BZI-2-RNAi Linien unterschiedlich stark ausgeprägt und zeigt große Ähnlichkeiten zu den für die von den BZI-1 $\Delta$ N Pflanzen beschriebenen Blüten. Für BZI-2-RNAi Pflanzen konnte eine reduzierte Auxin induzierte Organogenese an Blattscheiben und eine reduzierte Auxin bedingte epinastische Krümmung von Blattstreifen gezeigt werden (Zwafink, 2005). Dies deutet auf eine reduzierte Auxinantwort hin, wie es schon bei den BZI-1 $\Delta \mathrm{N}$ Pflanzen gezeigt werden konnte.

Der bZIP-Transkriptionsfaktor BZI-3 ist identisch zu dem von Yang et al., 2001 aus Nicotiana tabacum isolierten TBZF. BZI-3 wird ubiquitär exprimiert, zeigt aber eine verstärkte Transkription in Blüten. Diese ist in der Blütenentwicklung konstant, sinkt aber wieder in vollständig entwickelten Blüten. Die Menge an BZI-3 Transkript steigt in seneszenten Blättern proportional zur Verringerung des Chlorophyllgehaltes (Yang et al., 2001) und wird durch Kälte induziert, Saccharose hat aber keinen Einfluss auf die Transkription (Strathmann, 2003). In einer Bindungsstudie an das E1 Element des GH3 Promotors konnten trans-aktivierende Eigenschaften für BZI-3 festgestellt werden.

Auch für BZI-3 Überexpressionspflanzen konnte, wie bereits schon für die BZI-1 $\Delta \mathrm{N}$ und die BZI-2-RNAi Pflanzen eine reduzierte Auxin induzierte Wurzelregeneration von Blattscheiben und eine Auxin bedingte epinastische Krümmung von Blattstreifen festgestellt werden (Strathmann, 2003). BZI-3 OEX Pflanzen bilden kleinere Blütenorgane im Vergleich zum Wildtyp. Transgene BZI-3 Pflanzen, in denen die Expression von BZI-3 durch einen RNA Interference Ansatz reduziert ist, zeigen einen höheren Wuchs und 
dickere, dunkelgrünere Blätter. Bei einigen Linien treten Blattanomalien auf (Iven, 2004) und die Blüten sind kleiner (Zwafink, 2005).

Der bZIP-Transkriptionsfaktor BZI-4 wird fast ausschließlich in Blütenorganen exprimiert. Dabei ist die Expression besonders stark in den Stamina, schwächer in Kelch, Petalen und Pistill und konnte im Gynoeceum nicht nachgewiesen werden, ist aber unabhängig vom Entwicklungsstadium der Blüte (Strathmann et al., 2001). BZI-4 Überexpressionspflanzen haben im Vergleich zum Wildtyp einen gestauchten Wuchs mit kleineren Blüten, die dem Blütenphänotyp der BZI-1 $\Delta$ N Pflanzen ähneln (Strathmann, 2003).

Die bisherigen Ergebnisse deuten auf eine Beteiligung von BZI-1, BZI-2 und BZI-3 an der Auxinantwort hin. Vor allem BZI-1/BZI-2 Heterodimere könnten aufgrund der bisherigen Ergebnisse positive Regulatoren der Auxinantwort sein.

\subsection{BZI-1 interagiert mit dem Ankyrin-Repeat Protein ANK1}

In einem zweiten $\mathrm{Y} 2 \mathrm{H}$ Ansatz mit dem mögliche BZI-1 Interaktionspartner gefunden werden sollten, wurde ein interner Bereich, der die Aminosäuren 73 bis 244 umfasst und die $\alpha$-helikale Domäne beinhaltet, als Köder verwendet. In diesem Y2H Ansatz wurde ANK1 als Interaktionspartner von BZI-1 identifiziert. Diese Interaktion konnte indirekt in vitro durch eine Gelretardationsanalyse (EMSA) bestätigt werden (Kuhlmann et al., 2003). Das Ankyrin-Repeat Protein ANK1 hat einen Kodierbereich von 1053 Basenpaaren und ein berechnetes Molekulargewicht von 37,2 kDa. Die aminoterminalen 50 Aminosäuren von ANK1 weisen einen erhöhten Gehalt an Prolin (P), Glutamat (E), Serin (S) und Threonin (T) auf. Für Peptidsequenzen mit einer erhöhten Anzahl dieser Aminosäuren wird eine Rolle im proteolytischem Abbau angenommen und sie werden nach dem Einbuchstabenkürzel der entscheidenden Aminosäuren als PEST Domänen bezeichnet (Rechsteiner und Robers, 1996). Carboxyterminal besteht ANK1 aus der vierfachen Wiederholung des Ankyrin-Repeat Motivs. Ein Ankyrin-Repeat ist ein 33 Aminosäuren großes Motiv, das aus zwei antiparallelen $\alpha$-Helices und zwei $\beta$-Faltblättern besteht (Abbildung 2.3). Dabei sind die Ankyrin-Repeats II und III stark konserviert und die Motive I und IV zeigen einige Abweichungen von der Konsensussequenz, wie sie Sedgwick und Smerdon (1999) beschrieben haben. 
Die Aminosäuren an den Positionen, die wichtig für die Bildung der Sekundärstruktur sind, sind hoch konserviert (Rhode und Bork, 1993; Mosavi et al., 2002), denn die Faltung der Ankyrin-Repeats spielt eine wichtige Rolle für ihre Funktion (Mosavi et al., 2002).

Ankyrin-Repeat Motive kommen in Eukaryonten, Prokaryonten und einigen Viren vor (Sedgwick and Smerdon, 1999) und sind dabei Bestandteile von Proteinen mit verschiedensten Funktionen. Sie sind unter anderem beteiligt an Prozessen wie der Zell Zyklus Regulation oder Signaltransduktion, sind mitochondriale Enzyme, Zytoskelett interagierende Proteine, oder auch Toxine (Sedgwick and Smerdon, 1999). Für AnkyrinRepeats konnte gezeigt werden, dass sie Protein-Protein Interaktionen vermitteln. AnkyrinRepeat Proteine können sowohl mit heterologen Proteinen interagieren, als auch homodimerisieren (Bork, 1993; Lin et al., 1999).
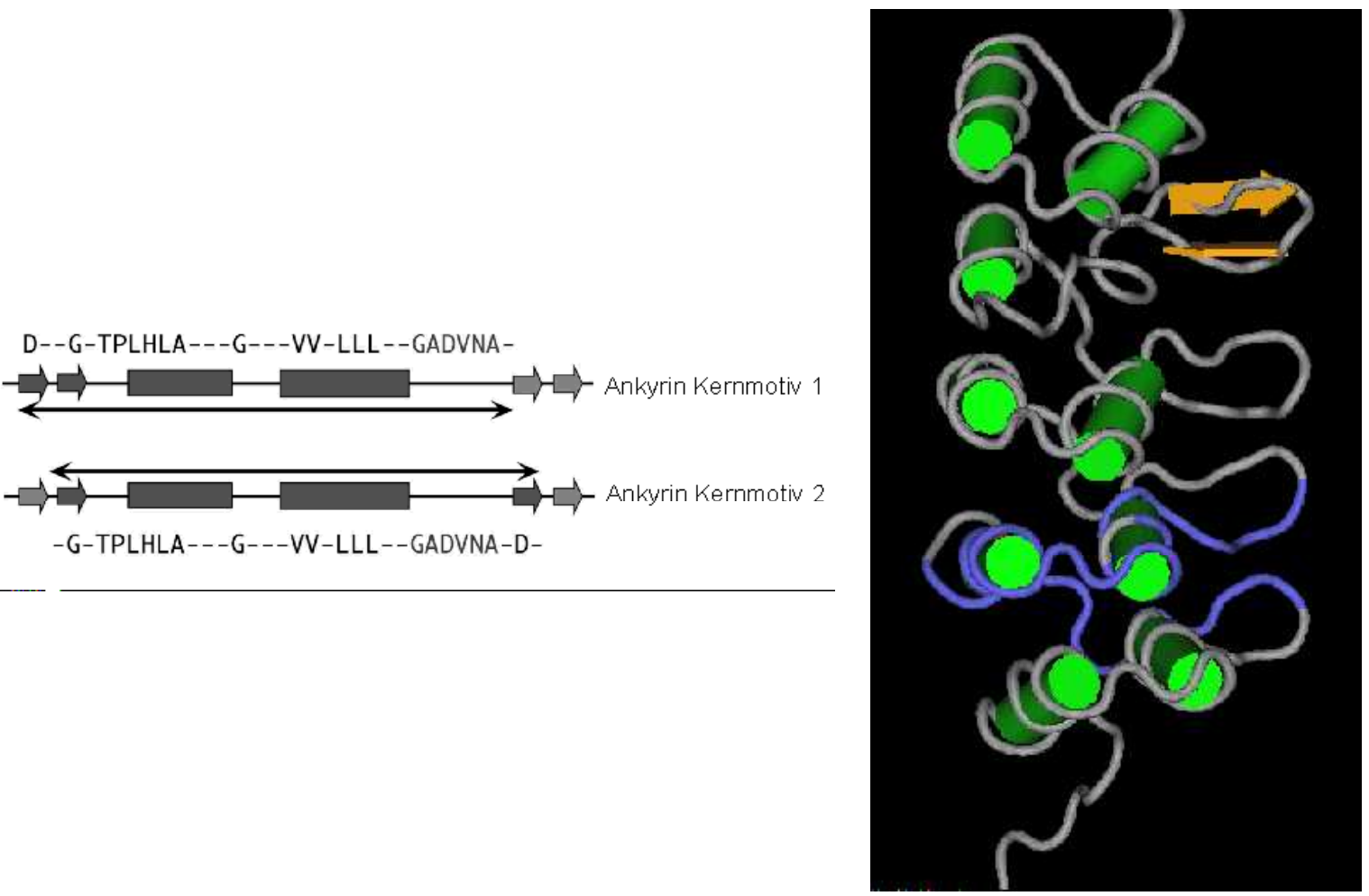

Abbildung 2.3: Die Sekundärstruktur und Tertiärstruktur der Ankyrin-Repeat Motive nach Sedgwick und Smerdon (1999). Sekundärstruktur (links): Die Balken stellen $\alpha$-Helices und die Pfeile $\beta$-Faltblätter dar. Der Doppelpfeil definiert das Kernmotiv. Tertiärstruktur (rechts): Die Zylinder zeigen die Lage der $\alpha$-Helices und die Pfeile die Lage der $\beta$ Faltblätter auf dem Aminosäurestrang an. Der blau angedeutete Bereich zeigt die Tertiärstruktur eines Ankyrin-Repeat Kernmotives an.

Für das Ankyrin-Repeat Protein ANK1 konnte eine spezifische Interaktion mit dem bZIPTranskriptionsfaktor BZI-1 gezeigt werden (Kuhlmann et al., 2003). BZI-1 $\Delta$ N Pflanzen 
zeigen eine reduzierte Auxin induzierte Organogenese an Blattscheiben (Heinekamp et al., 2004) und die TMV-induzierte Bildung von Läsionen ist verstärkt (Kuhlmann et al., 2003). Diese beobachteten Veränderungen sind abhängig von der Domäne DI von BZI-1. Transgenen Pflanzen, die BZI-1 Derivate überexprimieren, in denen neben der Aktivierungsdomäne $\mathrm{N}$ die ANK1 Interaktionsdomäne DI deletiert ist, zeigen eine Auxin induzierte Wurzelregeneration von Blattscheiben und TMV-induzierte HR-Läsionen wie der Wildtyp. Die mit ANK1 interagierende Domäne D1 ist somit essentiell für die Funktion von BZI-1 in planta.

Ein ANK1-GFP Fusionsprotein konnte im Cytosol, und ein BZI-1-GFP Fusionsprotein im Zellkern lokalisiert werden (Kuhlmann et al., 2003). Für BZI-1 konnte in Gelretardationsstudien eine Bindung des Homodimers an ACGT enthaltende cis-Elemente des GH3 Gens gezeigt werden. Diese Bindung konnte durch ANK1 inhibiert werden, ANK1 selber bindet jedoch nicht an dieses Motiv. Transkriptionelle Aktivierungseigenschaften konnten in Hefe und in planta für ANK1 nicht gezeigt werden. Möglicherweise ist ANK1 ein Regulator von BZI-1. So konnte für das Ankyrin-Repeat Protein NPR1 (,nonexpressor of PR genes'), aus Arabidopsis thaliana eine regulierende Funktion bei der Expression von PR Genen (,pathogen related') gezeigt werden. NPR1 multimerisiert cytosolisch durch Disulfidbrückenbindungen (Dong, 2004). Die Disulfidbrückenbindungen werden in Abhängigkeit des zellulären Redoxpotentials reduziert und NPR1 monomerisiert. Das NPR1 Monomer akkumuliert im Zellkern (Mou et al., 2003), wo es mit TGA-Transkriptionsfaktor interagiert.

Auch der Transkriptionsfaktor NFאB interagiert mit einem Ankyrin-Repeat Protein. IкB $\alpha$ (,inhibitor of $\kappa B^{\prime}$ ) maskiert bei dieser Interaktion die NLS (,nuclear localisation sequence') von NFkB, das dadurch im Cytosol zurückgehalten wird. Eine

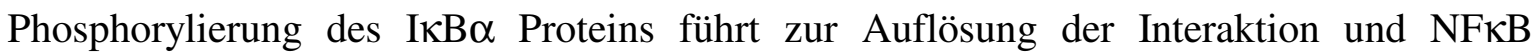
gelangt in den Zellkern (Jacobs et al., 1998; Huxford et al., 1998).

\subsection{ANK1 homologe Proteine}

Eine Datenbankanalyse zeigte für ANK1 Homologien mit Ankyrin-Repeat Proteinen aus verschiedenen Spezies (Abbildung 2.4).

Unter anderem konnten HBP1 (,helicase binding protein 1'; Van Der Heijden, 2002) und TIP1, 2 und 3 (,TGB12K-interacting protein'; Fridborg et al., 2003) in Nicotiana tabacum 
gefunden werden, die eine Sequenzidentität auf Aminosäureebene von 99\% zu ANK1 aufweisen.

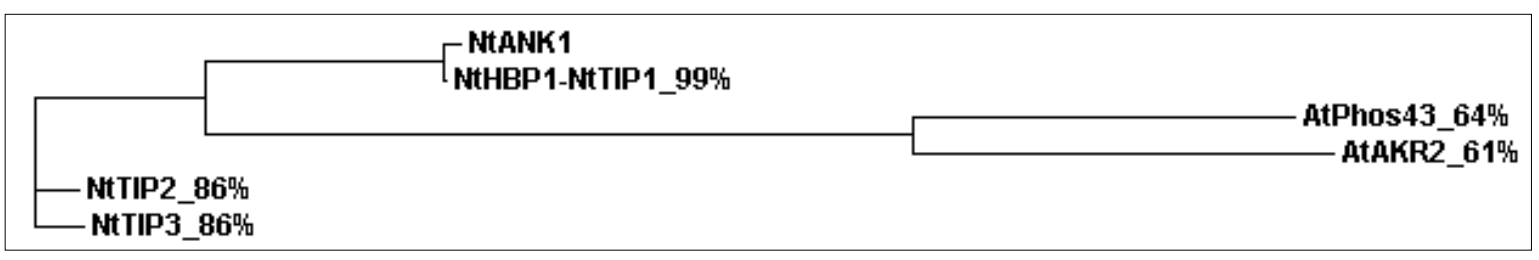

Abbildung 2.4: Cladogramm mit ANK1 und ANK1 homologen Proteinen. Angegeben sind die ersten beiden Buchstaben der Spezies und der Name des Proteins. Endständig sind die Abweichungen der Aminosäureidentität von ANK1 in Prozent. Nt: Nicotiana tabacum; At: Arabidopsis thaliana.

HBP1 und TIP1 wurden aus dem Kultivar SNN isoliert und wurden in unterschiedlichen Gruppen beschrieben, ANK1 hingegen ist aus dem Kultivar SR1. Dies könnte die leichten Unterschiede in der Sequenz erklären.

Van Der Heijden (2002) konnte eine Interaktion von HBP1 mit der HEL-Domäne (Helikase) der Alfalfa Mosaik Virus Replikase in einer Hefe-Interaktionsstudie zeigen, aber konnte dem Protein noch keine Funktion zuordnen. TIP1 interagiert mit der Replikase des Potato Virus X, dem TGB12K (,tripple gene block protein') in Hefe. Auch TIP2 und TIP3, die eine etwas schwächere Homologie zu ANK1 aufweisen, interagieren mit TGB12K, das für den Zell zu Zell Transport des Virus von Bedeutung sein könnte (Chapman et al., 1992; Fedorkin et al., 2001). Alle drei Proteine interagieren außerdem mit einer $\beta$-1,3-Glucanase, für die eine Funktion in der Regulation der SEL (, size exclusion limit') der Plasmodesmata, durch Kallose Degradation angenommen wird (Botha und Cross, 2000). Ein eindeutiger Nachweis der Funktion konnte von Fridborg et al., 2002 allerdings nicht erbracht werden.

Zwei weitere ANK1 hoch homologe Proteine sind von Wirdnam et al., 2004 aus Nicotiana plumbaginifolia entdeckt worden, die nicht in Abbildung 2.4 dargestellt sind, da diese Sequenzen bisher noch nicht verfügbar sind. Es wird eine Sequenzidentität auf Proteinebene von 98\% für GBP2 (,glucanohydrolase binding protein') mit ANK1 und von 96,3\% für GBP1 mit TIP2 beschreiben. Beide Proteine wurden in HefeInteraktionsstudien, bei denen eine $\beta-1,3-$ Glucanase (GLU 1) oder eine Chitinase (CHN 1) verwendet wurden, gefunden. GBP1 Überexpressions- und Antisense Pflanzen weisen einen reduzierten Gehalt an Stärke, Fruktose und Saccharose auf. Dieser Phänotyp geht einher mit der Bildung von nekrotischen Läsionen und mit der Expression der Markergene 
der Hypersensitiven Reaktion. Allerdings konnte keine Aussage über eine mögliche Funktion von GBP1 und GBP2 gemacht werden.

Das Ankyrin-Repeat Protein ANK1 zeigt auch signifikante Homologien zu den Proteinen AtPhos43 (Peck et al., 2001) und AKR2 (Yan et al., 2002) aus Arabidopsis thaliana. AtPhos43 wird innerhalb weniger Minuten nach Induktion mit dem bakteriellen Elicitor Flagellin (flg22) oder Chitin, einem pilzlichen Elicitor, phosphoryliert.

Für AKR2 konnte in einer Hefe-Interaktionsstudie eine Interaktion mit GF14 $\lambda$, einem 143-3 Protein gezeigt werden. GF14 $\lambda$ interagiert auch mit der APX 3 (Askorbat Peroxidase 3), die eine wichtige Funktion im $\mathrm{H}_{2} \mathrm{O}_{2}$ Abbau hat. In vitro Experimente konnten außerdem eine direkte Interaktion von AKR2 mit der APX 3 zeigen. Antisense Pflanzen zeigen kleine nekrotische Bereiche, in denen Yan et al., 2002 eine erhöhte $\mathrm{H}_{2} \mathrm{O}_{2}$ Produktion feststellen konnte. Diese Pflanzen exprimieren PR1 (,pathogen-related protein 1') und GST6 (Glutathion S-Transferase 6) stärker als der Wildtyp. Nach Infektionen mit Pseudomonas syringae pv. maculicola ES4326 zeigten antisense Pflanzen eine erhöhte Resistenz. Die Gruppe um Yan et al., 2002 postuliert, dass AKR2 ein negativer Regulator der PR1 Expression ist und das AKR2 an der Regulation des antioxidativen Metabolismus beteiligt ist.

Transgene Pflanzen, in denen die Expression ANK1 homologer Proteine reduziert oder verstärkt ist, exprimieren Stress induzierbare Gene, bilden Läsionen, interagieren mit Replikasen der Pathogene oder haben einen veränderten Kohlenhydrat Metabolismus. Aus diesem Grund wird für ANK1 und seine homologen Proteine eine Bedeutung in der Pathogenabwehr oder Stress-Reaktion der Pflanze angenommen. 


\subsection{Zielsetzung}

Der Fokus dieser Arbeit liegt auf der funktionellen Charakterisierung des Transkriptionsfaktors BZI-1 und des Ankyrin-Repeat Proteins ANK1, für die eine Interaktion in einer Hefe-Interaktionsstudie gezeigt werden konnte.

$\mathrm{Zu}$ Beginn dieser Arbeit ist die Bestätigung der Interaktion in planta. Für diese Studien eignete sich das Protoplasten ,Two-Hybrid' Verfahren und die BiFC (,Bimolecular Fluorescence Complementation') Methode, die gleichzeitig eine Bestimmung der zellulären Lokalisation ermöglicht.

Daran anschließen soll eine genauere Analyse der mechanistischen Bedeutung dieser Interaktion. Verschiedene putative Funktionen von ANK1 als Retentionsfaktor, Co-Faktor oder Repressor sind $\mathrm{zu}$ analysieren. In diesem Kontext ist der mögliche Einfluss verschiedener Stimuli auf die Lokalisation und Interaktion von ANK1 und BZI-1 zu untersuchen. Als Stimuli kommen aufgrund der Vorarbeiten an BZI-1 vor allem Auxin und Pathogene in Frage.

Ein weiterer Ansatz ist die Analyse der putativen Aktivierungs- oder Repressoreigenschaften in planta. Dazu sollen die BZI-1 Heterodimerisierungspartner BZI-2, BZI-3, und BZI-4 im Protoplasten System mit einbezogen werden. Ausgehend von der Interaktionsstudie werden diese Untersuchungen voraussichtlich Aufschluss über den Einfluss von ANK1 auf die transkriptionelle Aktivierung geben.

Im Rahmen dieser Arbeit soll die Expression von ANK1 und BZI-1 in transgenen Pflanzen mit eine ,RNA-Interference' Ansatz reduziert und für ANK1 Überexpressionspflanzen hergestellt werden. Diese transgenen Pflanzen werden dann im Rahmen der Pathogenantwort nach Infektion mit TMV und auf eine mögliche Veränderungen in der Auxinantwort untersucht. 


\section{$3 \quad$ Materialien}

\subsection{Organismen}

\subsubsection{Mikroorganismen}

\begin{tabular}{|c|c|c|}
\hline Stamm & Eigenschaften & Herkunft \\
\hline $\begin{array}{l}\text { Escherichia coli } \\
\text { DH5a }\end{array}$ & $\begin{array}{l}\text { F-, gyrA96(Nalr), recA1, relA1, thi-1, hsd'R17 } \\
\text { (rk-mk+), glnV44, deoR, D (lacZY A-argF) } \\
\text { U169 [p80dD(lacZ)M15] }\end{array}$ & Hanahan et al., 1983 \\
\hline $\begin{array}{l}\text { Escherichia coli } \\
\text { DB3.1 }\end{array}$ & $\begin{array}{l}\mathrm{F}^{-} \text {gyrA462 endA1 D( sr1- recA) mcrB mrr } \\
\text { hsdS20 }\left(\mathrm{r}_{\mathrm{B}}^{-}, \mathrm{m}_{\mathrm{B}}^{-}\right) \text {supE44 ara-14 galK2 lacY1 } \\
\text { proA2 rpsL20 }\left(\mathrm{Sm}^{\mathrm{r}}\right) \text { xyl-5 } \lambda^{-} \text {leu mtl-1. }\end{array}$ & Bernard, P., 1993 \\
\hline $\begin{array}{l}\text { Escherichia coli } \\
\text { XL1Blue }\end{array}$ & $\begin{array}{l}\text { recA1, endA1, gyrA96, hsdR17, supE44, lac, } \\
{\left[\mathrm{F}^{\prime} \text { proAB, laclq Z M15, Tn10(tetr)], thi }\right.}\end{array}$ & Bullock et al., 1987 \\
\hline $\begin{array}{l}\text { Agrobaterium tumefaciens } \\
\text { LBA } 4404\end{array}$ & pAL4404, SmR & Hokema et al., 1983 \\
\hline $\begin{array}{l}\text { Agrobaterium tumefaciens } \\
\text { GV3101RK }\end{array}$ & $\begin{array}{l}\text { pMP90RK } \\
\text { Rif }^{\mathrm{R}}, \mathrm{Gm}^{\mathrm{R}}, \mathrm{Km}^{\mathrm{R}}\end{array}$ & $\begin{array}{l}\text { Koncz, C., Schell, J., } \\
1986\end{array}$ \\
\hline $\begin{array}{l}\text { Agrobaterium tumefaciens } \\
\text { GV3101KR }\end{array}$ & $\begin{array}{l}\text { pMP90KR } \\
\text { Rif }^{\mathrm{R}}, \mathrm{Gm}^{\mathrm{R}}, \mathrm{Amp}^{\mathrm{R}}\end{array}$ & $\begin{array}{l}\text { Koncz, C., Schell, J., } \\
1986\end{array}$ \\
\hline TMV & & Niggeweg, 1999 \\
\hline
\end{tabular}

\subsubsection{Pflanzen}

Als Wildtyppflanzen wurden die Kultivare Xanthi und Samsun NN (SNN) von Nicotiana tabacum verwendet. Die transgenen Pflanzen sind in der nachfolgenden Tabelle aufgeführt. Für die BiFC Experimente wurden Nicotiana benthamiana Pflanzen verwendet.

\begin{tabular}{|c|c|c|c|}
\hline Pflanze & Kultivar & Eigenschaften & Referenz \\
\hline CHS8 & Xanthi & pchs8::gus; $\mathrm{Km}^{\mathrm{R}}$ & Schmidt et al., 1990 \\
\hline CHS8/ANK1-RNAi & Xanthi & $\begin{array}{l}\text { p35S::ANK1:ANK1 } \\
\text { (inverted); } \mathrm{Km}^{\mathrm{R}}, \mathrm{BASTA}^{\circledast}\end{array}$ & diese Arbeit \\
\hline CHS8/ANK1OEX & Xanthi & $\begin{array}{l}\text { p35S::ANK1; Km }{ }^{\mathrm{R}} \text {, } \\
\text { Hyg }^{\mathrm{R}}\end{array}$ & diese Arbeit \\
\hline CHS8/BZI-1- $\Delta \mathrm{N}$ & Xanthi & Tx::BZI-1- $\Delta \mathrm{N} ; \mathrm{Km}^{\mathrm{R}}, \mathrm{Hyg}^{\mathrm{R}}$ & Heinekamp, 2002 \\
\hline CHS8/BZI-1OEX & Xanthi & $\begin{array}{l}\text { Tx::BZI-1; Km }{ }^{\mathrm{R}} \\
\text { Hyg }^{\mathrm{R}}\end{array}$ & Heinekamp, 2002 \\
\hline CHS8/BZI-1-RNAi & Xanthi & $\begin{array}{l}\text { p35S::BZI-1:BZI-(inverted); } \\
\text { Km }^{\mathrm{R}}, \text { BASTA }^{\circledR}\end{array}$ & diese Arbeit \\
\hline
\end{tabular}




\subsection{Nukleinsäuren}

\subsubsection{Plasmide}

\begin{tabular}{|c|c|c|}
\hline Bezeichnung & Beschreibung & Referenz \\
\hline pBinHygTX & $\begin{array}{l}\text { pBinHyg-Derivat (Becker, 1991), enthält Fragment aus dem } \\
\text { TX-Promotor und pAocs, mcs; } \text { Hyg }^{\mathrm{R}} \text { in Pflanzen; } \mathrm{Km}^{\mathrm{R}} \text { in } \\
\text { Bakterien }\end{array}$ & Gatz et al., 1992 \\
\hline pBluescriptIIKS & Kloniervektor, lacZ $\alpha, \mathrm{Amp}^{\mathrm{R}}$ & Clontech \\
\hline pSK-T & Klonier- und Sequenziervektor, lacZ $\alpha, \mathrm{amp}^{\mathrm{R}}$ & $\begin{array}{l}\text { Kriete, } \\
\text { unveröffentlicht }\end{array}$ \\
\hline pFGC5941 & $\begin{array}{l}\text { pMas2' Promotor; BAR; p35S Promoter; ChsA intron; attR1, } \\
\mathrm{Cm}^{\mathrm{R}} \text {, ccdB, attR2; Km }{ }^{\mathrm{R}} ; \text { pBR322 ori, } \\
\text { GW-Eingangsvektor }\end{array}$ & $\begin{array}{l}\text { http://ag.arizona. } \\
\text { edu/chromatin/fg } \\
\text { c5941.html }\end{array}$ \\
\hline pFGC5941-ANK1 & $\begin{array}{l}\text { pMas2' Promotor; BAR; p35S Promoter; ChsA intron; attR1, } \\
\text { ANK1, attR2; Km }{ }^{\mathrm{R}} \text {; pBR322 ori }\end{array}$ & Böttner, 2003 \\
\hline pFGC5941-BZI-1 & $\begin{array}{l}\text { pMas2' Promotor; BAR; p35S Promoter; ChsA intron; attR1, } \\
\text { BZI-1, attR2; } \mathrm{Km}^{\mathrm{R}} ; \text { pBR322 ori }\end{array}$ & diese Arbeit \\
\hline pPR1a & 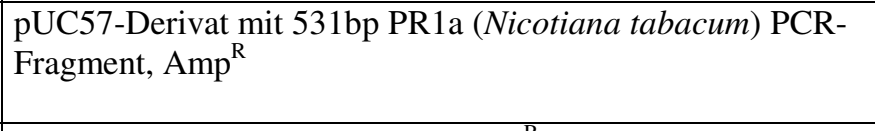 & $\begin{array}{l}\text { Cutt et al., } 1988 \\
\text { Plasmid von M. } \\
\text { Dröge }\end{array}$ \\
\hline pGWB15 & $\begin{array}{l}\text { 35S Promotor; 3xHA-tag; attR1, } \mathrm{Cm}^{\mathrm{R}} \text {, ccdB, attR2; GW- } \\
\text { Expressionsvektor }\end{array}$ & Nakagawa, 2002 \\
\hline pGWB15-ANK1 & 35S Promotor; 3xHA-tag; attR1, ANK1, attR2 & diese Arbeit \\
\hline pDONR223 & pUC ori; $\mathrm{Sm}^{\mathrm{R}}$; attL1, $\mathrm{Cm}^{\mathrm{R}}$, ccdB, attL2; GW-Eingangsvektor & Invitrogen, 2001 \\
\hline pDON-ANK1 & pUC ori; $\mathrm{Sm}^{\mathrm{R}}$; attL1, ANK1, attL2 & Böttner, 2003 \\
\hline pDON-ANK1mutI & pUC ori; $\mathrm{Sm}^{\mathrm{R}}$; attL1, ANK1mutI, attL2 & diese Arbeit \\
\hline pDON-ANK1mutII & pUC ori; $\mathrm{Sm}^{\mathrm{R}}$; attL1, ANK1mutII, attL2 & diese Arbeit \\
\hline pDON-ANK1mutIII & pUC ori; $\mathrm{Sm}^{\mathrm{R}}$; attL1, ANK1mutIII, attL2 & diese Arbeit \\
\hline pDON-BZI-1 & pUC ori; $\mathrm{Sm}^{\mathrm{R}}$; attL1, BZI-1, attL2 & diese Arbeit \\
\hline pDON-BZI-2 & pUC ori; $\mathrm{Sm}^{\mathrm{R}}$; attL1, BZI-2, attL2 & Iven, 2004 \\
\hline pDON-BZI-3 & pUC ori; $\mathrm{Sm}^{\mathrm{R}} ;$ attL1, BZI-3, attL2 & Iven, 2004 \\
\hline pDON-BZI-4 & pUC ori; $\mathrm{Sm}^{\mathrm{R}}$; attL1, BZI-4, attL2 & Iven, 2004 \\
\hline $\mathrm{pE}$ & $\begin{array}{l}\text { pEXSG-YFP Derivat mit deletiertem YFP, p35S-Promotor, } \\
\text { attR1, Cm }{ }^{\mathrm{R}}, \operatorname{ccdB} \text {, attR2, RK2 ori, Amp }{ }^{\mathrm{R}}, \mathrm{GW}- \\
\text { Expressionsvektor }\end{array}$ & $\begin{array}{l}\text { Carsjens, } \\
\text { unveröffentlicht }\end{array}$ \\
\hline pE-ANK1 & $\begin{array}{l}\text { p35S-Promotor, attR1, ANK1, attR2, GW-Expressionsvektor, } \\
\text { RK2 ori, Amp }{ }^{\mathrm{R}} \text {, }\end{array}$ & diese Arbeit \\
\hline pE-ANK1mutI & $\begin{array}{l}\text { p35S-Promotor, attR1, ANK1mutI, attR2, GW- } \\
\text { Expressionsvektor, RK2 ori, Amp }{ }^{\mathrm{R}} \text {, }\end{array}$ & diese Arbeit \\
\hline pE-ANK1mutIII & $\begin{array}{l}\text { p35S-Promotor, attR1, ANK1mutIII, attR2, GW- } \\
\text { Expressionsvektor, RK2 ori, Amp }^{\mathrm{R}} \text {, }\end{array}$ & diese Arbeit \\
\hline pE-BZI-1 & $\begin{array}{l}\text { p35S-Promotor, attR1, BZI-1, attR2, GW-Expressionsvektor, } \\
\text { RK2 ori, Amp }{ }^{\mathrm{R}} \text {, }\end{array}$ & diese Arbeit \\
\hline pE-SPYCE & $\begin{array}{l}\text { pE-Vektor mit GW-Kassette des pSPYCE-35S; 35S } \\
\text { Promotor, HA-tag, CE-tag, attR1, Cm }{ }^{\mathrm{R}}, \mathrm{ccdB}, \text { attR2, RK2 } \\
\text { ori, Amp }{ }^{\mathrm{R}}, \mathrm{GW} \text {-Expressionsvektor }\end{array}$ & $\begin{array}{l}\text { Weltmeier et al., } \\
2006\end{array}$ \\
\hline pE-SPYCE(-) & $\begin{array}{l}\text { pE-SPYCE mit deletierter GW-Kassette, 35S Promotor, HA- } \\
\text { tag, CE-tag, RK2 ori, Amp }\end{array}$ & $\begin{array}{l}\text { Carsjens, } \\
\text { unveröffentlicht }\end{array}$ \\
\hline pE-SPYCE-ANK1 & $\begin{array}{l}\text { 35S Promotor, HA-tag, CE-tag, attR1, ANK1, attR2, RK2 } \\
\text { ori, Amp }{ }^{\mathrm{R}}, \mathrm{GW} \text {-Expressionsvektor }\end{array}$ & diese Arbeit \\
\hline pE-SPYCE-ANK1mutI & $\begin{array}{l}\text { 35S Promotor, HA-tag, CE-tag, attR1, } \mathrm{Cm}^{\mathrm{R}} \text {, ANK1mutI, } \\
\text { RK2 ori, Amp }{ }^{\mathrm{R}}, \mathrm{GW} \text {-Expressionsvektor }\end{array}$ & diese Arbeit \\
\hline $\begin{array}{l}\text { pE-SPYCE- } \\
\text { ANK1mutIII }\end{array}$ & $\begin{array}{l}\text { 35S Promotor, HA-tag, CE-tag, attR1, ANK1mutIII, attR2, } \\
\text { RK2 ori, Amp }{ }^{\mathrm{R}} \text {, GW-Expressionsvektor }\end{array}$ & diese Arbeit \\
\hline pE-SPYCE-BZI-1 & $\begin{array}{l}\text { 35S Promotor, HA-tag, CE-tag, attR1, } \mathrm{Cm}^{\mathrm{R}}, \mathrm{ccdB}, \text { attR2, } \\
\text { RK2 ori, Amp }{ }^{\mathrm{R}}, \mathrm{GW} \text {-Expressionsvektor }\end{array}$ & diese Arbeit \\
\hline
\end{tabular}




\begin{tabular}{|c|c|c|}
\hline Bezeichnung & Beschreibung & Referenz \\
\hline pE-SPYNE & $\begin{array}{l}\text { pE-Vektor mit GW-Kassette des pSPYNE-35S; 35S } \\
\text { Promotor, HA-tag, NE-tag, attR1, Cm }{ }^{\mathrm{R}}, \mathrm{ccdB} \text {, attR2, RK2 } \\
\text { ori, Amp }{ }^{\mathrm{R}}, \mathrm{GW} \text {-Expressionsvektor }\end{array}$ & $\begin{array}{l}\text { Weltmeier et al., } \\
2006\end{array}$ \\
\hline pE-SPYNE(-) & $\begin{array}{l}\text { pE-SPYNE mit deletierter GW-Kassette, 35S Promotor, HA- } \\
\text { tag, CE-tag, RK2 ori, Amp }{ }^{R}\end{array}$ & $\begin{array}{l}\text { Weltmeier et al., } \\
2006\end{array}$ \\
\hline pE-SPYNE-ANK1 & $\begin{array}{l}\text { 35S Promotor, HA-tag, NE-tag, attR1, ANK1, attR2, RK2 } \\
\text { ori, Amp }{ }^{\mathrm{R}}, \mathrm{GW} \text {-Expressionsvektor }\end{array}$ & diese Arbeit \\
\hline pE-SPYNE-ANK1mutI & $\begin{array}{l}\text { 35S Promotor, HA-tag, NE-tag, attR1, ANK1mutI, attR2, } \\
\text { RK2 ori, Amp }{ }^{\mathrm{R}}, \mathrm{GW} \text {-Expressionsvektor }\end{array}$ & diese Arbeit \\
\hline $\begin{array}{l}\text { pE-SPYNE- } \\
\text { ANK1mutIII }\end{array}$ & $\begin{array}{l}\text { 35S Promotor, HA-tag, NE-tag, attR1, ANK1mutIII, attR2, } \\
\text { RK2 ori, Amp }{ }^{\mathrm{R}} \text {, GW-Expressionsvektor }\end{array}$ & diese Arbeit \\
\hline pE-SPYNE-BZI-1 & $\begin{array}{l}\text { 35S Promotor, HA-tag, NE-tag, attR1, BZI-1, attR2, RK2 ori, } \\
\text { Amp }^{\mathrm{R}} \text {, GW-Expressionsvektor }\end{array}$ & diese Arbeit \\
\hline pENSG-YFP & $\begin{array}{l}\text { p35SS Promotor, attR1, } \mathrm{Cm}^{\mathrm{R}}, \mathrm{ccdB}, \text { attR2, RK2 ori, } \mathrm{Amp}^{\mathrm{R}} \text {, } \\
\text { GW-Expressionsvektor }\end{array}$ & $\begin{array}{l}\text { Consonni, C } \\
2001\end{array}$ \\
\hline pENSG-YFP-ANK1 & $\begin{array}{l}\text { p35SS Promotor, attR1, ANK1, attR2, RK2 ori, Amp }{ }^{\mathrm{R}}, \mathrm{GW}- \\
\text { Expressionsvektor }\end{array}$ & diese Arbeit \\
\hline $\begin{array}{l}\text { pENSG-YFP- } \\
\text { ANK1mutI }\end{array}$ & $\begin{array}{l}\text { p35SS Promotor, attR1, ANK1mutI, attR2, RK2 ori, Amp }{ }^{\mathrm{R}} \text {, } \\
\text { GW-Expressionsvektor }\end{array}$ & diese Arbeit \\
\hline $\begin{array}{l}\text { pENSG-YFP- } \\
\text { ANK1mutIII }\end{array}$ & $\begin{array}{l}\text { p35SS Promotor, attR1, ANK1mutIII, attR2, RK2 ori, Amp }{ }^{\mathrm{R}} \text {, } \\
\text { GW-Expressionsvektor }\end{array}$ & diese Arbeit \\
\hline pENSG-YFP-BZI-1 & $\begin{array}{l}\text { p35SS Promotor, attR1, BZI-1, attR2, RK2 ori, Amp }{ }^{\mathrm{R}}, \mathrm{GW}- \\
\text { Expressionsvektor }\end{array}$ & diese Arbeit \\
\hline Gal4-UAS-GUS & $\begin{array}{l}\text { alter Name: BT10-GAL4; 4x GAL4-DNA-Bindestelle, pUC } \\
\text { ori, 35S-Minimalpromotor, GUS-Reportergen, Amp }\end{array}$ & $\begin{array}{l}\text { Weisshaar B, } \\
1999\end{array}$ \\
\hline pROK219-NAN & CaMV 35S-Promotor, pUC19-Derivat, Amp ${ }^{R}$ & $\begin{array}{l}\text { Kirby und } \\
\text { Kavanagh, } 2002\end{array}$ \\
\hline pHBT- $\Delta$ GFP & $\begin{array}{l}\text { pHBTL-sGFP Derivat (Sheen, unveröffentlicht), Entfernung } \\
\text { des } s G F P \text { Gens durch NcoI/NotI-Verdau, Klenow-'fill-in' } \\
\text { und Religation, pUC ori, Amp }{ }^{\mathrm{R}}\end{array}$ & $\begin{array}{l}\text { Heinekamp, } \\
2002\end{array}$ \\
\hline HBT-GUS-NCO & $\begin{array}{l}\text { pUC18 Derivat, -389 bis -46 Region des CaMV 35S } \\
\text { Promotors, -188bp aus dem 5'-Bereich des C4ppdkZn1-Gens } \\
\text { (Zea mays) mit der TATA-Box und Teilen des 5'-UTRs, } \\
\text { sGFP-s65T, Amp }\end{array}$ & $\begin{array}{l}\text { Thurow C, } \\
\text { unveröffentlicht }\end{array}$ \\
\hline pHBTL-BDGW & $\begin{array}{l}\text { p35S-Promotor, GAL4 }{ }_{(1-147)} \mathrm{BD} \text {, attR1, } \mathrm{Cm}^{\mathrm{R}}, \mathrm{ccdB} \text {, attR2, } \\
\text { pUC ori, Amp }{ }^{\mathrm{R}}, \mathrm{GW} \text {-Expressionsvektor }\end{array}$ & $\begin{array}{l}\text { Ehlert et al., } \\
2006\end{array}$ \\
\hline pHBTL-BD-ANK1 & $\begin{array}{l}\text { p35S-Promotor, GAL4 }{ }_{(1-147)} B D \text {, attR1, ANK1, attR2, pUC } \\
\text { ori, Amp }^{R}\end{array}$ & diese Arbeit \\
\hline pHBTL-BD-ANK1mutI & $\begin{array}{l}\text { p35S-Promotor, GAL4 }{ }_{(1-147)} B D \text {, attR1, ANK1mutI, attR2, } \\
\text { pUC ori, Amp }{ }^{R}\end{array}$ & diese Arbeit \\
\hline pHBTL-BD-ANK1mutII & $\begin{array}{l}\text { p35S-Promotor, GAL4 }{ }_{(1-147)} B D \text {, attR1, ANK1mutII, attR2, } \\
\text { pUC ori, Amp }\end{array}$ & diese Arbeit \\
\hline $\begin{array}{l}\text { pHBTL-BD- } \\
\text { ANK1mutIII }\end{array}$ & $\begin{array}{l}\text { p35S-Promotor, GAL4 }{ }_{(1-147)} \mathrm{BD}, \text { attR1, ANK1mutIII, attR2, } \\
\text { pUC ori, Amp }\end{array}$ & diese Arbeit \\
\hline pHBTL-BD-BZI-1 & $\begin{array}{l}\text { p35S-Promotor, GAL4 }{ }_{(1-147)} \text { BD, attR1, BD-BZI-1, attR2, } \\
\text { pUC ori, Amp }\end{array}$ & diese Arbeit \\
\hline pHBTL-BD-BZI-2 & $\begin{array}{l}\text { p35S-Promotor, GAL4 }{ }_{(1-147)} \text { BD, attR1, BD-BZI-2, attR2, } \\
\text { pUC ori, Amp }{ }^{\mathrm{R}}\end{array}$ & diese Arbeit \\
\hline pHBTL-BD-BZI-3 & $\begin{array}{l}\text { p35S-Promotor, GAL4 }{ }_{(1-147)} \text { BD, attR1, BD-BZI-3, attR2, } \\
\text { pUC ori, Amp }\end{array}$ & diese Arbeit \\
\hline pHBTL-BD-BZI-4 & $\begin{array}{l}\text { p35S-Promotor, GAL4 }{ }_{(1-147)} \mathrm{BD}, \text { attR1, BD-BZI-4, attR2, } \\
\text { pUC ori, Amp }\end{array}$ & diese Arbeit \\
\hline pHBTL-ADGW & $\begin{array}{l}\text { p35S-Promotor, GAL4 }{ }_{(768-881)} \mathrm{AD} \text {, attR1, CmR, ccdB, attR2, } \\
\text { pUC ori, Amp }{ }^{\mathrm{R}}, \mathrm{GW} \text {-Expressionsvektor }\end{array}$ & $\begin{array}{l}\text { Weltmeier et al., } \\
2006\end{array}$ \\
\hline pHBTL-AD-ANK1 & 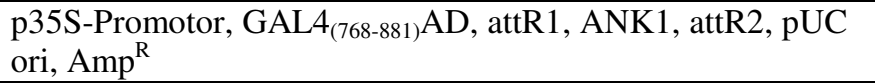 & diese Arbeit \\
\hline pHBTL-AD-ANK1mutI & $\begin{array}{l}\text { p35S-Promotor, GAL4 }{ }_{(768-881)} A D \text {, attR1, ANK1mutI, attR2, } \\
\text { pUC ori, } A m p^{R}\end{array}$ & diese Arbeit \\
\hline
\end{tabular}




\begin{tabular}{|c|c|c|}
\hline Bezeichnung & Beschreibung & Referenz \\
\hline $\begin{array}{l}\text { pHBTL-AD- } \\
\text { ANK1mutII }\end{array}$ & 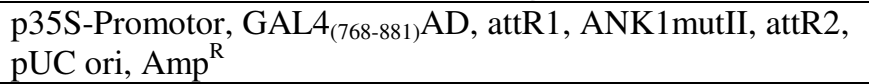 & diese Arbeit \\
\hline $\begin{array}{l}\text { pHBTL-AD- } \\
\text { ANK1mutIII }\end{array}$ & $\begin{array}{l}\text { p35S-Promotor, GAL4 }{ }_{(768-881)} \mathrm{AD}, \text { attR1, ANK1mutIII, attR2, } \\
\text { pUC ori, Amp }\end{array}$ & diese Arbeit \\
\hline pHBTL-AD-BZI-1 & $\begin{array}{l}\text { p35S-Promotor, GAL4 }{ }_{(768-881)} \mathrm{AD}, \text { attR1, BZI-1, attR2, pUC } \\
\text { ori, Amp }{ }^{\mathrm{R}}\end{array}$ & diese Arbeit \\
\hline pHBTL-AD-BZI-2 & $\begin{array}{l}\text { p35S-Promotor, GAL4 }{ }_{(768-881)} \mathrm{AD} \text {, attR1, BZI-2 attR2, pUC } \\
\text { ori, } \mathrm{Amp}^{\mathrm{R}}\end{array}$ & diese Arbeit \\
\hline pHBTL-AD-BZI-3 & $\begin{array}{l}\text { p35S-Promotor, GAL4 } 4_{(768-881)} A D \text {, attR1, BZI-3 attR2, pUC } \\
\text { ori, Amp }\end{array}$ & diese Arbeit \\
\hline pHBTL-AD-BZI-4 & 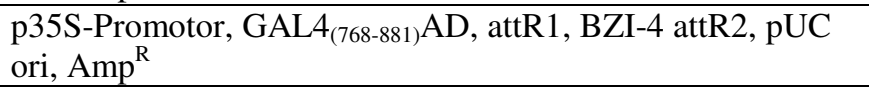 & diese Arbeit \\
\hline pHBTL-HAGW & $\begin{array}{l}\text { p35S-Promotor, 3xHA-tag, attR1, CmR, ccdB, attR2, pUC } \\
\text { ori; Amp }{ }^{\mathrm{R}} \text {, GW-Expressionsvektor }\end{array}$ & $\begin{array}{l}\text { Ehlert } \text { et al., } \\
2006\end{array}$ \\
\hline pHBTL-HA-ANK1 & $\begin{array}{l}\text { p35S-Promotor, 3xHA-tag, attR1, ANK1, attR2, pUC ori; } \\
\text { Amp }^{\mathrm{R}}\end{array}$ & diese Arbeit \\
\hline pHBTL-HA-BZI-1 & $\begin{array}{l}\text { p35S-Promotor, 3xHA-tag, attR1, BZI-1, attR2, pUC ori; } \\
\text { Amp }^{\mathrm{R}}\end{array}$ & diese Arbeit \\
\hline $\begin{array}{l}\text { pHBTL-NLS-HA- } \\
\text { ANK1 }\end{array}$ & $\begin{array}{l}\text { p35S-Promotor, NLS(SV40), 3xHA-tag, attR1, CmR, ccdB, } \\
\text { attR2, pUC ori; Amp }{ }^{\mathrm{R}} \text {, }\end{array}$ & diese Arbeit \\
\hline
\end{tabular}

\subsubsection{Oligonukleotide}

Die Oligonukleotide wurden nach Vorgabe der Basensequenz von den Firmen Invitrogen oder Operon synthetisiert und in lyophilisierter Form geliefert.

\begin{tabular}{|c|c|c|c|}
\hline Name & $\begin{array}{c}\text { Sequenz } \\
\text { (in 5'-3' Richtung) }\end{array}$ & $\begin{array}{c}\text { Position in der } \\
\text { Stammsammlung }\end{array}$ & Verwendung \\
\hline GW-kasREVattB2 & $\begin{array}{l}\text { CCGGTACCACCACTTTGT } \\
\text { ACAAGAAAGCTGGGTGTC } \\
\text { ACAGAAACA }\end{array}$ & 263 & $\begin{array}{l}\text { zur Konstruktion des } \\
\text { pHBTL-NLS-HA- } \\
\text { ANK1 Vektors }\end{array}$ \\
\hline N.t. gh3 lower & $\begin{array}{l}\text { CAAAATAACCCATGTTTG } \\
\text { GCATG }\end{array}$ & 117 & GH3-Sonde \\
\hline N.t. gh3 upper & $\begin{array}{l}\text { CCTCACTAGCTCTGGAAC } \\
\text { GTCAG }\end{array}$ & 116 & GH3-Sonde \\
\hline $\mathrm{p} 35 \mathrm{~S} 1$ & $\begin{array}{l}\text { ATTGATGTGATATCTCCA } \\
\text { CTGAC }\end{array}$ & 169 & unterschiedlich \\
\hline $\mathrm{P} 40$ & $\begin{array}{l}\text { GCCGGTACCTCCACTTCA } \\
\text { TCTC }\end{array}$ & 068 & BZI-1 Primer \\
\hline P41 & $\begin{array}{l}\text { GGATCCATGCCTTGAGTT } \\
\text { GTTTC }\end{array}$ & 069 & BZI-1 Primer \\
\hline $\mathrm{P} 42$ & $\begin{array}{l}\text { TCTCCTTACACGTTTTGCA } \\
\text { TCAGC }\end{array}$ & 070 & BZI-1 Primer \\
\hline $\mathrm{P} 43$ & $\begin{array}{l}\text { CTCATCCAAGAAGGCATT } \\
\text { GTCAT }\end{array}$ & 071 & BZI-1 Primer \\
\hline P44 & $\begin{array}{l}\text { CAGATTGCTCTCTAGATG } \\
\text { AACCACTGGTTG }\end{array}$ & 072 & BZI-1 Primer \\
\hline $\mathrm{P} 45$ & $\begin{array}{l}\text { CATTCTCCTTACACGTTTT } \\
\text { GCATCAGCTG }\end{array}$ & 073 & BZI-1 Primer \\
\hline P46 & $\begin{array}{l}\text { CAGCTGATGCAAAACGTG } \\
\text { TAAGGAGAATG }\end{array}$ & 074 & BZI-1 Primer \\
\hline P50 & $\begin{array}{l}\text { CAACCAGTGGTTCATCTA } \\
\text { GAGAGCAATCTG }\end{array}$ & 082 & BZI-1 Primer \\
\hline P54 & $\begin{array}{l}\text { GGATCATCTTGCACAGGT } \\
\text { ACAGCAGCG }\end{array}$ & 076 & BZI-1 Primer \\
\hline P57 & $\begin{array}{l}\text { AGATGCTCCAAGCTAGCA } \\
\text { ACCCGCTGC }\end{array}$ & 083 & BZI-1 Primer \\
\hline
\end{tabular}




\begin{tabular}{|c|c|c|c|}
\hline Name & $\begin{array}{c}\text { Sequenz } \\
\text { (in 5'-3' Richtung) }\end{array}$ & $\begin{array}{c}\text { Position in der } \\
\text { Stammsammlung }\end{array}$ & Verwendung \\
\hline P75 & $\begin{array}{l}\text { CGGAAGAGCTTCGATTCA } \\
\text { TCATC }\end{array}$ & 101 & BZI-1 Primer \\
\hline P76 & $\begin{array}{l}\text { GCAGCGGTTGGGGAATCA } \\
\text { AC }\end{array}$ & 102 & BZI-1 Primer \\
\hline pAK-10 & $\begin{array}{l}\text { AATCTGAGCACACTTCAC } \\
\text { CTCGCC }\end{array}$ & 304 & ANK1 Primer \\
\hline pAK-2 & $\begin{array}{l}\text { GGTGCTACCTCTTCCGCA } \\
\text { ATAC }\end{array}$ & 055 & ANK1 Primer \\
\hline pAK-3 & $\begin{array}{l}\text { GTATTGCGGAAGAGGTAG } \\
\text { CACC }\end{array}$ & 056 & ANK1 Primer \\
\hline pAK4 & $\begin{array}{l}\text { GCGGAGCAGATAGCGAA } \\
\text { AGATC }\end{array}$ & 057 & ANK1 Primer \\
\hline pAK5 & $\begin{array}{l}\text { GAGAATGGAGCCGCTGTA } \\
\text { ACTCTC }\end{array}$ & 058 & ANK1 Primer \\
\hline pAK6 & $\begin{array}{l}\text { ATCAAAGTTGGGGACGCT } \\
\text { CTCC }\end{array}$ & 059 & ANK1 Primer \\
\hline pAK8 & $\begin{array}{l}\text { GACATGGATGGATCCTGC } \\
\text { ATCAAC }\end{array}$ & 061 & ANK1 Primer \\
\hline pBZI-1 3UTR2 & $\begin{array}{l}\text { GCAAAATCTTCGGTGCAG } \\
\text { CTGGTG }\end{array}$ & 217 & BZI-1 qRT-Primer \\
\hline pBZI-1_3UTR & $\begin{array}{l}\text { GCAAAATCTTCGGTGCAG } \\
\text { CTGGTGCC } \\
\end{array}$ & 94 & BZI-1 qRT-Primer \\
\hline pGW-BZI-1_2 & $\begin{array}{l}\text { ACCACTTTGTACAAGAAA } \\
\text { GCTGGGTGTTATTGCTCTC } \\
\text { CCCTGCCTTGAG } \\
\end{array}$ & 332 & $\begin{array}{l}\text { zur Konstruktion des } \\
\text { pDON-BZI-1 } \\
\text { Entryklons }\end{array}$ \\
\hline pMUT1-ANKfor & $\begin{array}{l}\text { CAGCATTGCATTTTGCTCC } \\
\text { TGGATATGGCGAGGTG }\end{array}$ & 395 & $\begin{array}{l}\text { zur Konstruktion des } \\
\text { ANK1mutsIII }\end{array}$ \\
\hline pMUT1-ANKre & $\begin{array}{l}\text { CACCTCGCCATATCCAGG } \\
\text { AGCAAATGCAATGCTG }\end{array}$ & 396 & $\begin{array}{l}\text { zur Konstruktion des } \\
\text { ANK1mutsIII }\end{array}$ \\
\hline pNLS-HAGW & $\begin{array}{l}\text { GGTACCATGGCTCCCAAG } \\
\text { AAGAAGAGAAAGGTAGC } \\
\text { ATACCCATACGACGTTCC } \\
\text { GGACTACGCTTC }\end{array}$ & 173 & $\begin{array}{l}\text { zur Konstruktion des } \\
\text { pHBTL-NLS-HA- } \\
\text { ANK1 Vektors }\end{array}$ \\
\hline Rev 24 & $\begin{array}{l}\text { TTCACACAGGAAACAGCT } \\
\text { ATGACC }\end{array}$ & & unterschiedlich \\
\hline SEQ-L1 pDONR & $\begin{array}{l}\text { TCGCGTTAACGCTAGCAT } \\
\text { GGATCTC }\end{array}$ & 201 & unterschiedlich \\
\hline SEQ-L2 pDONR & $\begin{array}{l}\text { GTAACATCAGAGATTTTG } \\
\text { AGACAC }\end{array}$ & 202 & unterschiedlich \\
\hline $\mathrm{T} 3$ & $\begin{array}{l}\text { AATTAACCCTCACTAAAG } \\
\text { GG }\end{array}$ & 312 & unterschiedlich \\
\hline $\mathrm{T} 7$ & $\begin{array}{l}\text { TAATACGACTCACTATAG } \\
\text { GG }\end{array}$ & 313 & unterschiedlich \\
\hline Uni 24 & $\begin{array}{l}\text { ACGACGTTGTAAAACGAC } \\
\text { GGCCAG }\end{array}$ & & unterschiedlich \\
\hline
\end{tabular}




\subsubsection{Hybridisierungssonden}

\begin{tabular}{|l|l|l|l|}
\hline \multicolumn{1}{|c|}{ Gen } & \multicolumn{1}{|c|}{ Fragment } & \multicolumn{1}{c|}{ Plasmid } & \multicolumn{1}{c|}{ Referenz } \\
\hline ANK1 & EcoRI/BamHI (513 bp) & pANK-GFP & $\begin{array}{l}\text { Kuhlmann, 2002 } \\
\text { diese Arbeit }\end{array}$ \\
ANK1 & EcoRI/PstI (1209 bp) & pGAD-ANK1 (E154) & $\begin{array}{l}\text { Heinekamp, 2002 } \\
\text { diese Arbeit }\end{array}$ \\
\hline BZI-1 & XhoI/PstI (459 bp) & pSK-BZI-1 \\
BZI-1 3'UTR & PstI/Pup10I (187 bp) & & $\begin{array}{l}\text { Roux und Perrot- } \\
\text { Rechenmann, 1997 }\end{array}$ \\
\hline GH3 & 0,9 kb PCR-Fragment & & $\begin{array}{l}\text { Hofius D, } \\
\text { unveröffentlicht }\end{array}$ \\
\hline MtGH3upper/NtGH3lower & BamHI/SalI (800bp) & pSOS-MP30 (E234) & Cutt et al., 1988 \\
\hline PR1a & & pPR1a &
\end{tabular}

\subsection{Antikörper}

\begin{tabular}{|c|c|c|c|c|}
\hline Antikörper & Verdünnung & $\begin{array}{l}\text { Antigen- } \\
\text { größe }\end{array}$ & $\begin{array}{c}\text { zusätzliche } \\
\text { Informationen }\end{array}$ & Referenz \\
\hline $\begin{array}{l}\text { a-AKR2, polyklonal, rabbit } \\
\text { (Blut } 3 \text { und 4) }\end{array}$ & $1: 10000$ & $37,2 \mathrm{kDa}$ & & Hong Zang \\
\hline $\boldsymbol{\alpha}$-BZI-1, polyklonal, rabbit & $1: 2000$ & $48 \mathrm{kDa}$ & schwaches Signal & $\begin{array}{l}\text { Kuhlmann, } \\
2002\end{array}$ \\
\hline a-BZI-1g (aufgereinigt) & $1: 2000$ & $48 \mathrm{kDa}$ & schwaches Signal & Böttner, 2003 \\
\hline $\boldsymbol{\alpha}$-MYC, monoklonal, mouse & $1: 1000$ & $+1,3 \mathrm{Da}$ & Lagerung bei $-20^{\circ} \mathrm{C}$ & $\begin{array}{l}\text { CellSignallin } \\
\text { gTechn. }\end{array}$ \\
\hline $\boldsymbol{\alpha H A}$, polyklonal, rabbit & $1: 333$ bis $1: 1000$ & $+7,4 \mathrm{kDa}$ & $\begin{array}{l}\text { (3xHA); ü.N. } \\
\text { wechselnde Chargen }\end{array}$ & $\begin{array}{l}\text { SantaCruz } \\
\text { Biotechn. }\end{array}$ \\
\hline anti-mouse IgG, sheep & $1: 5000$ & & Peroxidase gekoppelt & Amersham \\
\hline $\begin{array}{l}\text { anti-rabbit IgG, polyklonal, } \\
\text { donkey }\end{array}$ & $1: 15000$ & & Peroxidase gekoppelt & Amersham \\
\hline
\end{tabular}

\subsection{Größenstandards}

\subsubsection{DNA-Größenstandard}

Als Fragmentlängenstandard wurden bei der Gelelektrophorese folgende DNA-Größenmarker verwendet:

\begin{tabular}{|l|l|}
\hline \multicolumn{1}{|c|}{ Marker } & \multicolumn{1}{|c|}{ Hersteller/Lieferant } \\
\hline$\lambda$ DNA PstI gespalten & Lambda-DNA mit PstI gespalten \\
\hline GeneRuler, 1kb ladder & Fermentas \\
\hline
\end{tabular}

\subsubsection{Protein-Größenstandard}

Als Größenstandard bei SDS-Gelen wurde folgender Marker verwendet:

\begin{tabular}{|c|l|}
\hline \multicolumn{1}{|c|}{ Marker } & \multicolumn{1}{|c|}{ Hersteller/Lieferant } \\
\hline BenchMark ${ }^{\mathrm{TM}}$ Prestained Protein Ladder & Fermentas \\
\hline
\end{tabular}




\subsection{Enzyme}

\begin{tabular}{|l|l|}
\hline \multicolumn{1}{|c|}{ Enzym } & \multicolumn{1}{c|}{ Hersteller/Lieferant } \\
\hline Alkalische Phosphatase (CIAP) & MBI Fermentas \\
\hline iProofTM High-Fidelity DNA Polymerase & Bio-Rad \\
\hline Klenow Polymerase & MBI-Fermentas \\
\hline Klenow-Polymerase exo- & MBI-Fermentas \\
\hline Lysozym & Serva \\
\hline MolTaq (Taq DNA Polymerase) & Molzym \\
\hline Pfu DNA Polymerase & Fermentas \\
\hline Pwo-DNA-Polymerase & peqlab \\
\hline Restriktionsenzyme & MBI-Fermentas, Gibco BRL, NEB \\
\hline RNase A (DNAse frei) & Qiagen \\
\hline T4-DNA-Ligase & Boehringer \\
\hline Taq DNA Polymerase & ABI PRISMTM \\
\hline
\end{tabular}

\subsection{Medien}

Alle Medien werden, wenn nicht anders angegeben, für $15 \mathrm{~min}$ bei $120^{\circ} \mathrm{C}$ und 1,2 bar autoklaviert.

\subsubsection{Pflanzenmedien}

2MS-Medium (Murasige \& Skoog, 1962): Murashige \& Skoog Medium

Sacharose

[für Mesophyllprotoplasten:

+ MES

$\mathrm{pH} 5,8$ mit $\mathrm{KOH}$

autoklavieren

B5-Infektionsmedium:

Gamborgs B5-Infektionsmedium

$\mathrm{NH}_{4} \mathrm{NO}_{3}$

MES

Saccharose

pH 5,7 mit $\mathrm{KOH}$

Medium für die Blattscheibentransformation:

$\begin{array}{ll}\text { Murashige \& Skoog Medium } & 4,59 \mathrm{~g} / 1 \\ \text { Glucose } & 16 \mathrm{~g} / \mathrm{l}\end{array}$

pH 5,7 mit $\mathrm{KOH}$
$4,59 \mathrm{~g} / 1$

$20 \mathrm{~g} / \mathrm{l}$

$0,5 \mathrm{~g} / 1]$

$3,71 \mathrm{~g} / 1$

$250 \mathrm{mg} / \mathrm{l}$

$500 \mathrm{mg} / \mathrm{l}$

$30 \mathrm{~g} / \mathrm{l}$

$16 \mathrm{~g} / \mathrm{l}$

$10 \mathrm{~g} / \mathrm{l}$

$5 \mathrm{~g} / \mathrm{l}$

$5 \mathrm{~g} / 1$

pH 7,4 mit $\mathrm{NaOH}$ 
Agrobakterium-Minimal-Medium (AMM) (Sambrook et al, 1989)

$\begin{array}{lll}20 \text { x T-Puffer: } & \mathrm{K}_{2} \mathrm{HPO}_{4} & 210 \mathrm{~g} / \mathrm{l} \\ & \mathrm{KH}_{2} \mathrm{PO}_{4} & 90 \mathrm{~g} / 1 \\ 20 \times \text { T-Salze: } & \mathrm{MgSO}_{4} \times 7 \mathrm{H}_{2} \mathrm{O} & 4 \mathrm{~g} / \mathrm{l} \\ & \mathrm{CaCl}_{2} & 0,2 \mathrm{~g} / 1 \\ & \mathrm{FeSO}_{4} & 0,1 \mathrm{~g} / 1 \\ & \mathrm{MnCl}_{2} & 0,04 \mathrm{~g} / 1 \\ & \mathrm{NH}_{4} \mathrm{Cl} & 20 \mathrm{~g} / 1 \\ & & \\ & 20 \times \mathrm{T}-P u f f e r & 50 \mathrm{ml} \\ \text { AMM: } & 20 \times \mathrm{T}-\text { Salze } & 50 \mathrm{ml} \\ & \text { Glucose } & 5 \mathrm{~g} / 1\end{array}$

YEB-Medium (Sambrook et al., 1989)

$\begin{array}{ll}\text { Beefextrakt } & 10 \mathrm{~g} / \mathrm{l} \\ \text { Hefeextrakt } & 2 \mathrm{~g} / \mathrm{l} \\ \text { Pepton } & 5 \mathrm{~g} / 1 \\ \text { Saccharose } & 5 \mathrm{~g} / 1 \\ \mathrm{MgSO}_{4} & 2 \mathrm{mM}\end{array}$

pH 7,0 mit $\mathrm{NaOH}$

\subsubsection{Zusätze für Medien}

\begin{tabular}{|c|c|c|}
\hline Zusatz & Stocklösung [mg/ml] & Endkonzentration [mg/l] \\
\hline $\begin{array}{l}\text { 6-BAP } \\
\text { (6-Benzylaminopurin) }\end{array}$ & 0,4 in $\mathrm{EtOH}$ & $\begin{array}{ll}0,2 & \text { (für Kallusbildung) } \\
2 & \text { (für Sprossbildung) } \\
0,02 & \text { (für Wurzelbildung) }\end{array}$ \\
\hline Ampicillin & 100 in $\mathrm{H}_{2} \mathrm{O}$ & 100 (für E.coli-Medien) \\
\hline Cefotaxim & 250 in $\mathrm{H}_{2} \mathrm{O}$ & 500 (für Pflanzenmedien) \\
\hline Gentamycin & 25 in $\mathrm{H}_{2} \mathrm{O}$ & 25 (für Pflanzenmedien) \\
\hline Hygromycin B & 50 in $\mathrm{H}_{2} \mathrm{O}$ & 40 (für Pflanzenmedien) \\
\hline IPTG (Isopropylthiogalactosid) & 26 in DMF & $50 \mu 1$ pro Platte \\
\hline Kanamycin & 50 in $\mathrm{H}_{2} \mathrm{O}$ & $\begin{array}{l}50 \text { (für E.coli-Medien) } \\
150 \text { (für A.tum-Medien) }\end{array}$ \\
\hline LBM (L-6100 Leptomycin B) & $\mathrm{EtOH}$ & $2 \mu \mathrm{M}$ \\
\hline NAA ( $\alpha$-Naphtylessigsäure) & 1 in DMSO & $\begin{array}{ll}2 & \text { (für Kallusbildung) } \\
0,02 & \text { (für Sprossbildung) } \\
2 & \text { (für Wurzelbildung) }\end{array}$ \\
\hline PTT (Phosphinotrypsin) & 10 & $300 \mu \mathrm{l}$ \\
\hline Rifampicin & 10 in Methanol & 50 \\
\hline Spectinomycin & 100 in $\mathrm{H}_{2} \mathrm{O}$ & $5 \mathrm{ml}$ (für A.tum-Medien) \\
\hline $\begin{array}{l}\text { X-Gal (5-Brom-4-chlor-3-indolyl- } \beta \\
\text {-D-galactopyranosid) }\end{array}$ & 20 in DMF & $50 \mu 1$ pro Platte \\
\hline
\end{tabular}

\subsubsection{Agar}

Festmedien für Bakterien enthalten zusätzlich 12 g/l Kobe-Agar, Festmedien für Pflanzen 7,4 g/l SelectAgar. Das Agar wird nach dem Einstellen des pH-Wertes aber vor dem Autoklavieren zugegeben.

\subsection{Lösungen und Puffer}

SSC $20 \times$ (Northern):
$2 \mathrm{M} \mathrm{NaCl}$

$0,3 \mathrm{M}$ Natriumcitrat $\mathrm{pH} \mathrm{7,0} \mathrm{mit} \mathrm{HCl}$ 
TAE $20 \times$ (Northern):

Church (Northern):

Stripp-Lösung (Northern):

Fällungspuffer (RNA-Extraktion):

Trizolpuffer (RNA-Extraktion):

MEN-Puffer 10x (RNA-Gel):

Sammelgel (SDS-PAGE):

Trenngel 12\% (SDS-PAGE):

1x Laufpuffer (SDS-PAGE):

Transferpuffer (Western):

TBS (Western):
$0,8 \mathrm{M}$ Tris

2,3\% (v/v) Essigsäure

$20 \mathrm{mM}$ EDTA

$7 \%$ SDS

$250 \mathrm{mM}$ NaPhosphat-Puffer ( $\mathrm{pH} 7,0)$

$1 \mathrm{mM}$ EDTA

$0,1 \%$ SDS

$1,2 \mathrm{M} \mathrm{NaCl}$

$0,8 \mathrm{M}$ tri-Natrium-Citrat

$380 \mathrm{ml} / 1$ Phenol mit 0,1 M Citrat-Puffer gesättigt 0,8 M Guanidiniumthiocyanat

0,4 M Ammoniumthiocyanat

$33,4 \mathrm{ml} / 1 \mathrm{Na}-$ Acetat (3 M pH 5,2 mit Essigsäure)

$5 \%$ Glycerin

$200 \mathrm{mM}$ MOPS

$50 \mathrm{mM}$ Natriumacetat

$10 \mathrm{mM}$ EDTA

pH 7,0 mit $\mathrm{NaOH}$

$20 \% \mathrm{MEN}$

$8 \%$ Glycerin

$56,7 \%$ Formamid

$5 \%$ Formaldehyd

0,001\% Bromphenolblau

$0,1 \%$ Ethidiumbromid

4mM EDTA pH 7,5

0,83 ml 30\% Acrylamid /BIS-Mix (19:1)

$0,63 \mathrm{ml} 1 \mathrm{M}$ Tris/HCL pH 6,8

$0,05 \mathrm{ml} 10 \%$ SDS

$0,05 \mathrm{ml} 10 \%$ APS

$0,005 \mathrm{ml}$ TEMED

$3,4 \mathrm{ml} \mathrm{H}_{2} \mathrm{O}$

$8 \mathrm{ml} \mathrm{30 \%}$ Acrylamid/BIS-Mix (19:1)

$5 \mathrm{ml}$ 1,5M Tris/HCL pH 8,8

$0,2 \mathrm{ml} 10 \%$ SDS

$0,2 \mathrm{ml} 10 \%$ APS

$0,008 \mathrm{ml}$ TEMED

$6,6 \mathrm{ml} \mathrm{H}_{2} \mathrm{O}$

$25 \mathrm{mM}$ Tris

$190 \mathrm{mM}$ Glycin

$0,1 \%(w / v)$ SDS

$192 \mathrm{mM}$ Glycin

$25 \mathrm{mM}$ Tris

$20 \%(\mathrm{v} / \mathrm{v})$ Methanol

$0,01 \%(w / v)$ SDS

$50 \mathrm{mM}$ Tris

$150 \mathrm{mM} \mathrm{NaCl}$

$\mathrm{pH}$ 7,6 mit $\mathrm{HCl}$ 
TBST (Western):

TBS

$0,1 \%$ Tween 20

Färbelösung für Proteine auf Nitrocellulosemembranen:

$0,02 \%$ Ponceau S

$3 \%$ Trichloressigsäure

Fixierlösung (Coomassie):

$25 \%(\mathrm{v} / \mathrm{v})$ Isopropanol

$10 \%(\mathrm{v} / \mathrm{v})$ Essigsäure

Färbelösung (Coomassie):

0,006\% (w/v) Coomassie Brilliant Blue G-250

$10 \%(\mathrm{v} / \mathrm{v})$ Essigsäure)

Entfärbebad (Coomassie):

$10 \%(\mathrm{v} / \mathrm{v})$ Essigsäure

Ladepuffer für Agarosegele (OX):

$10 \mathrm{ml} \mathrm{TBE}$

$10 \mathrm{ml}$ Glycerin (87\%)

$0,2 \%$ Bromphenolblau

$0,2 \%$ Orange $\mathrm{G}$

$0,2 \%$ Xylencyanol

Harnstoffextraktionspuffer:

Ethidiumbromidbad:

TE-Puffer:

Enzymlösung (P2H):

PEG (25\%) (P2H):

W5-Waschlösung (P2H):

K3S (P2H):
4M Harnstoff

$16,6 \%$ Glycerin $(100 \%)$

$5 \%$ B-Mercaptoethanol

$5 \%$ SDS

Ein paar Krümel Bromphenolblau

0,5 $\mu$ g Ethidiumbromid $/ \mathrm{ml}_{2} \mathrm{O}$

$10 \mathrm{mM}$ Tris/ $\mathrm{HCl}$
$1 \mathrm{mM}$ EDTA
pH 8,0

$0,5 \%$ Cellulase [w/v]

$0,2 \%$ Macerozym [w/v]

-in K3S aufnehmen und $10 \mathrm{ml}$ Aliquots; $-20^{\circ} \mathrm{C}$

5 g PEG 6000

1,64 g Mannitol

$0,47 \mathrm{~g} \mathrm{Ca}\left(\mathrm{NO}_{3}\right)_{2}+4 \mathrm{H}_{2} \mathrm{O}$

-mit $\mathrm{H}_{2} \mathrm{O}$ auf $20 \mathrm{ml}$, steril filtrieren, $-20^{\circ} \mathrm{C}$

9,2 $\mathrm{g} \mathrm{CaCl}_{2}+2 \mathrm{H}_{2} \mathrm{O}$

$4,5 \mathrm{~g} \mathrm{NaCl}$

$0,2 \mathrm{~g} \mathrm{KCl}$

$0,5 \mathrm{~g}$ Glucose

$0,5 \mathrm{ml} 0,5 \mathrm{M}$ MES (pH 5,8)

-mit $\mathrm{H}_{2} \mathrm{O}$ auf $0,5 \mathrm{l}$, steril filtrieren, $4^{\circ} \mathrm{C}$

68,45 g Saccharose

$5 \mathrm{ml}$ Makroelemente

$5 \mathrm{ml}$ Mikroelemente

2,5 ml Fe-EDTA-Lösung

$0,5 \mathrm{ml}, 1 \mathrm{mg} / \mathrm{ml} \mathrm{NAA}$

$100 \mu \mathrm{l}, 1 \mathrm{mg} / \mathrm{ml} 6-\mathrm{BAP}$

$0,5 \mathrm{ml}, 10 \mathrm{mg} / \mathrm{ml}$ Thiamin (Vit B1)

$50 \mu 1,10 \mathrm{mg} / \mathrm{ml}$ Pyridoxin (Vit. B6)

$50 \mu 1,10 \mathrm{mg} / \mathrm{ml}$ Nikotinsäure

- mit $\mathrm{H}_{2} \mathrm{O}$ auf 0,51 , steril filtrieren, $4^{\circ} \mathrm{C}$ 
K3M (P2H):

K3-Makroelemente (P2H):

K3-Mikroelemente (P2H):

Fe-EDTA-Lösung (P2H):

GUS-Ex-Puffer:

frisch dazu:

MUG-Gebrauchslösung:

MUN-Gebrauchslösung:

Stop-Puffer (GUS/NAN-Aktivität):

AS-Medium (100ml):

Epinastie-Puffer:
$15 \mathrm{~g}$ Sacharose

36,5 g Mannitol

$0,5 \mathrm{ml}, 1 \mathrm{mg} / \mathrm{ml} \mathrm{NAA}$

$100 \mu 1,1 \mathrm{mg} / \mathrm{ml} 6$-BAP

$0,5 \mathrm{ml}, 10 \mathrm{mg} / \mathrm{ml}$ Thiamin (Vit B1)

$50 \mu \mathrm{l}, 10 \mathrm{mg} / \mathrm{ml}$ Pyridoxin (Vit. B6)

$50 \mu 1,10 \mathrm{mg} / \mathrm{ml}$ Nikotinsäure

- mit $\mathrm{H}_{2} \mathrm{O}$ auf 0,5l, Filter-Sterilisation, $4^{\circ} \mathrm{C}$

$1,25 \mathrm{~g} \mathrm{KNO}_{3}$

$0,12 \mathrm{~g} \mathrm{NH}_{4} \mathrm{NO}_{3}$

$0,125 \mathrm{~g} \mathrm{MgSO}_{4}+7 \mathrm{H}_{2} \mathrm{O}$

$0,075 \mathrm{~g} \mathrm{NaH}_{2} \mathrm{PO}_{4}+\mathrm{H}_{2} \mathrm{O}$

$0,067 \mathrm{~g}\left(\mathrm{NH}_{4}\right)_{2} \mathrm{SO} 4$

$0,45 \mathrm{~g} \mathrm{CaCL}_{2}+2 \mathrm{H}_{2} \mathrm{O}$

$0,05 \mathrm{~g}$ m-Inositol

- auf 0,51 mit $\mathrm{H}_{2} \mathrm{O}$, autoklavieren

$0,0375 \mathrm{~g} \mathrm{KJ}$

$0,5 \mathrm{~g} \mathrm{MnSO}_{4}+\mathrm{H}_{2} \mathrm{O}$

$0,1 \mathrm{~g} \mathrm{ZnSO}_{4}+7 \mathrm{H}_{2} \mathrm{O}$

$0,15 \mathrm{~g} \mathrm{H}_{3} \mathrm{BO}_{4}$

$0,0125 \mathrm{~g} \mathrm{Na} 2 \mathrm{MoO}_{4}+2 \mathrm{H}_{2} \mathrm{O}$

$73,3 \mu 10,75 \mathrm{mM} \mathrm{CoCl}_{2}+6 \mathrm{H}_{2} \mathrm{O}$

$0,00125 \mathrm{~g} \mathrm{CuSO}_{4}$

- mit $\mathrm{H}_{2} \mathrm{O}$ auf 0,5l, autoklavieren

$2,78 \mathrm{~g} \mathrm{FeSO}_{4}+7 \mathrm{H}_{2} \mathrm{O}$

$3,72 \mathrm{~g} \mathrm{Na}_{2} \mathrm{EDTA}+2 \mathrm{H}_{2} \mathrm{O}$

- mit $\mathrm{H}_{2} \mathrm{O}$ auf 0,5 1, autoklavieren

50mM Natriumphosphat-Puffer $\mathrm{pH} 7,2$

$10 \mathrm{mM}$ EDTA

0,1\% Triton X100

$0,1 \%$ Sarkosyl

$5 \mu 1$ ß-Mercaptoethanol/10ml Puffer

4mM 4-MUG

10ml GUS-Ex-Puffer (pH 7,5)

$1 \mathrm{mM}$ MUN

GUS-Ex-Puffer $(\mathrm{pH} 7,0)$

$0,2 \mathrm{M} \mathrm{Na}_{2} \mathrm{CO}_{3}$ (GUS)

$0,33 \mathrm{M} \mathrm{Na}_{2} \mathrm{CO}_{3}(\mathrm{NAN})$

$1 \mathrm{ml}-1 \mathrm{M} \mathrm{MgCl} 2$

$1 \mathrm{ml}$ - 1M MES-KOH pH5,6

$0,1 \mathrm{ml}-150 \mathrm{mM}$ Acetosyringone

10mM Saccharose

$10 \mathrm{mM} \mathrm{KCl}$

$0,5 \mathrm{mM}$ MES

pH 6,0 (mit 0,1 M Bis-Tris-Propan) 


\subsection{Kits}

\begin{tabular}{|c|c|}
\hline Kit & Hersteller/Lieferant \\
\hline $\begin{array}{l}\text { BigDye }{ }^{\mathrm{TM}} \text { Terminator Cycle Sequencing Ready Reaction Kit } \\
\text { v3.1 }\end{array}$ & Perkin-Elmer \\
\hline Enhanced Chemiluminescence ${ }^{\mathrm{TM}}$ Plus Kit $\left(\mathrm{ECL}^{+}\right)$ & AmershamPharmacia \\
\hline Megaprime $^{\mathrm{TM}}$ DNA Labelling Systems & AmershamPharmacia \\
\hline Nucleobond $^{\circledR}$ PC 500 & Machery-Nagel \\
\hline Nucleospin ${ }^{\circledR}$ Extract & Machery-Nagel \\
\hline Nuleospin ${ }^{\circledR}$ Plasmid & Machery-Nagel \\
\hline pGEM $\left.^{(}-{ }^{(}\right)$Vector Systems & Promega \\
\hline Qiagen Plasmid-Preparations Kit (Midi/Maxi) & Qiagen \\
\hline QuikChange ${ }^{\circledR}$ Site-Directed Mutagenesis Kit & Stratagene \\
\hline
\end{tabular}

\subsection{Geräte}

\begin{tabular}{|c|c|c|}
\hline Gerät & Modell & Hersteller/Lieferant \\
\hline Autoklav & $3870 \mathrm{ELV}$ & Tuttnauer \\
\hline Automatische Pipetten & $2,10,20,200,1000$ & Gilson \\
\hline Fluorometer & CytoFluor II Plate Reader & Perseptive \\
\hline Biofuge & pico & Heraeus \\
\hline Bioimager (Phosphoimager) & BAS-1000 & Fuji \\
\hline Digitalkamera & Coolpix & Nikon \\
\hline Digitalkamera & C4742-98 & Hamamatsu \\
\hline Eismaschine & AF-20 & Scotman \\
\hline Elektroporationsapparatur & $\begin{array}{l}\text { Gene pulser@ II } \\
\text { Pulse Controller Plus }\end{array}$ & BioRad \\
\hline Feinwaage, Waage & SPO51,SAC62, 1207 MP2 & Scaltec, Sartorius \\
\hline Gefriertruhe $-80^{\circ} \mathrm{C}$ & C54285 & New Brunswick Scientific \\
\hline Geldokumentationsanlage & & MWG Biotech \\
\hline Gelelektrophoresekammer (Agarose) & & $\begin{array}{l}\text { Werkstatt der Universität } \\
\text { Göttingen }\end{array}$ \\
\hline Handmonitor & Contamat & Eberline \\
\hline Heizblock & & Boekel Scientific \\
\hline Heizrührer & RCT basic & IKA Labortechnik \\
\hline Hybridisierungsofen & Hy-St-1 & Bachhofer \\
\hline Hybridisierungswasserbad & Belly Dancer & Sorvall \\
\hline Inkubationsschränke & & WTC binder; Memmert \\
\hline Klimaschrank & & Percival Scientific \\
\hline Kühlschränke & & Liebherr \\
\hline Kühlzentrifuge & Sorvall RC 5B Plus & DuPont \\
\hline Netzgeräte & EC 250-90 EC 105 & Apparatus Corporation \\
\hline PCR-Gerät, MiniCycler ${ }^{\mathrm{TM}}$ & PTC-150 & MJ Research, USA \\
\hline Peristatikpumpe & Cyclo 1 & Roth \\
\hline pH-Meter & HI 9321 & Hanna Instruments \\
\hline Photometer & Unikon $720 \mathrm{LC}$ & Kontron \\
\hline Polyacrylamid-Gelkammer & & AGS \\
\hline RNA-/DNA-Kalkulator & GenQuant II & Pharmacia \\
\hline Rotoren für Ultrazentrifuge & TFT 30.58; TFT 65.13 & Kontron \\
\hline Scanner & & Epson \\
\hline Schüttler & 3005 & GFL \\
\hline Schwingmühlen & MM 301 & Retsch \\
\hline Semi-Dry-Blot-Apparatur & & $\begin{array}{l}\text { Werkstatt der Universität } \\
\text { Bielefeld }\end{array}$ \\
\hline
\end{tabular}




\begin{tabular}{|l|l|l|}
\hline \multicolumn{1}{|c|}{ Gerät } & \multicolumn{1}{c|}{ Modell } & \multicolumn{1}{c|}{ Hersteller/Lieferant } \\
\hline Sequenzanalyseanlage & ABI PRISM 310 & Perkin-Elmer \\
\hline Speed vac Konzentrator & SK 100 H & Sarvant \\
\hline Spektralphotometer & Novaspek Biochrom & LKB \\
\hline Sterilbank & Microflow Laminar W. & Nunc \\
\hline Szintillationsmeßgerät & & $\begin{array}{l}\text { Raytest Isotopenmessgeräte } \\
\text { GmbH }\end{array}$ \\
\hline Tischzentrifuge & & Eppendorf \\
\hline Tischzentrifuge, gekühlt & 5414 & Eppendorf \\
\hline Ultrazentrifuge & 5403 & Kontron \\
\hline UV-Transilluminator & Centrikon T-1065 & Vilber Lourmat \\
\hline Vortex & FLX-20 M & Labinco BV, Niederlande \\
\hline Wasseraufbereitungsanlage & L46 & ELGA \\
\hline Wasserbäder & Option 4, Maxima & GFL \\
\hline Zählkammer & 1086 & Brand \\
\hline Zentrifuge & Fuchs-Rosenthal & Christ \\
\hline Zentrifuge, Ausschwingrotor & UJ3S & Hettich \\
\hline Leitfähigkeitsmessgerät & Universal 16 A & Hanna Instruments \\
\hline Spritze & HI 8733N & Braun \\
\hline Mikrotom & $\begin{array}{l}\text { Omnifix } \\
\text { (4) Solo, Ref } \\
9161306 V\end{array}$ & Reichert Jung \\
\hline $\begin{array}{l}\text { Mikroskop (mit u-WIBA, U-NWB } \\
\text { Filtern) }\end{array}$ & 2040 & Olympus \\
\hline Mikroskop, konfokal & BX60 & Leica \\
\hline & TCS SP2 AOBS & \\
\hline
\end{tabular}

\subsection{Chemikalien}

\begin{tabular}{|c|c|}
\hline Chemikalien & Hersteller/Lieferant \\
\hline$\beta$-Mercaptoethanol & Roth \\
\hline 2-[N-Morpholino]ethansulfonsäure (MES) & Sigma \\
\hline 6-Benzylaminopurin (6-BAP) & Sigma \\
\hline Agar Agar & Roth \\
\hline Agarose SeaKem LE & Biozym \\
\hline Ameisensäure & Roth \\
\hline Ammoniumperoxodisulfat (APS) & Biometra \\
\hline Ampicillin & AGS \\
\hline Bovine-Serum-Albumin (BSA) & Serva \\
\hline Bromphenol-Blau & Roth \\
\hline Carborundum (Siliciumcarbid, 200-450 mesh) & Aldrich \\
\hline Cefotaxim & Duchefa \\
\hline Chloralhydrat & Roth \\
\hline Coomassie Brilliant Blue G-250 & Bio-Rad \\
\hline Dimethylsulfoxid (DMSO) & Sigma; Roth \\
\hline Dithiothreitol (DTT) & Sigma \\
\hline DL-Lactic-Acid & Sigma \\
\hline dNTPs & MBI; Roth \\
\hline Ethidiumbromid (EtBr) & Roth \\
\hline Ethylendiamintetraacetat (EDTA) & AppliChem \\
\hline Formaldehyd & Roth \\
\hline Formamid & Fluka \\
\hline Gamborg's B5-Medium & Duchefa \\
\hline Glycerin $(87 \%)$ & Roth \\
\hline HEPES & Roth \\
\hline Hygromycin & Duchefa \\
\hline Isopropylthiogalactosid (IPTG) & BioTech Trade \\
\hline
\end{tabular}




\begin{tabular}{|c|c|}
\hline Chemikalien & Hersteller/Lieferant \\
\hline Kanamycin & Sigma \\
\hline Kinetin & Sigma \\
\hline LMB (Leptomycin B) & LC Laboratories \\
\hline Magermilchpulver & Glücksklee \\
\hline Methyl- Umbeliferyl-...Neuramidase (MUN) & BIOSYNTH \\
\hline Methylumbelliferon (4-MU) & Sigma \\
\hline Methylumbelliferyl- $\beta$-D-Glucoronid (MUG) & Duchefa \\
\hline MOPES & Sigma \\
\hline $\begin{array}{l}\text { MUN (2-(4-Methylumbelliferyl)-alpha-D-N-acetylneuraminic } \\
\text { acid, sodium salt ) }\end{array}$ & (Biochemica \& Synthetica) \\
\hline Murashige und Skoog Medium & Duchefa \\
\hline N,N-Dimethylformamid (DMF) & J.T. Baker Chemicals B. V. \\
\hline Natriumazid & Sigma \\
\hline Natriumhydroxid $(\mathrm{NaOH})$ & Merck \\
\hline Natriumhypochlorid & Roth \\
\hline organische Lösungsmittel (Alkohole etc.) & Merck; Roth \\
\hline Pepton & Roth \\
\hline PIPES & Roth \\
\hline Polyacrylamid (PAA)-Mix: $30 \%$ PAA + Bisacrylamid $(37,5: 1)$ & Roth \\
\hline Polyethylenglycol (PEG) 4000 & Fluka \\
\hline Ponceau & Sigma \\
\hline Rifampicin & Duchefa \\
\hline Saccharose & Roth \\
\hline Salze für Puffer etc. & AppliChem; Merck \\
\hline Salzsäure $(\mathrm{HCl})$ & Merck \\
\hline Select Agar & Life Technologies \\
\hline Select Yeast Extract (Hefeextrakt) & GIBCO BRL \\
\hline Sephadex G50 & Pharmacia \\
\hline Sodiumdodecylsulfat (SDS) & Roth \\
\hline Spermidin & Sigma \\
\hline Spermin Tetrahydrochlorid & Sigma \\
\hline TEMED & BIORAD, Roth \\
\hline Triton $\mathrm{X}-100$ & Roth \\
\hline Trypton & Oxoid \\
\hline Tween-20 & Roth \\
\hline X-Gal & BioTechTrade \\
\hline X-Gluc & Roth \\
\hline$\alpha$-Naphthalinessigsäure (NAA) & Sigma \\
\hline$\alpha-{ }^{32} \mathrm{P}$ dATP; $800 \mathrm{Ci} / \mathrm{mmol}$ & Hartmann Analytic \\
\hline
\end{tabular}

Standardchemikalien wurden von den Firmen Merck, Roth, Boehringer, Fluka oder Sigma bezogen.

\subsection{Verbrauchsmaterialien}

\begin{tabular}{|l|l|}
\hline \multicolumn{1}{|c|}{ Produkt } & \multicolumn{1}{c|}{ Hersteller/Lieferant } \\
\hline Alufolie & Roth \\
\hline Elektroporationsküvetten & BioRad \\
\hline Fliesspapier & Whatman \\
\hline Gläser für Pflanzensterilkultur & Weck \\
\hline Glasmaterialien: Flaschen, Pasteurpipetten, Erlenmeyerkolben & Brand, Schott \\
\hline Kunststoff-Einwegmaterial & Biozym; Eppendorf; Greiner; Roth \\
\hline Nylon-Membran Hybond $^{\mathrm{TM}}$-N & Amersham Life Scince \\
\hline Parafilm N $^{\mathrm{TM}}$ \\
\hline PVDF-Transfer-Membran Immobilon $^{\mathrm{TM}}$-P & American National Can \\
\hline
\end{tabular}




\section{$4 \quad$ Methoden}

\subsection{Anzucht von Mikroorganismen}

\subsubsection{Anzucht von E.coli}

Die Anzucht der E. coli Bakterien erfolgt auf LB-Festmedium, bzw. in LB-Flüssigmedium bei $37{ }^{\circ} \mathrm{C}$ ü.N. Die angeimpften Flüssigmedien in Reagenzgläsern werden im Roller inkubiert (Sambrook et al., 1989). Flüssigkulturen im Erlenmeyerkolben werden nach Überimpfen aus einer Vorkultur im Schüttler bei $250 \mathrm{rpm}$ inkubiert. Die Bakteriendichte wird photometrisch bei $600 \mathrm{~nm}$ gemessen, wobei der Wert 0,1 einem Titer von $2 \times 10^{7}$ Zellen entspricht. Zur Selektion wird dem Medium ein entsprechendes Antibiotikum zugesetzt.

\subsubsection{Anzucht von Agrobakterium tumefaciens}

Die Anzucht der A. tumefaciens Bakterien erfolgt in Agrobakterien-Minimal-Medium (fest und flüssig), oder in LB-Medium (fest und flüssig). Die Inkubation erfolgt bei $28^{\circ} \mathrm{C}$ für 3 Tage. Die Inkubation der Flüssigmedien erfolgt im Roller. (Sambrook et al., 1989). Zur Selektion wird dem Medium das entsprechende Antibiotikum zugesetzt.

\subsubsection{Lagerung der Bakterien}

Die Bakterien können auf den Platten bei $4{ }^{\circ} \mathrm{C}$ mittelfristig gelagert werden. Für längere Lagerung müssen Gefrierkulturen angelegt werden.

Anlage einer Gefrierkultur:

$750 \mu 1$ einer frischen ü.N.-Kultur mit $750 \mu 187 \%$ Glycerin versetzen

kräftig vortexen

schockgefrieren in Flüssigstickstoff

Lagerung bei $-80{ }^{\circ} \mathrm{C}$

\subsubsection{Anzucht des Tabak Mosaik Virus}

Die Anzucht und Isolierung des TMV-Virus erfolgte aus Tabak Blattgewebe nach Yalpani et al., 1991.

\subsection{Pflanzenanzucht}

\subsubsection{Gewebekultur}

Die Tabakpflanzen werden unter sterilen Bedingungen auf 2MS-Festmedium in Gläsern kultiviert. Die Anzucht erfolgt in Klimakammern oder in Klimaschränken bei $24^{\circ} \mathrm{C}$ am Tag und $22^{\circ} \mathrm{C}$ in der Nacht, wobei der Licht-Dunkel-Rhythmus 16:8 Stunden beträgt. Die Subkultivierung erfolgt unter sterilen Bedingungen durch Abtrennen und Überführen der vegetativen Spitze auf frisches Medium. Die Versuche zur Auxin induzierten Organogenese an Blattscheiben werden unter den gleichen Bedingungen kultiviert.

Die Tabakpflanzen für die Herstellung von Mesophyllprotoplasten wurden in bauchigen Weckgläsern angezogen mit dem etwas abgewandelten 2MS-Festmedium für Mesophyllprotoplasten Herstellung. Die Anzucht erfolgte unter gleichen Bedingungen wie zuvor beschrieben.

\subsubsection{Klimakammer/Gewächshaus}

Die Kultivierung der Pflanzen bis zur Blüte erfolgt unter unsterilen Bedingungen in Erde bei $22^{\circ} \mathrm{C}$ am Tag und $19^{\circ} \mathrm{C}$ in der Nacht, bei einer relativen Luftfeuchtigkeit von $85 \%$ in einem Licht-Dunkel-Rhythmus von 
16:8 Stunden. Als Erde wird zum Aussetzen Frühstdorfer Torf Typ P (Pikier), zum Umtopfen Frühsdorfer Torf Typ T (Topf) verwandt. Die Samenproduktion erfolgt im Gewächshaus unter Umweltbedingungen.

\subsection{Molekulargenetische Methoden}

\subsubsection{Polymerase-Kettenreaktion}

Die Polymerase-Kettenreaktion (PCR = , polymerase chain reaction') ist eine Methode, um DNA-Fragmente in vitro zu amplifizieren. Die Technik wurde zuerst von (Mullis und Faloona, 1987) beschrieben. Grundlage ist die Fähigkeit der DNA-Polymerase, einzelsträngige DNA zu einem Doppelstrang auf zu polymerisieren, wenn ein kurzer doppelsträngiger Startbereich vorliegt. Deshalb sind zwei Oligonukleotid-Primer erforderlich, die komplementär zu Bereichen der zu amplifizierenden DNA sind und die als Startpunkt für die Tochterstrang-Synthese dienen. Die beiden Primer begrenzen so auch das zu amplifizierende Fragment. Sie werden im Überschuss zugegeben. Zunächst wird die doppelsträngige DNA durch Erhitzen in Einzelstränge aufgetrennt. Beim anschließenden Abkühlen können sich die Primer an die DNA anlagern (,Annealing'). Es folgt dann die Gegenstrangsynthese durch die DNA-Polymerase bei mittlerer Temperatur. Durch Verwendung der Taq-Polymerase bleibt die Aktivität des Enzyms über den Hitzeschritt erhalten. Die zyklische Wiederholung der Schritte führt zur Anreicherung des gewünschten Fragments.

Beispiel für einen Reaktionsansatz:

- $\quad 2,5 \mu 110$ x PCR-Puffer $+\mathrm{MgCl}_{2}(\mathrm{MBI})$

- $0,25 \mu \mathrm{d}$ dNTPs (je $10 \mathrm{mM}$ )

- $0,25 \mu l$ Enhancer

- $1 \mu \mathrm{l}$ Primer $1(10 \mu \mathrm{M})$

- $1 \mu 1$ Primer $2(10 \mu \mathrm{M})$

- $\quad 0,5 \mu \mathrm{l}$ Taq DNA-Polymerase

- $\quad \mu 1$ DNA-Template

- $\quad 17 \mu \mathrm{l} \mathrm{H}_{2} \mathrm{O}$

Das verwendete PCR-Programm hängt von der Schmelztemperatur der Primer und dem verwendeten Template ab und muss für jede PCR individuell erstellt werden. Die Amplifikation wird in einem Thermocycler durchgeführt. Beispiel-Programm:

$\begin{array}{lllll} & \text { Erste Denaturierung } & 4^{\prime} & 95^{\circ} \mathrm{C} & \\ 25-35 & \text { Denaturierung } & 1^{\prime} & 95^{\circ} \mathrm{C} & \\ \text { Zyklen } & \text { Annealing } & 30^{\prime \prime} & 50-72^{\circ} \mathrm{C} & \text { (Primer } \mathrm{T}_{\mathrm{m}}{ }^{-} \text {abhängig)) } \\ & \text { Elongation } & 1^{\prime} / \mathrm{kb} & 72^{\circ} \mathrm{C} & \\ \text { Finale Elongation } & 10^{\prime} & 72^{\circ} \mathrm{C} & \end{array}$

Die Schmelztemperatur $\mathrm{T}_{\mathrm{m}}$ eines Primers errechnet sich nach folgender Formel:

- $\mathrm{T}_{\mathrm{m}}\left[{ }^{\mathrm{O}} \mathrm{C}\right]=69,3+0.41 \cdot(\% \mathrm{GC})-(650 / \mathrm{n})$

\subsubsection{Restriktionsspaltung von DNA}

Restriktionsendonukleasen (Desoxyribonukleasen) vom Typ II spalten Phosphodiester- Bindungen doppelsträngiger DNA an spezifischen Basensequenzen (Smith und Wilcox, 1970). Es gibt eine große Anzahl verschiedener Restriktionsendonukleasen, die jeweils bestimmte Erkennungssequenzen haben (Roberts, 1985). Je nach Enzym entstehen glatte DNA-Enden (,blunt ends“) oder 5'- bzw. 3'-überhängende Enden (,sticky ends“).

Die zur Restriktionsspaltung eingesetzte DNA (ca. 0,5-2 $\mu$ g Plasmid-DNA) sollte frei von Kontaminationen wie hohen Salzkonzentrationen, EDTA oder organischen Lösungsmitteln sein, um die Enzymaktivität nicht zu mindern. Die Reaktionen finden für 2-16 Stunden bei den für jedes Enzym optimalen Temperatur- und Pufferbedingungen (Spaltungspuffer von MBI oder Boehringer) statt. Es werden Enzymmengen von mindestens $1 \mathrm{U}$ Restriktionsenzym pro $\mu \mathrm{g}$ DNA eingesetzt. Weil die Enzymlösungen Glycerin enthalten, wird nicht mehr Restriktionsenzym als höchstens $10 \%$ des Endvolumens zugesetzt, da Glycerinkonzentrationen von mehr als $5 \%$ die Spezifität herabsetzen. Die meisten Restriktionsenzyme 
können durch eine Hitzebehandlung für 10 Minuten bei $65^{\circ} \mathrm{C}$ inaktiviert werden. Die Kontrolle der Spaltung erfolgt durch Agarosegelelektrophorese mit einem Aliquot des Ansatzes. Restriktionsspaltungen können zur Klonanalyse eingesetzt werden. Außerdem sind sie die Grundlage der Klonierungen (Cohen et al., 1973).

\subsection{3 ,Klenow-fill-in'}

Das Klenow-Fragment der DNA-Polymerase I besitzt eine 5'-3'-Polymerase und eine 3'-5Exonukleaseaktivität. Es kann bei Vorhandensein eines DNA-Matrizenstranges die komplementäre Polymerisation von Nukleotiden an eine freie 3'-OH-Gruppe katalysieren. Diese Reaktion wurde verwendet, um nach Restriktionsspaltungen überstehende 5'-DNA-Enden aufzufüllen. Für eine „Klenow-fill-in“Reaktion werden $2 \mu \mathrm{g}$ gespaltenes Plasmid, 1,5mM dNTP-Mix und 2U (Units) Klenow-DNA-Polymerase eingesetzt, der Ansatz wird für $15 \mathrm{~min}$ bei RT inkubiert. Die Reaktion kann durch $10 \mathrm{~min}$ Erhitzen auf $75^{\circ} \mathrm{C}$ abgestoppt werden.

\subsubsection{TA-Klonierung}

Die Taq-Polymerase produziert keine Fragmente mit glatten Enden, sondern schafft einen Überhang von einer Base, wobei es sich in den meisten Fällen um ein Adenosin handelt (Clark, 1988). Daher lassen sich Taq-amplifizierte PCR-Produkte gut in Vektoren mit Thymin-Überhang klonieren. Ein solcher Vektor ist pGEM $^{\circledR}-\mathrm{T}$ von Promega oder auch der hauseigen hergestellte psk-T Vektor.

Das Enzym T4-DNA-Ligase katalysiert die Bildung einer Phosphodiesterbindung zwischen der 3'-OHGruppe am Ende eines DNA-Stranges und der 5'-Phosphatgruppe am Ende eines anderen. Bei Anwesenheit von ATP erfolgt zunächst eine Aktivierung des Enzyms durch eine Adenylierung unter Abspaltung von Pyrophosphat gefolgt von einer Übertragung der AMP-Einheit auf das 5`-Ende des einen Stranges, wodurch eine Aktivierung des 5'-Phosphoratoms erfolgt. So kann ein nucleophiler Angriff der 3'- OH-Gruppe auf dieses aktivierte Phosphoratom erfolgen, wobei der Strang geschlossen und AMP freigesetzt wird.

- $\quad 5 \mu 12 x$ rapid ligation buffer in ein $1,5 \mathrm{ml}$ Eppendorfgefäß geben

- $\quad 1 \mu 1(50 \mathrm{ng})$ pGEM®-T oder psk-T Vektor zugeben

- $\quad$ PCR-Produkt zugeben (das Verhältnis Insert:Vektor sollte etwa 5:1 betragen)

- $\quad$ Mit H2O auf $9 \mu 1$ auffüllen

- $1 \mu 1 \mathrm{~T} 4$ DNA Ligase (4 Weiss units/ $\mu 1$ ) zugeben

- $\quad$ ü. N. bei $4^{\circ} \mathrm{C}$

Es werden $5 \mu \mathrm{l}$ des Ansatzes in $100 \mu \mathrm{l}$ chemisch kompetente E.coli-Zellen transformiert.

\subsubsection{Ligation}

Die Verknüpfung von zwei DNA-Fragmentenden geschieht mit Hilfe der T4-DNA-Ligase. Die Ligase katalysiert unter ATP-Verbrauch eine Phosphodiesterbindung zwischen benachbarten 5'-Phosphat- und 3'$\mathrm{OH}-G r u p p e n$. Für die Konstruktion von Plasmiden wird $50 \mathrm{fmol}$ linearisierte Vektor-DNA und in 10-100 fachen molaren Überschuss das zu inserierende Fragment eingesetzt. Die Reaktion erfolgt im Ligase-Puffer (40mM Tris-HCl; 10mM MgCl $2 ; 10$ mM DTT; 0,5mM ATP; pH 7,8) mit 4u T4-DNA-Ligase bei RT für 4h.

\subsubsection{Konstruktion der verwendeten Vektoren}

\subsubsection{Gateway ${ }^{\mathrm{TM}}$-Klonierung}

Bei Gateway-Klonierungen werden DNA-Segmente über ortsspezifische Rekombination zwischen verschiedenen Plasmiden transferiert. Das System basiert auf der ortsspezifischen Integration des Phagen Lambda in das Genom von E.coli. Um für die Rekombination verfügbar zu sein, müssen Erkennungssequenzen an das gewünschte DNA-Segment angefügt werden. Dies geschieht, indem man das gewünschte DNA-Stück mit Primern amplifiziert, die an den 5'-Enden die Erkennungssequenzen enthalten. Bei Gateway-Klonierungen werden 2 Reaktionen verwendet. Das DNA-Segment kann aus dem PCR-Produkt in der BP-Reaktion in einen GW-Eingangsvektor rekombiniert werden. Von dort aus kann es in der LRReaktion in verschiedene GW-Expressionsvektoren transferiert werden. Außerdem besteht die Möglichkeit, das DNA-Segment aus dem Ziel-Vektor in einer weiteren BP-Reaktion in einen anderen Eingangs-Vektor zu transferieren. 
Die BP- und LR-Reaktionen werden nach den Angaben des Herstellers (Invitrogen) durchgeführt. Anschließend werden $5 \mu 1$ des Ansatzes in $100 \mu$ l chemisch kompetente DH5 $\alpha$-Zellen transformiert.

\subsubsection{2. pNLS-HA-ANK1}

Aus dem pHBTL-HA-ANK1 Vektor wurde mittels PCR mit den Primern pNLS-HAGW und GWkass. REV ein 1281 bp langes Fragment amplifiziert, das im 5'Bereich die Sequenz der NLS und an den 5' und 3'Enden jeweils eine Acc65I-Schnittstelle einführt. Das PCR-Fragment wurde mit Acc65I verdaut und in einen ebenfalls mit Acc65I geöffneten pHBTL- $\Delta$ GFP Vektor ligiert. Um einen daraus Gateway kompatiblen Eingansvektor herzustellen, kann ein Austausch übe eine BP-Reaktion erfolgen, konnte aber im Rahmen dieser Arbeit nicht fertig gestellt werden.

pNLS-HAGW:

ACC65I NLS (SV40) Vektor (3xHA)--

GGT ACC ATG. GCT.CCC.AAG.AAG.AAG.AGA.AAG.GTA GCA TAC CCA TAC GAC GTT CCG GAC TAC GC

\subsubsection{Einfügen von Punktmutationen}

Zur spezifischen Mutagenese des ANK1 Gens wurden mutagenisierende Primer verwendet, die spezifische Punktmutationen in die Gensequenz einfügen. Verwendet wurde hierfür das Protokoll QuikChange ${ }^{\circledR}$ SiteDirected Mutagenesis Kit des Herstellers Stratagene.

\subsubsection{Dephosphorylierung von DNA-Enden}

Um Religationen von restriktionsgespaltenen Vektoren zu vermeiden, wurde der Reaktionsansatz im Anschluss an die Spaltung mit alkalischer Phosphatase (CIAP) entsprechend den Herstellerangaben behandelt. Die Inaktivierung des Enzyms erfolgte durch 10 minütige Inkubation bei $75^{\circ} \mathrm{C}$.

\subsubsection{Plasmid-Präparation}

Mit Hilfe des Nucleospin® Plasmid-Kits ist es möglich sehr schnell kleinere Mengen Plasmid-DNA aus E.coli Zellen zu gewinnen. Die Extraktion erfolgt nach dem Protokoll des Herstellers Macherey-Nagel. Präparative Mengen DNA mit hohem Reinheitsgrad werden mit Hilfe des Nucleobond ${ }^{\circledR}$ PC 500 Kits von Machery-Nagel präpariert. Die Durchführung erfolgt gemäß den Herstellerangaben.

\subsubsection{Isolierung von Plasmid-DNA aus Agrobakterien}

Zur Isolation von binären Vektoren aus Agrobakterien werden 10ml einer stationären Kultur pelletiert (20',

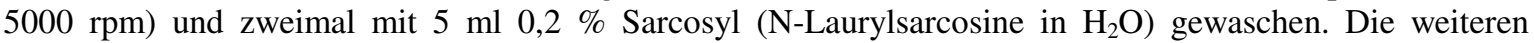
Schritte erfolgen mit Hilfe des QIAprep Spin Miniprep-Kits nach Herstellerangaben. Zur Elution der DNA wird der Eluationspuffer auf $70^{\circ} \mathrm{C}$ erhitzt und von dem Eluat $1 / 3$ zur Restriktionsanalyse eingesetzt.

\subsubsection{Konzentrations- und Reinheitbestimmung von Nukleinsäuren}

Zur Konzentrationsbestimmung wird der GeneQuant II der Firma Pharmacia verwendet. Da man die Absorption von Nukleinsäuren in einer wässrigen Lösung im UV-Bereich bei $260 \mathrm{~nm}$ messen kann, lässt sich hierdurch die Konzentration der DNA bestimmen. Das Absorptionsmaximum bei dieser Wellenlänge wird durch die Anregung des $\pi$-Elektronensystems in den Heterocyclen der Basen hervorgerufen. Bei einer Schichtdicke von $1 \mathrm{~cm}$ entspricht eine $\mathrm{OD}_{260 \mathrm{~mm}}$ von 1,0 einer Nukleinsäure-Konzentration von $50 \mu \mathrm{g} / \mathrm{ml}$ bei dsDNA und $40 \mu \mathrm{g} / \mathrm{ml}$ bei RNA. Im Vergleich zur Absorption bei der Wellenlänge 280nm, bei der die aromatischen Seitenketten von Proteinen angeregt werden, lässt sich der Quotient aus der Absorption der Wellenlängen 260/280 nm als ein Maß für den Reinheitsgrad der DNA- oder RNA-Präparation darstellen.

Der Reinheitsgrad sollte idealerweise zwischen 1,7 und 2,0 liegen. Gemessen werden 1:100 Verdünnungen der Präparationen. 


\subsubsection{Agarosegelelektrophorese von DNA-Molekülen}

Mit Hilfe der Agarosegelelektrophorese werden DNA-Moleküle nach ihrer Größe aufgetrennt (McDonell et al., 1977; Southern, 1979). DNA ist aufgrund des Zucker- Phosphat-Rückgrats negativ geladen. Im elektrischen Feld wandert sie somit zur Anode. Die Wanderungsgeschwindigkeit ist umso größer, je kleiner die DNA-Moleküle sind. Als Gelmatrix dient Agarose, ein gelierfähiges Polysaccharid, welches aus sich abwechselnden Einheiten von $\beta$-1,3-verknüpfter D-Galaktopyranose und $\alpha$-1,4- verknüpfter 3,6-Anhydro-LGalaktopyranose besteht. Der Trennbereich ist abhängig von der Agarosekonzentration, da sie die Porengröße beeinflusst. Je höher die Agarosekonzentration, desto kleiner die Poren, desto besser werden kleine Moleküle aufgetrennt. Zur Auftrennung großer Fragmente wird ein 0,7 prozentiges Gel benutzt. Kleine Fragmente, wie PCR-Produkte, werden in Gelen aufgetrennt, die $1 \%$ Agarose enthalten.

Ethidiumbromid (3,8-Diamino-6-ethyl-5-phenylphenantridiumbromid) dient zum Anfärben der DNA. Es bindet an die DNA, indem es zwischen die Basenpaare interkaliert. Der Komplex aus DNA und Ethidiumbromid fluoresziert unter UV-Licht und wird damit auf dem Transilluminator sichtbar.

\subsubsection{DNA-Elution aus Agarosegelen}

Für die Isolierung von DNA-Fragmenten aus Agarosegelen wird das Nucleospin® Extrakt Kit von Macherey-Nagel verwendet. Die Aufreinigung erfolgte nach dem Protokoll des Herstellers.

\subsubsection{Ethanolfällung von DNA aus wässrigen Lösungen}

Um DNA aus wässrigen Lösungen von Salzen $\mathrm{zu}$ reinigen und um eine definierte Konzentration zu erreichen, wurde sie einer Ethanolfällung unterzogen. Dabei wurde der DNA-Lösung 1/10 Volumen 3 M Natriumacetat, pH 5,2 zugegeben und mit zwei Volumen 100\% Ethanol gemischt. Die DNA fällt aus, während Salze und Verunreinigungen gelöst bleiben. Die Fällung erfolgte bei $-20^{\circ} \mathrm{C}$ für mindestens zwei Stunden. Danach wurde die DNA für 20 Minuten bei $13.000 \mathrm{rpm}$ pelletiert, mit $70 \%$ Ethanol gewaschen, getrocknet und in einem definierten Volumen $\mathrm{H}_{2} \mathrm{O}$ gelöst.

\subsubsection{DNA Sequenzierung}

Zum Sequenzieren der DNA wird ein Verfahren benutzt, das auf der kontrollierten Unterbrechung der DNASynthese beruht. Diese Methode wurde von (Sanger et al., 1977) entwickelt. Einzelsträngige DNA dient als Template für die Synthese eines neuen Stranges. Es wird ein Primer zugegeben, der mit der DNA hybridisieren kann. Die DNA-Polymerase I benötigt für ihre Syntheseaktivität einen kurzen Abschnitt doppelsträngiger DNA. Zusätzlich zu den Desoxyribonukleotiden werden auch Didesoxyribonukleotide (ddNTPs) in den Reaktionsansatz gegeben. Diesen fehlt die Hydroxylgruppe am 3'-C-Atom des Zuckers. Werden die ddNTPs in den neuen DNA-Strang eingebaut, so stoppt das Kettenwachstum, da keine weitere Phosphodiesterbindung gebildet werden kann. Über die unterschiedliche Länge der neu entstandenen DNAStränge lässt sich die Basenabfolge nach einer gelelektrophoretischen Auftrennung ermitteln. Längenunterschiede von einem Basenpaar können aufgelöst werden. Die ddNTPs sind unterschiedlich fluoreszenz-markiert, sodass nach einer Kapillar-Gelelektrophorese jeder DNA-Strang mit einer Laserapparatur detektiert wird. Bei dem Cycle Sequencing wird durch zyklisches Denaturieren und anschließende Neusynthese die Menge an zu analysierender DNA erhöht. Cycle Sequencing und Aufreinigung der DNA erfolgen mit dem ABI PRISM BigDye Terminator Cycle Sequencing Ready Reaction Kit. Die eingesetzte DNA wird mit dem Nucleospin® Plasmid-Kits isoliert.

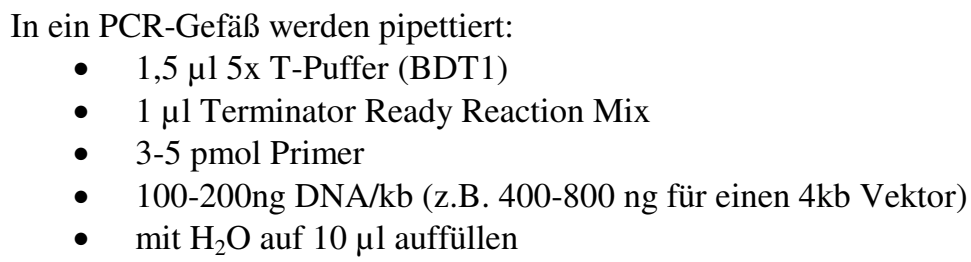


Im Thermocycler wird folgendes Programm benutzt:

- $\quad 95^{\circ} \mathrm{C} 1$ Minute initiale Denaturierung

- $\quad 95^{\circ} \mathrm{C} 10$ Sekunden Denaturierung

- $50{ }^{\circ} \mathrm{C} 5$ Sekunden Annealing (auf Primer abstimmen)

- $60{ }^{\circ} \mathrm{C} 3$ Minuten Elongation

- Schritte 2-4 29 mal wiederholen

- $\quad$ Lagerung bei $4{ }^{\circ} \mathrm{C}$

Damit die DNA sequenziert werden kann, muss sie gereinigt werden. Alle Verunreinigungen, vor allem aber ungebundene Terminatoren, stören die Sequenzierung.

- die $10 \mu \mathrm{l}$ Sequenzieransatz in 1,5 ml Eppendorfgefäße geben

- $\quad 40 \mu 170 \%$ Ethanol (unvergällt) zugeben

- vortexen

- Inkubation für 1 Stunde bei Raumtemperatur

- 20 Minuten bei RT/13.000rpm zentrifugieren

- Überstand vollständig abnehmen

- Pellet mit $125 \mu 170 \%$ Ethanol (unvergällt) waschen

- 10 Minuten bei RT/13.000rpm zentrifugieren

- Überstand vollständig abnehmen

- Pellet 1 Minuten bei $95{ }^{\circ} \mathrm{C}$ mit offenem Deckel trocknen

- Pellet in $10 \mu \mathrm{l} \mathrm{HiDi}$ aufnehmen, kann so direkt im Sequenziergerät verwendet werden

\subsection{Herstellung kompetenter Escherichia coli}

Für die Herstellung kompetenter Zellen nach einer modifizierten Methode von (Inoue et al., 1990) werden Bakterien des E. coli-Stammes DH5 $\alpha$ verwendet.

- $\quad 0,8 \mathrm{ml}$ einer Übernachtkultur in $40 \mathrm{ml}$ LB-Medium überimpfen

- Anzucht der Kultur bis zum Erreichen einer $\mathrm{OD}_{600}$ von 0,5

- Je $10 \mathrm{ml}$ der Kultur in Greiner-Röhrchen überführen

- $\quad$ Minuten, $6000 \mathrm{x} \mathrm{g}, 4^{\circ} \mathrm{C}$ abzentrifugieren

- Pellet in $5 \mathrm{ml} 50 \mathrm{mM} \mathrm{CaCl} 2\left(4^{\circ} \mathrm{C}\right)$ resuspendieren

- 30 Minuten auf Eis inkubieren

- $\quad \min , 6000 \mathrm{x} \mathrm{g}, 4{ }^{\circ} \mathrm{C}$ abzentrifugieren

- Zellen in $2 \mathrm{ml} 50 \mathrm{mM} \mathrm{CaCl} 2\left(4^{\circ} \mathrm{C}\right)$ und $0,4 \mathrm{ml} 87 \%$ Glycerin aufnehmen

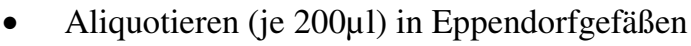

- in flüssigem Stickstoff schockgefrieren

- Die Aufbewahrung erfolgt bis zur weiteren Verwendung bei $-80^{\circ} \mathrm{C}$.

\subsection{Herstellung kompetenter Agrobacterium tumefaciens}

Für die Herstellung kompetenter Agrobacterium tumefaciens wird eine ü.N. Kultur der Bakterien in YEBMedium verwendet und in $250 \mathrm{ml}$ Medium verdünnt. Nachdem die Kultur bei $28^{\circ} \mathrm{C}$ eine $\mathrm{OD}_{600}$ von 0,5 erreicht hat wird sie durch Zentrifugation $\left(5^{\prime}, 5000 \mathrm{rpm}\right)$ geerntet und die Zellen werden 3-mal in $4^{\circ} \mathrm{C}$ sterilem $\mathrm{H}_{2} \mathrm{O}$ gewaschen. Das Pellet wird in $1 \mathrm{ml} 15 \%$ Glycerin resuspendiert, zu je $50 \mu \mathrm{l}$ aliquotiert und in flüssigem $\mathrm{N}_{2}$ eingefroren. Die kompetenten Zellen können bis zur Verwendung bei $-80^{\circ} \mathrm{C}$ gelagert werden. 


\subsection{Gentransfer}

\subsubsection{Transformation von Escherichia coli}

Kompetente $E$. coli-Zellen sind in der Lage, Plasmid-DNA aus dem Umgebungsmedium aufzunehmen. Mit Hilfe der nachfolgenden Methode werden E. coli-Zellen mit Plasmid-DNA transformiert (Hanahan, 1983).

- Die kompetenten Zellen auf Eis auftauen

- Zugabe der Plasmid-DNA (200-300 ng)

- Inkubation für 30 Minuten bis mehrere Stunden auf Eis (Anheftung der DNA an die Zellen)

- Hitzeschock der Zellen für 2 Minuten bei $42^{\circ} \mathrm{C}$ (Aufnahme der DNA)

- Zugabe von 0,8 ml LB-Medium

- $\quad$ Regeneration der Zellen bei $37^{\circ} \mathrm{C}$ für 30 Minuten auf dem Schüttler

- Transformationsansatz auf LB-Selektionsmedium ausplattiert.

\subsubsection{Blau-Weiß-Selektion}

Für die Blau-Weiß-Selektion muss die Klonierungsstelle im Vektor innerhalb des lacZ-Gens liegen. lacZ codiert für die ersten 146 aminoterminalen Aminosäuren ( $\alpha$-Peptid) der $\beta$-Galaktosidase. Sie können zusammen mit einem inaktiven Enzym, dem die Aminosäuren 11-41 fehlen, eine funktionierende $\beta$ Galaktosidase bilden ( $\alpha$ - Komplementation). Das aktive Enzym hydrolysiert das Substrat X-Gal, das daraufhin durch Luftoxidation eine blaue Färbung zeigt. Bakterienstämme mit dem inaktiven Enzym können durch Aufnahme eines Plasmids, das das lacZ-Gen trägt, nach Induktion mit IPTG X-Gal umsetzen. Wird die Sequenz des lacZ-Gens jedoch durch den Einbau von fremder DNA in das Plasmid unterbrochen, so bleibt die Bakterienkolonie weiß.

Dieses Verfahren erleichtert die Selektion der Kolonien mit rekombinanten Plasmiden. Die Platten, auf denen eine Blau-Weiß-Selektion durchgeführt wird, werden mit $50 \mu \mathrm{l} \mathrm{X-Gal-Lösung}(20 \mathrm{mg} / \mathrm{ml})$ und $50 \mu 1$ IPTGLösung $(0,1 \mathrm{M})$ beschichtet. Animpfen und Inkubation finden wie gewohnt statt.

\subsubsection{Colony-Screen mittels PCR}

Um potentiell positive Klone aus der Blau-Weiß Selektion (weiße Kolonien) noch in einer PCR zu verifizieren, können die Plasmide mit Hilfe einer Schnelllyse mittels kochen isoliert werden:

- $\quad 10 \mu \mathrm{l} \mathrm{H}_{2} \mathrm{O}$ in ein PCR-Cup geben

- Kolonien mit einem sterilen Zahnstocher picken

- auf eine Masterplatte überimpfen

- den restlichen Teil der am Zahnstocher befindlichen Zellen in den $10 \mu 1 \mathrm{H} 2 \mathrm{O}$ resuspendieren

- 10 Minuten $/ 95^{\circ} \mathrm{C}$ (Zellen lysieren, DNasen denaturieren)

- auf Eis lagern

- $\quad$ entsprechenden Mastermix für PCR zugeben

\subsubsection{Transformation von Agrobacterium tumefaciens}

Die Transformation von Agrobacterium tumefaciens - Zellen mit DNA erfolgt mittels Elektroporation (Dower et al., 1988). Die Zellen auf Eis aufgetaut, mit der zu transformierenden DNA versetzt und in eine Elektroporationsküvette (Elektrodenabstand $2 \mathrm{~mm}$ ) überführt. Die Transformation erfolgt im Elektroporator bei einer Stromstärke von $2,5 \mathrm{kV}$, Kapazität von $25 \mu \mathrm{F}$ und Widerstand von $400 \Omega$. Die Zellen werden nach der Elektroporation mit $1 \mathrm{ml}$ SOC-Medium versetzt und $1 \mathrm{~h}$ bei $28^{\circ} \mathrm{C}$ regeneriert. Nach der Regeneration werden die Zellen auf Selektionsmedium ausplattiert und 2-3 Tage bei $28^{\circ} \mathrm{C}$ inkubiert.

\subsubsection{Stabile Transformation von Nicotiana tabacum}

Sämtliche im Rahmen dieser Arbeit erstellten transgenen Pflanzen entstanden mit Hilfe des Agrobacterium tumefaciens-vermittelten Gentransfers. Eine Pflanze bildet bei Befall mit dem Bodenbakterium $A$. tumefaciens Tumore, die so genannten Wurzelhalsgallen. A. tumefaciens besitzt durch sein Ti-Plasmid (Tumor-induzierendes Plasmid) die Fähigkeit, eigenes genetisches Material (Transfer-DNA, T-DNA) in verletzte Pflanzenzellen zu transferieren und in deren Genom einzubauen. Die T-DNA wird durch zwei 
border-Sequenzen begrenzt. Nur die zwischen den border-Sequenzen liegende DNA wird ins Pflanzengenom transferiert. Durch die auf der T-DNA lokalisierten Gene produziert die Pflanzenzelle Phytohormone, die ein tumorartiges Wachstum des Gewebes hervorrufen, sowie Opine, die von den Agrobakterien als N- und CQuelle genutzt werden. Durch gezielte Veränderungen dieses Gentransfersystems ist es nun möglich, mit Hilfe von Agrobakterien Pflanzenzellen gezielt mit ausgewählten Genen zu transformieren. Dabei bedient man sich heute des binären Vektorsystems (Hoekema et al., 1984). Die für den DNA-Transfer notwendigen Funktionen werden auf zwei Plasmide aufgeteilt. Der gesamte T-DNA-Bereich des Ti-Plasmids wurde deletiert, womit es nicht mehr tumor-induzierend ist, aber weiterhin die Fähigkeit, T-DNA in die Pflanze zu transferieren besitzt. Die vir-(Virulenz) Funktion liegt im verwendeten Agrobakterien Stamm auf einem Helferplasmid. Eine modifizierte T-DNA wird auf einem kleinen zweiten Plasmid zur Verfügung gestellt. Dabei kann die DNA zwischen den border-Sequenzen durch Fremdgene mit einem Selektionsmarker (z.B. Resistenz gegen die Antibiotika Hygromyzin oder Kanamyzin) ausgetauscht werden. Durch Infektion von Pflanzengewebe mit diesen gentechnisch veränderten Agrobakterien kann man einzelne transgene Pflanzenzellen erzeugen, die sich unter geeigneten Hormonbedingungen zunächst zu Kallusgewebe und schließlich zu neuen Pflanzensprossen entwickeln. Durch Regeneration auf antibiotikahaltigem Medium ist eine Selektion der transformierten Pflanzenzellen durch den Selektionsmarker auf der modifizierten T-DNA möglich.

Für die Transformation werden Blätter von in Sterilkultur gewachsenen Pflanzen verwendet. Die Mittelrippe wird entfernt und die Blätter in $2 \mathrm{~cm}^{2}$ große Stücke zerteilt. Die Blattstücke werden mit 200-400 $\mu$ l einer 2 Tage-Kultur der Agrobakterien im Dunklen bei RT in B5-Infektionsmedium co-kultiviert. Nach 3 Tagen werden die Blattstückchen mit sterilem $\mathrm{H}_{2} \mathrm{O}$ gründlich gewaschen und auf sterilem Filterpapier getrocknet. Die Blattscheiben werden anschließend auf das Pflanzenmedium mit Hormonen 1mg/l 6-BAP (6Benzylaminpurin) und 0,1mg/l NAA ( (1-Naphtylessigsäure) zur Sprossbildung in Petrischalen ausgebracht. Zur Selektion der transgenen Zellen ist dem Medium Antibiotikum zugesetzt. Das Wachstum der Agrobakterien wird durch Cefotaxim unterdrückt. Nach gelungener Sprossbildung werden die Sprosse auf hormonfreies MS-Selektionsmedium überführt und weiterkultiviert.

\subsubsection{Transiente Transfektion von Nicotiana tabacum}

\section{Mesophyllprotoplasten}

Eine schnelle Analyse zur Lokalisation, Interaktion und Aktivierung von Proteinen in planta wurde in dieser Arbeit durch die transiente Transfektion von Nicotiana tabacum Mesophyllprotoplasten durchgeführt. Dazu wurde das Protokoll von Ausubel et al., 1993 und Sambrook und Russel, 2001 modifiziert. Als Ausgangsmaterial für die Gewinnung von Mesophyllprotoplasten dienen steril gewachsene Tabakblätter des Kultivars SNN, die in Rundbauch-Gläsern angezogen werden. Alle Arbeitsschritte werden unter sterilen Bedingungen und bei Raumtemperatur durchgeführt. Die Puffer werden in mehrfach autoklavierten Flaschen angesetzt.

1.Tag:

- $\quad$ sterile Blätter auf der Unterseite einritzen, Abstand 1-2mm

- $10 \mathrm{ml}$ Enzymlösung in einer Petrischale vorlegen und die Blätter mit der Unterseite darauf legen

- $\quad$ ü.N., $25^{\circ} \mathrm{C}$, dunkel

2.Tag (vorsichtig arbeiten)

- Protoplasten herausschütteln

- $1 \mathrm{ml}$ K3S vorlegen; Protoplasten durch ein Sieb $(0,125 \mathrm{~mm})$ schütten und in einen Greiner überführen

- $\quad$ mit K3S nachspülen (2x1ml Platte; $1 \mathrm{ml}$ Sieb)

- 5 min, 480 rpm (lebenden Zellen schwimmen auf) alte Zentrifuge, Beschleunigung 3

- Pellet und Unterstand abnehmen (Peristaltik-Pumpe)

- $\quad$ auf $20 \mathrm{ml}$ mit $\mathrm{W} 5$, resuspendieren

- $\quad \min , 670 \mathrm{rpm}$, (Beschleunigung 2, keine Bremse)

- Überstand abnehmen

- $\quad$ auf $20 \mathrm{ml}$ mit $\mathrm{W} 5$, resuspendieren

- 1 min, 670 rpm (Beschleunigung 2, keine Bremse)

- $\quad$ Überstand abnehmen und in 10ml W5 resuspendieren

- Protoplasten können nun mehrere Stunden bei RT stehen gelassen werden (maximal 4 Stunden, danach sinkt die Transformationsrate) 
- Zellen in einer Fuchs-Rosenthal-Zählkammer bestimmen

- 1 min, 670 rpm (Beschleunigung 2, keine Bremse)

- Pellet in K3M (auf $1 \times 10^{6}$ Zellen $/ \mathrm{ml}$ ) resuspendieren

- 5 min inkubieren

Bestimmung der Protoplasten pro ml: $\quad$ Anzahl $=$ Xx5x1000x10, wobei X die Anzahl an Protoplasten in einem kleinen Quadrat ist. Transformation:

- $\quad 2 \mathrm{ml}$ Eppis mit vorgelegter DNA $(40 \mu \mathrm{g}, 20 \mu \mathrm{l})$

- $\quad$ in die schräg gestellten Eppis $100 \mu$ l Protoplastensuspension laufen lassen (abgeschnittene gelbe Spitzen), Deckel vorsichtig schließen

- durch invertieren vorsichtig mischen (etwa 3x)

- $\quad$ schräg stellen und $200 \mu \mathrm{l}$ PEG (25\%) hinein pipettieren, vorsichtig invertieren (etwa 8x)

- Deckel schließen und 20 min inkubieren

- $\quad 900 \mu 1 \mathrm{~K} 3 \mathrm{M}^{*}$ dazu (invertieren, bis keine Schlieren mehr vorhanden sind)

- $\quad$ ü.N. (ca. 20h) bei schwachem Licht

*) Bei den Induktionen mit NAA für die Interaktionsanalysen im P2H System oder für die Bestimmung der Aktivierungseigenschaften, wurden K3M-Puffer ohne und mit 50 $\mathrm{M}$ NAA verwendet.

3.Tag (nicht mehr steril):

für Lokalisation:

Die mittlere Phase wird auf 0,25 ml abgenommen. Die Protoplasten können direkt nach einer vorsichtigen Resuspendierung auf einen Objektträger gegeben und analysiert werden. Wenn induziert wurde, wurde der Mittelstand 4 Stunden vor der Analyse abgenommen und die Protoplasten induziert.

für Protoplasten ,Two-Hybrid' Analyse:

- Mittelstand entfernen, auf $0,5 \mathrm{ml}$

- $\quad$ mit W5 auf $2 \mathrm{ml}$ auffüllen und vorsichtig invertieren

- $1 \mathrm{~min}, 670 \mathrm{rpm}$, alles abnehmen

- $\quad$ in flüssigem Stickstoff bis auf weiteres aufbewahren

\subsubsection{Protoplasten ,Two-Hybrid' (P2H) Analyse}

Um die Interaktion von ANK1 mit BZI-1 in planta nachzuweisen, wurde das P2H (Protoplasten TwoHybrid; Ehlert et al., 2006) System verwendet, das auf der Methode des Matchmaker ${ }^{\circledR}$ GAL4 Y2H System (Clontech, 1996) beruht.

Der Transkriptionsfaktor GAL4 besitzt einen modularen Aufbau (Brent und Ptashne 1985; Ma und Ptashne 1987). Die GAL4-Bindedomäne (BD) (Keegan et al., 1987) vermittelt die Bindung des Transkriptionsfaktors an die GAL4-UAS (,Upstream Activating Sequences') (Guarente et al., 1982; Ginger et al., 1985)und die GAL4-Aktivierungsdomäne (AD) (Ma und Ptashne 1987) vermittelt eine transkriptionelle Aktivierung.

Normalerweise kommen diese beiden GAL4-Domänen im selben Protein vor. Um eine Interaktion von zwei Proteinen zu untersuchen, werden die GAL4-Aktivierungs- und GAL4-Bindedomäne mit jeweils einem dieser Proteine fusioniert. Kommt es zu einer nicht kovalenten Protein-Protein-Interaktion dieser beiden Proteine, werden die GAL4-Domänen wieder in räumliche Nähe zueinander gebracht und der GAL4 Transkriptionsfaktor wird funktionell rekonstituiert, was eine Expression des nachgeschalteten Reportergens zur Folge hat.

Im P2H System kontrolliert das GAL4-UAS Promotorelement die Expression des Reportergens $\beta$ Glukuronidase (GUS). Dieses Enzym spaltet das künstliche Substrat 4-Methylumbelferyl- $\beta$-D-Glucuronid (4-MUG) und man erhält Methylumbeliferon, das sich fluorometrisch bestimmen lässt. Die Menge des umgesetzten Substrats ist proportional zur Aktivität des Reportergens.

Zur Korrektur der Variation der einzelnen Ansätzen in einem Experiment, wurde zusätzlich das Pro $355:$ NAN (Neuraminidase) Plasmid eingeführt (Kirby und Kavanagh, 2002; Ehlert et al., 2006). Dieses konstitutiv exprimierte Gen kodiert für das NAN Enzym, ein Codon-optimierte nanH aus Clostridium perfringens, das das künstliche Substrat MUN (,2`-(4-Methylumbelliferyl)-alpha-D-N-acetylneuraminic acid, sodium salt') spaltet. 
In allen Transformationen wurden die Reporterplasmide GAL4-UAS 4 :GUS und Reporterplasmid Pro $_{355}$ :NAN zur Normalisierung, zusätzlich zu den Effektorkonstrukten, co-transformiert und die Expression wurde transient in Tabak Mesophyllprotoplasten durchgeführt. Als Effektorplasmide wurden die Gateway kompatiblen Vektoren pHBTL-BDGW und pHBTL-ADGW verwendet, in denen die jeweiligen Gene mit den entsprechenden Domänen fusioniert waren.

$\begin{array}{cc}\text { pro Ansatz: } & 9 \mu \mathrm{g} \text { pGAL4-UAS-GUS } \\ 3 \mu \mathrm{g} \text { pROK219-NAN } & 28 \mu \mathrm{g} \text { Effektorplasmide } \\ \text { Negativkontrolle } 9 \mu \mathrm{g} \text { pGAL4-UAS-GUS } \\ 3 \mu \mathrm{g} \text { pROK219-NAN } \\ 28 \mu \mathrm{g} \text { pHBTL- } \Delta \mathrm{GFP} \\ \text { Positivkontrolle: } 20 \mu \mathrm{g} \text { HBT-GUS-NCO } \\ 17 \mu \mathrm{g} \text { pHBTL- } \Delta \mathrm{GFP} \\ 3 \mu \mathrm{g} \text { pROK219-NAN }\end{array}$

\subsubsection{Aktivierungsstudien in Tabak Mesophyllprotoplasten}

Zur Bestimmung der Aktivierungseigenschaften wurde das $\mathrm{P} 2 \mathrm{H}$ System verwendet, wie es in 4.6.6.1 beschrieben ist. Als Effektorplasmide wurden hier allerdings die Gateway kompatiblen Vektoren pHBTLBDGW und pHBTL-HAGW verwendet, in denen die jeweiligen Gene mit den entsprechenden Domänen fusioniert sind.

\subsubsection{Messung der B-Glukuronidase (GUS)- Aktivität}

Der Nachweis der GUS-Reportergenaktivität erfolgt durch einen modifizierten GUS-Assay (Jefferson et al., 1987). Die ß-Glukuronidase (GUS) ist das Genprodukt des GUS-Reportergens. Das GUS-Enzym ist in der Lage $\beta$-Glukuronide in D-Glukuronsäuren und einem aglykonischen Rest zu spalten. Setzt man das künstliche Substrat 4-Methylumbeliferyl-3-D-Glucuronid (4-MUG) ein, so erhält man nach der Hydrolyse das fluoreszierende Molekül Methylumbeliferon (MU). Durch die Stärke der Fluoreszenz in den Ansätzen lässt sich die umgesetzte Menge MU quantifizieren und die Aktivität des GUS-Enzyms bestimmen. Die Anregung des MU erfolgt bei 360nm, die Emission bei 460nm.

Probe wird in $150 \mu \mathrm{l}$ GUS-Ex-Puffer (pH7,2) aufgenommen

10 min, $13000 \mathrm{rpm}, \mathrm{RT}$

$100 \mu 1$ der Proteinsuspension in ein Well der Mikrotiterplatte überführen

$100 \mu 1$ MUG-Gebrauchslösung zugeben und mischen

10 min bei $37^{\circ} \mathrm{C}$ inkubieren (dunkel)

$100 \mu 1$ des Reaktionsansatzes in ein neues Well überführen und die Reaktion durch Zugabe von $100 \mu$ l GUSStopp-Puffer abstoppen $\left(\mathrm{t}_{0}\right)$

$60 \mathrm{~min}$ bei $37^{\circ} \mathrm{C}$ inkubieren (dunkel)

Reaktionsansatz mit $100 \mu$ l GUS-Stopp-Puffer abstoppen $\left(\mathrm{t}_{60}\right)$

Die Quantifizierung der Fluoreszenz erfolgt im CytoFluor II Plate Reader. Die GUS-Aktivität wurde nach folgender Formel berechnet:

GUS-Aktivität $[\mathrm{pmol} /(\mathrm{min} * \mathrm{mg})]=\frac{\Delta \mathrm{F} / 10}{\mathrm{t}^{*} \mathrm{mg}}$

$\Delta \mathrm{F}=$ Differenz der Fluoreszenz $\mathrm{t}_{60}-\mathrm{t}_{0}$

10 Fluoreszenzeinheiten entsprechen 1 pmol MUG-Umsatz.

$\mathrm{mg}=$ eingesetzte Gesamtproteinmenge in $\mathrm{mg}$

\subsubsection{Messung der Neuraminidase (NAN)- Aktivität}

Die Neuraminidase (NAN) ist das Genprodukt des NAN-Reportergens. NAN ist ein Codon-optimiertes nanH aus Clostridium perfringens. Das NAN-Enzym setzt das künstliche Substrat ,2-(4-Methylumbelliferyl)alpha-D-N-acetylneuraminic acid' (MUN) um und man erhält nach der Hydrolyse das fluoreszierende Molekül Methylumbeliferon (MU). Durch die Stärke der Fluoreszenz in den Ansätzen lässt sich die umgesetzte Menge MU quantifizieren und die Aktivität des NAN-Enzyms bestimmen. Die Anregung des 
MU erfolgt bei 360nm, die Emission bei 460nm (Kirby und Kavanagh, 2002; Ehlert et al., 2006). Die MUNMessung erfolgt parallel zu der MUG-Messung:

- $\quad$ Probe wird in $150 \mu \mathrm{l}$ GUS-Ex-Puffer, pH 7,2 aufgenommen

- $10 \mathrm{~min}, 13000 \mathrm{rpm}, \mathrm{RT}$

- $10 \mu \mathrm{l}$ der Proteinsuspension in ein Well der Mikrotiterplatte überführen

- $10 \mu \mathrm{l}$ MUG-Gebrauchslösung zugeben und mischen

- $\quad 10$ min bei $37^{\circ} \mathrm{C}$ inkubieren (dunkel)

- $\quad 3,3 \mu 1$ des Reaktionsansatzes in ein neues Well überführen und die Reaktion durch Zugabe von $200 \mu 1$ NAN-Stopp-Puffer abstoppen $\left(\mathrm{t}_{0}\right)$

- 60 min bei $37^{\circ} \mathrm{C}$ inkubieren (dunkel)

- $\quad 3,3 \mu l$ des Reaktionsansatzes in ein neues Well überführen und die Reaktion durch Zugabe von $200 \mu 1$ NAN-Stopp-Puffer abstoppen $\left(\mathrm{t}_{60}\right)$

- Die Quantifizierung der Fluoreszenz erfolgt im CytoFluor II Plate Reader. Die NAN-Aktivität wird entsprechend der GUS-Aktivität berechnet.

Das Verhältnis zwischen den GUS- und NAN-Aktivitäten wird als relative GUS/NAN-Aktivitäten in , units' angegeben. Die relativen GUS/NAN-Aktivitäten werden wie folgt berechnet:

$$
\text { GUS/NAN-Aktivitäten [units] }=\frac{\text { GUS-Aktivität }}{\text { NAN-Aktivität }}
$$

\subsubsection{Transiente Expression in Nicotiana benthamiana}

\subsubsection{Bimolecular Fluorescence Complementation' (BiFC)}

Eine Bestimmung der Proteininteraktion wurde mit der BiFC Methode durchgeführt (Walter et al., 2004; Hu et al., 2002). Das YFP-Protein (,Yellow Fluorescence Protein') ist in diesem System in ein amino- und ein carboxyterminales Fragment geteilt, die einzeln nicht fluoreszieren. Diese Fragmente werden an die zu untersuchenden Proteine fusioniert. Wenn die YFP-Fragmente durch eine Protein-Protein Interaktion der an sie fusionierten Proteine wieder in räumliche Nähe gebracht werden, so wird die Funktion des YFP rekonstituiert. Die Fusionsproteine werden durch Agrobacterium Infiltration in Nicotiana benthamiana Blättern transient exprimiert. Die Expressionsvektoren (pE-SPYNE-GW und pE-SPYCE-GW) wurden mit Hilfe des Gateway ${ }^{\circledR}$ Systems hergestellt. Für die Transformation wurde der Agrobacterium tumefaciens Stamm GV3101 RK verwendet, der auf AMM-Platten (Rif50, Gent 25, Kan50, Carb50) kultiviert wurde. Es wurde immer zusätzlich das p19k-Protein (Agrobakterium t. p19k) transformiert. Das p19k-Protein des ,bushy stunt virus' wird zur Unterdrückung des , gene silencing' verwendet. Die Tabakpflanzen sollten 2-3 Wochen alt sein. In älteren Pflanzen sinkt die Transformationsrate.

- $\quad$ animpfen der Agrobakterien-Stämme in YEB (Rif50, Gent 25, Kan50, Carb50)

- zusätzlich das Agrobakterium t. p19k in YEB(Rif50, Gent 25, Kan50) animpfen

- $\quad$ ü.N. $29^{\circ} \mathrm{C}$, Schüttler

- $\quad$ bei OD600 = 0,8; $15 \mathrm{~min}, 4000 \mathrm{rpm}, \mathrm{RT}$

- $\quad$ in AS-Medium resuspendieren

- die Agrobakterien und Agrobakterium t. p19k im gleichen Verhältnis mischen $(1: 1: 1)$

- $\quad 4 h$ bei RT inkubieren, Pflanzen in der Inkubationszeit gut wässern

- mit einer Spritze (Omnifix ${ }^{\circledR} 40$ Solo, Ref 9161306V) in die Unterseite der Blätter infiltrieren

- $\quad 48 \mathrm{~h}$ Inkubation (Klimakammer)

\subsubsection{Bestimmung der Lokalisation von YFP-Fusionsproteinen}

YFP-Fusionsproteine werden entsprechend der BiFC Methode transient in Nicotiana benthamiana exprimiert. Verwendet wurde der Gateway kompatible Expressionsvektor pENSG-YFP. 


\subsection{Detektion fluoreszenzmarkierter Proteine}

Die Analysen der in Tabak Mesophyllprotoplasten transient exprimierten YFP-Proteine wurde mit dem Fluoreszenzmikroskop BX60 der Firma Olympus und mit dem konfokalen Mikroskop TCS SP2 AOBS der Firma Leica durchgeführt. Die Analysen der transienten Expression von BiFC-Konstrukten in Nicotiana benthamiana wurden ausschließlich mit dem konfokalen Mikroskop mit folgenden Einstellungen durchgeführt:

BX60:

Detektion YFP:

Detektion YFP und Chlorophyllanregung:

TCS SP2 AOBS:

YFP-Anregung mit einem Argon Laser:

Detektion:

Chlorophyll-Anregung (Argon-Laser):

Detektion:

\author{
Anregungsfilter \\ Sperrfilter (U-WIBA) \\ Sperrfilter (U-NWB) \\ 460- $495 \mathrm{~nm}$ \\ $510-550 \mathrm{~nm}$ \\ $510 \mathrm{~nm}$ \\ $488 \mathrm{~nm}$ \\ 510- $580 \mathrm{~nm}$ \\ $514 \mathrm{~nm}$ \\ 650-700 nm
}

\subsection{Biochemische Methoden}

\subsubsection{RNA Extraktion mit Trizol}

Die Methode basiert auf einer Phenol/Chloroform Extraktion. Da RNA sich besser in der hydrophilen, wässrigen Phase löst, während Chlorophyll und andere Bestandteile besser in der hydrophoben ChloroformPhase gelöst werden, können sie so voneinander getrennt werden.

Die beiden Thiocyanat-Salze im Extraktionspuffer inhibieren RNasen und verhindern so eine Degradation der RNA (Chomczynski, 1993; Chomczynski und Sacchi, 1987).

- $\quad$ 0,2 g Blattmaterial in N2 aufmörsern und in ein $2 \mathrm{ml}$ Eppendorfgefäß überführen

- $\quad$ 1,5 ml Trizolpuffer hinzugeben

- Gefäß auf dem Vortexer fixieren und 5 Minuten schütteln

- $300 \mu \mathrm{l}$ Chloroform hinzugeben

- $\quad$ erneut 5 Minuten schütteln

- $\quad 30$ Minuten bei $4^{\circ} \mathrm{C} / 12.000 \mathrm{~g}$ zentrifugieren

- Überstand (ca. 1,2ml) in ein neues Gefäß überführen

- $\quad 420 \mu \mathrm{l}$ Fällungspuffer und $420 \mu \mathrm{l}$ Isopropanol zugegeben

- Invertieren und 10 Minuten bei RT inkubieren

- $\quad 15$ Minuten bei $4^{\circ} \mathrm{C} / 12.000 \mathrm{~g}$ abzentrifugieren

- Überstand abnehmen

- Pellet in $250 \mu 170 \%$ EtOH resuspendieren

- 10 Minuten bei $4^{\circ} \mathrm{C} / 12.000 \mathrm{~g}$ abzentrifugieren

- Minuten lufttrocknen

- $\quad$ in $50 \mu \mathrm{l} \mathrm{H} 2 \mathrm{O}$ lösen (Inkubation 20 min. bei RT auf dem Schüttler

\subsubsection{Northernblot Analyse}

Im Northernblot-Verfahren wird die $\mathrm{zu}$ analysierende RNA durch eine denaturierende Agarosegelelektrophorese zunächst aufgetrennt und nach Kontrolle des Gellaufs auf dem Transilluminator durch einen Kapillarblot auf eine Nylonmembran übertragen. Durch Hybridisierung des Filters mit radioaktiv markierten einzelsträngigen DNA-Sonden ist es möglich, diejenigen RNA-Transkripte durch Autoradiographie sichtbar zu machen, die komplementär zu der eingesetzten Sonde sind.

\subsubsection{Auftrennung von RNA in denaturierenden Agarosegelen}

Um die elektrophoretische Größenauftrennung von RNA-Molekülen zu ermöglichen, muss die Elektrophorese unter denaturierenden Bedingungen stattfinden, da sonst die Sekundärstrukturen das 
Laufverhalten beeinflussen würden. Die Elektrophorese findet deshalb in einem Formaldehyd-haltigen Agarosegel statt:

- $\quad$ 1,5 g Agarose in $112,5 \mathrm{ml} \mathrm{H} \mathrm{O}_{2} \mathrm{O}$ aufkochen

- $\quad$ unter Rühren auf ca. $60^{\circ} \mathrm{C}$ abkühlen lassen

- $15 \mathrm{ml}$ 10x MEN-Puffer und 22,5 $\mathrm{ml} 37 \%$ Formaldehyd dazu geben

Als Laufpuffer dient 1 x MEN-Puffer. Die je $10 \mu \mathrm{g}$ der RNA-Proben werden mit Wasser auf das gleiche Volumen abgeglichen und mit je $10 \mu \mathrm{l}$ RNA-Probenpuffer (2,5x) versetzt. Die Denaturierung der Proben erfolgt bei $65^{\circ} \mathrm{C}$ für $10 \mathrm{~min}$. Bis zum Auftragen der Proben werden diese auf Eis gehalten.

\subsubsection{Kapillarblot}

Durch den Kapillarblot wird die aufgetrennte RNA auf eine Nylonmembran übertragen (Abbildung 4.1.)

- Zwei Lagen Fließpapier mit 10 x SSC äquilibrieren und so auf einer ebenen Platte legen, dass die Enden in ein 10 x SSC-Pufferreservoir tauchen

- Das RNA-Gel luftblasenfrei mit der Oberseite nach unten auf das Fließpapier legen

- Die Nylonmembran luftblasenfrei auf das Gel auflegen

- Drei Lagen Fließpapier und Papiertüchern oben drauf

- Mit einem Gewicht (ca. 500 g) gleichmäßig beschweren

- Über Nacht blotten

- $\quad$ RNA durch zweistündige Inkubation bei $80^{\circ} \mathrm{C}$ auf der Filteroberfläche fixieren

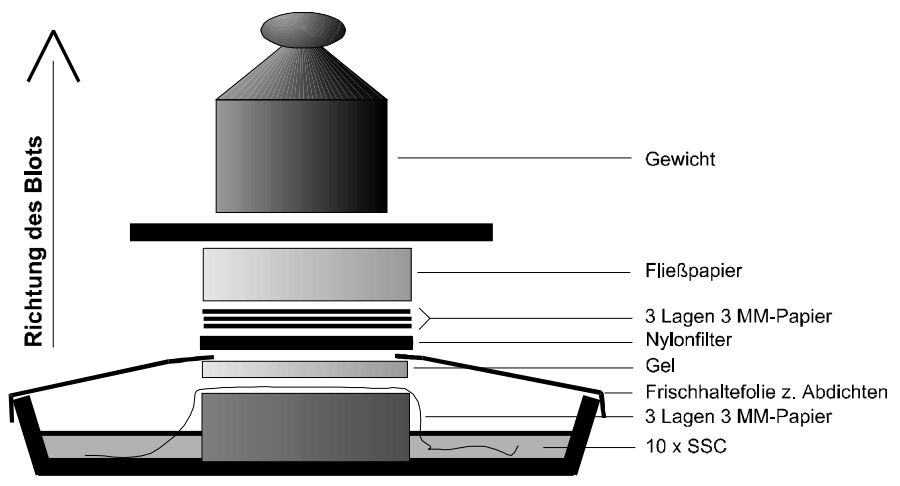

Abbildung 4.1: Aufbau eines Northernblots.

\subsubsection{Herstellen einer radioaktiv markierten DNA-Sonde}

Für die Herstellung radioaktiv markierter Hybridisierungssonden wird ein DNA Fragment nach Restriktionsspaltung oder ein PCR-Produkt aus einem Agarosegel eluiert. Die Markierungsreaktion erfolgt nach der Random-Prime-Labeling-Methode (Feinberg und Vogelstein, 1983; Feinberg und Vogelstein, 1984), bei der Hexanukleotide zufälliger Sequenz an die Matrizen-DNA binden. Die gebundenen Hexanukleotide dienen dann als Primer für die Neusynthese eines komplementären Stranges durch die Klenow-Polymerase unter Einbau von radioaktiven Nukleotiden. Die verwendete Klenow-Polymerase ist modifiziert, so dass sie keine Exonukleaseaktivität (exo-) mehr besitzt. Die Markierungsreaktion wird mit Hilfe des Megaprime-DNA-labeling-system Kits von Amersham Pharmacia vorgenommen. Die Durchführung erfolgt nach dem Protokoll des Herstellers, wobei jeweils $3 \mu$ [ [32P] dATP zugefügt werden. Nach zweistündiger Inkubation bei $37{ }^{\circ} \mathrm{C}$ wird die Reaktion durch Zugabe von $70 \mu \mathrm{l} \mathrm{H}_{2} \mathrm{O}$ gestoppt. Nicht eingebaute Nukleotide und Primer werden durch Gelfiltration über eine Sephadex G50-Säule abgetrennt. Als Säule dient eine $1 \mathrm{ml}$ Einwegspitze, die mit einem Fließpapierkügelchen verschlossen und dann mit dem Säulenmaterial beladen wird. Das Packen der Säule sowie die Elution der Sonde erfolgt jeweils durch Zentrifugation bei $2000 \mathrm{rpm}$ für $5 \mathrm{~min}$ in der Hettichzentrifuge mit Ausschwingrotor. Die gereinigte Sonde wird in einem verschraubbaren Eppendorfgefäß aufgefangen. 


\subsubsection{Hybridisierung der Northern Blot Membran}

Durch Hybridisierung der Membran mit radioaktiv markierten, einzelsträngigen DNA Sonden lassen sich komplementäre RNA-Transkripte auf der Membran lokalisieren. Die Spezifität, mit der die Sonde an die RNA bindet, ist abhängig von der Salzkonzentration und der Temperatur. Bei hoher Salzkonzentration und niedriger Temperatur ist die Stabilität unspezifischer DNA-RNA-Hybride größer als in Lösungen niederer Salzkonzentration und höherer Temperatur. Durch die Absenkung der Salzkonzentration in den Waschlösungen erhöht man die Stringenz. Die Methode ist modifiziert nach (Church und Gilbert, 1984).

Die zu analysierende Membran 30 Minuten bei $65^{\circ} \mathrm{C}$ in einer Hybridisierungsröhre mit $15 \mathrm{ml}$ Hybridisierungslösung (Church) inkubieren

- Die Sonden-DNA 10 Minuten bei $95^{\circ} \mathrm{C}$ denaturieren

- Zugabe der Sonden-DNA zu ca. $15 \mathrm{ml}$ Hybridisierungslösung in die Hybridisierungsröhre

- Hybridisierung bei $65^{\circ} \mathrm{C}$ über Nacht im Roller

- Zur Abtrennung unspezifisch gebundener Sonden-DNA die Membran zweimal 30 Minuten mit 2x $\mathrm{SSC} / 0,1 \%$ SDS in der Röhre waschen

- Weitere 30 Minuten im Bellydancer mit 1x SSC /0,1\% SDS waschen

- optional für weitere 15 - 30 Minuten mit 0,5x SSC /0,1\% SDS waschen

Für den Nachweis der Radioaktivität wird die Membran in Folie eingeschweißt und mit einem IP-Screen exponiert. Die Dauer der Exposition hängt von der Menge der nachweisbaren Radioaktivität ab. Sie betrug für diese Arbeit in der Regel ein bis zwei Tage. Die Auswertung erfolgt mit Hilfe des Bioimagers (BAS-1000 von Fuji). Zur Quantifizierung werden die Programme PCBAS ${ }^{2} .09$ und TINA®2.0 der Firma Raytest verwendet. Die Normalisierung der detektierten Signale wird über den Vergleich mit der dokumentierten Ethidiumbromid-Färbung der RNA erreicht.

\subsubsection{Rehybridisierung}

Die auf der Filteroberfläche fixierte RNA kann nacheinander mit mehreren verschiedenen Sonden hybridisiert werden. Dazu müssen die auf dem Filter befindlichen radioaktiven Sonden aus der vorhergehenden Hybridisierung durch Denaturierung der RNA-DNA-Hybride in Waschlösungen mit geringer Salzkonzentration bei hoher Temperatur abgelöst werden. Die Membran wird durch Zugabe kochendheißer 0,1\%iger SDS-Lösung für 1 Stunde bei $74{ }^{\circ} \mathrm{C}$ gewaschen. Danach ist der Filter für eine erneute Hybridisierung einsetzbar.

\subsubsection{Westernblot Analyse}

\subsubsection{Präparation von pflanzlichen Gesamtprotein-Extrakten unter denaturierenden Bedingungen}

Das Blattgewebe wird unter $\mathrm{N}_{2}$ (liq.) aufgemörsert, 50-200 mg des Pulvers im gefrorenen Zustand in ein Eppendorfgefäß eingewogen, mit der dreifachen Menge (w/v) Harnstoffextraktionspuffer aufgenommen, gevortext und bei $65 \mathrm{C}$ für 10' inkubiert. Nach 5' Inkubation werden die Eppendorfgefäße mehrmals invertiert. Anschließend wird der Rohextrakt $15^{\prime}$ bei $15000 \mathrm{rpm}$ und RT zentrifugiert, um Zelltrümmer und DNA abzutrennen. $2 / 3$ Volumen des Überstandes werden in ein neues Eppendorfgefäß überführt. Die Proteinextrakte werden bis zur weiteren Verwendung bei $-80 \mathrm{C}$ gelagert. Vor Auftragung in der SDS-PAGE werden die 20 min bei $65 \mathrm{C}$ inkubiert. Die Proben können dann direkt auf das Gel appliziert werden.

\subsubsection{Diskontinuierliche SDS-Polyacrylamid-Gelelektrophorese}

Durch die diskontinuierliche Sodiumdodecylsulfat (SDS)-Polyacrylamid-Gelelektrophorese (PAGE) werden Proteine in ihrer denaturierten Form der Größe nach durch die Polyacrylamidgel-Matrix nach Anlegen eines elektrischen Feldes aufgetrennt (modifiziert nach Laemmli, 1970). Für die Polacrylamid-Gelelektophorese wird das AGS-Gelsystem eingesetzt. Die Porengröße der Polyacrylamid-Matrix kann durch das Verhältnis der Acrylamid-Konzentration zur Konzentration des Quervernetzen N-N-Methylenbisacrylsäureamid bestimmt werden. Die radikalische Polymerisation erfolgt nach Zugabe von Ammoniumpersulfat (APS) und wird durch $\mathrm{N}, \mathrm{N}, \mathrm{N}^{\prime}, \mathrm{N}^{\prime}$-Tetramethylethylendiamin (TEMED) katalysiert. Für die optimale Auftrennung der nachzuweisenden Proteine mit einer Größe von ca. 50-65 kDa wird ein 12 prozentiges Trenngel verwendet. Nach dem Giessen des Trenngels wird zur Oberflächenglättung mit Isobutanol oder optional bei 
höherprozentigen Gelen mit $\mathrm{H}_{2} \mathrm{O}$ überschichtet. Zur gleichmäßigen Auftrennung der Proteine wird, nach Abgießen des Überstandes auf dem Trenngel, ein Sammelgel mit den Probenauftragstaschen gegossen. Die Proteinextrakte werden wie in 4.8.3.1 beschrieben hergestellt und aufgetragen. Die Elektrophorese erfolgte in Laufpuffer ca. 30' bei 90 V zum Durchlaufen der Proteine durch das Sammelgel und anschließend bei 120V bis die BPB-Bande das unter Ende des Gels erreicht hat. Zur Bestimmung der Molekulargewichte wird auf jedes Gel ein Proteingrößenstandard mit aufgetrennt.

\subsubsection{Transfer von Proteinen auf PVDF-Membranen}

Um Proteine aus SDS-PAGE Gelen immunologisch oder radioaktiv detektieren zu können, müssen diese auf einen Trägerfilter (PVDF oder Nitrocellulose) übertragen werden. Eine einfache, effektive Methode stellt der nach Kyhse-Andersen, 1984 modifizierte Semi-dry Blot (Westernblot) dar. Hierfür wird eine PVDFMembran in Gelgröße mit Methanol aktiviert und in Transferpuffer equilibriert, ebenso wie jeweils 6 Lagen Whatmann-Papier. Der Aufbau der Apparatur erfolgt analog der Abbildung 4.2.

Der Transfer erfolgt durch das Anlegen einer Spannung zwischen den Graphitplatten bei einer konstanten Stromstärke von $140 \mathrm{~mA}$ pro Gel $\left(2 \mathrm{~mA} / \mathrm{cm}^{2}\right.$ Gelfläche). Der erfolgreiche Transfer kann durch eine vorübergehende Anfärbung der Proteine auf der Membran mit Ponceau S-Färbelösung sichtbar gemacht werden. Die Membran lässt sich durch TBS wieder vollständig entfärben.

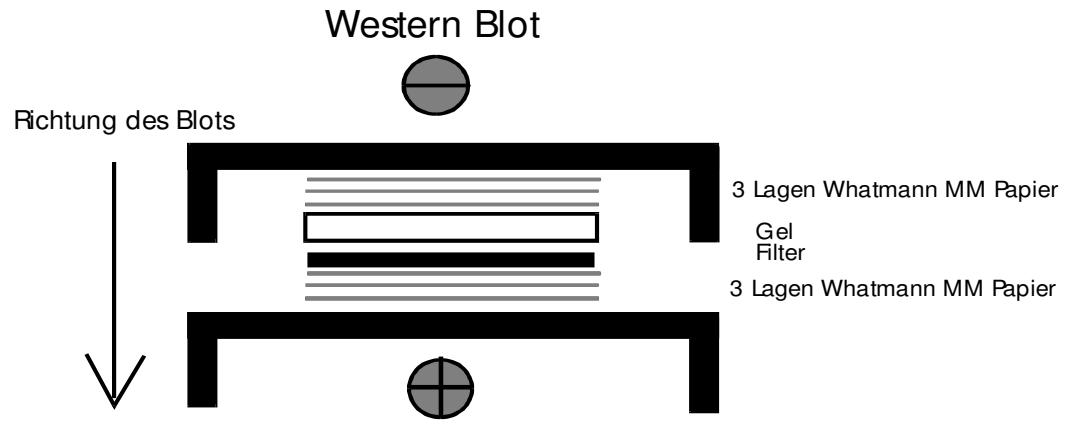

Abbildung 4.2:Aufbau eines Western Blots.

\subsubsection{Immunologische Detektion}

Die Immunodetektion erfolgt mittels zweier Antikörper, wobei der Primärantikörper das zu detektierende Protein erkennt und der Sekundärantikörper, der mit dem Enzym Peroxidase gekoppelt ist, spezifisch an den Primärantikörper bindet. Die an den zweiten Antikörper gebundene Peroxidase katalysiert die Oxidation des Substrates Luminol. Bei dieser Reaktion kommt es zu einer Chemilumineszenz, die durch Belichtung eines Röntgenfilms nachgewiesen werden kann. Die Oberfläche der Membran wurde zu Beginn der Detektion mit unspezifischen Proteinen durch eine $2 \mathrm{~h}$ Inkubation mit TBS-T (Tris-buffered Saline), mit 5\% Magermilchpulver abgesättigt. Die Inkubation mit dem Primärantikörper erfolgt ebenfalls für $2 \mathrm{~h}$ in $20 \mathrm{ml}$ TBS-T mit 5\% Magermilch. Der unspezifisch gebundene Antikörper wird durch dreimaliges 10' waschen mit TBS-T entfernt. Vor der Inkubation mit dem Sekundärantikörper erfolgt ein erneutes 1h Blocken der Membran mit TBS-T mit 5\% Milchpulver. Der Sekundärantikörper in 20ml TBS-T mit 5\% Milchpulver eingesetzt. Zur Entfernung des unspezifisch gebundenen Antikörpers wird die Membran 5x 5' mit TBS gewaschen. Alle Inkubation erfolgten bei RT auf dem Schüttler. Zum indirekten Nachweis der Proteine wird der ECL (EnhancedChemiLuminescence) oder $\mathrm{ECL}^{+}$-Kit der Firma Amersham verwendet. Der Nachweis basiert auf der Umsetzung des Substrates Luminol durch die an den 2. Antikörper gekoppelte Peroxidase unter Emittierung von Licht. Dieses wird durch die Exposition auf einem Röntgenfilm (Cronex 10T) dokumentiert. Die Entwicklung des Films erfolgte 5' im Entwickler-Bad (LX24, Kodak), 5' Stopp-Bad und anschließend 5' im Fixier-Bad (AL4, Kodak).

\subsubsection{Coomassie-Protein-Färbung}

Um Proteinbanden in SDS-PAGE-Gelen sichtbar zu machen, lassen sich diese mit dem Farbstoff Coomassie Brillant Blue G-250 anfärben. Hierfür wird das Gel 30' in der Fixierlösung geschwenkt. Nach Verfärbung der BPB-Bande ins Gelbliche wird das Gel in der Färbelösung 30'-60' inkubiert. Die Entfärbung des Gel 
erfolgt in dem Entfärbebad unter wiederholtem Wechsel der Lösung für mehrere Stunden. Optional kann der Vorgang durch kurzes Erwärmen in der Mikrowelle beschleunigt werden.

\subsection{Messung des Chlorophyllgehalts}

Die Messung des Gesamtchlorophyllgehalts ist eine photometrische Methode. Da Landpflanzen und damit auch Arabidopsis zwei verschiedene Chlorophylle besitzen, die auch ein leicht unterschiedliches Absorptionsmaximum haben (Chlorophyll a bei $665 \mathrm{~nm}$ und Chlorophyll b bei $650 \mathrm{~nm}$ ), wird die Extinktion der hergestellten Rohextrakt-Lösung bei beiden Wellenlänge gemessen und anschließend verrechnet.

- Pflanzenmaterial in flüssigem Stickstoff aufmörsern und je $100 \mathrm{mg}$ in gefrorenem Zustand in 1,5 ml Eppendorfgefäße überführen

- $1 \mathrm{ml}$ Methanol dazu

- 30 Minuten bei $60^{\circ} \mathrm{C}$ inkubieren

- 10 Minuten bei RT/13.000rpm zentrifugieren

- Überstand in neues Eppendorfgefäß überführen

- Messung einer 1:20 Verdünnung am Photometer bei 650 und 665 nm (Extinktion muss $<0,5$ sein)

- Berechnung des Chlorophyllgehalts mit folgender Formel (Holden, 1965):

$\mathrm{E}(650) * 0,025+\mathrm{E}(665) * 0,005=\mathrm{mg}$ Gesamtchlorophyll pro ml Messlösung

\subsection{Trypan-Blue Anfärbung von abgestorbenen Zellen}

Trypan-Blue färbt die unter anderem Leitgefäße von Pflanzen und tote Pflanzenzellen an. Eine angepasste Methode wurde verwendet (Arabidopsis: A Laboratory Manual). Das Blattgewebe wurde in einer Petrischale mit der Färbelösung (12,5 ml Lactic Acid, $10 \mathrm{ml}$ Glycerin, $10 \mathrm{ml}$ Phenol, 7,5 $\mathrm{ml} \mathrm{H}_{2} \mathrm{O}, 80 \mathrm{ml}$ Ethanol, $48 \mathrm{~g}$ Trypan-Blue) überdeckt und für 30 Sekunden in der Mikrowelle erhitzt und dann 24 Stunden inkubiert. Die Entfärbung des Blattmaterials erfolgte durch mehrfach wiederholte Inkubation für ca. 6 Stunden in einer Entfärbungslösung (250 g Chloralhydrat, $100 \mathrm{ml} \mathrm{H} \mathrm{H}_{2} \mathrm{O}$ ). Die entfärbten Proben können in 60\% Glycerin aufbewahrt werden.

\subsection{Herstellung von Mikrotomschnitten}

Für die Analyse von Blattquerschnitten von Tabakblättern wurden Mikrotomschnitte nach Kondo und Ushiki (1985) und Lang (2006) angefertigt. Bei dieser sehr einfachen Methode bleiben allerdings Luftblasen zurück, die als schwarze Punkte auf den Aufnahmen zu erkennen sind.

- Proben in EtOH entfärben

- $\quad 1 \mathrm{~h}$ in einer 3:1 (EtOH /PEG2000) Verdünnung bei $55^{\circ} \mathrm{C}$

- $\quad 1,5 \mathrm{~h}$ in einer $1: 1$ Verdünnung

- $\quad 1,5 \mathrm{~h}$ in einer 1:3 Verdünnung

- Zweimal $1 \mathrm{~h}$ (eventuell $2 \mathrm{~h}$ ) in $100 \%$ PEG2000 (schmilzt bei $55^{\circ} \mathrm{C}$; die Temperatur kann auch höher sein)

- langsame Kristallisation durch langsames Absenken der Temperatur herbeiführen

- Das PEG vorsichtig um die Probe etwas entfernen

- Probenblock in das Mikrotom einspannen und gerade schneiden

- die einzelnen Schnitte werden mit einer Pinzette abgenommen und auf einen Objektträger gelegt

- Nachdem ein Deckglas darüber gelegt worden ist, wird das PEG vorsichtig mit H2O gelöst und kann nun unter dem Mikroskop analysiert werden 


\subsection{Epinastie-Test}

Keller und Van Volkenburgh (1997) konnten an Tabak Blattstreifen zeigen, dass Auxin eine stärkere Streckung der Zellen der adaxialen Blattseite im Vergleich zu den Zellen der abaxialen Blattseite hervorruft. Die zu beobachtende Krümmung der Blattstreifen ist ein Maß für die Empfindlichkeit der Zellen gegenüber dem hormonellen Reiz. Sie ist stark abhängig vom Entwicklungszustand bzw. Alter des verwendeten Gewebes.

Dazu werden 10 x 1,5 mm große Streifen parallel zu den sekundären Blattadern im mittleren Teil des Blattes mit einer Rasierklinge aus den Blättern ausgeschnitten und in einer Petrischale mit $30 \mathrm{ml}$ Epinastie-Puffer ohne oder mit $10 \mu \mathrm{M}$ NAA für 24 Stunden bei Raumtemperatur und Schwachlicht inkubiert.

Die epinastische Krümmung der Blattstreifen wurde photographiert und in verschieden Krümmungskategorien eingeteilt.

\subsection{Induktion von Tabak-Blattscheiben}

Zur Induktion der Genexpression im Tabakblattgewebe wurden ca. 4-6 Wochen alte, in Erde kultivierte Tabakpflanzen verwendet. Für die Induktionsversuche werden Blattscheiben (Durchmesser 2,2cm) mit einem Korkbohrer ausgestochen. Alle Induktionssubstanzen sind in $50 \mathrm{mM}$ Kaliumphosphat bei einem $\mathrm{pH}-\mathrm{Wert}$ von 5,8 gepuffert. Die Induktionschemikalien werden unmittelbar vor dem Start des Versuches zugesetzt. Die Induktion des Blattgewebes erfolgt in Petrischalen und wird durch Zugabe des Puffers mit der Induktionssubstanz gestartet. Die entnommenen Proben werden in flüssigem Stickstoff eingefroren und bis zur weiteren Verarbeitung bei $-80^{\circ} \mathrm{C}$ gelagert.

\subsection{Infektion mit dem Tabak-Mosaik-Virus}

Zur Infektion mit TMV wird das Lysat auf ein mit Carborundum versetztes Stück Zellstoff getropft und damit gleichmäßig sanft die Blattoberfläche gerieben. Es werden komplett expandierte Blätter im unteren Drittel der Pflanzen infiziert. Die Infektion erfolgt wie bei Yalpani et al., 1991 beschrieben. Das Ergebnis der Infektion wird zur phänotypischen Bestimmung photographiert.

\subsection{Leitfähigkeitsmessung (,Ion Leakage’)}

Nach der Infektion mit TMV kommt es in Tabak mit dem Resistenzgen N zu einem HR-induzierten Zelltod. Der Ionenaustritt aus den absterbenden Zellen kann unter Verwendung der ,Ion Leakage' Methode gemessen werden (Greenberg und Ausubel, 1993; Mittler et al., 1998, Portier et al., 1999). Die Methode wurde angepasst.

Nach der Infektion mit TMV werden zu angegebenen Zeitpunkten mit einem Korkbohrer (Durchmesser: 22 $\mathrm{mm}$ ) neun Blattscheiben von mehreren Blättern ausgestochen und abaxial in eine Petrischale mit $30 \mathrm{ml}$ Wasser (bidest) gelegt. Nach $30 \mathrm{~min}$ wurden die Blattscheiben in eine neue Petrischale mit $30 \mathrm{ml}$ Wasser überführt. Die Petrischale wurde mit Parafilm verschlossen und 6 Stunden in einer Klimakammer inkubiert. Das Wasser wurde dann in einen Greiner überführt und in einem Wasserbad bei $25^{\circ} \mathrm{C}$ wurde die Leitfähigkeit mit dem Leitfähigkeitsmessgerät HI 8733N nach den Angaben des Herstellers bestimmt. 


\subsection{Verwendete Programme}

- VectorNTI 10.1.1 (Invitrogen Corporation) - Bearbeitung von DNA- und Proteinsequenzen

- Chromas1.55 (Technelysium, 1998) - Analyse von Sequenzierdaten

- Blast (Altschul et al., 1997; Schäffer et al., 2001) - Programme zur Suche von ähnlichen DNA- oder Proteinsequenzen

- ExPASy (Gasteiger et al., 2003) - Proteomic Server zur Analyse von Proteinsequenzen und Strukturen und Server für viele andere nützliche Programme

- NetNES 1.1 (La Cour et al., 2004) - spezielle Proteinsequenzanalyse für putative NES-Sequenzen

- ClustalW 1.83 (Cladogram nach: Kimura, 1983)

- $\quad$ Microsoft Office 2003

- $\quad$ PcBAS $^{\circledR} 2.09$ (Raytest)

- $\quad$ Tina $^{\circledR} 2.0$ (Raytest) 


\section{$5 \quad$ Ergebnisse}

\subsection{Analyse der in planta Interaktion von ANK1 und BZI-1}

Der bZIP-Transkriptionsfaktor BZI-1 besteht aus mehreren konservierten Domänen. Zwei dieser Domänen, der Leucin-Zipper und die $\alpha$-helikale Domäne können Protein-ProteinInteraktionen vermitteln (Kapitel 2.1).

Um Interaktionspartner von BZI-1 zu finden, wurden im Vorfeld dieser Arbeit zwei verschiedene Hefe-Interaktionsstudien durchgeführt. Als BZI-1 Interaktionspartner konnten BZI-2, BZI-3, BZI-4 (Strathmann et al., 2001) und das Ankyrin-Repeat Protein ANK1 (Kuhlmann et al., 2003) gefunden werden.

Die Ergebnisse zur Interaktion zwischen BZI-1 und ANK1 beruhen auf in vitro Nachweisen (siehe Kapitel 2.3) oder auf Interaktionsstudien in Hefe. Obwohl das Hefe System ein in vivo Nachweis ermöglicht, können die erhaltenen Ergebnisse entscheidend von der tatsächlichen Interaktion zweier Proteine in planta abweichen (Ehlert et al., 2006). Als erster Schritt zur Aufklärung der Funktion von ANK1 und BZI-1 musste deshalb eine Bestätigung der BZI-1 ANK1 Interaktion in planta erfolgen.

\subsubsection{In planta Interaktion von ANK1 und BZI-1 im Protoplasten Two- Hybrid System}

Um die Interaktion von ANK1 mit BZI-1 in planta nachzuweisen, wurde das $\mathrm{P} 2 \mathrm{H}$ (Protoplasten Two-Hybrid; Ehlert et al., 2006) System verwendet, das auf der Methode des Matchmaker $^{\circledR}$ GAL4 Y2H Systems (Clontech, 1996) beruht. Der Transkriptionsfaktor GAL4 besitzt einen modularen Aufbau (Brent und Ptashne 1985; Ma und Ptashne 1987). Die GAL4-Bindedomäne (BD; Keegan et al., 1987) vermittelt die Bindung des Transkriptionsfaktors an die GAL4-UAS (,Upstream Activating Sequences'; Guarente et al., 1982; Ginger et al., 1985) und die GAL4-Aktivierungsdomäne (AD; Ma und Ptashne 1987) vermittelt eine transkriptionelle Aktivierung.

Im P2H System kontrollierte das GAL4-UAS Promotorelement die Expression des Reportergens $\beta$-Glucuronidase (GUS). Die Menge des umgesetzten Substrats ist proportional zur Aktivität des Reportergens. Zur Korrektur der Variationen in den einzelnen Ansätzen in einem Experiment wurde im P2H System der Pro $35 s$ sAN 
(Neuraminidase) Plasmid eingeführt (Kirby und Kavanagh, 2002; Ehlert et al., 2006) und die MUN-Messung erfolgt analog zu der MUG-Messung.

In allen Transformationen wurden das Reporterplasmid GAL4-UAS 4 :GUS und das Reporterplasmid Pro $35 s$ :NAN zusätzlich zu den Effektorkonstrukten in Tabak Mesophyllprotoplasten co-transformiert.

In Hefe konnten transaktivierende Eigenschaften von BZI-1 gezeigt (Heinekamp et al., 2002) und in planta durch transiente Expression in BY2 (,bright yellow 2') Mesophyllprotoplasten bestätigt werden (Heinekamp, 2003). Auch ANK1 zeigt leichte Aktivierungseigenschaften in Hefe (Böttner, 2003).

Für die Ermittlung der Aktivierungseigenschaften von ANK1 und BZI-1 wurden diese jeweils als BD-Fusionen exprimiert, für die Interaktion entsprechend als BD- oder ADFusion co-exprimiert. Als Negativkontrolle diente eine Expression der Reporterplasmide und als Positivkontrolle wurde das Pro $_{355}$ :GUS Plasmid verwendet, das das GUS Gen konstitutiv exprimiert.

Die Expression von BD-ANK1 weist im Vergleich zur Negativkontrolle nur eine sehr leicht verstärkte Aktivierung auf (Abbildung 5.1, A). Wird hingegen BD-ANK1 zusammen mit AD-BZI-1 exprimiert, kommt es $\mathrm{zu}$ einer deutlichen Steigerung der Reportergenaktivität. ANK1 zeigt also nur sehr schwache Autoaktivierungseigenschaften und interagiert mit BZI-1 in planta.

Wird BZI-1 als Bindedomänenfusion exprimiert, so zeigt sich eine leichte GUSAktivierung im Vergleich zu Negativkontrolle (Abbildung 5.1, B). Die GUS-Aktivität liegt bei der Interaktion mit ANK1 nur um das 1,9fache höher als die GUS-Aktivität der Autoaktivierung von BZI-1. Diese relativ geringe Steigerung im Vergleich zur Steigerung der Interaktion zwischen BD-ANK1 und AD-BZI-1 liegt an der hohen Autoaktivierungseigenschaft von BZI-1. 
(A)

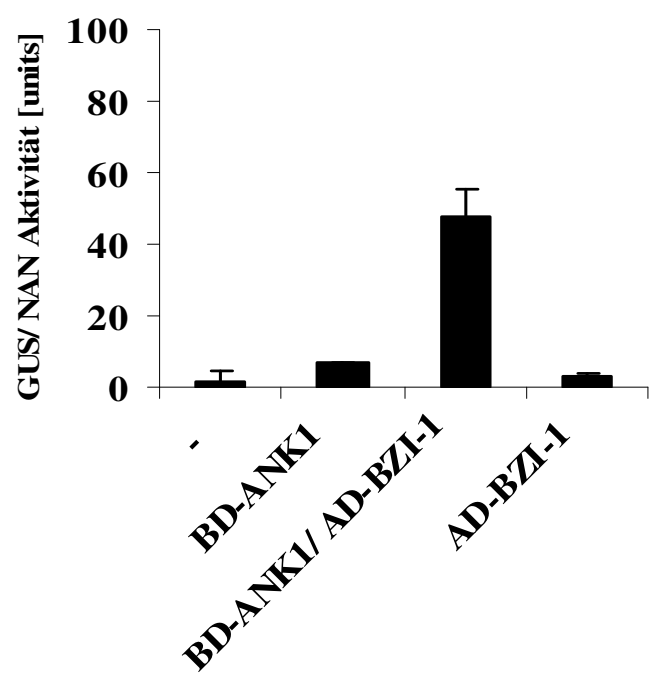

(B)

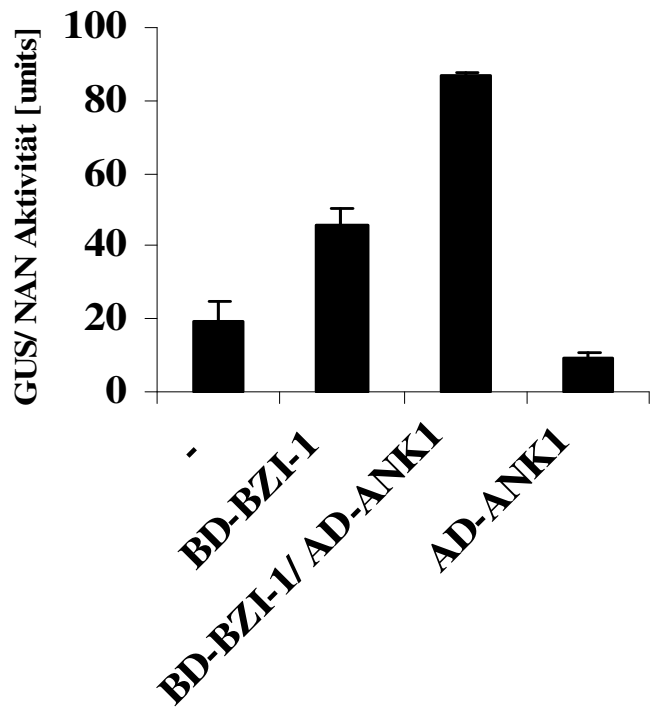

Abbildung 5.1: Analyse der BZI-1 ANK1 Interaktion in Tabak Mesophyllprotoplasten mit der P2H Methode. (A) ANK1 als Bindedomänen-Fusion. Die Positivkontrolle zeigt eine Aktivität von 1432 units. (B) BZI-1 als Bindedomänen-Fusion. Die Positivkontrolle zeigt eine Aktivität von 3028 units.

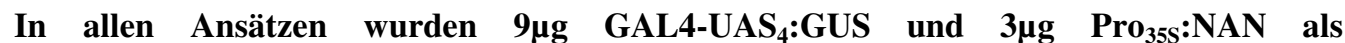
Reporterplasmide und $14 \mu \mathrm{g}$ des jeweiligen Effektorplasmids transformiert. Mit dem Einsatz unspezifischer DNA wurden unterschiedliche Mengen an DNA in den Ansätzen ausgeglichen. Die Positivkontrolle wird aufgrund der besseren Übersicht nicht dargestellt. -: Negativkontrolle; BD: GAL-4 Bindedomäne; AD: GAL-4 Aktivierungsdomäne; Die genauen Messwerte sind im Anhang angegeben. Die Versuche wurden dreimal mit vergleichbaren Resultaten wiederholt.

Wie aus Abbildung 5.1 (A und B) ersichtlich, zeigt auch die Negativkontrolle eine leichte Reportergenaktivierung. Hierfür können endogene Faktoren verantwortlich gemacht werden, die an die GAL4-UAS binden können. Als Kontrollen wurden neben der Negativkontrolle auch die AD-Fusionen von ANK1 und BZI-1 transformiert (Abbildung 5.1, A und B). Diese Fusionsproteine können aufgrund der nicht vorhandenen GAL4-BD nicht an das Promotorelement binden und führen somit zu keiner verstärkten Aktivierung des Reportergens. Es ist darauf hinzuweisen, dass die Negativkontrolle in Abbildung 5.1 (B) deutlich höher als die AD-ANK1 Fusion ist. Dies zeigt deutlich, dass es im Protoplasten Two-Hybrid System zu Schwankungen der Expression kommen kann.

Zusammenfassend konnte gezeigt werden, dass ANK1 nur sehr schwache und BZI-1 stärkere Autoaktivierungseigenschaften in planta besitzen. Außerdem konnte die Interaktion zwischen beiden in planta bestätigt werden. 


\subsubsection{BZI-1 interagiert auch mit den bZIP-Transkriptionsfaktoren BZI-2, BZI-3 und BZI-4}

Neben BZI-1 konnten die bZIP-Transkriptionsfaktoren BZI-2, BZI-3 und BZI-4 in Nicotiana tabacum als mögliche BZI-1 Interaktionspartner identifiziert werden (Strathmann et al., 2001). Ein Interaktionsnachweis in Pflanzen wurde bisher noch nicht durchgeführt. Strathmann (2003) konnte für die Transkriptionsfaktoren BZI-1, BZI-2, BZI3, und BZI-4 leichte Autoaktivierungseigenschaften in Hefe feststellen. Für BZI-1 konnten Aktivierungseigenschaften in planta bereits gezeigt werden (Heinekamp et al., 2002). Für BZI-2, BZI-3 und BZI-4 fehlen diese Untersuchungen.

Für den in planta Aktivierungs- und Interaktionsnachweis wurde ebenfalls das $\mathrm{P} 2 \mathrm{H}$ System verwendet, wie es in 5.1.1 genauer beschrieben ist.

Die Ergebnisse in Abbildung 5.2 (A) zeigen, dass BZI-1 und BZI-4 im Vergleich zu BZI-2 und BZI-3 nur eine schwache Autoaktivierung besitzen. Dabei ist das Aktivierungspotential von BZI-4 um einen Faktor 4 höher als das Aktivierungspotential von BZI-1. Der Transkriptionsfaktor BZI-2 hat ein vielfach stärkeres Aktivierungspotential im Vergleich zu BZI-1 (Faktor 40) oder BZI-4 (Faktor 10). BZI-3 zeigt noch einmal eine zweifach höhere Autoaktivierung als BZI-2.

In dem Experiment in Abbildung 5.2 (A) wurde auch getestet, ob die bZIPTranskriptionsfaktoren BZI-1, BZI-2, BZI-3 und BZI-4 fusioniert an die Aktivierungsdomäne, das Reportergen aktivieren können. Aufgrund der fehlenden GAL4Bindedomäne kam es zu keiner Bindung und somit zu keiner Reportergenaktivierung.

Wird nur BZI-1 als Bindedomänen-Fusion exprimiert, werden die Autoaktivierungseigenschaften ersichtlich, wie sie bereit in Kapitel 5.1.1 gezeigt werden konnten (Abbildung 5.2, B). Werden zusätzlich zu BZI-1 als Bindedomänen-Fusion BZI-1, BZI-2, BZI-3 und BZI-4 als Aktivierungsdomänen-Fusion transformiert, wird die Reportergen Expression noch weiter verstärkt. BZI-1 bildet Homodimere, und Heterodimere mit den Transkriptionsfaktoren BZI-2, BZI-3 und BZI-4. Dabei ist die Interaktionsstärke, gemessen durch die Expression des Reportergens, sehr unterschiedlich. Die Reportergenaktivität nach der Expression von BZI-1 schwankt in den einzelnen Wiederholungen zwischen 1,5- und zweifach und zeigt damit im Vergleich zu den CoExpressionen von BZI-1 mit BZI-2, BZI-3 und BZI-4, die schwächste Reportergenaktivität. Nach der Co-Expression von BZI-1/BZI-4 liegt die Reportergenaktivität leicht über der Expression des Reportergens der BZI-1 Expression. 
Die Co-Expression von BZI-1 mit BZI-3 zeigt eine Aktivierung des Reportergens um den Faktor drei und die Co-Expression von BZI-1 mit BZI-2 zeigt mit dem Faktor sechs die deutlich höchste Reportergenaktivität.

(A)

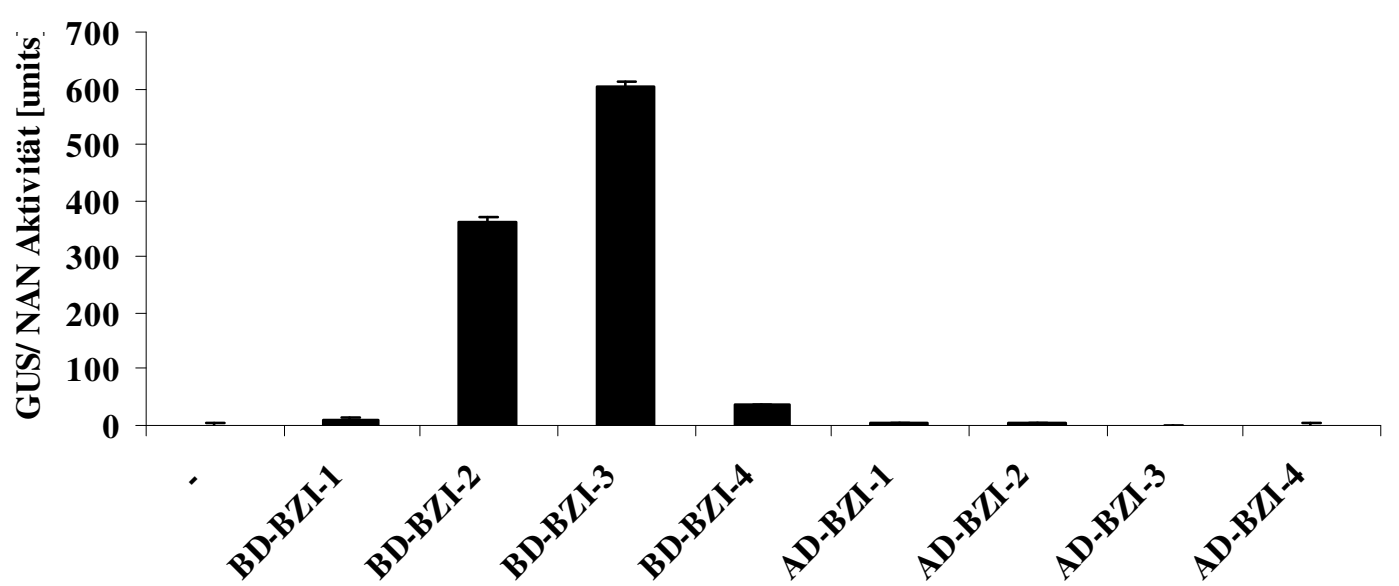

(B)

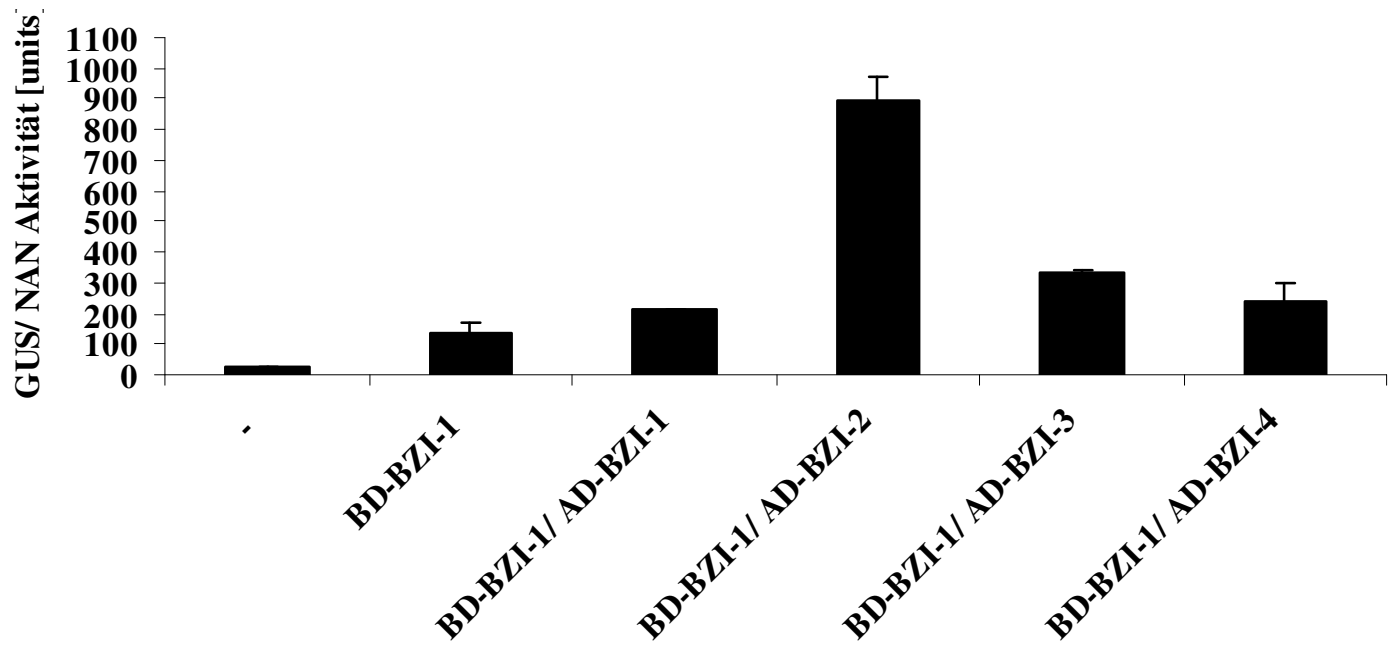

Abbildung 5.2: Analyse der Autoaktivierungseigenschaften und Interaktionsstudie der bZIPTranskriptionsfaktoren BZI-1, BZI-2, BZI-3 und BZI-4 in Tabak Mesophyllprotoplasten mit der P2H Methode. (A) Analyse der Autoaktivierung von BZI-1, BZI-2, BZI-3 und BZI-4. Die Positivkontrolle zeigt eine Aktivität von 1537 units. (B) Interaktionsstudie von BZI-1 mit den bZIP-Transkriptionsfaktoren BZI-1, BZI-2, BZI-3 und BZI-4. Die Positivkontrolle zeigt eine Aktivität von 2078 units.

In allen Ansätzen wurden 9 $\mu$ gAL4-UAS4:GUS und $3 \mu \mathrm{g}$ Pro35S:NAN als Reporterplasmide sowie $14 \mu \mathrm{g}$ des jeweiligen Effektorplasmids transformiert. Mit dem Einsatz unspezifischer DNA wurden unterschiedliche Mengen an DNA in den Ansätzen ausgeglichen. Die Positivkontrolle wird aufgrund der besseren Übersicht nicht dargestellt. -: Negativkontrolle; BD: GAL-4 Bindedomäne; AD: GAL-4 Aktivierungsdomäne; Die genauen Messwerte sind im Anhang angegeben. Die Versuche wurden dreimal mit vergleichbaren Resultaten wiederholt.

Es konnte gezeigt werden, dass alle vier bZIP-Transkriptionsfaktoren ein Aktivierungspotential in planta besitzen, wobei die Stärke dieser Aktivierungsdomänen 
sehr unterschiedlich ist. BZI-1 bildet Homodimere, aber bevorzugt Heterodimere mit BZI2, BZI-3 und in geringem Maße mit BZI-4.

\subsubsection{ANK1 interagiert spezifisch mit BZI-1 und nicht mit den bZIP- Transkriptionsfaktoren BZI-2, BZI-3 und BZI-4}

Eine Interaktion von ANK1 mit BZI-1 in planta konnte bereits in 5.1.1 gezeigt werden. Untersuchungen, ob die Interaktion zwischen ANK1 und BZI-1 spezifisch ist, oder ob ANK1 auch mit weiteren bZIP-Transkriptionsfaktoren interagieren kann, wurden bisher noch nicht durchgeführt.

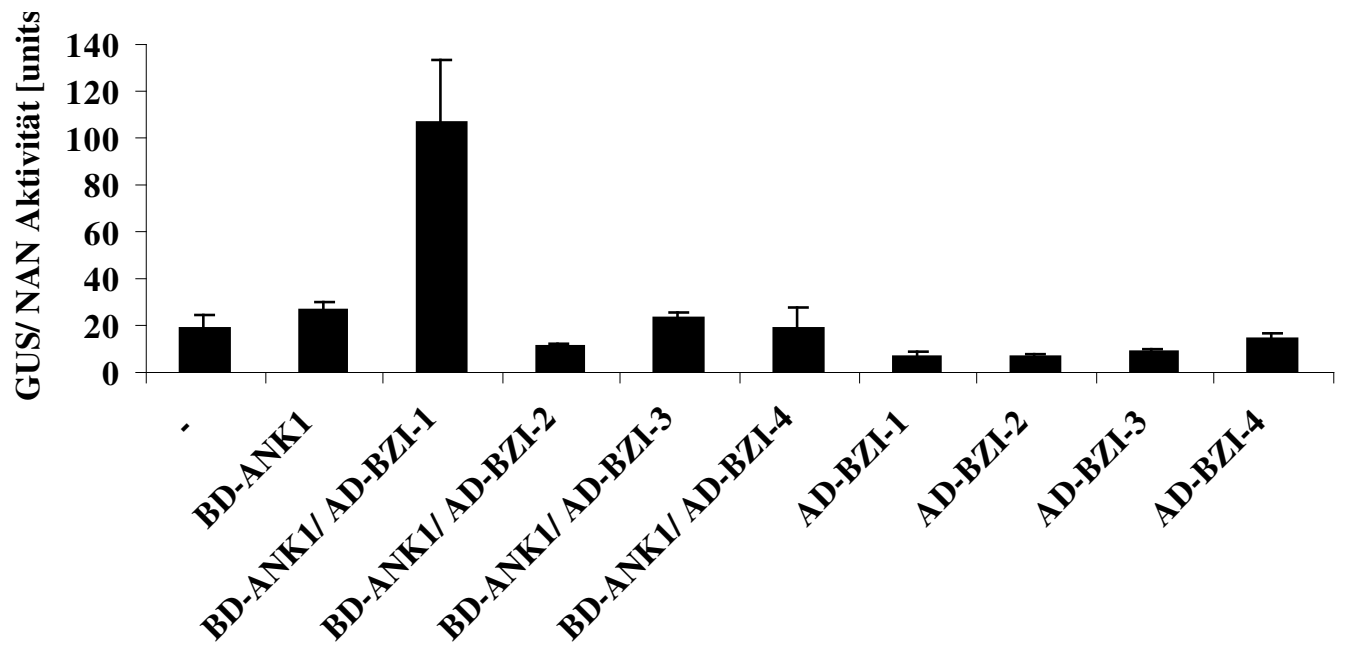

Abbildung 5.3: Interaktionsstudie von ANK1 mit den bZIP-Transkriptionsfaktoren BZI-1 bis BZI-4 in Tabak Mesophyllprotoplasten mit der P2H Methode. In allen Ansätzen wurden 9 $\mu$ g

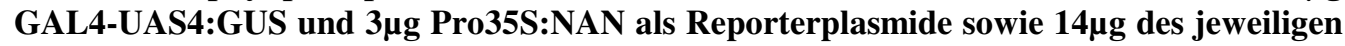
Effektorplasmids transformiert. Mit dem Einsatz unspezifischer DNA wurden unterschiedliche Mengen an DNA in den Ansätzen ausgeglichen. Die Positivkontrolle zeigt eine Aktivität von 3028 units und wird aufgrund der besseren Übersicht nicht dargestellt. -: Negativkontrolle; BD: GAL-4 Bindedomäne; AD: GAL-4 Aktivierungsdomäne; Die genauen Messwerte sind im Anhang angegeben. Der Versuch wurde dreimal mit vergleichbaren Resultaten wiederholt.

Alleinige Transformation der BZI-1, BZI-2, BZI-3 und BZI-4 als AktivierungsdomänenFusionen führen zu keiner verstärkten Aktivierung des Reporters (Abbildung 5.3). Wird ANK1 als Bindedomänen-Fusion zusammen mit BZI-1 als Aktivierungsdomänen-Fusion co-transformiert, kommt es zu einer deutlich verstärkten Expression des Reportergens, im Vergleich zur Aktivierung durch die alleinige Transformation von ANK1. Wird ANK1 jeweils mit den Aktivierungsdomänen-Fusionen von BZI-2, BZI-3 und BZI-4 cotransformiert, kommt es zu keiner höheren Transkription des GUS-Reportergens. 
Es konnte gezeigt werden, dass ANK1 mit dem bZIP-Transkriptionsfaktor BZI-1 aber nicht mit den bZIP-Transkriptionsfaktoren BZI-2, BZI-3 und BZI-4 interagiert.

\subsubsection{Durch Mutationen in den Ankyrin-Repeat Motiven II oder III wird die ANK1/BZI-1 Interaktion zerstört}

C-terminal beinhaltet das Ankyrin-Repeat Protein ANK1 eine vierfache Wiederholung des Ankyrin-Repeats Motivs (Kuhlmann et al., 2002; zur Übersicht: Sedgwick and Smerdon, 1999; Mosavi et al., 2004). Ankyrin-Repeat Domäne vermitteln Protein-Protein Interaktionen (Michaely and Bennett, 1992; Bork 1993).

Sollte die Ankyrin-Repeat Domäne in ANK1 diese Funktion der Interaktion mit BZI-1 übernehmen, müsste eine Mutation in den Ankyrin-Repeat Motiven die ANK1/BZI-1 Interaktion schwächen oder zerstören. $\mathrm{Zu}$ diesem Zweck wurden verschiedene Punktmutationen in den stark konservierten Ankyrin-Repeats II und III von ANK1 mit dem QuikChange ${ }^{\circledR}$ Site-Directed Mutagenesis Kit (Stratagene) eingeführt.

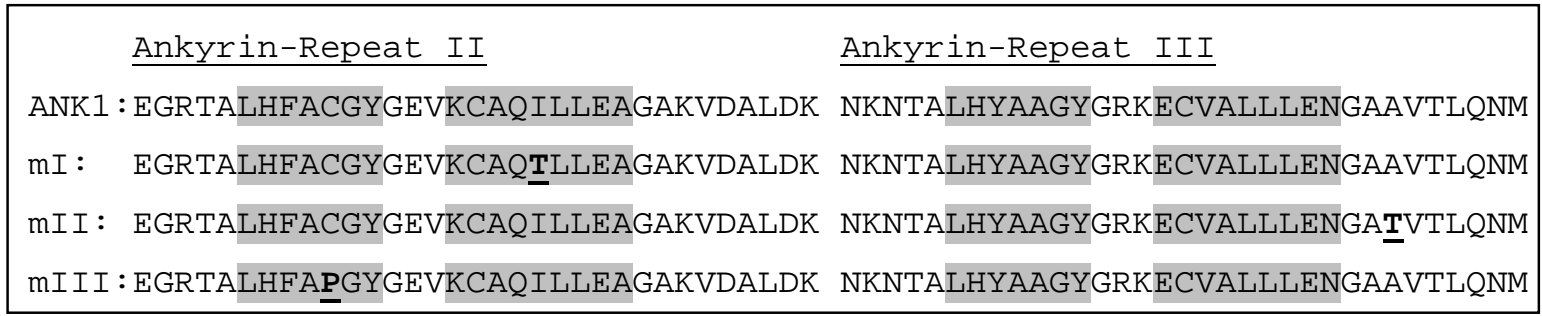

Abbildung 5.4: Aminosäurevergleich der unterschiedlichen Mutationen in den Ankyrin-Repeat Motiven II und III von ANK1. Die ANK1-Mutanten sind mit mI bis mIII abgekürzt. Die $\alpha$-Helices sind grau unterlegt und die Punktmutationen in den einzelnen Mutanten sind unterstrichen und fett hervorgehoben. Eine Auflistung der Aminosäureabkürzungen ist im Anhang angegeben.

In Abbildung 5.4 sind die Aminosäuresequenzen der Ankyrin-Repeat Motive II und III von ANK1 und der ANK1 Mutanten mit den verschiedenen Punktmutationen dargestellt. Die $\alpha$-Helices wurden grau unterlegt und die Punktmutationen sind unterstrichen und fett hervorgehoben.

In Mutation I und III wurde jeweils eine Punktmutation im Bereich des zweiten AnkyrinRepeat Motivs eingeführt. Dabei wurde in der ersten Mutation in der zweiten $\alpha$-Helix ein Alanin mit einem Threonin ausgetauscht. Threonin ist eine polare Aminosäure, die eher nicht in $\alpha$-Helices vorkommt und deswegen die $\alpha$-Helix unterbrechen könnte. In Mutation III wurde die erste $\alpha$-Helix durch einen Austausch mit einem Prolin unterbrochen. Prolin wurde verwendet, weil es die Ausbildung von regelmäßigen Sekundärstrukturen wie $\alpha$ - 
Helices und $\beta$-Faltblätter stört. Prolin hält die Proteinstruktur durch die sekundäre Aminogruppe, in einer starren Konfiguration, wozu ein Amidwasserstoff verwendet wird, der in anderen Aminosäuren H-Brücken ausbildet (Creighton, 1993).

In der Mutation II wurde wiederum versucht, die ANK1/BZI-1 Interaktion durch einen Austausch eines Alanins mit einem Threonin im Ankyrin-Repeat Motiv III zu erreichen. In diesem Fall wurde dabei aber eine Aminosäure außerhalb der $\alpha$-Helices gewählt, um eine möglichst geringen Veränderung der Proteinstruktur von ANK1 zu bewirken.

Der Nachweis der Reduktion der ANK1/BZI-1 Interaktion sollte im Protoplasten ,TwoHybrid' System erbracht werden, wie es in 5.1 .1 beschrieben ist.

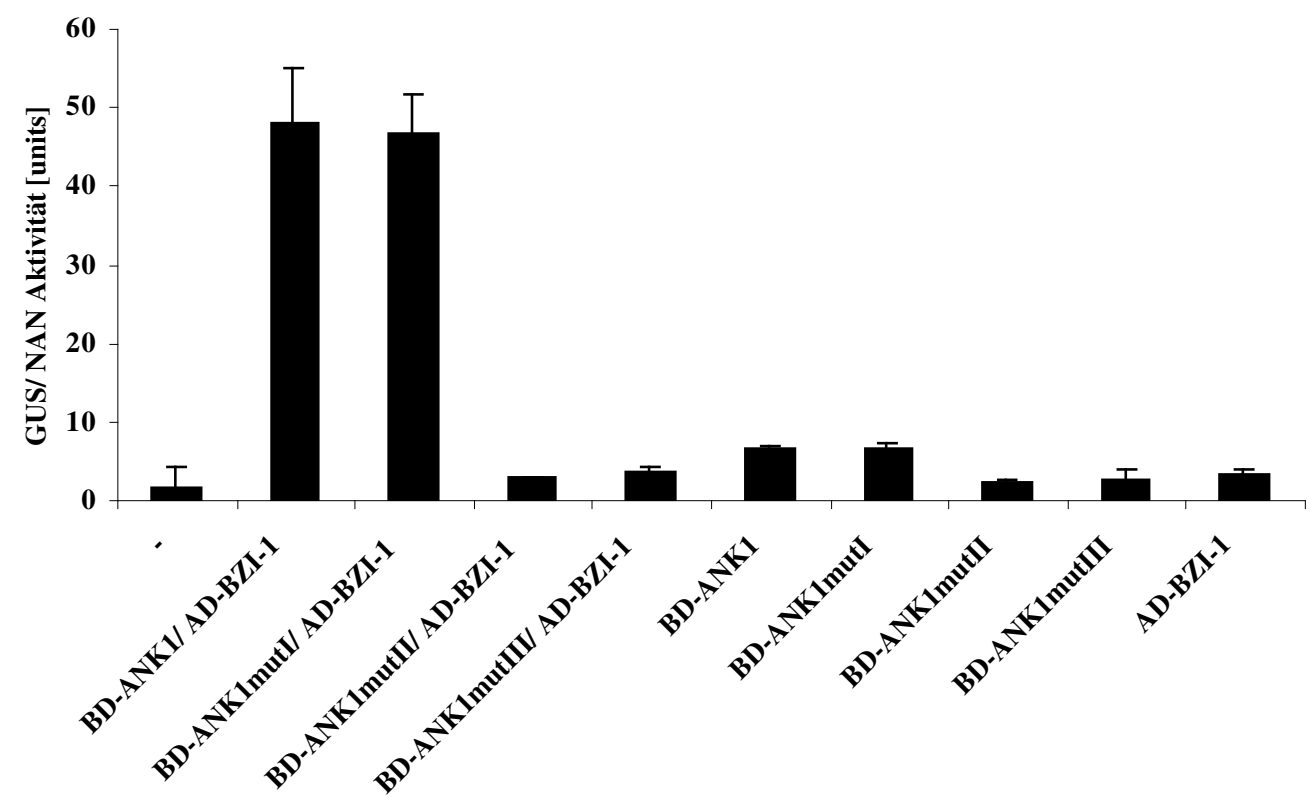

Abbildung 5.5: Analyse der Interaktion zwischen den ANK1 Mutanten und BZI-1 in Tabak Mesophyllprotoplasten mit der P2H Methode. In allen Ansätzen wurden 9 $\mu$ g GAL4UAS $_{4}$ :GUS und $3 \mu$ Pro Prs $_{35}$ :NAN als Reporterplasmide sowie 14 $\mu$ g des jeweiligen Effektorplasmids transformiert. Mit dem Einsatz unspezifischer DNA wurden unterschiedliche Mengen an DNA in den Ansätzen ausgeglichen. Die Positivkontrolle zeigt eine Aktivität von 1432 units und wird aufgrund der besseren Übersicht nicht dargestellt. -: Negativkontrolle; BD: GAL-4 Bindedomäne; AD: GAL-4 Aktivierungsdomäne; Die genauen Messwerte sind im Anhang angegeben. Der Versuch wurde dreimal mit vergleichbaren Resultaten wiederholt.

Die Ergebnisse in Abbildung 5.5 zeigen, dass im Vergleich zu der Interaktion von ANK1 mit BZI-1, die Interaktion von ANK1mutI mit BZI-1 nicht reduziert ist. Diese Mutation hat keinen Einfluss auf die Interaktion. Durch die ANK1 Mutationen mutII und mutIII kommt es jedoch zu einer Aufhebung der Interaktion zwischen ANK1 und BZI-1. Die Expression des Reportergens ist auf dem Niveau der Negativkontrolle. Werden die Bindedomänen-Fusionen von ANK1 und den ANK1 Mutationen alleine transformiert, 
zeigt ANK1mutI eine leichte Autoaktivierung des Reportergens, in der Höhe der Autoaktivierung von ANK1. ANK1mutII und ANK1mutIII zeigen keine Autoaktivierungseigenschaften mehr.

Die Analyse der Interaktion zwischen BZI-1 als Bindedomänenfusion und den ANK1 Mutanten zeigt diesen Unterschied nicht so deutlich (Daten nicht gezeigt). Dies liegt an der höheren Autoaktivierungseigenschaft von BZI-1.

Eine Expression von ANK1 und den ANK1 Mutationen als BD-Fusionen konnte in Tabak Mesophyllprotoplasten sowohl mit dem ANK1 spezifischen $\alpha$ AKR2 als auch mit dem $\alpha B D$ Antikörper nicht nachgewiesen werden (Daten nicht gezeigt). Die Expression von BD-ANK1 und BD-ANK1mutI kann aber durch die Aktivierung des Reportergens indirekt bestätigt werden (Abbildung 5.5). Generell hat die Mutation in den Ankyrin-Repeat Motiven aber keinen Einfluss auf die Expression der ANK1 Mutanten, wie es für die Expression von ANK1mutIII (Kapitel 5.2.2) oder das Fusionsprotein YFP-ANK1mutIII in Nicotiana benthamiana Epidermiszellen in Kapitel 5.2.3 gezeigt werden konnte.

Spezifische Mutationen im Bereich der Ankyrin-Repeat Domäne können die Interaktion zwischen ANK1 und BZI-1 zerstören. Somit sind die Ankyrin-Repeat Motive von ANK1 essentiell für die Interaktion mit BZI-1.

\subsubsection{Nachweis der in planta Interaktion von ANK1 und BZI-1 mittels der ,Bimolecular Fluorescence Complementation'}

Die Interaktion zwischen ANK1 und BZI-1 konnte im P2H System gezeigt werden. Es ist jedoch wichtig, Ergebnisse mit verschiedenen Methoden zu verifizieren. Eine weitere Strategie zur in planta Analyse einer Protein-Protein Interaktion ist die Technik der BiFC (,Bimolecular Fluorescence Complementation', bezeichnet auch als SPLIT-YFP; Walter et al., 2004; Hu et al., 2002). Das YFP-Protein (,Yellow Fluorescence Protein') ist in diesem System in zwei nicht fluoreszierende Fragmente geteilt. Diese Fragmente werden an die zu untersuchenden Proteine fusioniert. Wenn die YFP-Fragmente durch eine Protein-Protein Interaktion der an sie fusionierten Proteine wieder in räumliche Nähe gebracht werden, so wird die Funktion des YFP und damit die Fluoreszenz rekonstituiert.

Mit dieser Technik lässt sich nicht nur eine Aussage über eine Protein-Protein Interaktion machen, sondern auch über die Lokalisation dieser Interaktion. Dabei ist allerdings zu beachten, dass der Prozess nicht dynamisch ist. Eine über die fusionierten Proteine 
zustande gekommene Rekonstitution der YFP-Fragmente ist wahrscheinlich nicht reversibel (Bhat et al., 2006).

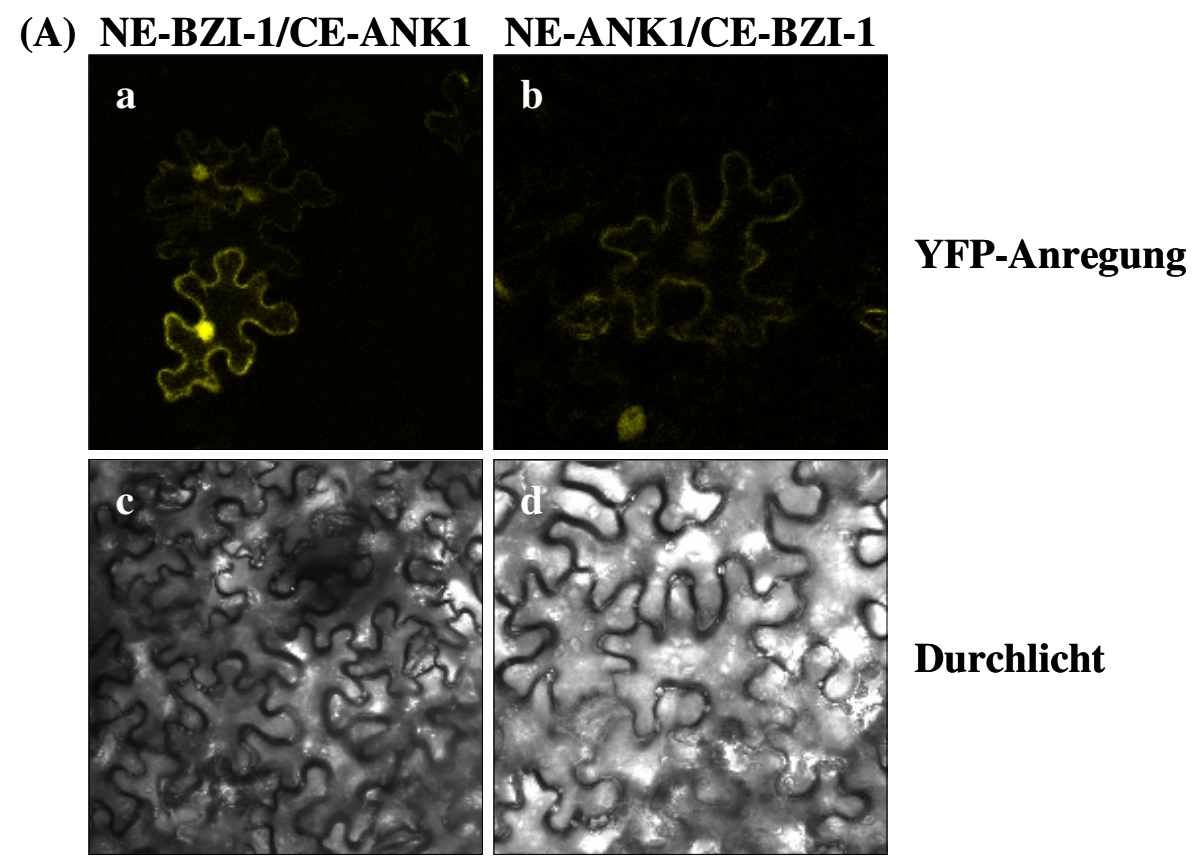

(B)
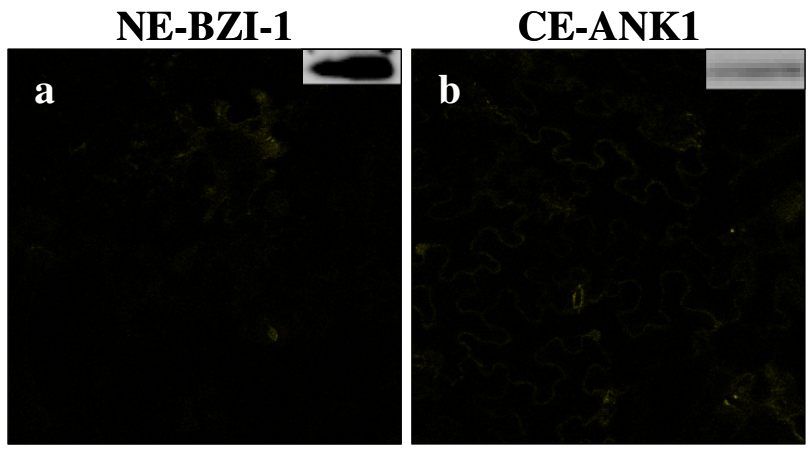

YFP-Anregung

NE-BZI-1/ CE

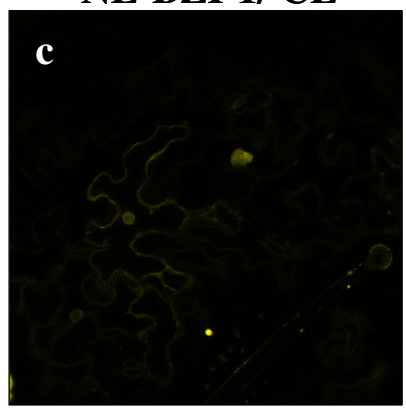

CE-ANK1/ NE

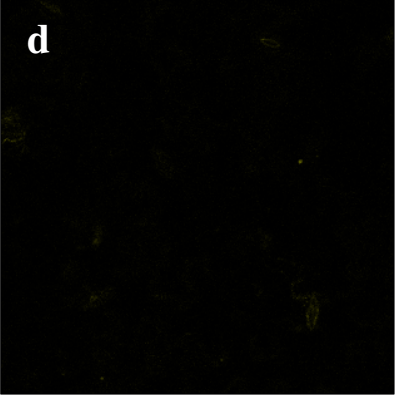

YFP-Anregung

Abbildung 5.6: Analyse der Interaktion von ANK1 und BZI-1 mittels Bimolecular Fluorescence Complementation. BZI-1 und ANK1 wurden an das N-terminale (NE) oder C-terminale (CE) Fragment von YFP fusioniert und nach Agrobacterium Co-Infiltration transient in Nicotiana benthamiana Blättern exprimiert. (A) (a) Co-Expression von NE-BZI-1 und CE-ANK1; (b) Co-Expression von NE-ANK1 und CE-BZI-1; (c) und (d) Durchlicht (B) starke Anregung der Kontrollen: (a) Expression von NE-BZI-1; (b) Expression von CEANK-1; (c) Co-Expression von CE-ANK-1 und NE; (d) Co-Expression von CE-ANK-1 und NE. Eine Kontrolle der Expression durch einen immunologischen Nachweis mit einem $\alpha$ MYC-Antikörper (NE-BZI-1) und einem $\alpha H A$-Antikörper (CE-ANK1) wurde in den Fenstern in (B, a und b) abgebildet. Der Versuch wurde dreimal mit vergleichbaren Resultaten wiederholt. 
Um die Interaktion von ANK1 mit BZI-1 im BiFC System zu testen, wurde die DNA in Pflanzentransformationsplasmide inseriert, die das N-terminale oder C-terminale Fragment von YFP tragen. Dies ermöglicht eine transiente Expression durch Agrobacterium Infiltration in Nicotiana benthamiana (Yang et al., 2000; Voinnet et al., 2003; Witte et al., 2004). Als Kontrolle dient die alleinige Expression der unfusionierten YFP-Fragmente NE und $\mathrm{CE}$ (,N-terminal/C-teminal fragment expression').

Die Ergebnisse in Abbildung 5.6 (A) zeigen eine eindeutige Interaktion von ANK1 und BZI-1 im BiFC System. Dabei konnte die Interaktion zwischen NE-BZI-1 und CE-ANK1 immer besser detektiert werden als die Interaktion zwischen NE-ANK1 und CE-BZI-1 (A, a und b). Lokalisiert ist diese Interaktion sowohl im Cytosol als auch im Zellkern.

In Abbildung 5.6 (B, a und b) sind die YFP-Fragmente, fusioniert an ANK1 oder BZI-1, einzeln exprimiert und in Abbildung 5.6 (B, c und d) sind diese Fragmente mit dem entsprechenden YFP-Fragment NE und CE co-transformiert dargestellt. In allen Expressionen sind unter starker Anregung die epidermalen Zellen sichtbar. Bei einer Anregungsenergie, die ausreichend für den Nachweis der Interaktion von ANK1 und BZI1 im BiFC System war, konnten die Kontrollen nicht angeregt werden. Eine Expression wurde immunologisch nachgewiesen (Abbildung 5.6).

Mit dem BiFC System konnte eine in planta Interaktion zwischen ANK1 und BZI-1 gezeigt werden die sowohl im Cytosol als auch im Zellkern lokalisiert ist.

\subsection{Untersuchung der zellulären Lokalisation von ANK1 in Abhängigkeit verschiedener Stimuli}

BZI-1 konnte vor allem im Zellkern lokalisiert werden (Heinekamp et al., 2002), aber für ANK1 konnte eine cytosolische Lokalisation festgestellt werden (Kuhlmann et al., 2003). Dies gilt auch für das ANK1 homologe Protein aus Nicotiana tabacum TIP1 (Firdborg et al., 2002) und AKR2 aus Arabidopsis thaliana ist cytosolisch- und kernlokalisiert (Yan et al., 2003). Aber für die Interaktion von ANK1 mit BZI-1 konnte allerdings eine Lokalisation im Cytosol und Zellkern festgestellt werden. Könnte somit die Lokalisation eine funktionelle Bedeutung für die Interaktion haben?

Es gibt verschiedene Beispiele für die Interaktion zwischen einem Ankyrin-Repeat Protein und Transkriptionsfaktoren. Ein Beispiel ist das cytosolisch lokalisierte Ankyrin-Repeat Protein I $\mathrm{B} \alpha$ (,inhibitor of $\left.\kappa \mathrm{B}^{\prime}\right)$. I $\mathrm{\kappa} \mathrm{B} \alpha$ bildet einen Komplex mit dem Transkriptionsfaktor 
NFKB. Diese Interaktion maskiert die NLS (,nuclear localisation sequence') des NFkB und wird dadurch im Cytosol zurückgehalten. Nach Induktion kommt es zur Phosphorylierung

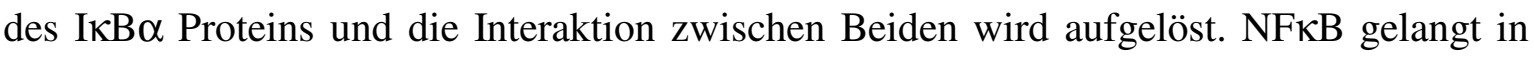
den Zellkern (Jacobs et al., 1998; Huxford et al., 1998).

Ein weiteres Beispiel ist das Ankyrin-Repeat Protein NPR1 aus Arabidopsis thaliana. Im Cytosol multimerisiert NPR1 durch intermolekulare Disulfidbindungen. Nach PathogenInfektion kommt es zu einem veränderten zellulären Redoxpotential, wodurch die intermolekularen Disulfidbrückenbindungen von NPR1 reduziert werden und NPR1 monomerisiert. Die monomere Form von NPR1 akkumuliert im Zellkern (Mou et al., 2003) und interagiert mit den TGA-Transkriptionsfaktoren, die wie BZI-1 zu den bZIPProteinen gehören.

Aus diesem Kontext heraus stellen sich mehrere Fragen zur ANK1-BZI-1 Interaktion:

- Wie konnte eine Interaktion von ANK1 und BZI-1 festgestellt werden, wenn sie in unterschiedlichen Kompartimenten lokalisiert sind?

- Kann es zu einer Veränderung der Lokalisation von ANK1 durch einen Stimulus kommen?

- Kommt es zu einer Multimerisierung von ANK1?

- Dient ANK1 als cytosolischer Retentionsfaktor für BZI-1?

\subsubsection{ANK1 homodimerisiert im Cytosol}

Um die Fragestellung zu klären, ob ANK1 homodimerisieren kann, wurde das P2H System verwendet, wie es in 5.1.1 beschrieben wurde. Dazu wurde ANK1 an die GAL4-Bindeund GAL4-Aktiverungsdomäne fusioniert und in Tabak Mesophyllprotoplasten cotransformiert.

Wird ANK1 als Bindedomänen-Fusion transformiert, so zeigt sich im Vergleich zur Negativkontrolle eine leichte Aktivierung des Reportergens (Abbildung 5.7, A). Wird ANK1 als Bindedomänen- und Aktivierungsdomänen Fusion co-transformiert, kommt es $\mathrm{zu}$ einer Verdopplung der Expression des Reportergens. Die Interaktion der Homodimerisierung ist allerdings, im Vergleich mit der Interaktion zwischen ANK1 und BZI-1, sehr schwach. Als Kontrolle wurden ANK1 und BZI-1 als AktivierungsdomänenFusionen transformiert, was zu keiner Reportergenaktivierung führte. 
(A)

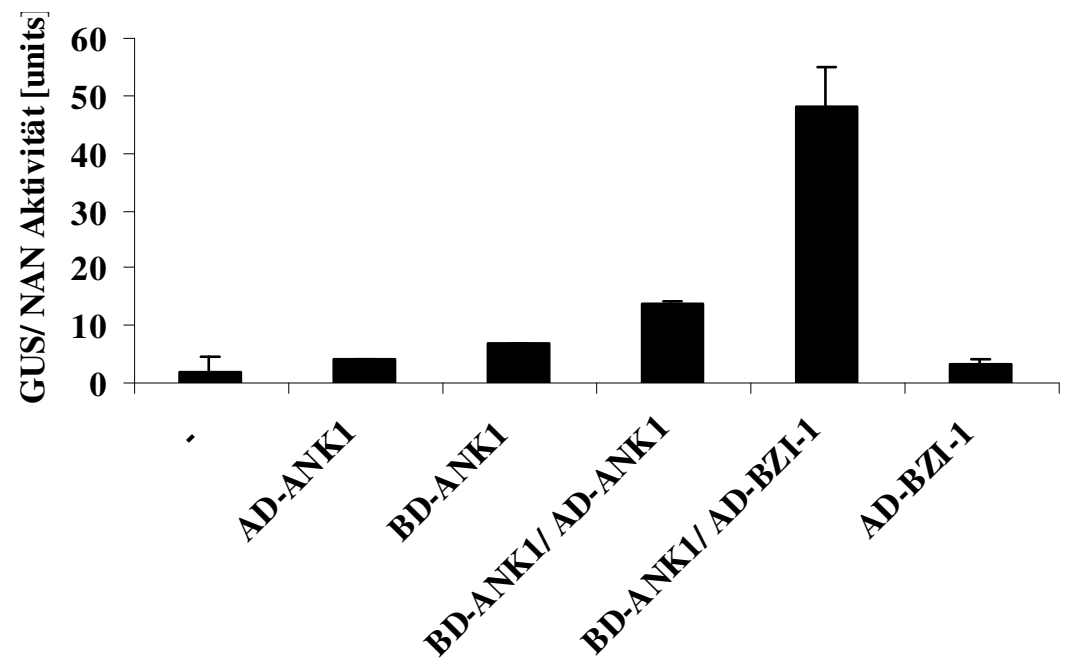

(B)

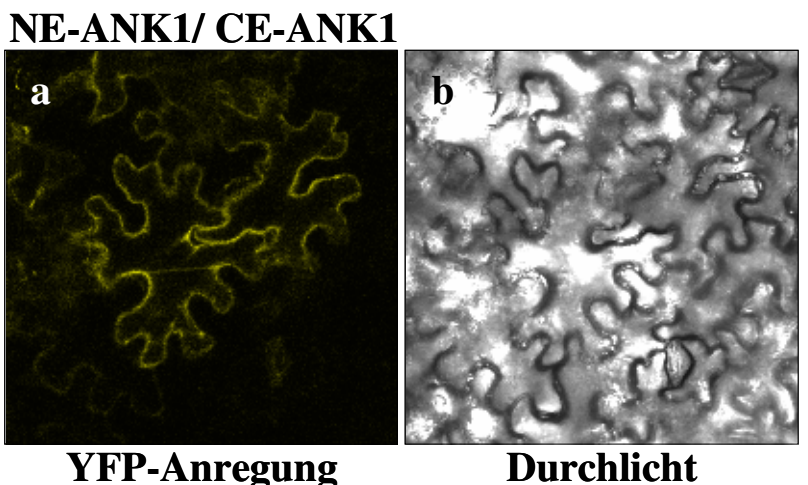

Abbildung 5.7: In planta Nachweis der ANK1 Homodimerisierung. (A) Analyse in Tabak Mesophyllprotoplasten mit der P2H Methode. In allen Ansätzen wurden 9 $\mu$ g GAL4UAS $_{4}$ :GUS und $3 \mu$ Pro Prs $_{35}$ :NAN als Reporterplasmide sowie $14 \mu \mathrm{g}$ des jeweiligen Effektorplasmids transformiert. Mit dem Einsatz unspezifischer DNA wurden unterschiedliche Mengen an DNA in den Ansätzen ausgeglichen. Die Positivkontrolle zeigt eine Aktivität von 1432 units und wird aufgrund der besseren Übersicht nicht dargestellt. -: Negativkontrolle; BD: GAL-4 Bindedomäne; AD: GAL-4 Aktivierungsdomäne; Die genauen Messwerte sind im Anhang angegeben. Die Versuche wurden dreimal mit vergleichbaren Resultaten wiederholt. (B) Analyse der Homodimerisierung mittels Bimolecular Fluorescence Complementation. ANK1 wurde an das $\mathrm{N}$-terminale (NE) oder C-terminale (CE) Fragment von YFP fusioniert und nach Agrobacterium Co-Infiltration transient in Nicotiana benthamiana Blättern exprimiert. Die Aufnahmen der Epidermis wurden mit einem konfokalen Mikroskop durchgeführt. Die Versuche wurden dreimal mit vergleichbaren Resultaten wiederholt. (a) CoExpression von NE-ANK1 und CE-ANK1 (b) Durchlicht.

Da ein YFP-ANK1 Fusionsprotein cytosolisch lokalisiert ist (Kuhlmann et al., 2003), lässt sich annehmen, dass diese Homodimerisierung im Cytosol stattfindet. Zur Bestätigung dieser These und als weiterer Interaktionsnachweis wurde die Homodimerisierung im BiFC System getestet. ANK1 wurde an das N-terminale und das C-terminale YFPFragment fusioniert und nach Agrobakterien-Infiltration transient in Nicotiana benthamiana exprimiert. 
Die Ergebnisse in Abbildung 5.7 (B) zeigen eine Homodimerisierung von ANK1, die cytosolisch lokalisiert ist.

Es konnte mit der P2H und der BiFC Methode gezeigt werden, dass ANK1 Homodimere bildet, wobei die Interaktion im Protoplasten 'Two-Hybird' System im Vergleich zur Interaktion zwischen ANK1 und BZI-1 relativ schwach ist. Mit diesen Methoden lässt sich aber keine Aussagen über eine mögliche Multimerisierung, wie im Fall von NPR1, treffen.

\subsubsection{ANK1 fungiert nicht als Retentionsfaktor von BZI-1}

ANK1 ist hauptsächlich cytosolisch lokalisiert, interagiert aber mit BZI-1, das vor allem kernlokalisiert ist. In Kapitel 5.2.1 konnte gezeigt werden, dass die Interaktion zwischen ANK1 und BZI-1 im BiFC System cytosolisch- und kernlokalisiert ist. Es wäre möglich, dass ANK1 ein Retentionsfaktor von BZI-1 ist und dementsprechend wäre die im BIFC System sichtbare Zellkernlokalisation von ANK1 ein Artefakt, das möglicherweise durch die Überexpression entstanden ist.

Um zu analysieren, ob ANK1 ein Retentionsfaktor von BZI-1 ist, wurden im BiFC System YFP-BZI-1 mit ANK1 bzw. ANK1mutIII transient in Nicotiana benthamiana coexprimiert.

Die Ergebnisse in Abbildung 5.8 (a) zeigen eine deutliche Lokalisation von YFP-BZI-1 im Zellkern, wie es in Heinekamp et al., (2002) für eine transiente Expression in Protoplasten beschrieben wurde. Eine Co-Expression von YFP-BZI-1 mit ANK1 führt zu keiner Veränderung der Lokalisation von BZI-1, wie es zu erwarten wäre, wenn ANK1 ein Retentionsfaktor von BZI-1 wäre (Abbildung 5.8, b). Als Kontrolle für die Funktion von ANK1 als Retentionsfaktor wurde ANK1mutIII co-transformiert (Abbildung 5.8, c). In ANK1mutIII wurde das Ankyrin-Repeat II mutiert, was zu der Zerstörung der Interaktion mit BZI-1 führt (siehe Kapitel 5.1.4). Diese Co-Transformation zeigt keine Veränderung der Lokalisation von YFP-BZI-1. 


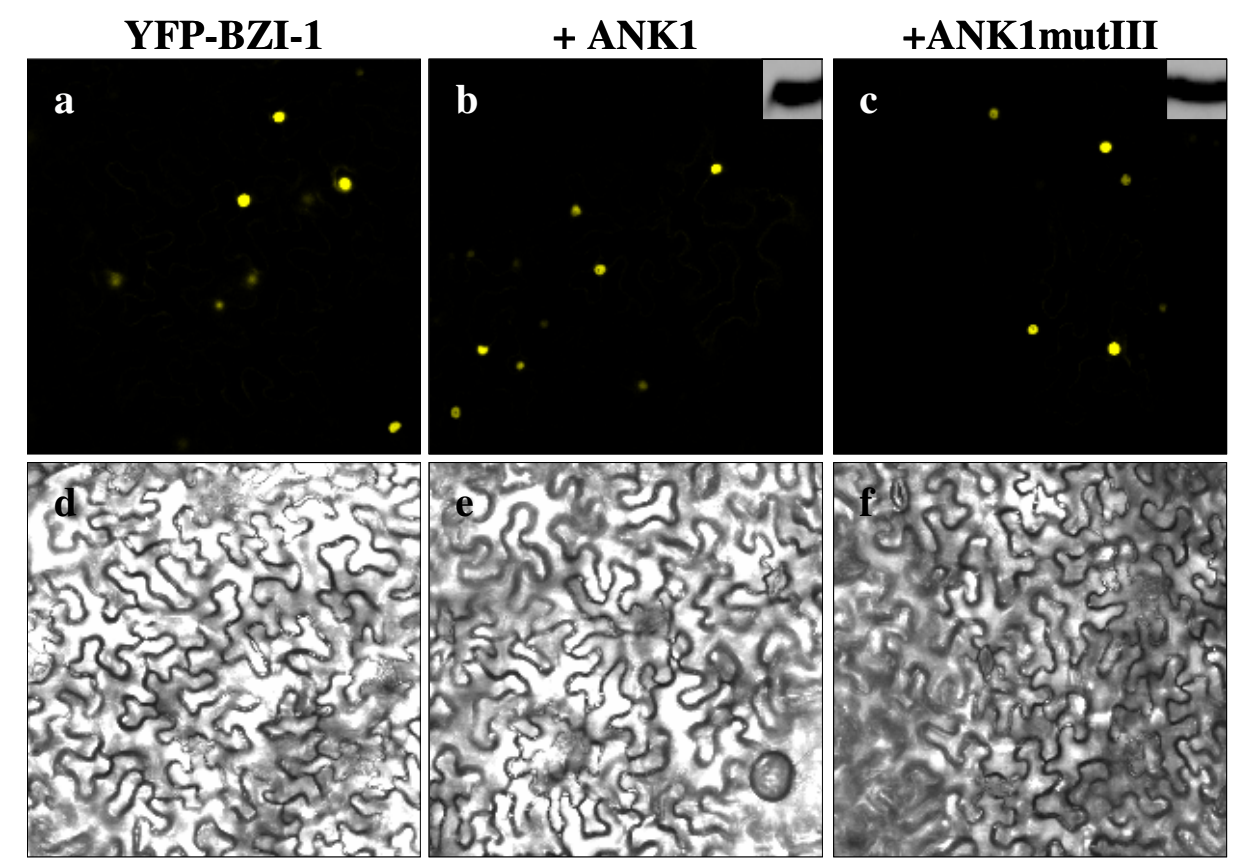

Abbildung 5.8: Bestimmung der Lokalisation von YFP-BZI-1 in Abhängigkeit von ANK1 oder ANK1mutIII. Die Fusionsproteine wurden transient, durch Agrobacterium Infiltration in Nicotiana benthamiana Blättern exprimiert. Die Aufnahmen der Epidermis wurden mit einem konfokalen Mikroskop durchgeführt. Die Fenster in (b) und (c) zeigen den immunologischen Nachweis von ANK1 und ANK1mutIII mit dem $\alpha$ AKR2 Antikörper. (a) Expression von YFP-BZI-1 (b) Co-Expression von YFP-BZI-1 und ANK1 (c) CoExpression von YFP-BZI-1 und ANK1mutIII (d, e und f) Durchlicht. Der Versuch wurde dreimal mit vergleichbaren Resultaten wiederholt.

Eine Funktion des Ankyrin-Repeat Proteins ANK1 als Retentionsfaktor von BZI-1 konnte somit nicht bestätigt werden.

\subsubsection{Durch BZI-1 Überexpression gelangt YFP-ANK1 in den Zellkern}

Es ist nun zu analysieren, ob eine Überexpression von BZI-1 zu einer Kernlokalisation von ANK1 führen kann. Zur Untersuchung dieser Theorie wird YFP-ANK1 zusammen mit BZI-1 transient in Nicotiana benthamiana co-exprimiert.

In Abbildung 5.9 (A, a) ist $\mathrm{zu}$ erkennen, dass YFP-ANK1 überwiegend cytosolisch lokalisiert ist. Auch die Expression von YFP-ANK1mutIII zeigt eine bevorzugte Lokalisation im Cytosol (Abbildung 5.9; B, a). Die Mutation des zweiten Ankyrin-Repeats hat also keinen Einfluss auf die Lokalisation oder Expression von ANK1. 
(A)

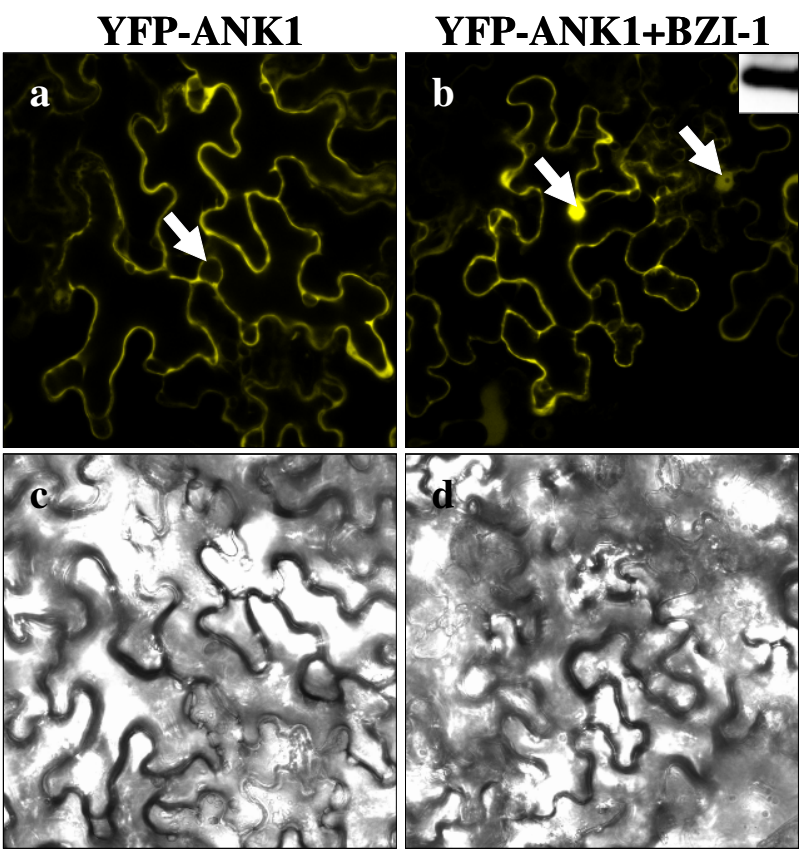

(B)

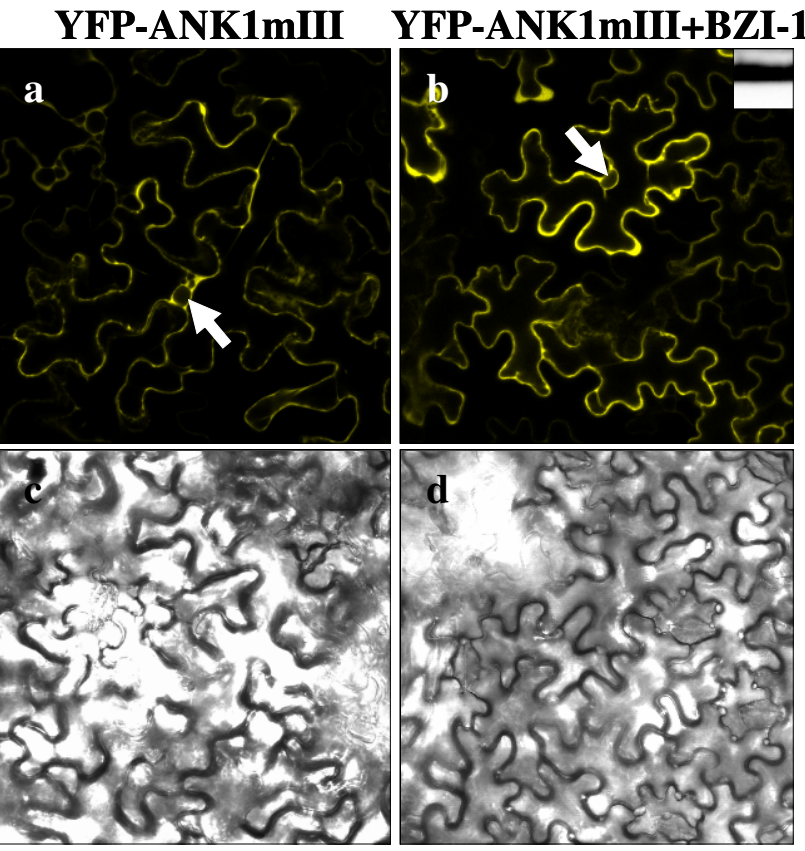

Abbildung 5.9: Bestimmung der Lokalisation von YFP-ANK1 oder YFP-ANK1mutIII in Abhängigkeit von BZI-1. Die Fusionsproteine wurden transient, durch Agrobacterium Infiltration in Nicotiana benthamiana Blättern exprimiert. Die Aufnahmen der Epidermis wurden mit einem konfokalen Mikroskop durchgeführt. Die Fenster in $(A, b)$ und $(B, b)$ zeigen den immunologischen Nachweis von BZI-1 mit dem $\alpha$ BZI-1 Antikörper. (A) (a) Expression von YFP-ANK1 (b) Co-Expression von YFP-ANK1 und BZI-1 (2) (a) Expression von YFP-ANK1mutIII (b) Co-Expression von YFP-ANK1mutIII und BZI-1 (A, c und d), (B, c und d) Durchlicht. Der Versuch wurde dreimal mit vergleichbaren Resultaten wiederholt.

Durch eine Co-Expression von YFP-ANK1 mit BZI-1 kommt es zu einer Verschiebung der Lokalisation von YFP-ANK1 und es ist nicht mehr nur cytosolisch lokalisiert, sondern auch im Zellkern (Abbildung 5.9; A, b). Eine Co-Expression von BZI-1 mit YFP- 
ANK1mutIII, das durch eine Mutation in der Ankyrin-Repeat Domäne nicht mehr mit BZI-1 interagiert, führt jedoch zu keiner Verschiebung der Lokalisation von ANK1 (Abbildung 5.9; B, b). Ein immunologischer Nachweis mit dem $\alpha$ BZI-1 Antikörper bestätigte die Expression des unfusionierten BZI-1-Proteins.

Die Interaktion zwischen ANK1 und BZI-1 ist damit eine Vorraussetzung für die Lokalisation von ANK1 im Zellkern.

\subsubsection{Nach der Inhibierung des Kernexports akkumuliert ANK1 im Kern}

ANK1 konnte im Cytosol lokalisiert werden, aber durch Co-Expression mit BZI-1 konnte eine Kernlokalisation von ANK1 festgestellt werden (Kapitel 5.2.4). Es stellt sich die Frage, ob ANK1 eine konservierte NLS (,nuclear localisation sequence'; Görlich und Kutay, 1999) oder NES (,nuclear export sequence'; Fischer et al., 1995; Wen et al., 1995) besitzt, die eine Vorraussetzung für einen Kernimport oder -export wären.

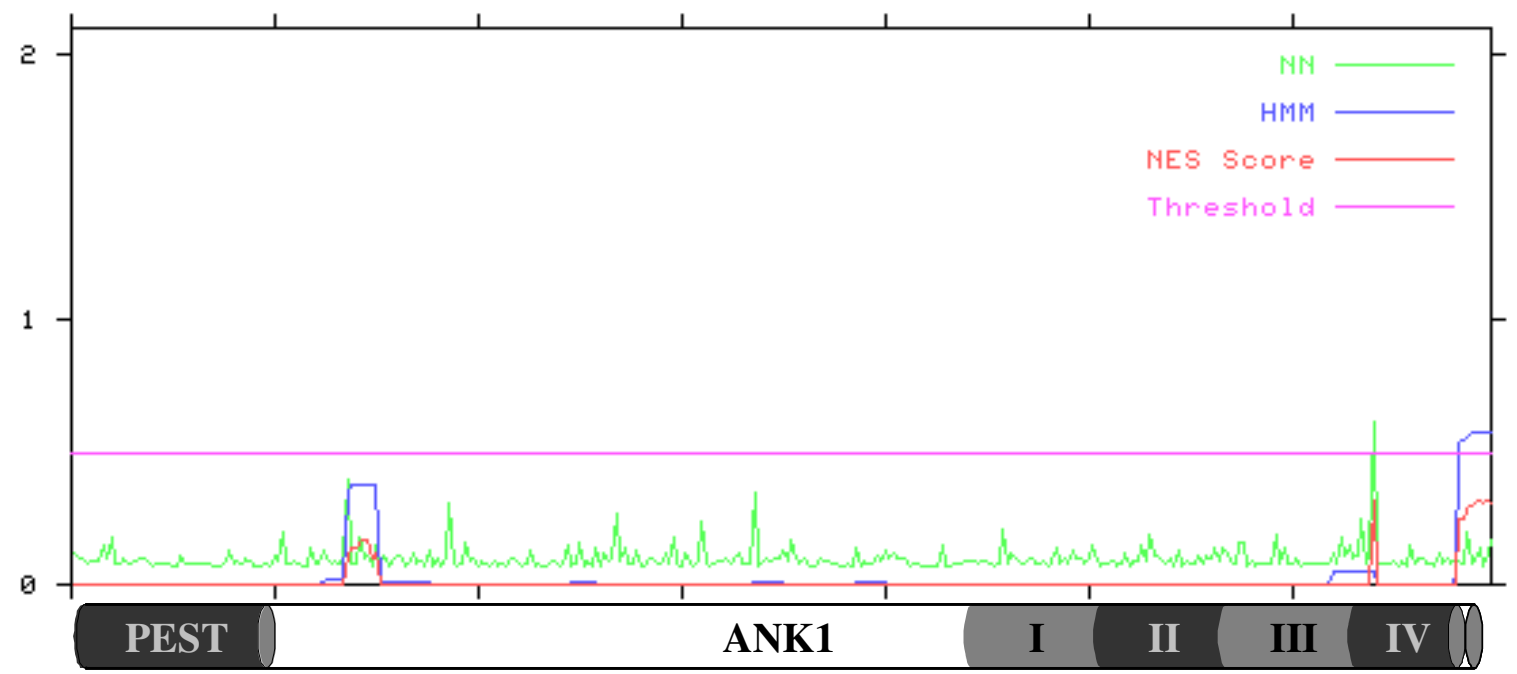

Abbildung 5.10: Bestimmung von konservierten Kernexportsequenzen in der Aminosäuresequenz von ANK1. Verwendet wurde die Analysesoftware NetNES 1.1. Angezeigt werden die Vorraussagen für eine mögliche NES (NES Score; rot) mit dem HMM (,Hidden Markov Models'; blau) und dem NN (,Artifical Neuronal Network'; grün) Algorithmus. Der Grenzwert für eine NES-Voraussage ist pink dargestellt. Darunter ist schematisch die ANK1 Sequenz dargestellt. Aminoterminal ist die PEST-Domäne (PEST) und Carboxyterminal sind die Ankyrin-Repeats (I, II, III, IV) hervorgehoben.

In einer in silico Analyse mit dem Programmen InterPro Scan (Mulder et al., 2007) und PredictNLS (Cokol et al., 2000) konnte keine konservierte NLS gefunden werden. Auch eine NES konnte von InterPro Scan nicht detektiert werden. Das Programm NetNES 1.1 (La Cour et al., 2004) prognostiziert Leucin reiche NES Sequenzen in eukaryotischen 
Proteinen. Eine Analyse der ANK1 Proteinsequenz ergab keinen direkten Treffer aber einen leichte Überschreitung des Grenzwertes des ,Hidden Markov Models' (HMM) oder des ,Artifical Neuronal Network' (NN) im Bereich der Aminosäure 320 und der Aminosäuren 341 bis 350 (Abbildung 5.10). Diese Regionen könnten eine NES Funktion haben. Die Aminosäuren liegen im C-terminalen Bereich von ANK1 innerhalb des vierten Ankyrin-Repeats.

Aus diesem Grund wurde der C-terminale Bereich von ANK1, der die Ankyrin-Repeat Motive enthält, genauer analysiert. Nach Görlich et al., 1999, ist eine NES meist reich an Leucinen, C-terminal lokalisiert und besitzt eine Konsensussequenz mit der Aminosäureabfolge LXXXLXXLXL, wobei ,L' für Leucin und ,X' für beliebige Aminosäuren steht. In der Veröffentlichung von Haasen et al., 1999 konnte unter anderem für AtRanBP1a und AtRanBP1b eine C-terminal lokalisierte NES bestätigt werden, die nicht mit der Konsensussequenz von Görlich übereinstimmt (Abbildung 5.11). Nach Feng et al., 1999 kann die Konsensussequenz LXXXLXXLXL in den beiden Leucinen an Position eins und zwei mit Alanin, einer weiteren hydrophoben Aminosäure ausgetauscht werden, während die Leucine an Position drei und vier nicht verändert werden können.

\begin{tabular}{|lll|}
\hline ANK1 & $(333)$ & KLNNQQEVLKLLEKDVFL \\
TIP2 & $(332)$ & KLNNQNEVLKLLEKDAFL \\
TIP3 & $(331)$ & KLNNQNEVLKLLEKDAFL \\
AKR2 & $(325)$ & KLNSQLEVVKLLEKDAFL \\
AtPhos43 & $(327)$ & RLNNQLDVVKLLEKDAFL \\
& & \\
RanBP1a & $(171)$ & DTAGLLEKLTVEETKTEE \\
RanBP1C & $(170)$ & EAAGLIENLSVEENISEE \\
NES & & LXXXLXXLXL \\
\hline
\end{tabular}

Abbildung 5.11: Aminosäurevergleich der Sequenzen im C-terminalen Bereich, die die NES von RanBP1a einschließt. ANK1 (Kuhlmann et al., 2003), TIP2 und TIP3 (Fridborg et al., 2002), AKR2 (Yan et al., 2001), AtPhos43 (Peck et al., 2001), RanBP1a (Haizel et al., 1997), RanBP1c (Xia et al., 1996). NES: NES-Konsensussequenz nach Görlich et al., 1999.

Abbildung 5.11 zeigt deutlich, dass AKR2 und AtPhos43, die ANK1 homologen Proteine aus Arabidopsis thaliana an allen vier relevanten Positionen der potentiellen NES eine hydrophobe Aminsäuren besitzen. ANK1 sowie TIP2 und TIP3, zwei ANK1 homologe Proteine aus Nicotiana tabacum zeigen nur an Position zwei der putativen NES keine hydrophobe Aminosäure. In allen fünf Beispielen wurde bisher noch keine weitere Analyse der Lokalisation durchgeführt.

Der Proteinexport aus dem Zellkern wird unter anderem durch das Exportin 1 vermittelt. Exportin 1 ist ein Zellkern Exportrezeptor, der Proteine mit einer Leucin-reichen NES 
erkennt und diese exportiert (Haasen et al., 1999). In S. pombe, Säugetieren und Arabidopsis thaliana kann der Export durch Exportin 1 mit LMB (Leptomycin B) inhibiert werden (Fornerod et al., 1997a; Haasen et al., 1999; zur Funktion von LMB: Fornerod et al., 1997; Kudo et al., 1998; Kudo et al., 1999).
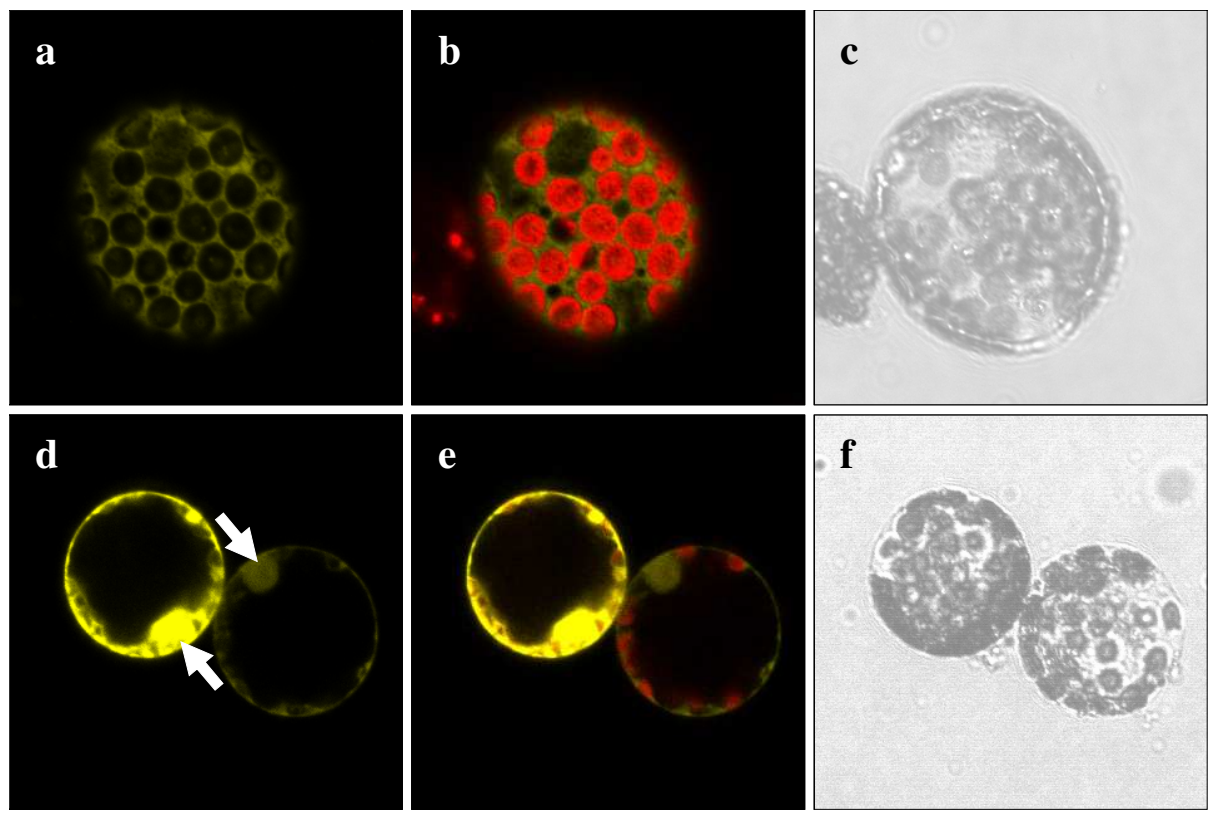

Abbildung 5.12: Lokalisation von YFP-ANK1 nach Inhibierung des Kernexports mit LMB. YFPANK1 wurde transient, durch Agrobacterium Infiltration in Tabak Mesophyllprotoplasten exprimiert. Die Aufnahmen wurden mit einem konfokalen Mikroskop durchgeführt. Der Versuch wurde dreimal mit vergleichbaren Resultaten wiederholt. (a) Expression von YFP-ANK1 und vier Stunden Inkubation mit dem Lösungsmittel Ethanol (b) Überlagerung der YFP-Anregung mit der ChlorophyllAnregung (c) Durchlicht (d) Expression von YFP-ANK1 und vier Stunden Inkubation mit $2 \mu$ M LMB (e) Überlagerung der YFP-Anregung mit der Chlorophyll-Anregung (f) Durchlicht. Die Pfeile deuten auf den Zellkern der Protoplasten.

Der Einfluss von LMB auf die Lokalisation von ANK1 wurde in Tabak Mesophyllprotoplasten untersucht. YFP-ANK1 wurde transient exprimiert und vier Stunden mit $2 \mu \mathrm{M}$ LMB inkubiert. Als Kontrolle diente eine Inkubation mit dem Lösungsmittel Ethanol. Wie in Abbildung 5.12 (a) zu sehen ist, zeigen mit Ethanol inkubierte Protoplasten keine Veränderung der Lokalisation, ANK1 bleibt cytosolisch lokalisiert. Werden Protoplasten die YFP-ANK1 exprimieren, mit LMB inkubiert, kommt es dagegen $\mathrm{zu}$ einer gleichmäßigen Verteilung von YFP-ANK1 im Cytosol und im Zellkern. Dies konnte in etwa 30\% der transformierten Protoplasten beobachtet werden. 


\subsubsection{Nach Auxingabe akkumuliert ANK1 im Zellkern}

Im vorhergehenden Kapitel 5.1.5 konnte gezeigt werden, dass ANK1 auch im Zellkern lokalisiert sein kann. Jedoch ist ein endogener Stimulus für die Translokation von ANK1 in den Zellkern bisher noch nicht bekannt. Es gibt verschieden Hinweise auf Faktoren, die ANK1 oder BZI-1 phosphorylieren können. Weiterhin wird BZI-1 nach Infektion mit Pseudomonas phosphoryliert (Kuhlmann, 2002). Auch das ANK1 homologe Protein AtPhos43 wird nach Induktion mit flg22, einem bakteriellen Elicitor, innerhalb von wenigen Minuten phosphoryliert (Peck et al., 2001).

Heinekamp et al., 2004 konnte für BZI-1 eine Beteiligung an der Auxin induzierten Transkription zeigen. Es besteht die Möglichkeit, dass Auxin oder der Elicitor flg22 einen Einfluss auf die Lokalisation von ANK1 haben.

Um eine induzierte Zellkernlokalisation von ANK1 zu untersuchen, wurde YFP-ANK1 transient in Tabak Mesophyllprotoplasten exprimiert. Diese Protoplasten wurden dann mit verschiedenen Substanzen inkubiert.

Nach einer Induktion mit $50 \mu$ M NAA (,1-Naphtyleacetic acid') für vier Stunden, kommt es in ca. 20\% der transformierten Protoplasten zu einer Akkumulation von YFP-ANK1 im Zellkern (Abbildung 5.13; A, d und B, a). In mit YFP-ANK1 transformierten Protoplasten, die als Kontrolle mit dem Lösungsmittel DMSO inkubiert wurden, ist YFP-ANK1 weiterhin ausschließlich cytosolisch lokalisiert (Abbildung 5.13; A, a).

Eine veränderte Lokalisation nach Induktion mit flg22 konnte nicht beobachtet werden (Daten nicht gezeigt), aber aus Zeitgründen konnte diese Aspekt der Arbeit nicht mehr ausreichend geklärt werden. Die Lokalisation von YFP-BZI-1 wurde durch Auxininduktion nicht verändert (Daten nicht gezeigt). 

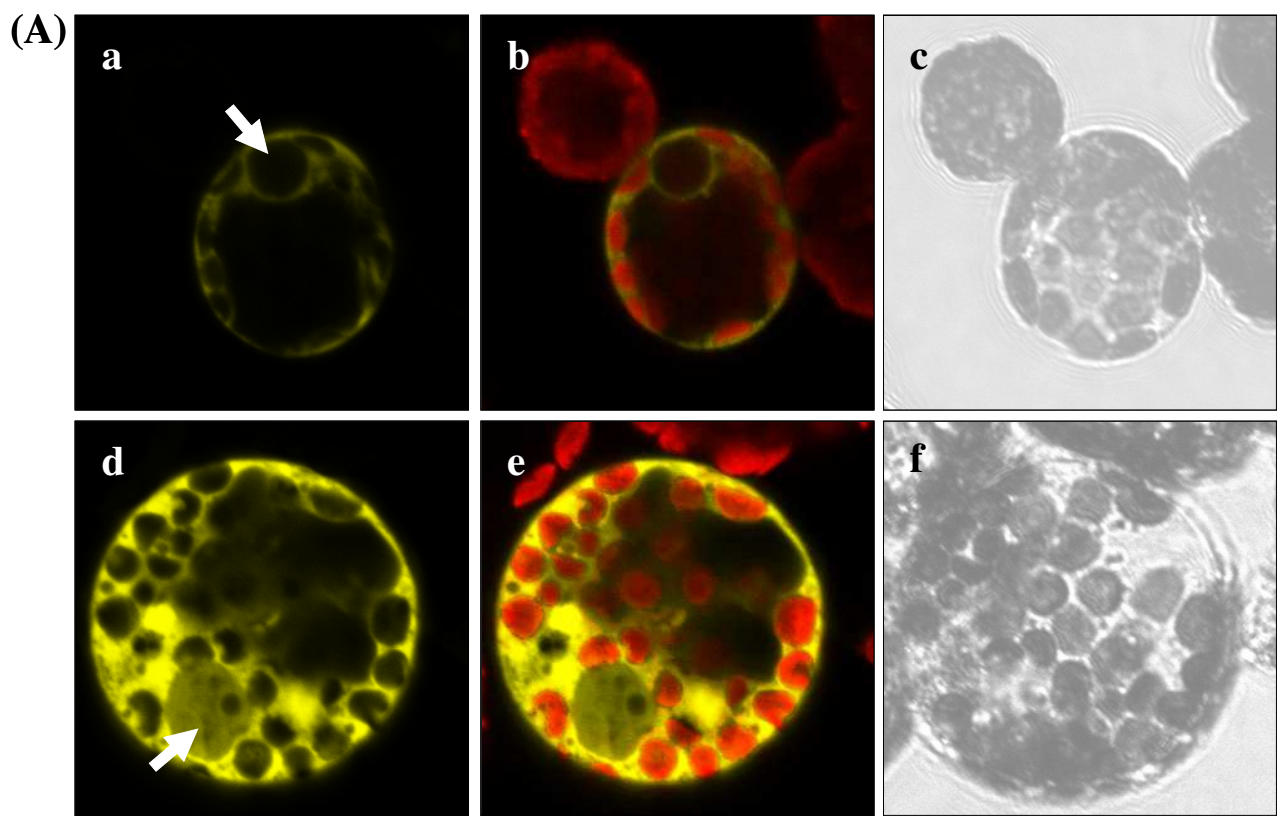

(B)
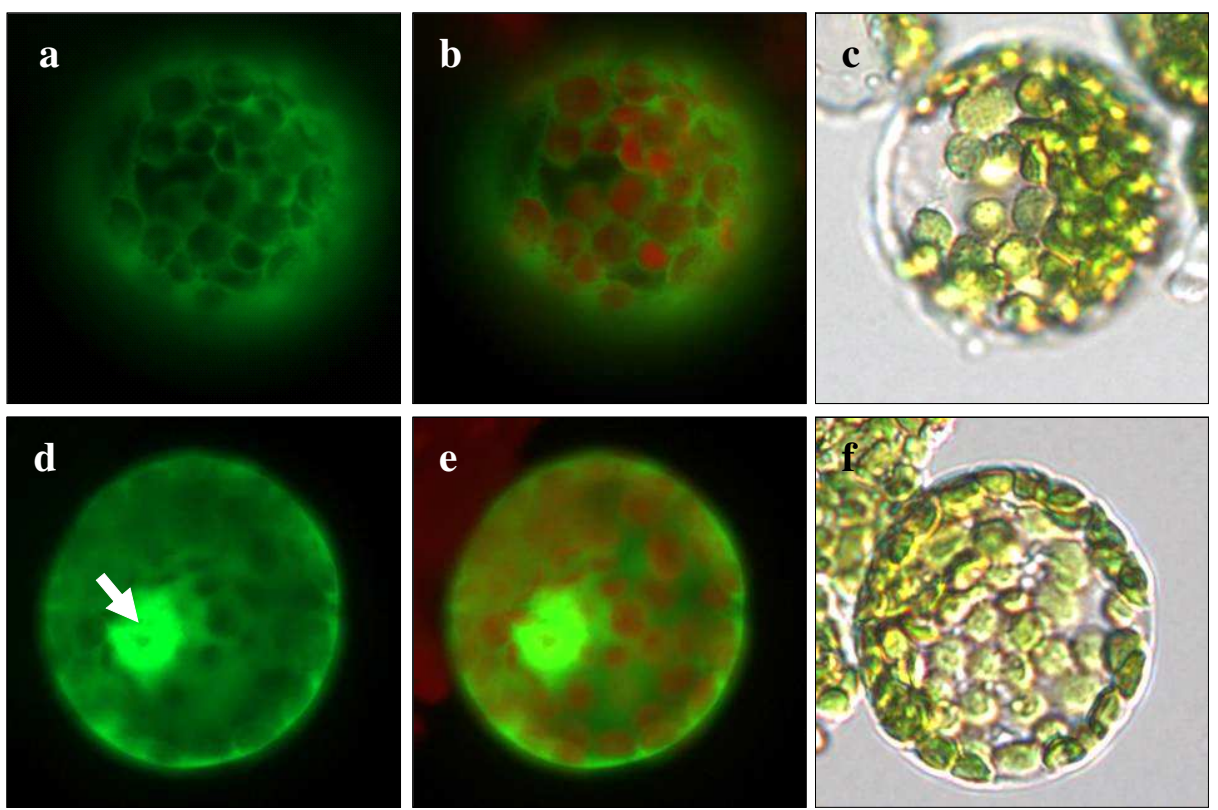

Abbildung 5.13: Lokalisation von YFP-ANK1 nach Induktion mit NAA. YFP-ANK1 wurde transient durch Agrobacterium Infiltration in Tabak Mesophyllprotoplasten exprimiert. (A) (a) Expression von YFP-ANK1 und eine vierstündige Inkubation mit dem Lösungsmittel DMSO (b) Überlagerung der YFP-Anregung mit der Chlorophyll-Anregung (c)

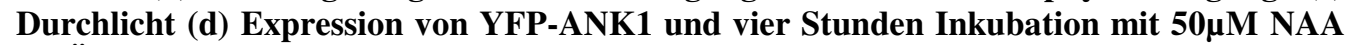
(e) Überlagerung der NAA-Inkubation mit der Chlorophyll-Anregung (f) Durchlicht. Die Pfeile deuten auf den Zellkern der Protoplasten. Die Aufnahmen wurden mit einem konfokalen Mikroskop durchgeführt. (B) Die Aufnahmen wurden an einem Lichtmikroskop mit YFP-Filter durchgeführt. (a) Detektion der YFP-ANK1 Expression (510- $550 \mathrm{~nm}$ ) (b) Detektion der YFP-ANK1 Expression und des Chlorophylls (ab 510 nm) (c) Durchlicht (d) Detektion von YFP-ANK1 nach vier Stunden Inkubation mit 50 $\mu$ M NAA (e) YFP- und Chlorophyll-Detektion der NAA-Induktion (f) Durchlicht. Die Versuche wurden dreimal mit vergleichbaren Resultaten wiederholt. 


\subsubsection{Die Expression von ANK1 und BZI-1 ist nach Auxininduktion nicht verändert}

Um die Induzierbarkeit der Expression von ANK1 und BZI-1 durch Auxin zu untersuchen, wurden Tabak Blattscheiben ausgestochen und in Puffer inkubiert. Es wurde Auxin in verschiedenen Konzentrationen zugegeben und zu den angegebenen Zeitpunkten (siehe Abbildung 5.14) wurden Proben genommen. Wie in Abbildung 5.14 (a) zu erkennen, kommt es zu keiner veränderten Transkription von ANK1 und BZI-1 nach Induktion mit 10 $\mu \mathrm{M}$ oder $50 \mu \mathrm{M}$ NAA. Eine transkriptionelle Aktivierung ist in der Kontrolle und in den Auxininduktionen $\mathrm{zu}$ beobachten und somit unabhängig von der Auxininduktion. Die Expression des BZI-1 Proteins konnte mit dem vorhandenen BZI-1 Antikörper nicht nachgewiesen werden. Die ANK1 Expression ist über einen Zeitraum von 48 Stunden konstant und verändert sich auch nicht nach einer Induktion mit $50 \mu \mathrm{M}$ NAA (Abbildung $5.14, \mathrm{~b})$.

Der $\alpha$ AKR2 Antikörper wurde gegen das ANK1 homologe Protein AKR2 aus Arabidopsis thaliana hergestellt (Yan et al., 2002), erkennt aber auch das ANK1 Protein aus Nicotiana tabacum (Daten nicht gezeigt).

(A)

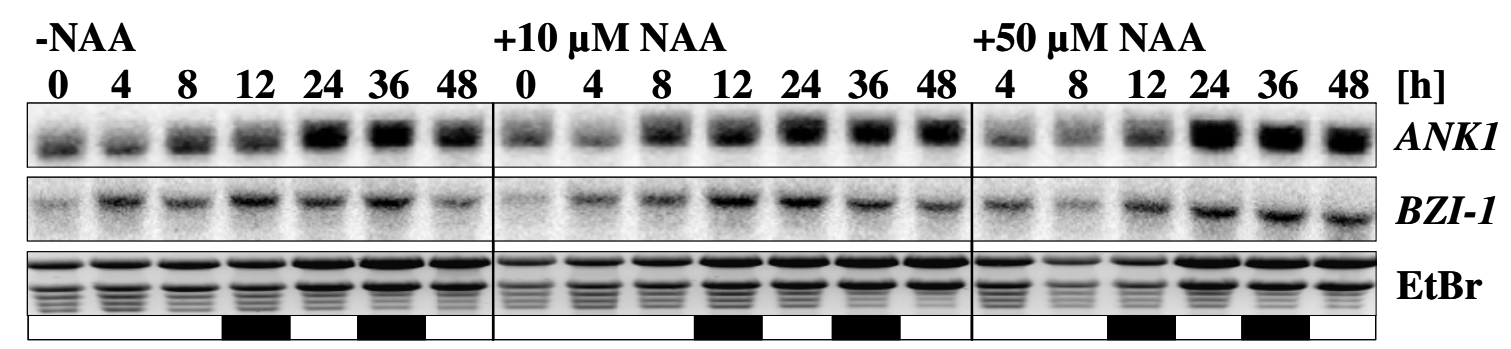

(B)

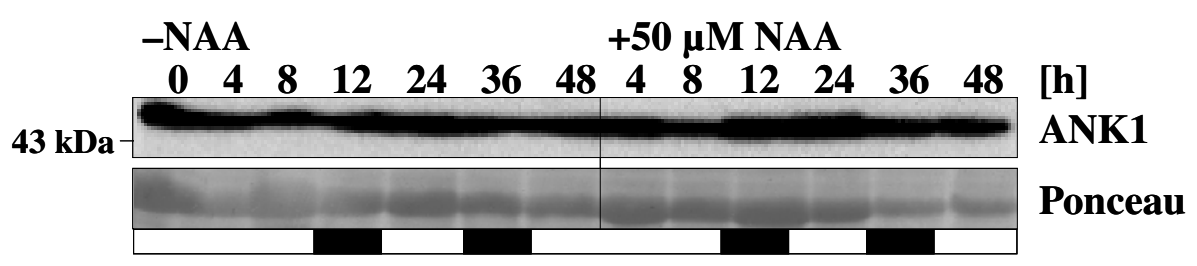

Abbildung 5.14: Analyse der ANK1 und BZI-1 Expression nach Induktion mit NAA von Tabak Blattscheiben. (A) Nachweis der Transkription von ANK1 und BZI-1 ohne und nach Induktion mit $10 \mu \mathrm{M}$ oder $50 \mu \mathrm{M}$ NAA (,1-Naphtyleacetic acid'). (B) Immunologischer Nachweis der ANK1 Expression mit dem $\alpha A K R 2$ Antikörper. Das ANK1-Protein läuft etwa auf einer Höhe von 44 kDa. Der Balken im unteren Bildbereich zeigt den Tag/Nacht Rhythmus an, wobei die dunklen Bereiche die Nacht markieren. 


\subsection{Aktivierungseigenschaften von ANK1 und BZI-1}

Im uninduzierten Zustand sind die YFP-Fusionsproteinen von ANK1 und BZI-1 in unterschiedlichen Kompartimenten lokalisiert. Es konnte aber gezeigt werden, dass ANK1 unter verschiedenen Bedingungen im Zellkern akkumuliert (Kapitel 5.2.4 und 5.2.4). Dies deutet auf eine Funktion von ANK1 im Zellkern hin. In einem P2H Ansatz konnten für ANK1 geringe Autoaktivierungseigenschaften gezeigt werden (Kapitel 5.1.1), aber eine DNA-Bindedomäne oder eine Aktivierungsdomäne ist in ANK1 nicht bekannt. ANK1 könnte aber, da eine Interaktion mit dem DNA bindenden Transkriptionsfaktor BZI-1 festgestellt wurde (Kapitel 5.1.3), Co-Aktivierungseigenschaften besitzen. Für ANK1 konnte bisher noch kein Zielgen identifiziert werden und für ANK1 und BZI-1 wurden keine Unterschiede in der transkriptionellen Aktivierung eines Reportergens mit einer Promotor:GUS Fusion mit dem E1-Element des GH3-Promotors gefunden (Daten nicht gezeigt). Aus diesem Grund wurde das artifizielle P2H System verwendet, wie es in Kapitel 5.1.1 beschrieben wurde.

\subsubsection{In Abhängigkeit von Auxin verstärkt ANK1 die BZI-1/BZI-2 vermittelte Genaktivierung}

Im Kapitel 5.1 konnte gezeigt werden, dass ANK1 sowie BZI-1, BZI-2, BZI-3, und BZI-4 unterschiedliche Autoaktivierungseigenschaften besitzen und das ANK1 spezifisch nur mit BZI-1 interagiert. Weiterhin konnte eine veränderte Lokalisation von ANK1 nach Auxingabe gezeigt werden (Kapitel 5.2.5).

ANK1 könnte in Abhängigkeit von Auxin, durch eine veränderte Lokalisation Einfluss auf die transkriptionelle Aktivierung haben. Dabei könnte ANK1 die DNA-Bindung oder Dimerisierung von BZI-1 beeinflussen. Auxin könnte aber auch einen Einfluss auf die Autoaktivierungen von ANK1, BZI-1, BZI-2, BZI-3, oder BZI-4 haben. Eine Untersuchung der Autoaktivierungen von ANK1, BZI-1, BZI-2, BZI-3, und BZI-4 in Abhängigkeit von Auxin muss deshalb der Analyse der putativen Co-Aktivator Eigenschaften von ANK1 vorausgehen. 


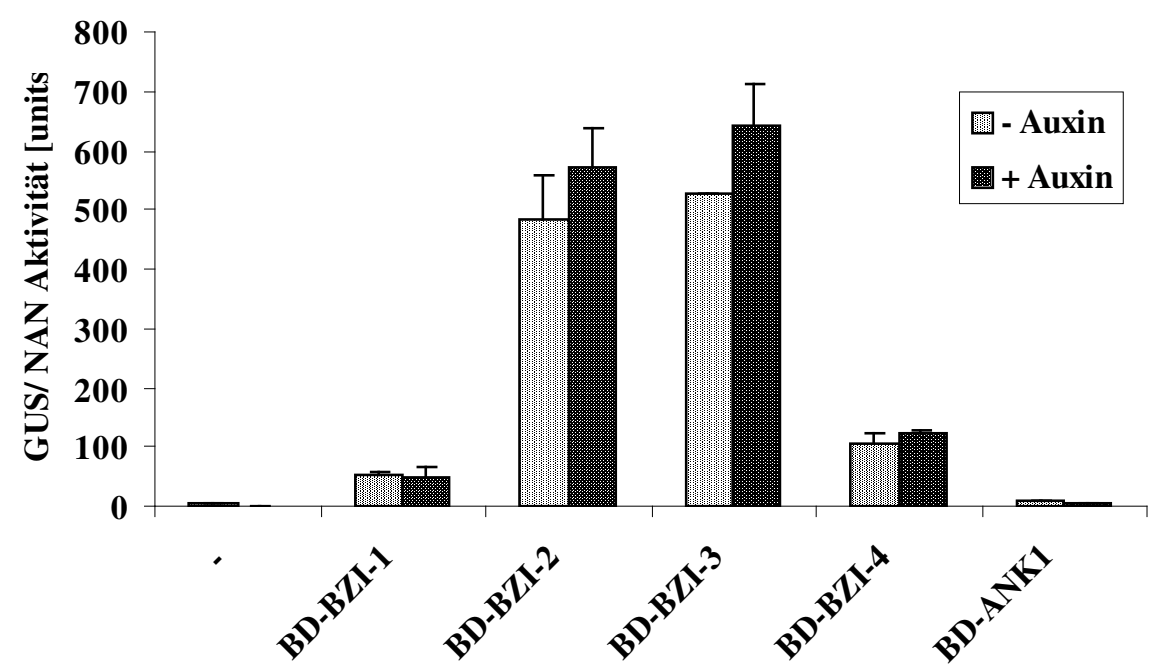

Abbildung 5.15: Analyse der transkriptionelle Aktivierungseigenschaften von ANK1 und BZI-1, -2, -3 und -4 ohne und nach Induktion mit Auxin in Tabak Mesophyllprotoplasten mit der P2H Methode. In allen Ansätzen wurden $9 \mu$ g GAL4-UAS G $_{4}$ GUS und $3 \mu \mathrm{g}$ Pro $_{355}$ :NAN als Reporterplasmide sowie $14 \mu \mathrm{g}$ des jeweiligen Effektorplasmids in Tabak Mesophyllprotoplasten transformiert. Mit dem Einsatz unspezifischer DNA wurden unterschiedliche Mengen an DNA in den Ansätzen ausgeglichen. Die Positivkontrollen zeigen eine Aktivität von 1423 units und werden aufgrund der besseren Übersicht nicht dargestellt. _: Negativkontrolle; BD: GAL-4 Bindedomäne; Die genauen Messwerte sind im Anhang angegeben. Die Versuche wurden zweimal für BZI-3 und BZI-4, und dreimal für BZI-1, BZI-2 und ANK1 mit vergleichbaren Resultaten wiederholt.

Die Bestimmung der Autoaktivierung von ANK1, BZI-1, BZI-2, BZI-3 und BZI-4 in Abhängigkeit von exogen appliziertem Auxin erbrachte nur geringe Unterschiede zum uninduzierten Zustand (Abbildung 5.15). Bei BZI-2 und BZI-3 kommt es nach Auxingabe zu einem leichten Anstieg der Reportergen Expression.

Es wurden nun die Aktivierungseigenschaften der Interaktionen zwischen BZI-1 und BZI1, BZI-2, BZI-3, oder BZI-4 in Abhängigkeit von Auxin getestet. Zusätzlich wurde noch ANK1 als putativer Co-Aktivator getestet, indem ANK1 mit BZI-1 und BZI-1, BZI-2, BZI-3, oder BZI-4 co-transformiert wurde (Abbildung 5.16). Dazu wurde BZI-1 an die GAL4-Bindedomäne fusioniert und die mit BZI-1 interagierenden Faktoren BZI-1, -2, -3 und -4 und ANK1 wurden ohne Aktivierungsdomänen-Fusion co-transformiert. Die einzelnen Co-Transformationen und ihre Reportergenaktivierungen sind in Abbildung 5.16 abzulesen. Der Versuch wurde mehrfach wiederholt, dargestellt ist ein repräsentativer Versuch.

Ohne Auxininduktion kommt es bei der transkriptionellen Aktivierung des Reportergens bei allen Interaktionen durch die Co-Expression von ANK1 zu keiner deutlichen Veränderung. Werden die Protoplasten mit Auxin induziert, zeigen die Dimere von BDBZI-1 mit ANK1, BZI-1, BZI-2, BZI-3, oder BZI-4 nur geringe Unterschiede zu den 
uninduzierten Dimeren. Gelegentlich zeigt aber auch die Interaktion zwischen BD-BZI-1 und BZI-2 eine leicht verstärkte transkriptionelle Aktivierung nach Auxininduktion.

Ein Unterschied ist jedoch bei den verschiedenen Interaktionen von BD-BZI-1 und ANK1 mit BZI-1, BZI-2, BZI-3, oder BZI-4 zu beobachten. Die Reportergenaktivierung der Auxin induzierten Co-Transformation von BD-BZI-1 und ANK1 mit BZI-1, BZI-3 oder BZI-4 entspricht der Reportergenaktivierung im uninduzierten Zustand. Aber die CoTransformation von BD-BZI-1 mit ANK1 und BZI-2 zeigt einen starken Effekt auf die transkriptionelle Aktivierung des Reportergens nach Auxininduktion.

ANK1 verstärkt die BZI-1/BZI-2 vermittelte Genaktivierung in Abhängigkeit von Auxin und die Rolle von ANK1 könnte dabei die eines Co-Aktivators sein. Analysen mit den mutierten Ankyrin-Repeat Proteinen ANK1muts könnten weiter Aufschluss über die Auxin abhängige Verstärkung der BZI-1/BZI-2 vermittelte Genaktivierung durch ANK1 geben.

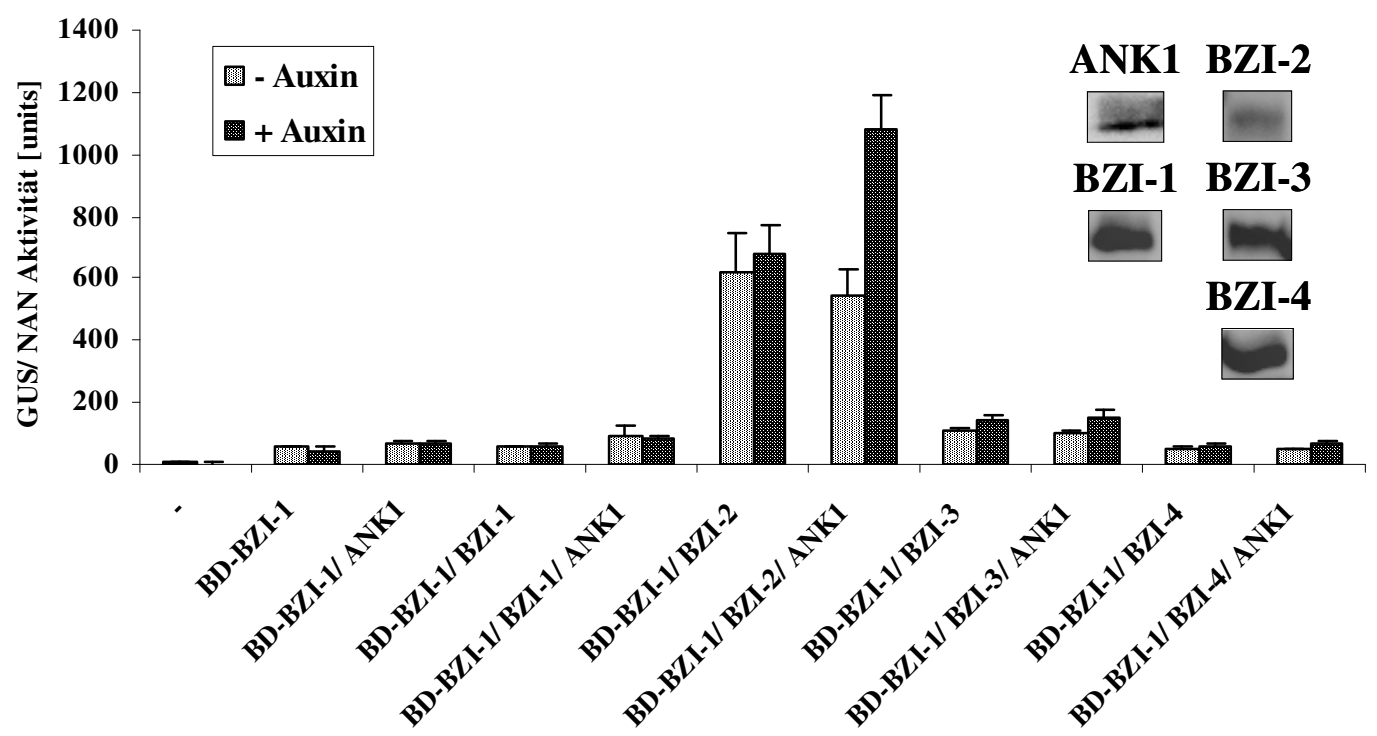

Abbildung 5.16: Analyse der Aktivierungseigenschaften nach Co-Transformation ohne und nach Induktion mit Auxin in Tabak Mesophyllprotoplasten mit der P2H Methode. Es wurden BD-BZI-1 mit ANK1, BZI-1, BZI-2, BZI-3, oder BZI-4 oder BD-BZI-1 und ANK1 mit BZI-1, BZI-2, BZI-3, und BZI-4 co-transformiert. In allen Ansätzen wurden 9 $\mu$ g GAL4-

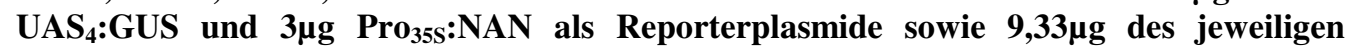
Effektorplasmids in Tabak Mesophyllprotoplasten transformiert. Mit dem Einsatz unspezifischer DNA wurden unterschiedliche Mengen an DNA in den Ansätzen ausgeglichen. Die Positivkontrollen zeigen eine Aktivität von 2681 units werden aufgrund der besseren Übersicht nicht dargestellt. -: Negativkontrolle; BD: GAL-4 Bindedomäne Die genauen Messwerte sind im Anhang angegeben. Die Versuche wurden fünfmal mit vergleichbaren Resultaten wiederholt. Der immunologische Nachweis der Expressionen die an einen HA-Tag fusionierten Proteine wurde mit einem $\alpha$ HA-Antikörper durchgeführt und ist im rechten Bereich des Diagramms dargestellt. 


\subsubsection{Die Lokalisierung von ANK1 im Zellkern verstärkt die BZI-1 - BZI-2 vermittelte Genaktivierung}

Durch verschiedene Stimuli kann ANK1 im Zellkern lokalisiert werden (Kapitel 5.2.4 und 5.2.4) und zeigt im Komplex mit BZI-1 und BZI-2 Co-Aktivierungseigenschaften in Abhängigkeit von Auxin (Kapitel 5.3.1).

In den Interaktionsstudien ist ANK1 an eine GAL4-Aktivierungs- oder Bindedomäne fusioniert. Diese beinhalten eine NLS. Werden aber die einzelnen Faktoren auf ihre Aktivierungseigenschaften in einem Komplex untersucht, so werden sie nur an einen HATag fusioniert exprimiert, der keine NLS beinhaltet. Faktoren, die keine endogene NLS besitzen, könnten so nicht in den Zellkern transloziert werden. Ohne die nötige Induktion konnte somit ANK1 nicht oder nur unzureichend in den Zellkern gelangen. Dadurch könnten die schwachen Aktivierungen in den Aktivierungsstudien mit ANK1 zu erklären sein. Aus diesem Grund wurde in dieser Arbeit ein Plasmid hergestellt, das eine Nterminale Fusion an die SV40-NLS an ANK1 ermöglicht. Die SV40-NLS wurde schon mehrfach erfolgreich in Pflanzen verwendet (Van der Krol and Chua, 1991; Yang et al., 2000).

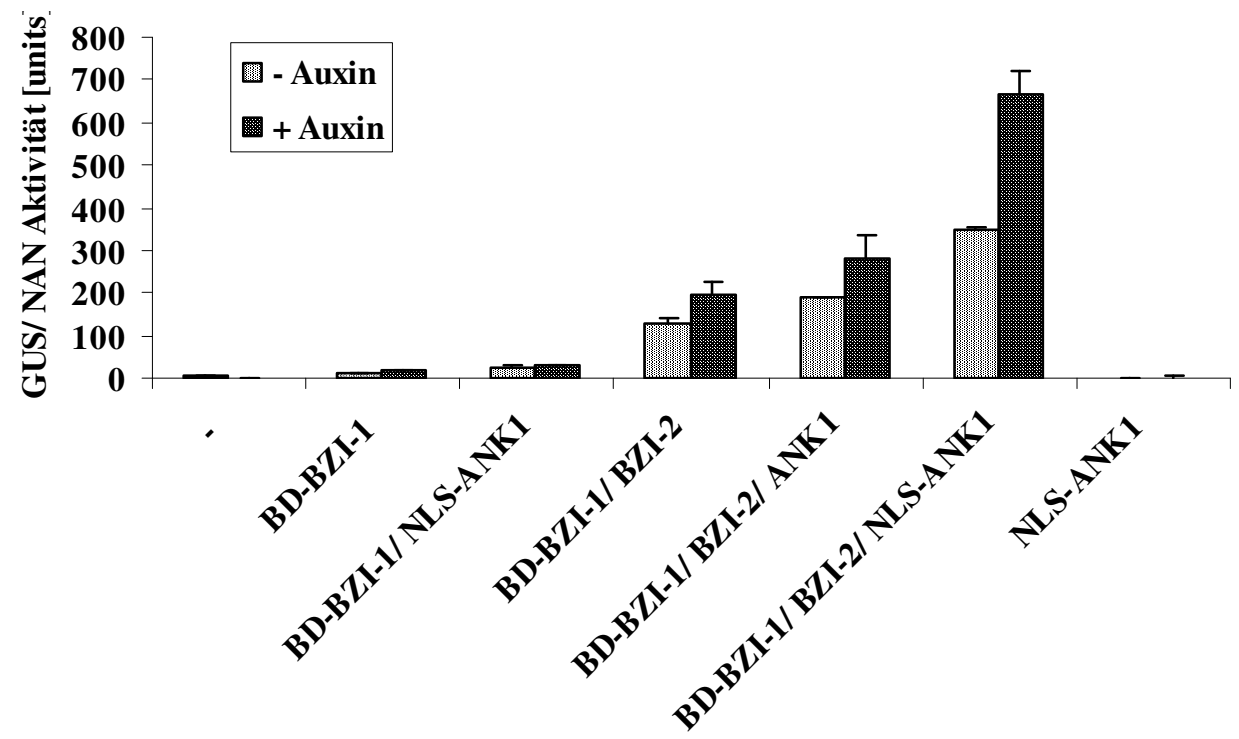

Abbildung 5.17: Analyse der Aktivierungseigenschaften der Interaktionen von NLS-ANK1, BZI-1 und BZI-2 ohne und nach Induktion mit Auxin in Tabak Mesophyllprotoplasten mit der P2H Methode. In allen Ansätzen wurden 9 $\mu$ g GAL4-UAS G $_{4}$ GUS und $3 \mu \mathrm{g}$ Pro $_{35 \mathrm{~s}}$ :NAN als Reporterplasmide sowie $9,33 \mu$ des jeweiligen Effektorplasmids in Tabak Mesophyllprotoplasten transformiert. Mit dem Einsatz unspezifischer DNA wurden unterschiedliche Mengen an DNA in den Ansätzen ausgeglichen. Die Positivkontrollen zeigen eine Aktivität von 1208 units und wurden aufgrund der besseren Übersicht nicht dargestellt. -: Negativkontrolle; BD: GAL-4 Bindedomäne Die genauen Messwerte sind im Anhang angegeben. Die Versuche wurden zweimal mit vergleichbaren Resultaten wiederholt. 
In Abbildung 5.17 ist zu erkennen, dass die Reportergenaktivierung der Co-Expression von BD-BZI-1, BZI-2 und NLS-ANK1 im uninduziertem Zustand deutlich höher ist, als die Co-Expression von BD-BZI-1, BZI-2 und ANK1 nach Auxininduktion. Die Lokalisation von ANK1 im Zellkern ist ausreichend für eine verstärkte Reportergenexpression. Eine Auxininduktion der Co-Expression von BD-BZI-1, BZI-2 und NLS-ANK1 führt dann nochmals zu einer deutlichen Steigerung der Reportergenaktivität gegenüber dem uninduziertem Zustand. Es konnte gezeigt werden, dass ANK1 nach Auxininduktion im Zellkern akkumuliert (Kapitel 5.2.6). Weiterhin konnte gezeigt werden, dass BZI-1 und ANK1 in Tabak Mesophyllprotoplasten interagieren (Abbildung 5.1). ANK1 könnte deshalb ein Co-Aktivator von BZI-1 sein. 


\subsection{Herstellung und Charakterisierung transgener ANK1 und BZI-1 Pflanzen}

Um die Funktionen von ANK1 und BZI-1 in planta aufzuklären, wurde mittels transgener Ansätze die Menge von ANK1 und BZI-1 erhöht oder reduziert. BZI-1 Überexpressionspflanzen (BZI-1OEX) wurden bereits von Thorsten Heinekamp (2002) hergestellt und in dieser Arbeit verwendet. ANK1 Überexpressionspflanzen (ANK1OEX), ANK1-RNA interference Pflanzen (ANK1-RNAi) und BZI-1 RNA interference Pflanzen (BZI-1-RNAi) wurden im Rahmen dieser Arbeit erzeugt und charakterisiert.

\subsection{1 Überexpression von ANK1 in Nicotiana tabacum}

Transgene Pflanzen, in denen die ANK1 Expression erhöht ist, wurden bereits währende der Diplomarbeit hergestellt (Böttner, 2003). Die Anzahl der nach der Transformation in Nicotiana tabacum regenerierten Pflanzen war allerdings sehr gering. Weiterhin konnte keine starke Überexpression in diesen Pflanzen festgestellt werden. Eine Aussage über den möglichen Einfluss einer ANK1 Überexpression konnte deshalb nicht gemacht werden.

Aus diesen Gründen wurden in dieser Arbeit nochmals ANK1 Überexpressionspflanzen hergestellt. Dafür wurde der ANK1-Kodierbereich in den Gateway ${ }^{\circledR}$ kompatiblen Überexpressionsvektor pGWB15 (Nakagawa T, 2002) inseriert. In diesem Plasmid steht ANK1 unter der Kontrolle des konstitutiven CaMV35S Promotors. Ein N-terminal fusionierter dreifacher HA-Tag ermöglicht eine immunologische Detektion des ANK1 Proteins (Maniattis et al., 1982; Hopp et al., 1988). Die Transformation in Nicotiana tabacum wurde mit Hilfe des Agrobacterium tumefaciens vermittelten Gentransfers durchgeführt.

Wie in Abbildung 5.18 (A) zu sehen, ist die Transkription von ANK1 in allen getesteten Linien stärker als die Transkription im Wildtyp (WT), außer in der Linie \#5. ANK1OEX \#5 zeigt keine Transkription von ANK1. Die ANK1 Überexpressionspflanzen wurden auch mittels immunologischer Detektion unter Verwendung eines $\alpha H A$ Antikörpers analysiert. Dieser erkennt über den dreifachen HA-Tag des Fusionsproteins ausschließlich das transgene ANK1, unabhängig vom endogenen ANK1. Durch einen Westernblot mit dem $\alpha \mathrm{HA}$ Antikörper konnten mehrere ANK1 überexprimierende Linien identifiziert werden (Abbildung 5.18, B). Die Linien ANK1OEX \#1, \#2, \#3, \#15, \#20.2 und \#30 zeigten die 
stärkste ANK1 Expression. Ein Expressionsvergleich mit dem Wildtyp ist mit dem $\alpha \mathrm{HA}$ Antikörper nicht möglich, da dieser das endogene ANK1 nicht detektiert.

Eine Detektion der ANK1 Überexpression wurde auch mit dem $\alpha$ AKR2 Antikörper durchgeführt (Daten nicht gezeigt). Die Größe des überexprimierten Fusionsproteins mit $44 \mathrm{kDa}$ weicht nur gering von der Größe des endogenen ANK1 mit 37,2 kDa ab und ist dadurch in einer immunologischen Detektion nicht von der endogenen Bande zu unterscheiden. Weiterhin unterscheidet sich die Bandenstärke der ANK1OEX Pflanzen nicht von der Bandenstärke der Wildtyp Pflanzen. Daraus lässt sich schließen, dass die ANK1 Überexpression in den ANK1OEX Pflanzen nicht besonders stark ist.

Für die weiteren Exprimente wurden vor allem die Linien ANK1OEX \#2 und \#3 verwendet.

(A)

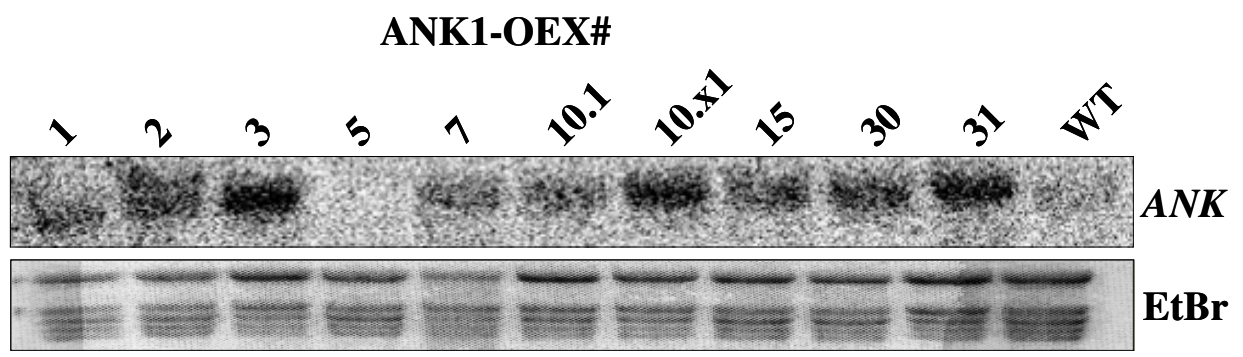

(B) ANK1-OEX\#

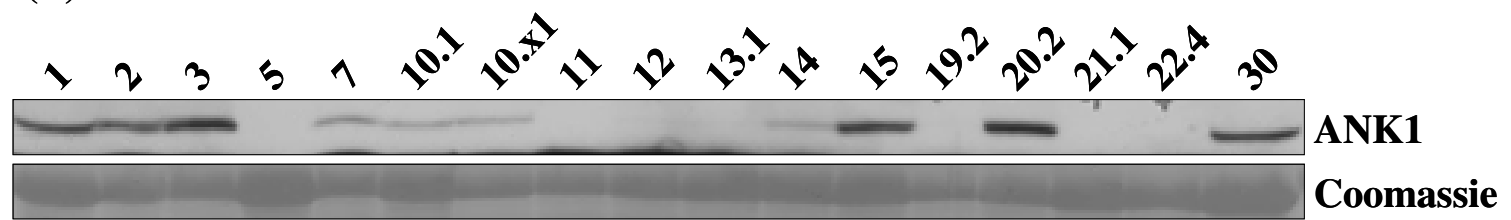

Abbildung 5.18: Molekulare Charakterisierung der ANK1 Expression in transgenen ANK1OEX Pflanzen. (A) Nachweis der Transkription von ANK1 mit einer ANK1-spezifischen Northern Sonde. (B) Immunologischer Nachweis der ANK1 Expression mit dem $\alpha \mathrm{HA}$ Antikörper. Das ANK1-Fusionsprotein läuft etwa auf einer Höhe von 44 kDa. 


\subsubsection{Phänotypische Charakterisierung der ANK1-Überexpressionspflanzen}

Die ANK1OEX Linien wurden in Erdkultur angezogen und phänotypisch charakterisiert (Tabelle 5.1). Die ANK1 überexprimierenden Linien zeigen dabei keinen Unterschied im Vergleich zum Wildtyp.

Tabelle 5.1: Überblick über die Expressionsstärke und die Phänotypen der transgenen ANK1OEX Linien. n.d.: Wert nicht bestimmt; -: keine Transkription/Translation festgestellt; +, ++, +++: Expressionsstärken, aufsteigend gekennzeichnet, =: wie WT.

\begin{tabular}{|c|c|c|c|c|}
\hline ANK1-OEX & Transkription & Translation & Phänotyp & Blüten \\
\hline$\# 1$ & + & ++ & $=$ & n.d. \\
\hline$\# 2$ & + & ++ & $=$ & $=$ \\
\hline \#3 & ++ & +++ & $=$ & $=$ \\
\hline$\# 5$ & - & - & $=$ & $=$ \\
\hline \#7 & + & + & $=$ & n.d. \\
\hline \#10.1 & + & + & $=$ & n.d. \\
\hline$\# 10 . x 1$ & ++ & + & $=$ & n.d. \\
\hline \#14 & n.d. & + & $=$ & n.d. \\
\hline \#15 & + & +++ & $=$ & $=$ \\
\hline$\# 20.2$ & n.d. & +++ & $=$ & $=$ \\
\hline \#22.1 & n.d. & n.d & $=$ & n.d. \\
\hline$\# 22.4$ & n.d. & - & $=$ & n.d. \\
\hline$\# 30$ & + & +++ & $=$ & $=$ \\
\hline \#31 & ++ & n.d. & $=$ & n.d. \\
\hline \#34 & n.d. & n.d. & $=$ & n.d. \\
\hline
\end{tabular}

Neben der vegetativen Beurteilung wurden auch die Blütenmorphologie und die Samenentwicklung der ANK1 überexprimierenden Linien analysiert. Die Blüten zeigen keinen Unterschied zum Wildtyp und auch die Samenproduktion der ANK1OEX Linien weist keine Veränderung im Vergleich zum Wildtyp auf (Daten nicht gezeigt).

\subsubsection{Reduktion der ANK1 Expression in Nicotiana tabacum}

Während der Diplomarbeit wurden transgene Tabakpflanzen hergestellt, in denen ANK1 durch einen RNA Interference Ansatz stark reduziert war (Böttner, 2003). In den verschiedenen Linien konnte die ANK1 Expression nicht mehr nachgewiesen werden und alle Linien zeigten über das ganze Blatt verteilte, hellere Stellen ohne Chlorophyll, die verstärkt um die Leitgefäße auftraten und als Läsionen bezeichnet wurden.

Nach TMV Infektion wiesen die ANK1-RNAi Pflanzen deutlich weniger HR-Läsionen auf als der Wildtyp. Dieser Unterschied in der Läsionsausprägung verschwand jedoch über einen Zeitraum von einem halben Jahr ganz. Eine erneute Anzucht aus gewonnenem 
Saatgut führte ebenfalls nicht mehr zu dem beobachteten Phänotyp nach TMV-Infektion. Um festzustellen, ob die neu erhaltenen transgenen Pflanzen wieder den Phänotyp nach TMV-Infektion ausprägen, wie er bereits beobachtet werden konnte, wurden noch einmal ANK1-RNAi Pflanzen hergestellt. Ein weiterer Grund war die geringe Zahl an transgenen Linien, die nach der ersten Transformation regeneriert werden konnte.

Es wurde der RNAi Vektor pFGC-ANK1 verwendet. (Waterhouse et al., 1998; zur Übersicht: Horiguchi, 2004). Nach erfolgter Transformation mit den ANK1-RNAi Konstrukten bildeten sich über einen sehr langen Zeitraum von ca. fünf Monaten Kalli aus, aus denen sich nur wenige Pflanzen regenerierten. Aus diesem Grund wurden auch mehrere Linien von einem Kallus verwendet. Alle Linien mit dem gleichen Anfangsbuchstaben sind aus dem gleichen Kallus regeneriert. Die selektionierten ANK1RNAi Pflanzen wurden auf Transkriptions- und Translationsebene analysiert (Abbildung 5.19). Wie in Abbildung $5.19 \mathrm{zu}$ erkennen ist, ist die Expression von ANK1 in fast allen Linien nicht mehr zu detektieren. Nur die Linien ANK1-RNAi A2, A3 und F3 zeigen eine ANK1 Expression wie der Wildtyp und wurden nicht weiter charakterisiert.

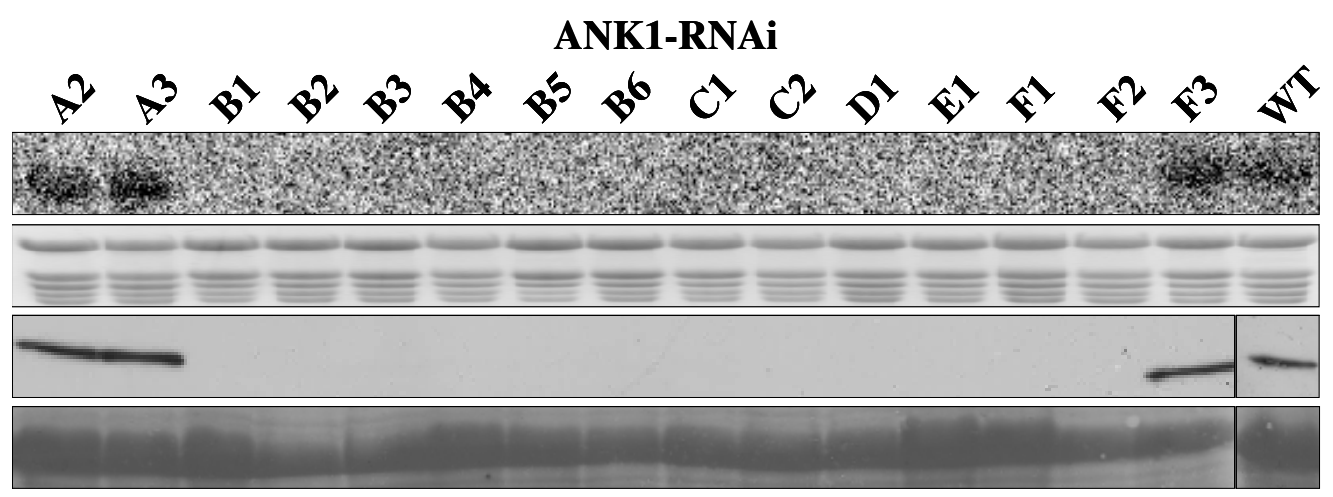

ANK1

EtBr

ANK1

Ponceau

Abbildung 5.19: Molekulare Charakterisierung der ANK1-RNAi Pflanzen. (A) Nachweis der Transkription von ANK1 mit einer ANK1-spezifischen Northern Sonde. (B) Immunologischer Nachweis der ANK1 Expression mit dem $\alpha$ AKR2 Antikörper. EtBr: Ethidiumbromid.

\subsubsection{Phänotypische Charakterisierung der ANK1-RNAi Pflanzen}

Eine erste Analyse des vegetativen Wachstums der ANK1-RNAi Linien zeigte starke Unterschiede zum Wildtyp. Die Linien wurden aufgrund ihrer Phänotypen in zwei Gruppen eingeteilt (Abbildung 5.20).

Die erste Gruppe ist charakterisiert durch leichte Läsionen, die über das Blatt verteilt sind, aber im Bereich des Leitgewebes gehäuft auftreten. Die ANK1-RNAi Pflanzen der ersten 
Transformation und diese Pflanzen wurden gemeinsam als ,Läsionsphänotyp' bezeichnet, da sie sich sehr ähneln. Die Stärke der Läsionsausprägung kann von Charge zu Charge variieren, es konnte aber nicht festgestellt werden, welche Bedingungen die Stärke des Phänotyps beeinflussen. Der Chlorophyllgehalt der ,Läsionsphänotypen’ ist reduziert und liegt bei etwa $75 \%$ des Wildtyps.

Die zweite Gruppe der ANK1-RNAi Linien wurde ,ledrig/krauser Phänotyp' genannt. Die Blätter diese Gruppe sind insgesamt dunkelgrüner und dicker als die des Wildtyps und haben ein ledriges Erscheinungsbild. Wie in Abbildung 5.20 D1 deutlich zu erkennen ist, zeigen die Blätter dieser Linien eine veränderte Anordnung der Seitenrippen. Es treten auch gelegentlich Blattanomalien in dieser Gruppe auf. Diese sind charakterisiert durch eine veränderte Wuchsform des Blattes. Dies können nur kleine Stellen auf einem Blatt (Abbildung 5.20, D1 rechts), oder auch ein unregelmäßiger Blattrand (Abbildung 5.20, F1 rechts) sein. Die Beispiele sind in Abbildung 5.20 mit Pfeilen markiert. Insgesamt sind diese Linien deutlich kleiner als der Wildtyp. Auch in der Gruppe ,ledrig/krauser Phänotyp' treten bei einigen der Linien vereinzelt Läsionen auf. Die Linie ANK1-RNAi F1 zeigt dies besonders stark. Sie wurde als ,intermediärer Phänotyp' bezeichnet, da sie Merkmale beider Gruppen zeigt. 


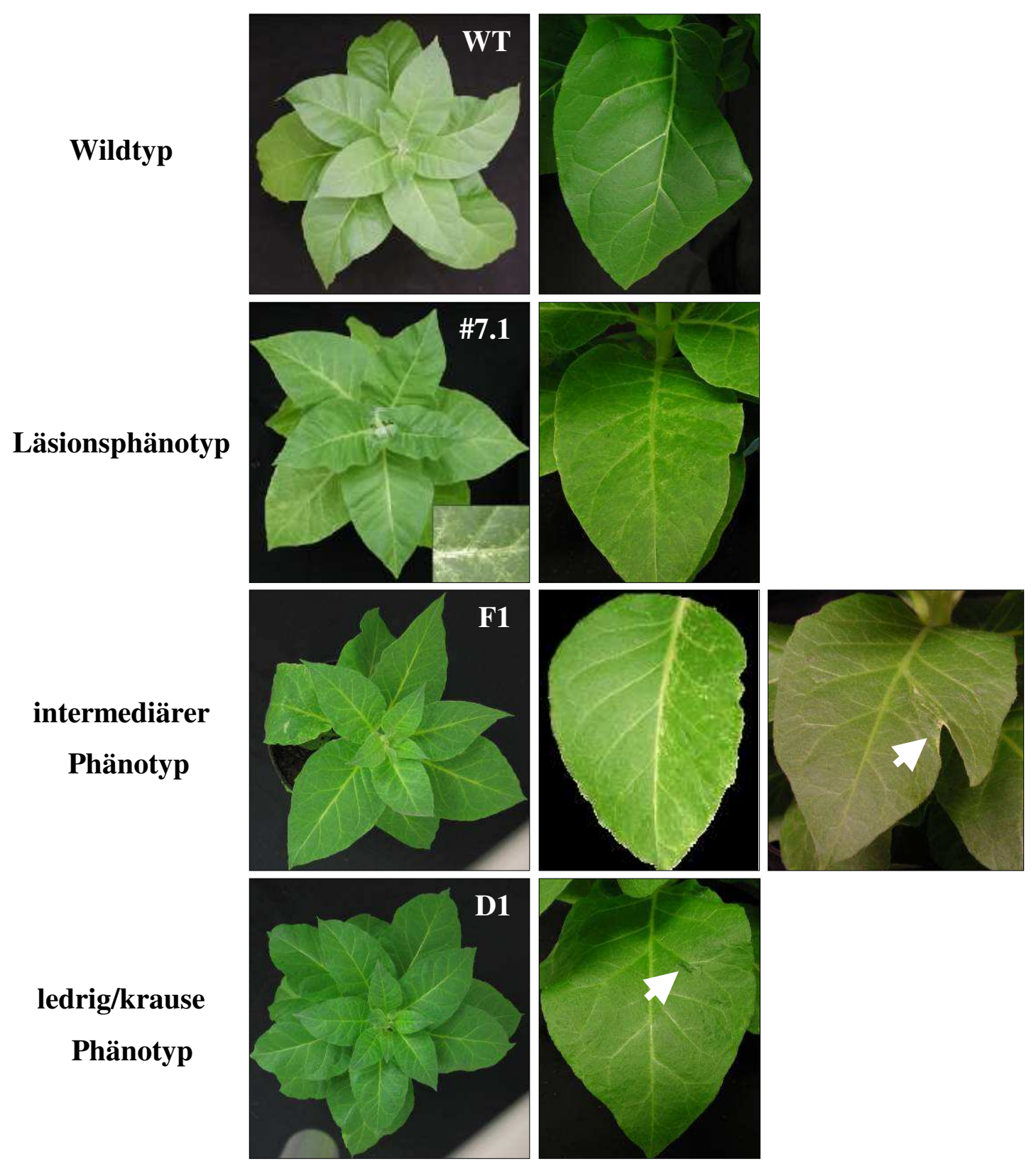

Abbildung 5.20: Phänotypischer Vergleich von typischen Vertretern der verschiedenen ANK1-RNAi Phänotypen mit dem Wildtyp. Gezeigt sind die Aufsicht der Pflanzen (links) und jeweils ein typisches Blatt (Mitte) jeder Linie. Rechts ist ein weiters Blatt der Linie F1 mit einer starken Blattanomalie abgebildet. Die Pfeile deuten auf Blattanomalien. WT: Wildtyp; \#7.1: ANK1-RNAi \#7.1; F1: ANK1-RNAi F1; D1: ANK1-RNAi D1. 
Aufgrund der nicht zu detektierenden ANK1 Expression konnten die Phänotypen nicht mit der Menge von ANK1 korreliert werden. Eine Übersicht über die verschiedenen transgenen ANK1-RNAi Linien ist in Tabelle 5.2 aufgeführt.

Tabelle 5.2: Überblick über die Expressionsstärke und die Phänotypen der ANK1-RNAi Linien. Die Pflanzen des ersten Transformationsansatzes nummeriert und die Linien der zweiten Transformation mit Buchstaben benannt. Linien: ANK1-RNAi Linien; Größe: Größe der transgenen Pflanze im Vergleich zum Wildtyp; n.b: Wert nicht bestimmt; -: keine Transkription/Translation festgestellt; -, +, ++, +++: Läsionsausprägung, aufsteigend gekennzeichnet, =: wie WT; (ledrig/kraus) schwächere Ausprägung des ledrig/krausen Phänotyps; Gruppen: ledrig (ledrig/krauser Phänotyp); Läsion (Läsionsphänotyp); inter (intermediärer Phänotyp).Fehler! Keine gültige Verknüpfung.

Die auftretenden Läsionen in den ANK1-RNAi Pflanzen wurden genauer analysiert. Eine Läsion kann sowohl durch eine Verletzung, als auch als Antwort auf ein Pathogen das eine HR (,hypersensitive response') induzierten Zelltod auslöst, hervorgerufen werden.

Um zu untersuchen, ob die Ausprägung der Läsionen auf einem HR ähnlichen Zelltod beruht, wurden Blattgewebestücke mit Trypan Blue angefärbt. Die Zellmembran von lebenden Zellen ist für Trypan Blue nicht permeabel und lassen sich deswegen mit Trypan Blue nicht anfärben. Eine Trypan Blue Anfärbung des Läsionsphänotypen ANK1-RNAi B4 zeigte keinen Unterschied zum Wildtyp, wie es in Abbildung 5.21 (A, a und d) zu erkennen ist. Als Kontrolle diente eine mit TMV infizierte Wildtyppflanze (A, b und c). Die im Rahmen der hypersensitiven Reaktion abgestorbenen Zellen dieser vier Tage alten TMV Infektion ließen sich mit Trypan Blue anfärben. Die Läsionen der Gruppe der Läsionsphänotypen entstehen somit nicht durch ein Absterben der Zellen. 
(A)
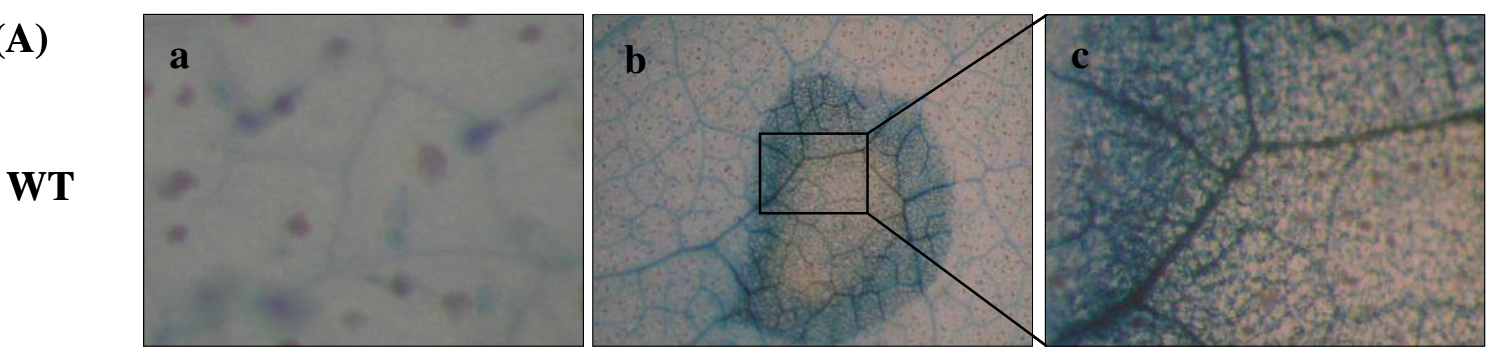

d

ANK1i

\#7.1

(B)

WT

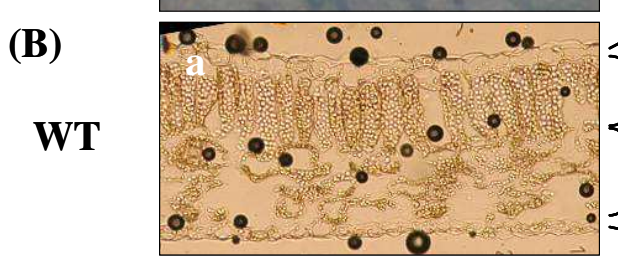

Epidermis

Palisadenparenchym

ANK1i

B4

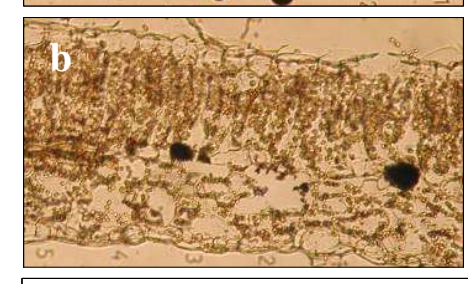

Schwammparenchym

(C)

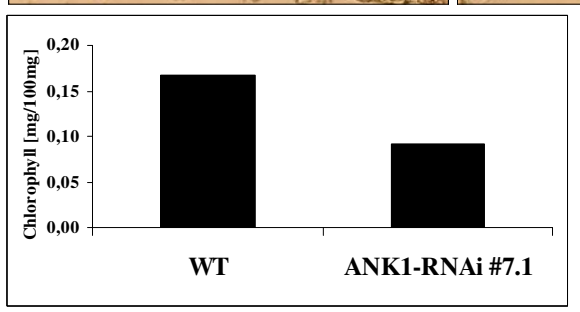

Abbildung 5.21: Analyse der Läsionen der Gruppe der ,Läsionsphänotypen' der ANK1-RNAi Pflanzen. (A) Trypan-Blue Anfärbung eines Wildtyp- und eines ANK1-RNAi \#7.1 Blattes. (a) Wildtyp (WT); (b) Wildtyp nach TMV-Infektion. Eine im Rahmen der hypersensitiven Reaktion entstandene Läsion ist angefärbt. (c) Ausschnitt der Läsion (d) ANK1-RNAi \#7.1 (ANK1i \#7.1) (B) Querschnitte eines Wildtyp- und eines ANK1-RNAi B4 Blattes. (a) Wildtyp (WT); Die Unterteilung des Blattes in Epidermis, Palisaden- und Schwammparenchym ist dargestellt. (b) ANK1-RNAi B4 (ANK1i B4) ohne Läsion (c) ANK1-RNAi B4, visuell festgestellter Beginn der Läsion. Der Pfeil deutet auf den Übergang zwischen Wildtyp Blattmorphologie und Läsion. (d) ANK1-RNAi B4, Läsion. (C) Bestimmung des Chlorophyllgehalts des Wildtyps (WT) und der ,Läsionsphänotyp' Linie ANK1-RNAi \#7.1.

Von Blättern mit deutlichen Läsionen, wurden Mikrotomschnitte angefertigt (Abbildung 5.21, B). In einem Blattquerschnitt eines Wildtypblattes ist deutlich die Unterteilung zwischen Palisaden- und Schwammparenchym zu erkennen (B, a). Abgeschlossen werden diese Gewebe jeweils von einer einschichtigen Epidermis. Wird ein Blatt eines ,Läsionsphänotypen' angeschnitten, weisen die Bereiche ohne Läsionen die gleiche 
Morphologie wie ein Wildtypblatt auf $(\mathrm{B}, \mathrm{b})$. Wird hingegen eine Läsion angeschnitten, fehlt die geordnete Struktur und das Palisadenparenchym. Die Dicke des Blattes nimmt an den Stellen der Läsionen nicht merklich ab. Ein Schwammparenchym ähnliches Gewebe ersetzt das Palisadenparenchym. Eine Messung des Chlorophyllgehalts in den ,Läsionsphänotypen' bestätigt, dass in diesen Linien die Menge an Chlorophyll im Vergleich zum Wildtyp reduziert ist (Abbildung 5.21, C).

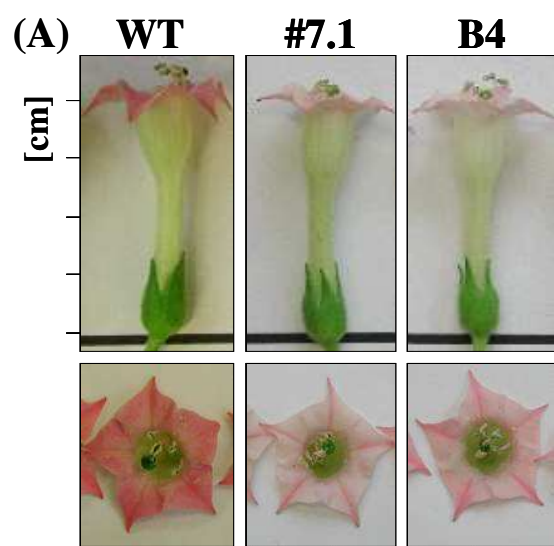

Läsionsphänotyp

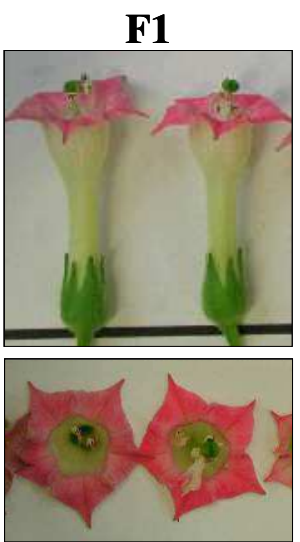

intermediär
D1

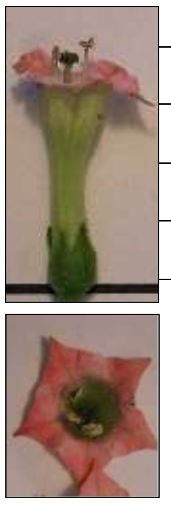

ledrig/
(B)

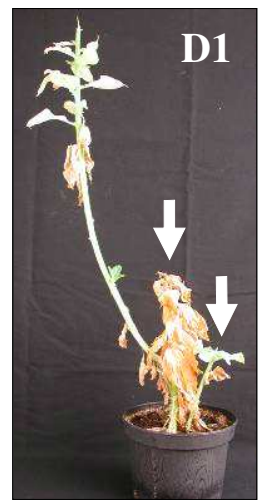

Abbildung 5.22: (A) Vergleich der Blüten-Morphologie der ANK1-RNAi Linien mit dem Wildtyp. Die Skalierung ist in Zentimetern angegeben. WT (Wildtyp); \#7.1, B4, D1, F1: ANK1-RNAi Linien; (B) Seneszente ANK1-RNAi D1 Linie. Die Pfeile deuten auf verschiedene Triebe der Linie. Erklärung der Details siehe Text. intermediär: ,intermediärer Phänotyp'; ledrig/kraus: ,ledrig/krauser Phänotyp'.

Eine Analyse der Blütenmorphologie der ANK1-RNAi Pflanzen zeigt, dass die ,Läsionsphänotypen' geringfügig kleinere Blüten wie der Wildtyp und eine etwas hellere Farbe besitzen (Abbildung 5.22, A). Der Menge des Samen pro Samenkapsel entspricht dem des Wildtyps. Eine Abweichung vom Wildtyp zeigen der ,ledrig/krause Phänotyp’ und der ,intermediäre Phänotyp'. Diese Pflanzen entwickelten etwas größenreduzierte Blüten. und es reiften meist keine Samenkapseln heran, sondern fallen nach einer gewissen Zeit ab. Nur selten konnte eine Samenkapsel mit wenigen Samen geerntet werden. Bildet ein Blütenstand keine Samenkapseln, entwickeln sich nach einiger Zeit weitere Triebe. Dies geschieht so lange, bis die Pflanze vollständig seneszent ist. In Abbildung 5.22 (B) ist als Beispiel die Linie ANK1-RNAi D1 aufgeführt. Zu erkennen ist der Haupttrieb mit noch wenigen seneszenten Blättern und zwei weitere Triebe, die bereits seneszente Blätter zeigen. 


\subsubsection{Reduktion der BZI-1 Expression in Nicotiana tabacum}

Zum besseren Verständnis der Funktion von BZI-1 wurden BZI-1 Überexpressions- und BZI-1 $\Delta \mathrm{N}$ Pflanzen hergestellt, in denen die N-terminale Aktivierungsdomäne von BZI-1 deletiert ist (Heinekamp et al., 2002). Die Überexpression des BZI-1 $\Delta$ N Konstruktes hat bei Dimerisierung mit einem endogenen bZIP-Transkriptionsfaktor einen dominantnegativen Effekt auf die Zielgenexpression. (Strathmann et al., 2001). Diese BZI-1 $\Delta \mathrm{N}$ Pflanzen zeigen ein verändertes Wachstum und eine reduzierte Auxinantwort (Kuhlmann et al., 2003). Transgene Pflanzen in denen die BZI-1 Expression reduziert ist, wurden bisher noch nicht hergestellt. Dies sollte im Rahmen dieser Arbeit mit Hilfe eines ,RNAInterferenz' Ansatzes geschehen. Dieser Ansatz führt zu einer spezifischen Reduktion der BZI-1 Expression. Es wurde, wie schon für die Reduktion von ANK1, die gesamte kodierende Sequenz von BZI-1 in den RNA Interference Vektor pFGC5941 inseriert (zur genaueren Beschreibung siehe Kapitel 5.4.2).

Es wurde versucht, die erhaltenen transgenen BZI-1-RNAi Pflanzen auf Transkriptionsund Tranlationsebene zu charakterisieren. Die Menge an BZI-1 Transkript oszilliert im Tag-Nacht-Rhythmus. Dabei steigt die BZI-1 Transkription innerhalb einer Stunde nach Eintritt der Dunkelphase an (Heinekamp, 2002). Die Proben für die Bestimmung der BZI-1 Transkription in den transgenen Pflanzen wurden aus diesem Grund 1,5 Stunden nach Beginn der Dunkelphase genommen.

Der Wildtyp zeigt in der Dunkelphase ein schwaches Signal, wie es auch vorher schon gezeigt werden konnte (Abbildung 5.23). In allen transgenen Linien, detektiert die BZI-1 (Xhol/PstI) Sonde eine verstärkte BZI-1 Transkription. Möglicherweise detektiert diese Sonde aber auch den nicht vollständig abgebauten Antisense oder Sense Strang von BZI-1 des BZI-1-RNAi Vektors. Eine Bestimmung der BZI-1 Reduktion ist somit mit der BZI-1 (Xhol/PstI) Sonde nicht möglich. Aus diesem Grund wurde eine zweite Sonde hergestellt, die vor allem im 3'UTR bindet (BZI-1 3'UTR). Diese Sonde erkannte im Wildtyp neben der Bande die auch schon von der BZI-1 (XhoI/PstI) Sonde erkannt wurde eine zweite Bande, die etwas unterhalb der Ersten lag. Diese Bande trat nur in den BZI-1-RNAi Linien \#1.3 und \#2.2 auf und nicht in den weiteren analysierten Linien. Es könnte sich um eine post-transkriptional prozessierte BZI-1 RNA handeln, aber genauere Aussagen können zum Zeitpunkt der Abgabe dieser Arbeit noch nicht gemacht werden.

Es wurde versucht, die BZI-1 Transkription mit einer qRT-PCR zu quantifizieren. Dabei wurden mehrere Primerkombinationen ausprobiert, von denen jeweils ein Primer im 3' 
oder 5' UTR bindet. Da nur die kodierende Sequenz von BZI-1, ohne die UTRs in den RNAi Vektor inseriert wurde, sollte in der qRT-PCR nur das endogene BZI-1 Transkript erkannt werden. Leider zeigte auch diese Methode keine einheitlichen Resultate für die BZI-1 Menge, die in verschiedenen Versuchen für die einzelnen Linien unterschiedlich war.

Eine immunologische Analyse der BZI-1 Expression mit einem BZI-1 Antikörper konnte ebenfalls nicht durchgeführt werden, da der vorhandene BZI-1 Antikörper nicht sensitiv genug ist, um die schwache endogene BZI-1 Expression zu detektieren.

Zusammenfassend kann gesagt werden, dass trotz verschiedener Versuche, die Reduktion des endogenen BZI-1 Transkriptes in den transgenen BZI-1-RNAi Linien nicht eindeutig bestimmt werden konnte.

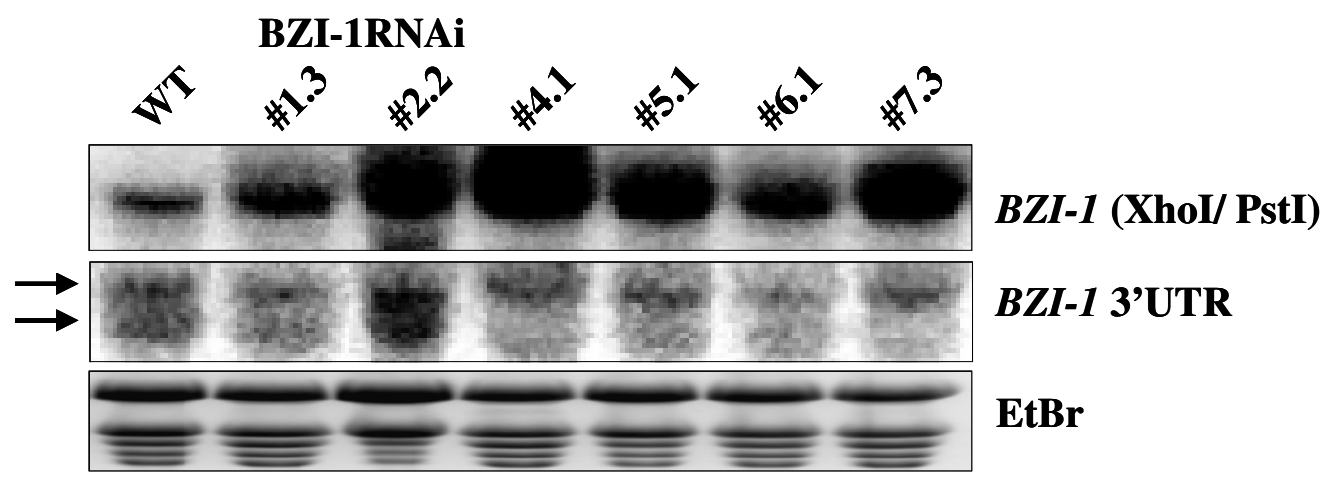

Abbildung 5.23: Northern Blot Nachweis der BZI-1 Transkription in BZI-1-RNAi Pflanzen. Das Blattmaterial wurde 1,5 Stunden nach Beginn der Dunkelphase geerntet. Es wurden jeweils $15 \mu$ g RA und BZI-1 spezifische Sonden eingesetzt. BZI-1 (XhoI/PstI): BZI-1 Sonde, die spezifisch für den kodierenden Bereich ist. BZI-1 3'UTR: BZI-1 Sonde, die vor allem im 3'UTR bindet. Die Pfeile deuten auf die mit der BZI-1 3'UTR Sonde detektierten Banden.

\subsubsection{Vegetatives Wachstum der BZI-1-RNAi Pflanzen}

Die BZI-1-RNAi Linien wurden auf vegetative Unterschiede zum Wildtyp analysiert. Die verschiedenen regenerierten BZI-1-RNAi Linien konnten dabei in zwei Gruppen eingeteilt werden.

Die erste Gruppe ist charakterisiert durch Pflanzen mit lanzettförmigen Blättern, die vermehrt Seitensprosse initiieren. Die Blätter dieser Linien weisen im Vergleich zum Wildtyp ein dunkleres Grün auf (Abbildung 5.24, Linie \#1.3). Diese Gruppe der ,lanzettförmigen Phänotypen’ erreicht dieselbe Wuchshöhe wie der Wildtyp. 
Die zweite Gruppe unterscheidet sich vom Wildtyp durch ledrig/krause, dunkelgrünere Blätter, wie sie schon bei den ANK1-RNAi Pflanzen zu beobachten waren, und weist öfters Blattanomalien und selten auch wenige Läsionen auf. Die Linien dieser Gruppe sind meist kleiner als der Wildtyp. Als stärkster Vertreter der Gruppe ,ledrig/krauser Phänotyp' konnte die Linie BZI-1-RNAi \#6.1 bestimmt werden.

(A)
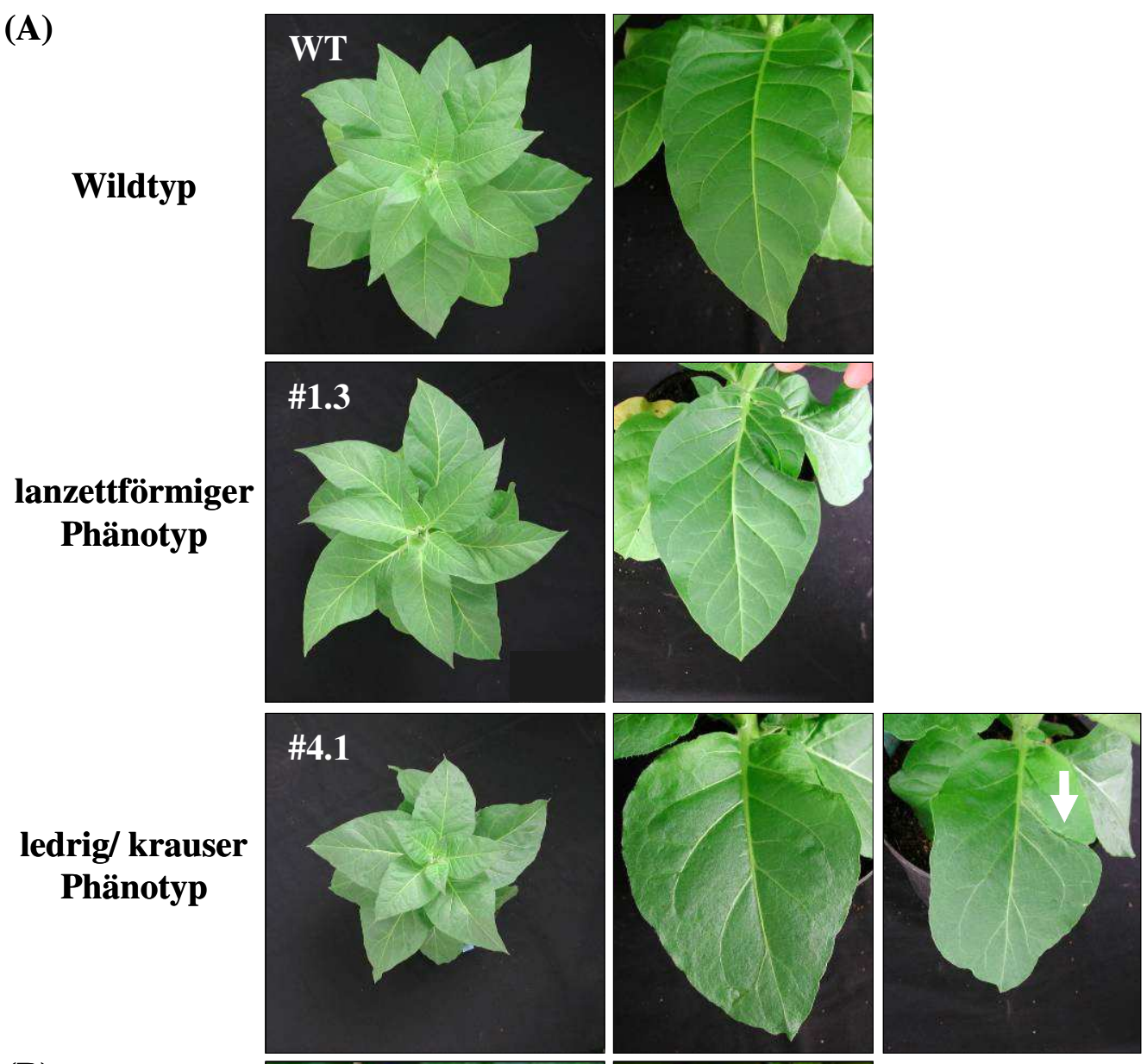

(B)
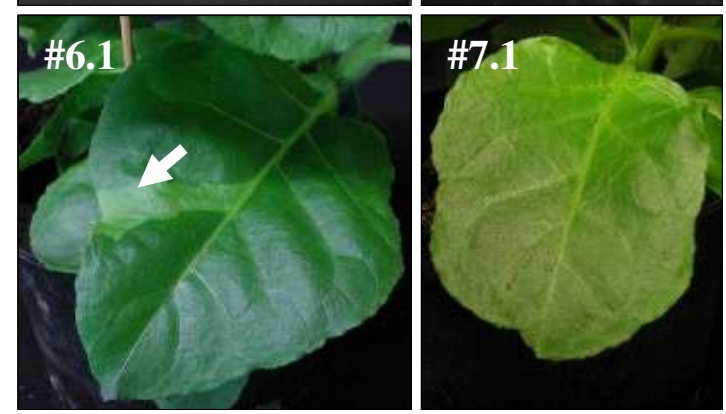

Abbildung 5.24: Phänotypischer Vergleich von typischen Vertretern der verschiedenen BZI-1-RNAi Phänotypen mit dem Wildtyp. (A) Gezeigt sind die Aufsicht der Pflanzen (links) und jeweils typische Blätter jeder Linie (rechts). (B) Zwei weitere Blätter der ledrig/krausen Phänotypen. \#6.1 zeigt eine größere Läsion und \#7.1 zeigt eine sehr starke Ausprägung des Phänotyps. WT: Wildtyp; \#1.3: BZI-1-RNAi \#1.3; \#4.1: BZI-1-RNAi \#4.1; \#6.1: BZI1-RNAi \#6.1; \#7.1: BZI-1-RNAi \#7.1. Die Pfeile deuten auf eine Blattanomalie (A, \#4.1) und auf eine Läsion (B, \#6.1). 
Die Linien BZI-1-RNAi \#2.1 bis \#2.4 zeigten bis auf geteilte Spitzen keinen Unterschied zum Wildtyp (Daten nicht gezeigt). Eine Übersicht über die einzelnen Linien und ihre Gruppenzugehörigkeit ist in Tabelle $5.3 \mathrm{zu}$ sehen.

Tabelle 5.3: Übersicht über die Phänotypen der BZI-1-RNAi Pflanzen. n.d.: Wert nicht bestimmt; -: keine Transkription/Translation festgestellt; +: Bildung von Seitensprossen; =: wie WT; (ledrig/kraus): schwächere Ausprägung des ledrig/krausen Phänotyps; Gruppen: lanzettförmig: lanzettförmiger Phänotyp; ledrig: ledrig/krauser Phänotyp; Größe: Größe der transgenen Linie im Vergleich zum Wildtyp.

\begin{tabular}{|c|l|c|c|c|}
\hline & & \multicolumn{3}{|c|}{ Phänotyp } \\
\cline { 3 - 5 } Gruppe & BZI-1-RNAi & Blätter & Größe & Seitensprosse \\
\hline lanzettförmig & $\# 1.2$ & lanzettförmig & $=$ & + \\
lanzettförmig & $\# 1.3$ & lanzettförmig & $=$ & + \\
\hline lanzettförmig & $\# 3.1$ & lanzettförmig & $1 / 2$ & + \\
lanzettförmig & $\# 3.2$ & lanzettförmig & $1 / 2$ & + \\
\hline lanzettförmig & $\# 5.1$ & lanzettförmig & $=$ & + \\
\hline ledrig & $\# 4.1$ & ledrig/ kraus & $3 / 4$ & - \\
ledrig & $\# 4.2$ & ledrig/ kraus & $3 / 4$ & - \\
\hline ledrig & $\# 6.1$ & ledrig/ kraus & $1 / 2$ bis 3/4 & $(+)$ fällt um \\
ledrig & $\# 6.2$ & ledrig/ kraus & $1 / 2$ bis 3/4 & n.d. \\
\hline ledrig & $\# 7.1$ & (ledrig/ kraus) & $=$ & + \\
ledrig & $\# 7.3$ & (ledrig/ kraus) & $=$ & + \\
\hline- & $\# 2.1$ & geteilte Spitzen & $=$ & - \\
- & $\# 2.2$ & geteilte Spitzen & $=$ & - \\
- & $\# 2.3$ & geteilte Spitzen & $=$ & - \\
- & $\# 2.4$ & geteilte Spitzen & $=$ & - \\
\hline
\end{tabular}

\subsubsection{Blütenmorphologie der BZI-1-RNAi Pflanzen}

Bei Pflanzen, die BZI- $1 \Delta \mathrm{N}$ überexprimieren, konnte eine Veränderung der Blütenmorphologie gezeigt werden (Heinekamp, 2003). In den BZI-1-RNAi Linien soll analysiert werden, ob die Reduktion von BZI-1 ebenfalls einen Effekt auf den Blütenphänotyp hat. In Abbildung 5.25 sind Blüten von einigen BZI-1-RNAi Linien abgebildet. Die Reduktion von BZI-1 in den transgenen Linien zeigt einen deutlichen Effekt auf die Blütenmorphologie, der sich in den einzelnen transgenen Linien auf verschiedene Weise ausprägt. Einzelne Linien zeigen nicht nur einen bestimmten Blütenphänotyp, sondern es können neben normalen Blüten morphologisch stark abweichende Formen auftreten (Tabelle 5.4). 


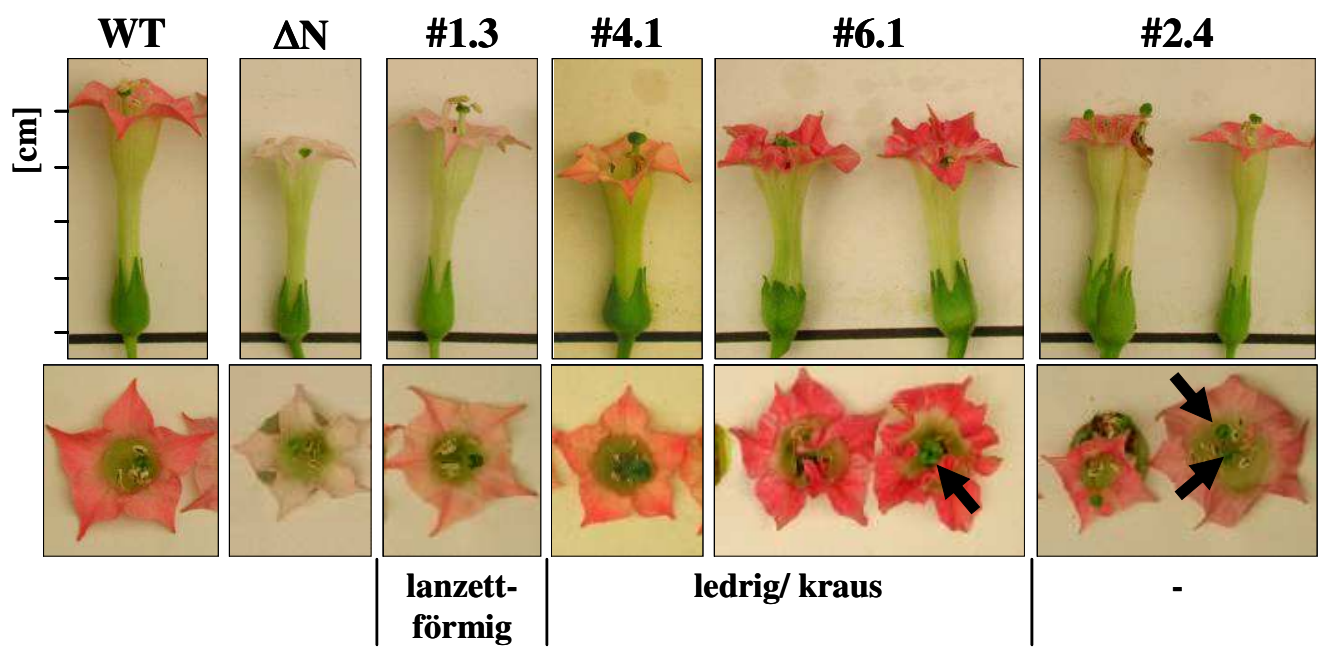

Abbildung 5.25: Vergleich der Blüten-Morphologie der BZI-1 $\Delta$ N und BZI-1-RNAi Linien mit dem Wildtyp. Die Skalierung ist in Zentimetern angegeben. WT: Wildtyp; $\Delta \mathrm{N}$ : BZi- $\Delta \mathrm{N}$; \#1.3, \#2.4, \#4.1, \#6.1: BZI-1-RNAi Linien; lanzettförmig: ,lanzettförmiger Phänotyp': ledrig/kraus: ,ledrig/krauser Phänotyp'; -: keiner Gruppe angehörend; Die Pfeile deuten auf die Narben verschiedener BZI-1-RNAi Linien.

Tabelle 5.4: Übersicht über die verschiedenen phänotypischen Veränderungen in den BZI-1-RNAi Linien. n.b: nicht bestimmt; =: Ausprägung wie Wildtyp.

\begin{tabular}{|c|c|}
\hline $\begin{array}{l}\text { BZI-1- } \\
\text { RNAi } \\
\text { Linien }\end{array}$ & Blütenmorphologie \\
\hline \multirow{2}{*}{$\# 1.2$} & Blüte verfrüht, farblich etwas heller \\
\hline & Blüte verfrüht, farblich etwas heller \\
\hline \multirow[t]{2}{*}{$\# 2.1$} & Blütenorgane bei einigen Blüten nur vierfach vorhanden \\
\hline & $\begin{array}{l}\text { Blütenorgane bei einigen Blüten nur vierfach vorhanden, teilweise mehrere } \\
\text { Blüten miteinander verwachsen }\end{array}$ \\
\hline \multirow{2}{*}{$\begin{array}{l}\# 2.2 \\
\# 2.3\end{array}$} & Blüte verfrüht, Blütenorgane bei einigen Blüten nur vierfach vorhanden \\
\hline & $\begin{array}{l}\text { Blüte verfrüht, Blütenorgane bei einigen Blüten nur vierfach vorhanden, } \\
\text { teilweise mehrere Blüten miteinander verwachsen }\end{array}$ \\
\hline \multirow{2}{*}{ \#3.1 } & n.b. \\
\hline & n.b. \\
\hline \multirow[t]{2}{*}{ \#4.1 } & $\begin{array}{l}\text { Blüte verspätet, Narbe vergrößert oft mehrteilig (drei oder vierteilig), Narbe teils } \\
\text { schwarz, Stamina verkürzt, kaum Samen }\end{array}$ \\
\hline & $\begin{array}{l}\text { Blüte verspätet, Narbe vergrößert oft mehrteilig (drei oder vierteilig), kaum } \\
\text { Samen }\end{array}$ \\
\hline$\# 5.1$ & $=$ \\
\hline \multirow{2}{*}{ \#6.1 } & $\begin{array}{c}\text { Stamina oft verwachen mit den Kronblättern, dann Pollensäcke verändert zu } \\
\text { Kronblätter, Narbe teilweise oder ganz schwarz, Narbe meist viergeteilt } \\
\text { manchmal normal oder dreigeteilt, kaum Samen }\end{array}$ \\
\hline & n.b. \\
\hline \#7.1 & $=$ \\
\hline \#7.3 & $=$ \\
\hline
\end{tabular}


Außer von den Linien BZI-1-RNAi \#7.1 und \#7.3 sind Blüten kleiner als die Wildtyps. Die BZI-1-RNAi Gruppe der , lanzettförmigen Phänotypen' zeigt allerdings kaum Unterschiede zum Wildtyp. In den anderen Linien kommt es oft zum Zusammenwachsen von je zwei Blüten oder es entwickeln sich Blüten die jeweils nur vier Blütenorgane besitzen (Abbildung 5.25, \#2.4 oder \#6.1). Die Gruppe der ,ledrig/krausen Phänotypen' zeigt einheitlich eine vergrößerte Narbe, wobei bei BZI-1-RNAi \#4.1 und \#6.1 die Narben teilweise drei- bis vierteilig sind (Abbildung 5.25 \#6.1, Pfeil). In \#6.1 sind die Narben gelegentlich schwarz verfärbt.

Alle Linien mit kleineren Blüten zeigen auch kleinere Samenkapseln und produzieren weniger Samen. Eine einheitliche Blütenmorphologie konnten nicht festgestellt werden.

\subsubsection{Analyse der Auxin Responsivität der transgenen Pflanzen}

Für die BZI-1 $1 \Delta \mathrm{N}$ Pflanzen konnte bereits eine reduzierte Auxinantwort gezeigt werden. Die endogene Auxin Konzentration ist dabei im Vergleich zum Wildtyp nicht verändert (Heinekamp et al., 2004). BZI-1 scheint somit an der Auxin vermittelten Transkription beteiligt zu sein. Es sollen nun auch die anderen transgenen Pflanzen auf ihre Reaktion auf Auxin getestet werden.

\subsubsection{Hormoninduzierte Organogenese an Tabak Blattscheiben}

Eine Möglichkeit, Pflanzen auf ihre Reaktion auf Auxin und Cytokinin hin zu testen ist die hormoninduzierte Organogenese (Fukazawa et al., 2000). Dabei werden Tabak Blattscheiben auf hormonhaltiges Medium ausgelegt und die dann stattfindende hormoninduzierte Organogenese analysiert. Es werden unterschiedliche Mengen von Auxin und Cytokinin in das Medium gegeben. Eine hohe Menge an Auxin im Verhältnis zu Cytokinin bewirkt im Wildtyp eine Ausbildung von Wurzeln. Wird umgekehrte mehr Cytokinin dem Medium zugesetzt, kommt es zur Ausbildung von Sprossen. Werden beide Hormone in hoher Konzentration im etwa gleichen Verhältnis zugesetzt, bildet sich Kallusgewebe. Ohne Hormone findet keine Organogenese statt.

Die Ergebnisse von Kuhlmann et al., 2002 und Heinekamp et al., 2004 für die BZI-1AN und die BZI-1 Überexpressionspflanzen konnten bestätigt werden. BZI-1 $\Delta \mathrm{N}$ Blattscheiben bilden kaum Wurzeln aus, wenn sie auf Auxin haltiges Wurzelinduktionsmedium ausgelegt werden. BZI-1OEX Blattscheiben zeigen auf diesem Medium keinen Unterschied zum Wildtyp (Abbildung 5.26). Auch die ANK1 Überexpressionspflanzen bilden Wurzeln wie der Wildtyp. Bei den ANK1-RNAi und BZI-1-RNAi Pflanzen muss 
jeweils zwischen den beiden Gruppen unterschieden werden. Die Gruppe der ,Läsionsphänotypen' der ANK1-RNAi Linien (z.B. ANK1-RNAi \#7.1) und die Gruppe der ,lanzettförmigen Phänotypen' der BZI-1-RNAi Linien (z.B. BZI-1-RNAi \#1.3) zeigen keinen Unterschied zum Wildtyp beim Wurzelwachstum. Dagegen ist das Wurzelwachstum der Gruppen der ,ledrig/krausen Phänotypen' beider transgenen RNAi Pflanzen (z.B. ANK1-RNAi D1 und BZI-1-RNAi \#4.1) stark reduziert. Alle transgenen Pflanzen zeigen keinen Unterschied zum Wildtyp auf, wenn sie auf Kallus- oder Sprossinduktionsmedium, oder auf Medium ohne Hormonzusatz ausgelegt werden (Daten nicht gezeigt). ANK1 und BZI-1 scheinen also keine Rolle bei der Cytokinin induzierten Genexpression zu spielen.
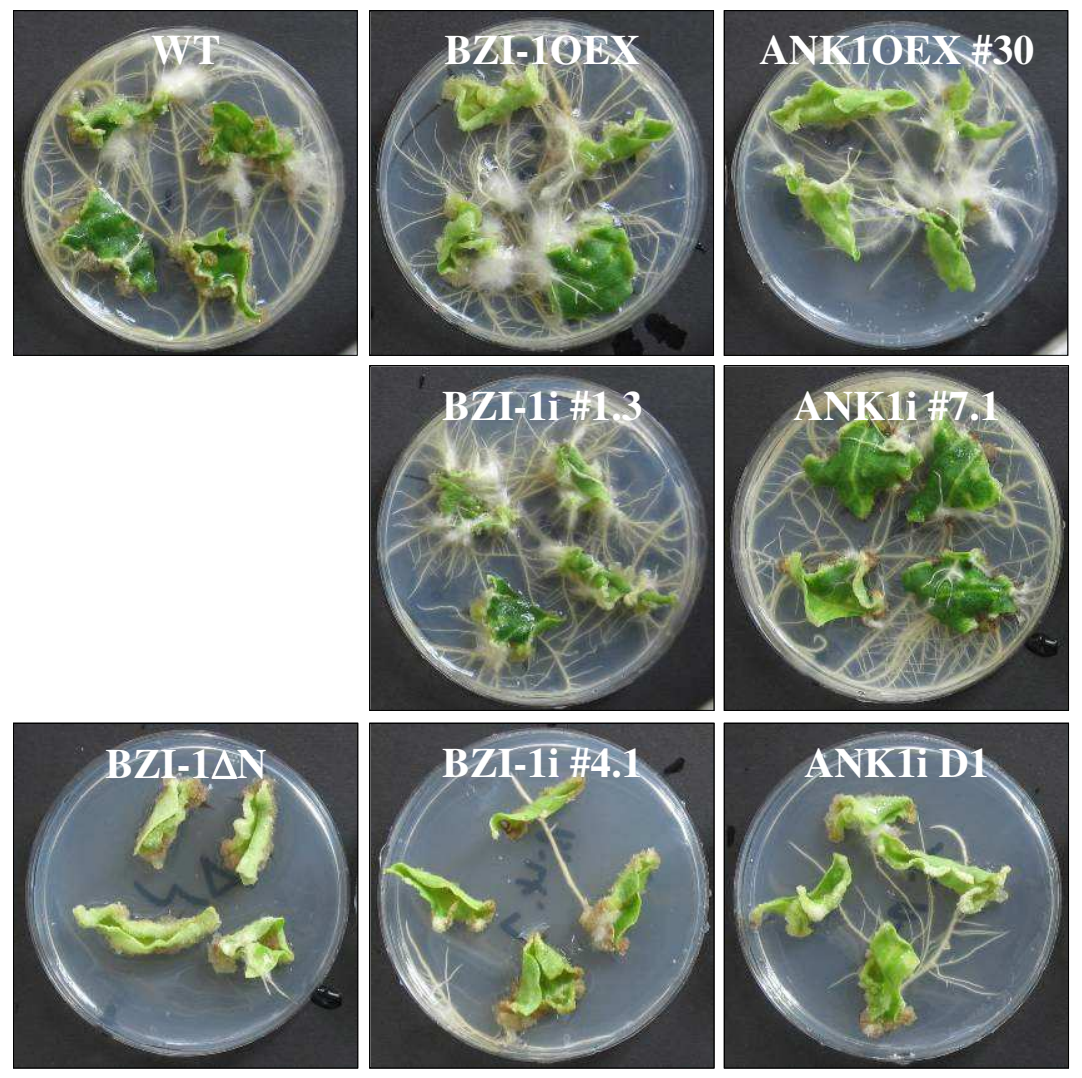

Abbildung 5.26: Hormoninduzierte Organogenese an Tabak Blattscheiben. Aufgeführt ist jeweils ein Beispiel für jede Gruppe aller untersuchten transgenen ANK1 und BZI-1 Überexpressions- und RNAi Pflanzen. Wurzelinduktionsmedium: 2MS + 0,3mg/l NAA und 0,02mg/l 6-BAP (6-Benzylaminopurin). Der Versuch wurde insgesamt zweimal wiederholt.

\subsubsection{Auxin induzierte Epinastie von Tabak Blattstreifen}

Eine exaktere Möglichkeit, die Auxin Suszeptibilität von Pflanzen zu bestimmen, ist der Epinastie Test an Blattstreifen (Keller und Van Volkenburgh, 1997). Im Epinastie Test werden Blattstreifen in einem Auxin haltigen Medium inkubiert. Das Auxin bewirkt eine Zellstreckung, wobei bei exogener Auxinversorgung der Blattstreifen die adaxiale 
Streckung stärker als die abaxile ist. Die daraus resultierende Krümmung kann bestimmt werden und dient als Maß für die Auxin bedingte Reaktion.

Für den Test der Auxin induzierten Epinastie an Tabak Blattstreifen wurden von jeder transgenen Pflanze mindestens 20 Blattstreifen ausgeschnitten und in Auxin haltigem Medium, oder Medium ohne Auxinzusatz inkubiert. Nach 24 Stunden wurden die Blattstreifen ausgemessen, photographiert und die Krümmungen in Winkelbereiche eingeteilt. In Abbildung 5.27 (A) sind die Photos des Wildtyps ohne und nach Auxin Induktion dargestellt. Ohne Auxin kommt es zu keiner starken Krümmung der Blattstreifen und nur wenige Blattstreifen erreichen einen Winkel von mehr als $45^{\circ}$. Werden die Wildtyp Blattstreifen in Auxin haltigem Medium inkubiert, kommt es zu einer Krümmung die hauptsächlich in einem Winkelbereich zwischen $91^{\circ}$ und $180^{\circ}$ liegt. Die gemessenen Winkelbereiche vom Wildtyp und typischen Vertretern der einzelnen transgenen Gruppen sind in den Diagrammen in Abbildung 5.27 (B) dargestellt. BZI-1 $\Delta$ N Blattstreifen weisen nur eine schwache Krümmung auf, wie es Heinekamp et al., 2004 bereits zeigen konnte. Diese Krümmung, die vor allem zwischen $0^{\circ}$ und $90^{\circ}$ liegt, ist etwas stärker als die im Wildtyp ohne Auxin, aber deutlich schwächer als die im Wildtyp mit Auxin. Die ,ledrig/krausen Phänotypen' der ANK1-RNAi und BZI-1-RNAi Pflanzen (z.B. ANK1RNAi D1 und BZI-1-RNAi \#4.1) sind auch deutlich schwächer gekrümmt als der Wildtyp mit Auxin. Der ,Läsionsphänotyp' der ANK-1RNAi Pflanzen (z.B. ANK1-RNAi \#7.1) und der ,lanzettförmige Phänotyp' der BZI-1 RNAi Pflanzen (z.B. BZI-1-RNAi \#1.3) zeigen eine intermediäre Krümmung zwischen dem Wildtyp mit und ohne Auxin. Ihre Krümmungen liegen vor allem im Bereich zwischen $46^{\circ}$ und $180^{\circ}$. Die Blattstreifen der Überexpressionspflanzen von ANK1 und BZI-1 krümmen sich in etwa wie die des Wildtyps.

Zusammenfassend kann gesagt werden, dass ANK1- und BZI-1-RNAi Pflanzen eine reduzierte Auxinantwort zeigen. Dabei scheinen die verschiedenen Gruppen in ihrer Auxinantwort unterschiedlich stark zu reagieren, wie schon bei der hormonregulierten Organogenese an Tabak Blattscheiben zu beobachten war. 
(A)
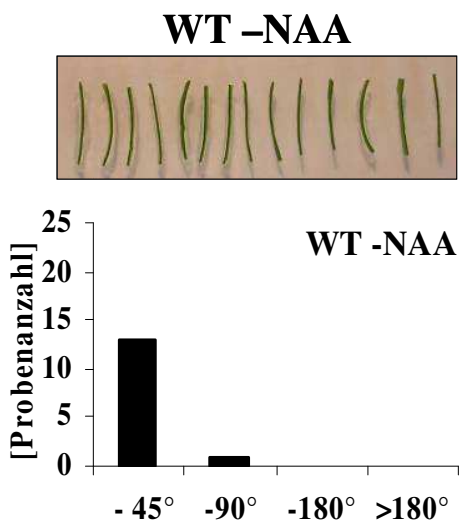
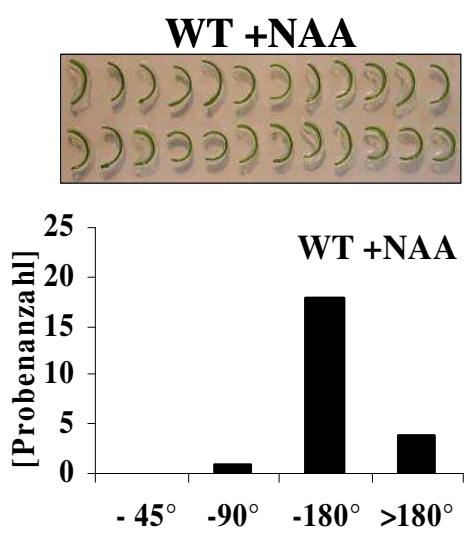

(B) Induktion mit NAA:
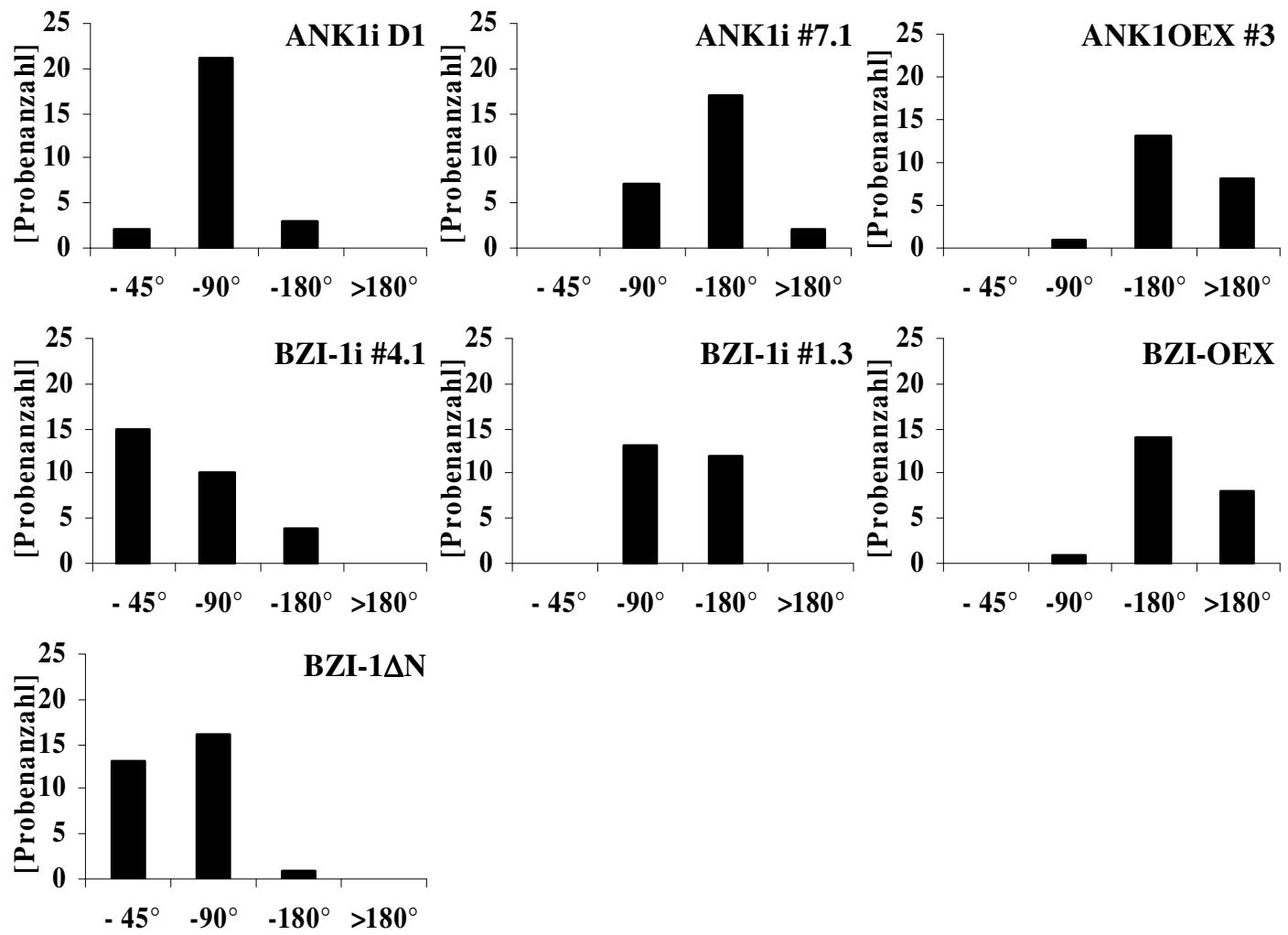

Abbildung 5.27: Darstellung der epinastatischen Krümmung von Tabak Blattstreifen nach Induktion mit $10 \mu M$ Auxin bei verschiedenen transgenen ANK1 und BZI-1 Pflanzen sowie dem Wildtyp. (A) Photos der Wildtyp Blattstreifen Induktion mit Auxin oder dem Lösungsmittel DMSO. Die gemessenen Krümmungen der Wildtyp Blattstreifen sind in Diagrammen dargestellt. (B) Darstellung der Blattkrümmung typischer Linien transgener ANK1 und BZI-1 Pflanzen nach Auxin Induktion in Diagrammen. Die Krümmung ist eingeteilt in Bereiche von $0^{\circ}$ bis $45^{\circ}, 46^{\circ}$ bis $90^{\circ}, 9^{\circ}$ bis $180^{\circ}$ und über $180^{\circ}$. Gemessen wurden jeweils mindestens 20 Blattstreifen. Der Versuch wurde zweimal mit vergleichbaren Ergebnissen wiederholt. ANK1i: ANK1-RNAi Linie; BZI-1i: BZI-1RNAi Linie. 


\subsubsection{Untersuchung der Funktion von ANK1 und BZI-1 in der Pathogenabwehr}

Es konnte für BZI-1 gezeigt werden, dass die Interaktion mit ANK1 nicht nur in der Auxinantwort, sondern auch für den TMV-induzierte Zelltod eine Rolle spielt (Kuhlmann et al., 2003).

\subsubsection{ANK1 und BZI-1 beeinflussen den TMV-induzierten Zelltod und nicht die Replikation des Tabak Mosaik Virus}

Während dieser Arbeit wurde eine Möglichkeit gesucht, verschiedene Ausprägungen des hypersensitiven Zelltods $\mathrm{zu}$ quantifizieren. Die in (Abbildung 5.20) dargestellten ,ledrig/krausen Phänotypen' zeigen im Vergleich zum Wildtyp einen verstärkten Zelltod als Antwort auf eine TMV-Infektion.

Nach der Infektion mit TMV kommt es in Tabak mit einer R-Gen (Resistenz) vermittelten Abwehr zu einem HR-induzierten Zelltod. Der Ionenaustritt aus den absterbenden Zellen kann unter Verwendung der ,Ion Leakage' Methode gemessen werden (Greenberg und Ausubel, 1993; Mittler et al., 1998; Portier et al., 1999). Dabei werden Blattproben in einem Flüssigmedium mit einer geringen Leitfähigkeit inkubiert. Die Veränderung der Leitfähigkeit des Mediums durch austretende Ionen wird bestimmt und dient als Maß für den Zelltod.

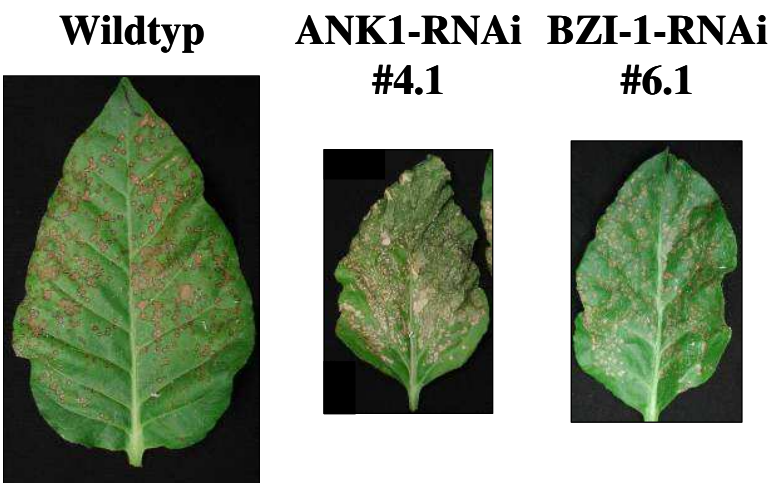

Abbildung 5.28: TMV-induzierte Läsionsbildung im Wildtyp und in jeweils einer ANK1- und BZI-1-
RNAi Linie vom ,ledrig/krauser Phänotyp'. Die Photos wurden vier Tage nach der TMV-
Infektion aufgenommen. Die Aufnahmen sind im gleichen Maßstab abgebildet.

Es wurden jeweils neun Blattscheiben von TMV-infizierten Tabak Linien in $30 \mathrm{ml}$ Wasser für sechs Stunden inkubiert und die Leitfähigkeit vor und nach der Inkubation bestimmt. In Abbildung 5.29 (A und B) sind die gemessenen Leitfähigkeiten vor Infektion (0 Tage) und 
ein bis vier Tage nach der TMV-Infektion dargestellt. Die Leitfähigkeit der transgenen ANK1 und BZI-1 Pflanzen wurde in zwei getrennten Experimenten gemessen. Zu beachten ist die unterschiedliche Skalierung der Diagramme.
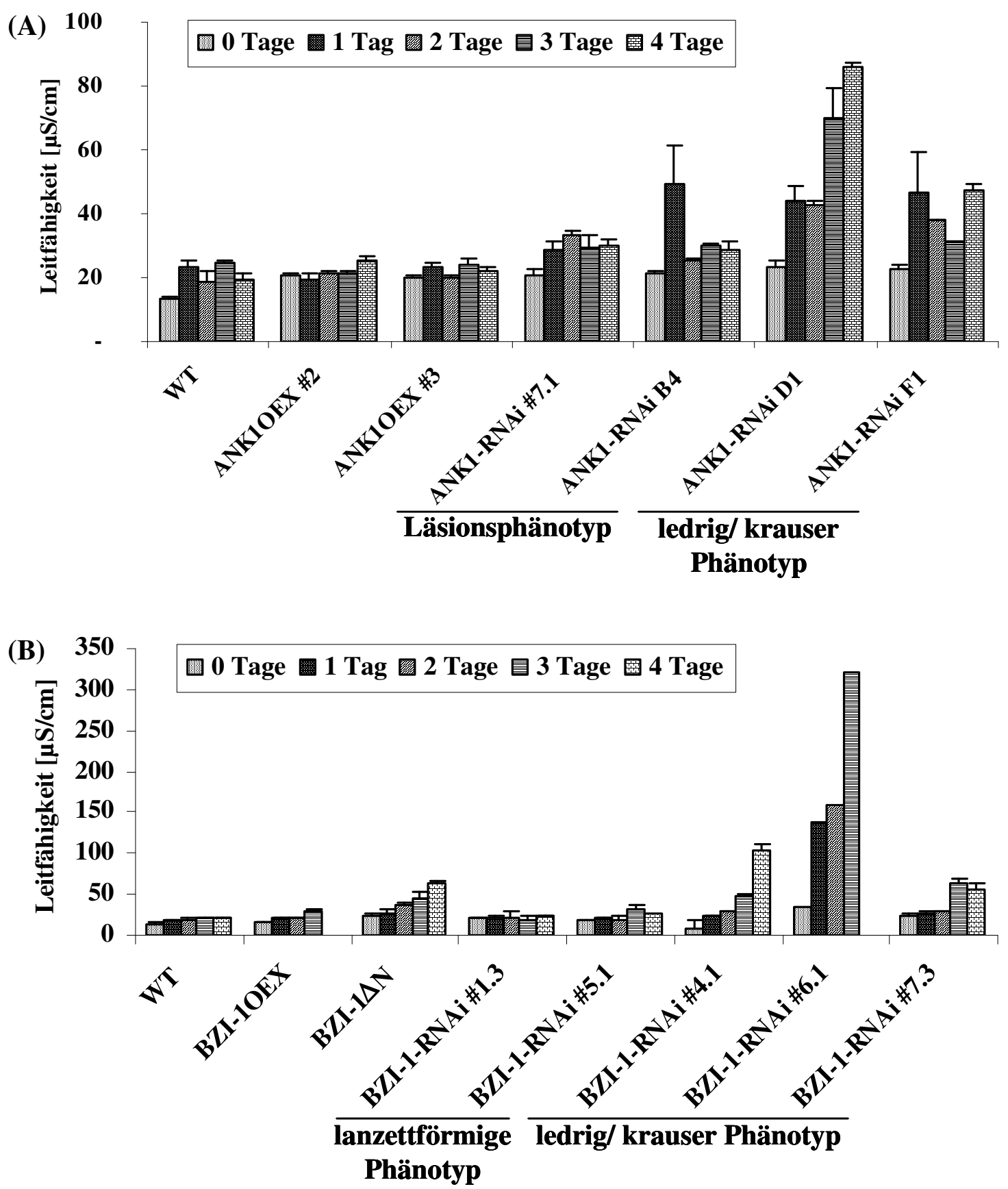

Abbildung 5.29: Quantifizierung des TMV-induzierten Zelltods mittels Leitfähigkeitsmessung. (A) Analyse des Zelltods in ANK1OEX und ANK1-RNAi Linien. (B) Analyse des Zelltods in BZI-1OEX und BZI-1-RNAi Linien, sowie der BZI-1 $\Delta$ N Pflanze. Bei der BZI-1OEX Pflanze fehlt der vier Tage Wert und bei der BZI-1RNAi \#6.1 Linie konnte keine vier Tage Probe mehr genommen werden, da sämtliches Blattmaterial abgestorben war. Gemessen wurde der Ionenaustritt an jedem Tag in einem Zeitraum von sechs Stunden. Der Versuch wurde zweimal wiederholt. 
Die ANK1OEX Pflanzen zeigen im Vergleich zum Wildtyp keinen veränderten Zelltod nach TMV-Infektion (Abbildung 5.29, A). Der TMV-induzierte Zelltod zeigt eine leichte Erhöhung bei den ,Läsionsphänotypen' (ANK1-RNAi \#7.1 und B4), wobei die Werte im Bereich der experimentellen Schwankungen liegen. Die ,ledrig/krausen Phänotypen' der ANK1-RNAi Pflanzen zeigen einen deutlich stärkeren Ionenaustritt und somit TMVinduzierten Zelltod im Vergleich zum Wildtyp.

Die BZI-1OEX Pflanzen zeigen keinen verstärkten, die BZI-1 $\Delta$ N Pflanzen dagegen einen stärkeren Zelltod nach TMV-Infektion, wie es schon in Kuhlmann et al., 2003 beschrieben wurde (Abbildung 5.29, B). Bei den BZI-1RNAi Linien kommt es wieder zur Aufteilung der Reaktion in die beiden beschriebenen Gruppen. Die ,lanzettförmigen Phänotypen’ (BZI-1-RNAi \#1.3 und \#5.1) zeigen einen Zelltod, der mit dem des Wildtyps vergleichbar ist. Die ,ledrig/krausen Phänotypen' der BZI-1RNAi Linien (BZI-1-RNAi \#4.1, \#5.1 und \#7.3) zeigen eine deutliche Verstärkung des Ionenaustritts und somit des Zelltods. Der Zelltod der BZI-1RNAi \#6.1 Linie war in diesem Versuch dermaßen stark, dass an Tag vier keine Probe zur Analyse des Ionenaustritts mehr genommen werden konnte. Das gesamte infizierte Blattmaterial war bereits abgestorben.

Die ,ledrig/krausen Phänotypen' zeigen einen deutlich stärkeren Zelltod nach TMVInfektion. Wenn ANK1 und BZI-1 an der TMV Abwehr beteiligt sind, müsste der verstärkte Zelltod mit einer gesteigerten viralen Vermehrung korrelieren.

Um dies zu analysieren, wurden von TMV-infizierten Pflanzen Blattproben für die Bestimmung der viralen Vermehrung genommen. Es wurde eine Northern Sonde verwendet, die das Transkript des MP30 (,movement protein 30') des TMV erkennt. In Abbildung 5.30 ist die Northern Blot Analyse der TMV-Replikation in verschiedenen transgenen ANK1 und BZI-1 Linien zu sehen.

Alle getesteten ANK1-RNAi und BZI-1-RNAi Linien, unabhängig vom Phänotyp, zeigen eine Expression des MP30 die mit der des Wildtyp zu vergleichen ist. Die Expression des MP30 ist in der BZI-1 $\Delta \mathrm{N}$ Pflanze ist etwas höher, liegt aber genauso wie die Expression des MP30 bei den RNAi Linien im Bereich der biologischen Schwankungen. Die Transkription von PRla, einem typischen Markergen der Pathogenantwort nach TMVInfektion unterscheidet sich kaum von der des Wildtyps. 


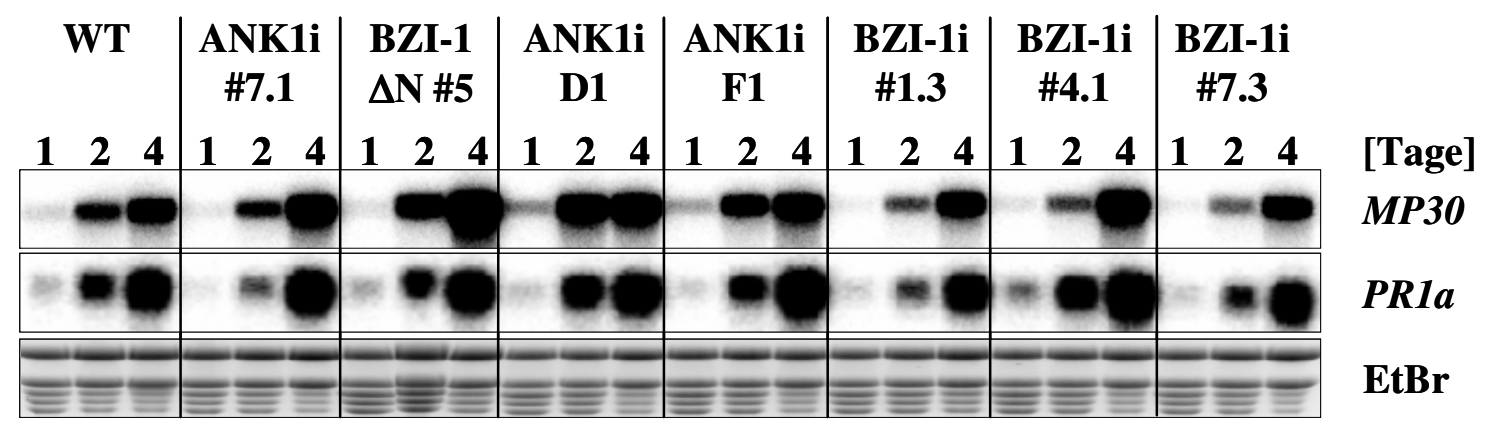

Abbildung 5.30: Analyse der TMV-Replikation in transgenen Pflanzen. Das Blattmaterial wurde zu den angegebenen Zeitpunkten geerntet. MP30: ,movement protein 30'; PR1a: ,pathogenesis related protein 1a'; EtBr: Ethidiumbromid; ANK1i: ANK1-RNAi; BZI-1i: BZI-1-RNAi. Der Versuch wurde zweimal wiederholt.

Zusammenfassend kann man sagen, dass in den transgenen ANK1-RNAi und BZI-1-RNAi Pflanzen ist der TMV-induzierte Zelltod verstärkt, aber die Vermehrung des Virus im normalen Schwankungsbereich liegt.

\subsubsection{Die Expression von ANK1 bleibt nach TMV-Infektion unverändert}

Die BZI-1 Transkription steigt nach Infektion mit Pseudomonas syringae pv. pisi und TMV innerhalb der ersten neun Stunden leicht an (Heinekamp et al., 2002).

Um zu untersuchen, ob die ANK1 Expression nach Infektion mit TMV ebenfalls reguliert ist, wurden Wildtyppflanzen mit TMV infiziert oder als Kontrolle mit Puffer behandelt.

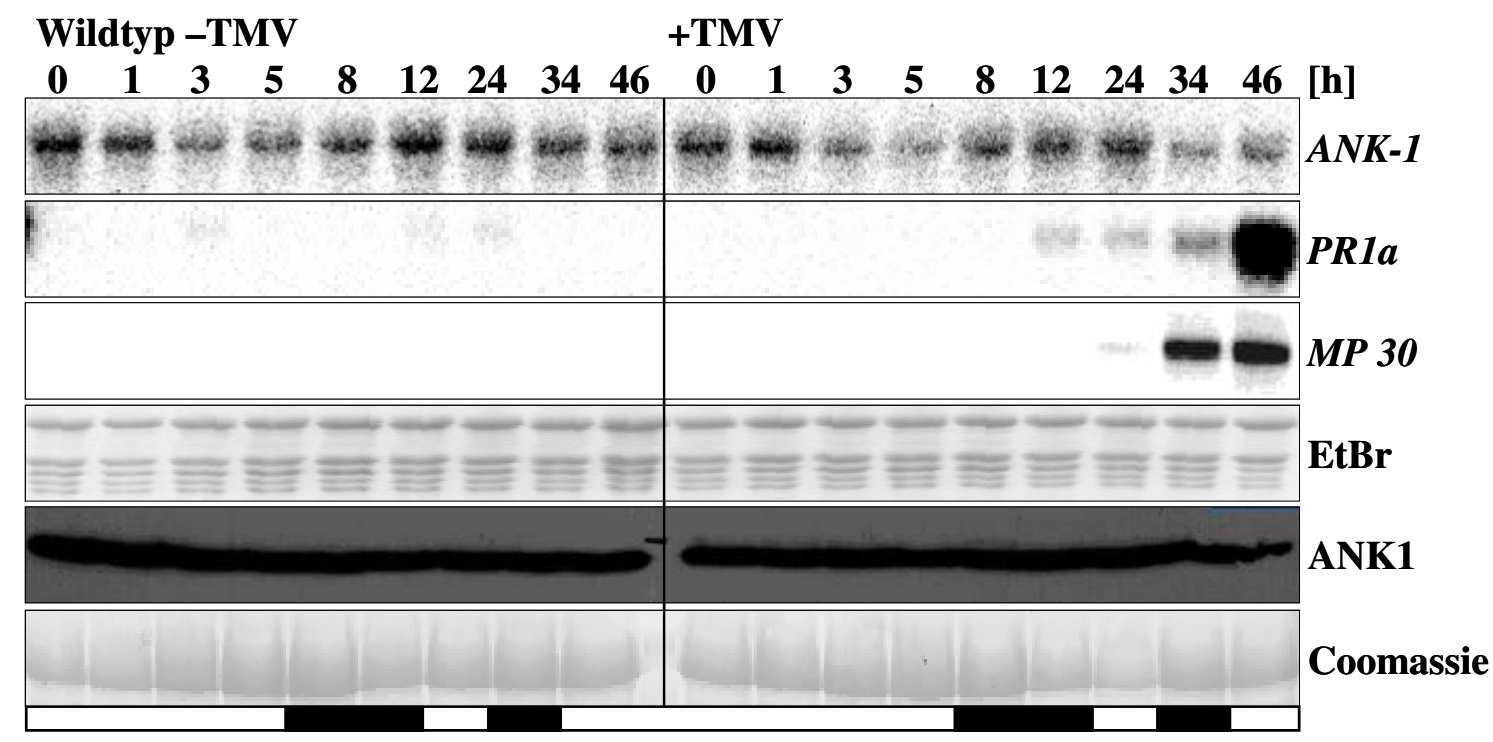

Abbildung 5.31: Analyse der ANK1 Expression nach TMV-Infektion. Wildtyppflanzen wurden mit TMV infiziert oder als Kontrolle mit Puffer behandelt. Die transkriptionelle Analyse wurde mit einer ANK1 spezifischen Northern Sonde durchgeführt und die Expression immunologisch, mit dem $\alpha$ AKR2 Antikörper nachgewiesen. ANK1 läuft auf einer Höhe von etwa 44 kDa. Der Balken im unteren Bildbereich zeigt den Tag-Nacht-Rhythmus an, wobei die dunklen Bereiche die Nacht markieren. Der Versuch wurde dreimal mit vergleichbaren Resultaten wiederholt. 
Die ANK1 Transkription nach TMV Infektion zeigt im Vergleich zur nicht infizierten Kontrolle keinen Unterschied. Die Analyse der PRIa und MP3O Transkription wurde zur Bestätigung der erfolgreichen TMV Infektion durchgeführt. Trotz der Tageszeit bedingten transkriptionellen Schwankungen von ANK1, zeigt die ANK1 Expression keine Veränderung nach Infektion mit TMV.

Die BZI-1 Transkription nimmt nach TMV-Infektion nur leicht ab. Die ANK1 Expression bleibt unverändert. Es ist anzunehmen, dass post-translationale Modifikationen von ANK1 oder BZI-1 eine Rolle in der Pathogenabwehr oder bei der Ausbildung der HR-induzierten Läsionen spielen. 


\section{Diskussion}

\subsection{Das Ankyrin-Repeat Protein ANK1 interagiert spezifisch mit dem bZIP-Transkriptionsfaktor BZI-1 in planta}

Das Ankyrin-Repeat Protein ANK1 interagiert mit dem bZIP-Transkriptionsfaktor BZI-1 in Hefe und in vitro (Kuhlmann et al., 2003). Eine Analyse der in planta Interaktion von ANK1 und BZI-1 wurde bisher noch nicht durchgeführt, aber die aus in Hefe und in vitro Experimenten erhaltenen Ergebnisse können entscheidend von den Ergebnissen in vivo abweichen (Ehlert et al., 2006).

In dieser Arbeit konnte die in planta Interaktion von ANK1 und BZI-1 mit dem P2H und dem BiFC System bestätigt werden. Außerdem interagiert BZI-1 mit den bZIPTranskriptionsfaktoren BZI-2, BZI-3, und BZI-4. ANK1 interagiert dagegen nicht mit diesen Transkriptionsfaktoren. Die in planta Interaktion zwischen ANK1 und BZI-1 ist spezifisch, wobei aber nicht ausgeschlossen werden kann, das ANK1 und BZI-1 mit weiteren, bisher noch nicht bekannten Proteinen interagieren.

Die P2H und BiFC Methoden haben beide gegenüber der Y2H Methode den Vorteil, dass sie in planta Methoden sind. Allerdings kann bei der P2H Methode die Protoplastierung und die darauf folgende Transformation in den Protoplasten Stress hervorrufen, der die Interaktionen oder die Expressionen der Fusionsproteine oder des Reportergens beeinflussen kann. Weiterhin ist die Interaktionsanalyse ein stark artifizielles System, in dem die untersuchten Proteine als Fusionsproteine exprimiert werden. Diese Fusionen können die räumliche Struktur oder auch die Funktion des Proteins beeinflussen. Zudem kann es durch die Überexpression der Proteine zur Detektion von falsch positiven Interaktionen kommen, wenn beide Proteine normalerweise nicht im gleichen Kompartiment der Zelle oder Gewebe der Pflanze vorkommen.

Eine Analyse der Lokalisation der interagierenden Proteine ist deshalb eine wichtige Voraussetzung für die Interpretation der Interaktionsdaten. In Hefe, im $\mathrm{P} 2 \mathrm{H}$ und im BiFC System konnte die Interaktion zwischen ANK1 und BZI-1 gezeigt werden, aber in allen Methoden werden die zu untersuchenden Proteine überexprimiert. Dies kann zu falschen Resultaten führen. Eine Co-Immunopräzipitation mit Kernextrakten währe zur Bestätigung der Interaktion im Zellkern unter natürlichen Bedingungen noch erforderlich. Allerdings sind hierfür Antikörper mit einer hohen Affinität zu ihrem Antigen nötig. 
Die Interaktionsdomänen konnten in BZI-1 durch Deletion und in ANK1 durch Mutation weiter eingegrenzt werden. Dabei wurde in einem Y2H Screen die $\alpha$-helikale BZI-1 Domäne DI (Aminosäuren 73-222), als ANK1 Interaktionsbereich identifiziert (Kuhlmann et al., 2003).

ANK1 beinhaltet Carboxyterminal eine vierfache Wiederholung eines Ankyrin-Repeat Motivs. Für Ankyrin-Repeats konnte gezeigt werden, dass sie Protein-Protein Interaktionen vermitteln (Sedgwick und Smerdon, 1999). Eine Ankyrin-Repeat Domäne besteht aus Paaren antiparallel nebeneinander liegender $\alpha$-Helices, die durch zwei $\beta$ Faltblätter miteinander verbunden sind. Die Struktur wird zusätzlich durch hydrophobe Aminosäuren der antiparallelen $\beta$-Faltblätter verstärkt. Die $\beta$-Faltblätter weisen in einem Winkel von nahezu $90^{\circ}$ von den $\alpha$-Helices weg und bilden so eine L-förmiges Schnittbild. Die Faltung der Ankyrin-Repeats spielt dabei eine wichtige Rolle für ihre Funktion (Mosavi et al., 2002). Eine Interaktion der Ankyrin-Repeat Domänen wird über die exponierten Bereiche der $\beta$-Faltblätter und die Oberfläche der Furche, die die $\alpha$-Helices bilden, vermittelt (Becerra et al., 2004).

Eine Analyse der Ankyrin-Repeats zeigte, dass die Ankyrin-Repeats II und III stark konserviert, aber die Repeats I und IV weniger stark konserviert sind. Aus diesem Grund wurden die Ankyrin-Repeats II und III mutiert. In der ersten Mutation von ANK1 (ANK1mutI) wurde ein Austausch eines Isoleucins mit einem Threonin in einer der $\alpha$ Helices durchgeführt. Threonin ist eine polare Aminosäure, die eher nicht in $\alpha$-Helices vorkommt und die $\alpha$-Helix unterbrechen kann. Diese Mutation führte zu keiner Störung der Interaktion von ANK1 und BZI-1.

In einer weiteren Mutation wurde ein Austausch eines Cysteins mit einem Prolin in der ersten $\alpha$-Helix des Ankyrin-Repeat II vorgenommen (ANK1mutIII). Cysteine bilden oft Disulfidbrückenbindungen, die intern zu einer Stabilisierung von Proteinen beitragen. Prolin hingegen wirkt aufgrund seiner starren Konfiguration negativ auf die Ausbildung von Sekundärstrukturen wie $\alpha$-Helices und $\beta$-Faltblätter und wird deshalb auch als „Helixbrecher“ bezeichnet. Diese ANK1 Mutation führte zur vollständigen Zerstörung der Interaktion zwischen ANK1 und BZI-1.

In der ANK1 Mutation II wurde wiederum ein Threonin eingefügt. In diesem Fall allerdings in ein $\beta$-Faltblatt des dritten Ankyrin-Repeats. Auch dieser Austausch führte zur Aufhebung der Interaktion. Es konnte gezeigt werden, dass Mutationen in den Ankyrin- 
Repeats die Interaktion zwischen ANK1 und BZI-1 zerstören können. Die Ankyrin-Repeat Domäne ist dabei für die Interaktion zwischen ANK1 und BZI-1 entscheidend.

Die mutierten ANK1 Proteine konnten nach der Expression in Tabak Mesophyllprotoplasten weder mit dem ANK1 spezifischen $\alpha$ AKR2 Antikörper noch mit einem $\alpha \mathrm{BD}$ Antikörper, der gegen die GAL4-Bindedomäne gerichtet ist, immunologisch nachgewiesen werden. Für das Ankyrin-Repeat Protein ANK1mutIII konnte eine Expression als HA- und als YFP-Fusion in Nicotiana benthamiana und in Protoplasten gezeigt werden. Folglich haben diese ANK1 Mutationen keinen Einfluss auf die Expression des Proteins. Ein immunologischer Nachweis der mutierten ANK1 Proteine in Tabak Mesophyllprotoplasten ist aber trotz des indirekten Nachweises weiterhin erforderlich.

Wie bereits erwähnt, konnte in Y2H Experimenten die erweiterte $\alpha$-helikale BZI-1 Domäne DI. bestehend aus den Aminosäuren 73- 222, als Interaktionsdomäne für die Interaktion mit ANK1 identifiziert werden. Es wurden deshalb Pflanzen hergestellt, in denen die BZI-1 Aktivierungsdomäne N (BZI-1 $\Delta \mathrm{N})$, oder zusätzlich auch die DI Domäne (BZI-1 $\Delta \mathrm{N} \Delta \mathrm{DI}$ ) deletiert ist (Kuhlmann et al., 2003; Heinekamp et al., 2004). Wildtyp, BZI-1 $\Delta \mathrm{N}$ und BZI-1 $\Delta \mathrm{N} \Delta \mathrm{DI}$ Pflanzen wurden auf die Auxin induzierte Wurzelregeneration in Organogenese Experimenten und auf TMV-induzierte Bildung von Läsionen hin untersucht. Dabei stellte sich heraus, dass die reduzierte Wurzelbildung und die verstärkte Läsionsbildung in den BZI-1 $\Delta \mathrm{N}$ Pflanzen bei den BZI-1 $\Delta \mathrm{N} \Delta \mathrm{DI}$ Pflanzen nicht zu beobachten war. Die BZI-1 $\Delta \mathrm{N} \Delta \mathrm{DI}$ Pflanzen verhielten sich wie der Wildtyp. Die Domäne DI, die für die Interaktion von BZI-1 mit ANK1 entscheidend ist, ist demnach wichtig für die BZI-1 Funktion in der Auxinantwort und dem TMV induzierten hypersensitiven Zelltod.

Es konnte eine spezifische Interaktion zwischen ANK1 und BZI-1 gezeigt werden, die auf der Seite von ANK1 durch die Ankyrin-Repeat Domäne und auf der Seite von BZI-1 durch die erweiterte Domäne DI vermittelt wird und diese Interaktion spielt möglicherweise eine Rolle in der Pflanze. 


\subsection{Auxin induziert die Akkumulation von ANK1 im Zellkern}

Für das Fusionsprotein YFP-BZI-1 konnte eine Lokalisation im Zellkern festgestellt werden, aber für das Fusionsprotein YFP-ANK1 traf dies nicht zu. YFP-ANK1 ist cytosolisch lokalisiert. Diese Ergebnisse konnten immunologisch mit cytosolischen und Zellkern-Extrakten bestätigt werden (Daten nicht gezeigt). Auch für das ANK1 homologe Arabidopsis Protein AtPhos43 konnte eine cytosolische Lokalisation gezeigt werden (Peck et al., 2001). Für AKR2 aus Arabidopsis thaliana hingegen wurde eine Lokalisation im Zellkern und im Cytosol beschrieben (Yan et al., 2003).

Eine Untersuchung der Interaktion von ANK1 und BZI-1 im BiFC System ergab eine Lokalisation beider Proteine im Zellkern und im Cytosol. Dieser Versuch zeigte zwar sehr schön die Interaktion von ANK1 und BZI-1 in einem weiteren in vivo Ansatz, allerdings könnte es sich bei einer der beiden Lokalisationen um ein Artefakt handeln.

Bei der BiFC Methode kommt es zur Rekonstitution der YFP-Fragmente durch die Interaktion der an sie fusionierten Proteine, allerdings ist dieser Prozess wahrscheinlich nicht reversibel (Bhat et al., 2006). Zusätzlich werden die Fusionsproteine überexprimiert, was zu einer sehr hohen Menge an Protein und damit zu einer Misslokalisation führen kann.

Aber wenn die Interaktion zwischen ANK1 und BZI-1 tatsächlich eine biologische Relevanz hat, welche Funktion könnte sie dann in der Zelle haben? Es gibt verschiedene Möglichkeiten für die Funktion diese Interaktion. ANK1 könnte z.B. ein cytosolischer Retentionsfaktor von BZI-1 sein. Ein Beispiel für ein Ankyrin-Repeat Protein als

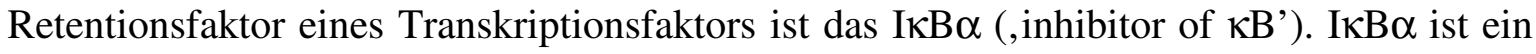
cytosolisch lokalisiertes Ankyrin-Repeat Protein, dass mit dem Transkriptionsfaktor NFkB (, nuclear factor $\kappa \mathrm{B}^{\prime}$ ) interagiert. Durch diese Interaktion maskiert $\mathrm{I} \kappa \mathrm{B} \alpha$ die NLS des NFkB, das dadurch eine Retention im Cytosol erfährt. Nach einem Stimulus wie z.B. Wachstumsfaktoren oder bakterielle Antigene kommt es zur Phosphorylierung des IкB $\alpha$ Proteins und die Interaktion zwischen beiden wird aufgelöst. NFkB gelangt in den Zellkern (Jacobs et al., 1998; Huxford et al., 1998).

Durch eine gleichzeitige Expression von YFP-BZI-1 und ANK1 konnte gezeigt werden, dass ANK1 keinen Einfluss auf die Lokalisation von BZI-1 hat. ANK1 wäre demnach kein 
Retentionsfaktor von BZI-1. Es kann aber mit diesem Ergebnis nicht ausgeschlossen werden, dass die Retention erst nach einem Stimulus stattfindet.

Wurden hingegen YFP-ANK1 und BZI-1 co-exprimiert, konnte eine Lokalisation von YFP-ANK1 neben dem Cytosol auch im Zellkern festgestellt werden. YFP-ANK1 ist also in Abhängigkeit von BZI-1 im Kern lokalisiert. Diese Lokalisation ist abhängig von der Interaktion mit BZI-1, denn wird anstelle von YFP-ANK1 YFP-ANK1mutIII, für das ein Verlust der Interaktionsfähigkeit mit BZI-1 gezeigt werden konnte, mit BZI-1 coexprimiert, kommt es zu keiner Verschiebung der ANK1 Lokalisation in den Kern. Eine Aussage über den Ort der Interaktion von YFP-ANK1 mit BZI-1 kann nicht getroffen werden. Die Interaktion könnte sowohl im Cytosol als auch im Zellkern stattfinden. Im Cytosol könnte neu translatiertes BZI-1 mit YFP-ANK1 interagieren und es mit in den Zellkern nehmen. Würde die Interaktion hingegen im Zellkern stattfinden, könnte dadurch die putative NES von ANK1 maskiert und der ANK1 Export inhibiert werden.

Für das Ankyrin-Repeat Protein NPR1 (,nonexpressor of PR genes'), aus Arabidopsis thaliana wurde eine induzierte Translokation in den Zellkern beschrieben (Mou et al., 2003). Dabei multimerisiert NPR1 cytosolisch durch intermolekulare Disulfidbrückenbindungen. Nach Pathogen-Infektion kommt es durch eine Änderung des Redox-Status der Zelle $\mathrm{zu}$ einer Reduzierung der intermolekularen Disulfidbrückenbindungen, und NPR1 monomerisiert. Die monomere Form von NPR1 akkumuliert im Zellkern und interagiert mit den TGA Faktoren, die zu der Gruppe der bZIP-Transkriptionsfaktoren gehören (Zhang et al., 1999; Fobert und Despres, 2005). Für ANK1 homologe Proteine konnte bisher, außer für ANK1, noch keine Interaktion mit einem bZIP-Transkriptionsfaktor identifiziert werden.

Für ANK1 konnte in Protoplasten 'Two-Hybird' und in BiFC Analysen eine Homodimerisierung gezeigt werden. Im Vergleich mit der Negativkontrolle und der Interaktion von ANK1 mit BZI-1 ist diese Interaktion im P2H System aber relativ schwach. Auch konnte mit Hilfe dieser Methoden keine Multimerisierung wie im Fall von NPR1 gezeigt werden. Für die Bestätigung dieser These sind weitere Experimente notwendig. Die Analyse mit Hilfe von nativen Gelen würde über eine mögliche Multimerisierung Aufschluss geben. Eine andere Möglichkeit ist die Auftrennung der Proteine und Proteinkomplexe mittels einer Gelfiltration mit anschießender immunologischer Detektion. In diesem System ließe sich auch der Einfluss von 
verschiedenen Stimuli auf die Homodimerisierung oder Multimerisierung von ANK1 untersuchen.

Die biologische Rolle der ANK1 Dimerisierung könnte in der Retention des AnkyrinRepeat Proteins im Cytosol liegen. Die Interaktion zwischen ANK1 und BZI-1 würde bei einer gleichzeitigen Überexpression von BZI-1 mit ANK1 dann mit einer Homodimerisierung des ANK1 Proteins konkurrieren. YFP-ANK1 würde in diesem Fall auch im Kern lokalisiert sein. In der Pflanze würde ein Stimulus eine Monomerisierung von ANK1 induzieren und die monomere Form würde im Zellkern akkumulieren. Bisher konnte allerdings noch keine bekannte NLS in ANK1 identifiziert werden. Lee et al., 2006 konnte aber eine neue NLS beschreiben, die aus der primären Sequenz alleine nicht ersichtlich ist. Auch ANK1 könnte demnach eine noch nicht näher charakterisierte NLS besitzen.

Eine weitere Möglichkeit ist die Diffusion des ANK1 Proteins in den Zellkern. Das Protein von ANK1 besitzt eine Größe von 37,2 $\mathrm{kDa}$. Damit liegt es unterhalb der Kernporenausschlussgröße von ca. $60 \mathrm{kDa}$ und kann sich demnach in der Zelle ungehindert verteilen (Haasen et al., 1999). Eine Retention durch die Bildung von Multimeren wäre in diesem Fall genauso denkbar, wie die Funktion einer NES die ANK1 aktiv aus dem Zellkern transportiert. Ein bestimmter Stimulus könnte dann zu Modifikation von ANK1 oder BZI-1 führen, woraufhin ANK1 und BZI-1 interagieren. Weiter Experimente müssen zeigen, ob ANK1 Multimere bildet und welcher Mechanismus für die ANK1 Akkumulation im Zellkern verantwortlich ist.

Nach der Inhibierung des Kernexports mit LMB einem Inhibitor des Exportin 1, konnte ANK1 im Zellkern lokalisiert werden. Das Exportin 1 erkennt eine NES mit der Aminosäureabfolge LXXXLXXLXL (Görlich et al., 1999). Neben dieser Sequenz konnten aber weitere NES Sequenzen gefunden werden, die geringfügig von der Konsensussequenz, wie sie Görlich et al., 1999 postuliert hat, abweichen (Haasen et al., 1999; Feng et al., 1999).

ANK1 beinhaltet eine C-terminal lokalisierte Sequenz mit der Aminosäureabfolge $\underline{L} N N Q Q E V \underline{L} \underline{L}$. Die Position und der Abstand zwischen den einzelnen Leucinen stimmt mit der Konsensussequenz überein. Nur an Position des zweiten Leucins ist statt des Leucins die polare Aminosäure Glutamin zu finden. Nach Feng et al., 1999 können die Leucine an Position eins und zwei mit Alanin, einer weiteren hydrophoben Aminosäure, ausgetauscht werden. Insgesamt passt die mögliche NES von ANK1 nicht ganz zu den 
bisher gefundenen funktionalen NES Sequenzen. Aber die Akkumulation von ANK1 im Zellkern durch die Inhibierung mit LMB, deutet auf die Funktionalität der NES in ANK1 hin.

Weitere Analysen dieser Sequenz sind notwendig. Eine Veränderung der putativen NES durch eine Punktmutation müsste die Interaktion mit dem Exportin 1 zerstören und ANK1 dann im Zellkern akkumulieren. Gelangt ANK1 nur durch einen bestimmten Stimulus in den Zellkern, würde ANK1 ohne diesen Stimulus trotz Mutation der NES nicht im Zellkern lokalisierbar sein. Da ANK1 aber nach LMB Behandlung im Zellkern akkumuliert, scheint ein Stimulus; der zur Translokation von ANK1 in den Zellkern führt, vorhanden zu sein.

Aber welcher Stimulus könnte für die Monomerisierung und/oder Translokation von ANK1 in den Zellkern verantwortlich sein? Es kommen mehrere Möglichkeiten in Frage, die sich aus den bisherigen Untersuchungen an BZI-1 oder ANK1 homologen Proteinen ergeben. So konnte für BZI-1 $\Delta \mathrm{N}$ Pflanzen eine verringerte Auxinantwort gezeigt werden (Heinekamp et al., 2004).

Die Expression von ANK1 und BZI-1 zeigt keinen Einfluss von Auxin auf ihre transkriptionelle Regulation. Nach Induktion mit Auxin kommt es zu einer Translokation von ANK1 in den Kern. Dies konnte allerdings nur in ca. $20 \%$ der Zellen nach einer Induktion mit $50 \mu \mathrm{M}$ NAA beobachtet werden. Wurde hingegen mit $10 \mu \mathrm{M}$ NAA induziert, wurden etwa 10\% Kernlokalisationen des YFP-ANK1 Proteins detektiert. Die Kernlokalisation von ANK1 nach der Induktion mit Auxin könnte aber auch nicht nur durch Auxin selbst bedingt sein, sondern auch durch die hohe Konzentration des Auxins, die die Produktion von ROS (,reacitve oxigen species') induzieren und dadurch Stress hervorrufen kann. So konnte Joo et al., 2005 zeigen, dass die Auxin induzierte Bildung von ROS wichtig für den Gravitropismus ist. Schopfer et al., 2002 konnte eine Auxin induzierte Generierung von Superoxid- und Hydroxylradikalen zeigen, die das Längenwachstum von Maiskeimlingen beeinflussen. Unter nicht physiologischen Bedingungen, wie die in den Induktionen verwendeten hohen Auxinkonzentrationen, könnte es deshalb zu einer starken Synthese von ROS gekommen sein.

Eine weitere Möglichkeit für einen Stimulus das für die Monomerisierung und/oder Translokation von ANK1 in den Zellkern verantwortlich sein könnte ist der bakteriellen Elicitor flg22. Peck et al., 2001 konnte für das Protein AtPhos43 aus Arabidopsis thaliana eine Phosphorylierung innerhalb weniger Minuten nach Stimulus mit flg22 zeigen. In 
Experimenten mit ANK1 konnte aber noch keine Veränderung der Lokalisation von ANK1 in Abhängigkeit von flg22 beobachtet werden. Dieser Punkt konnte allerdings am Ende dieser Arbeit noch nicht abschließend geklärt werden.

\subsection{Die bZIP-Transkriptionsfaktoren BZI-1 und BZI-2 kooperieren mit ANK1 bei der Kontrolle der pflanzlichen Auxinantwort}

Um einen möglichen Einfluss von ANK1 auf die transkriptionelle Zielgenaktivierung zu analysieren, wurden Aktivierungsstudien in Tabak Mesophyllprotoplasten durchgeführt. Die Co-Expressionen von BZI-1 und ANK1 mit BZI-1, BZI-3 oder BZI-4 führte zu keiner deutlich veränderten transkriptionellen Reportergenaktivierung nach Auxininduktion. Wurden BZI-1 und BZI-2 co-exprimiert, gab es nach Induktion mit Auxin auch keinen Unterschied zum uninduzierten Zustand. Nur die Co-Expression von BZI-1, BZI-2 und ANK1 führte nach Auxininduktion zu einer Verstärkung der Transkription des Reportergens. Diese Verstärkung ist mit einer Verdopplung zwar relativ schwach, aber reproduzierbar.

Auch die Auxin induzierte Akkumulation von ANK1 im Zellkern ist relativ schwach, was die relativ schwache Aktivierung des Reportergens in der Aktivierungsstudie erklären könnte. Durch die schwache Akkumulation von ANK1 im Zellkern kann ANK1 dort nur bedingt seine Funktion ausüben. In weiteren Versuchen müsste nach Bedingungen gesucht werden, unter denen ANK1 stärker im Zellkern akkumuliert, um ein besseres Verständnis der Funktion von ANK1 im Zellkern zu bekommen.

Da gezeigt werden konnte, dass nach Auxininduktion ANK1 im Zellkern akkumuliert, wurde ANK1 an eine NLS fusioniert. Durch die Co-Expression von BZI-1, BZI-2 und NLS-ANK1 in Tabak Mesophyllprotoplasten konnte eine deutlich erhöhte Reportergenexpression erzielt werden, als durch die entsprechende Co-Expression mit einem unfusionierten ANK1. Damit führte die artifizielle Misslokalisation von ANK1 im Zellkern zu einer deutlich stärkeren Transkription des Reportergens.

Welche Funktionen könnte ANK1 im Zellkern haben? Es kommen mehrere Möglichkeiten in Frage. ANK1 könnte ein Co-Aktivator der BZI-1/BZI-2 vermittelten Genaktivierung sein. ANK1, BZI-1 und BZI-2 würden dann als trimerer Komplex an den Promotor eines 
Zielgens binden. Eine Chromation Immunopäzipitation könnte zeigen, ob ANK1 als Interaktionspartner von BZI-1 tatsächlich mit dem Promotor assoziiert ist.

Möglicherweise liegt die Funktion von ANK1 aber auch direkt im Bereich der Promotorbindung von BZI-1. So konnte für NPR1 gezeigt werden, dass es die TGA1 DNA-Bindung stimuliert (Despres et al., 2003). Oder aber ANK1 ist an der Regulation der Heterodimerisierung von BZI-1 mit BZI-2 beteiligt.

Newman und Keatin (2003) konnten zeigen, dass die Interaktionen von bZIPTranskriptionsfaktoren nur zwischen bestimmten Partnern stattfindet. Dabei ist die Spezifität der Interaktion von der Länge bestimmter Aminosäuren wie Asparagin sowie weiterer geladener Aminosäuren im Leucin-Zipper und der Anwesenheit von interhelikalen elektrostatischen Interaktionen abhängig (Deppmann et al., 2004). Eine spezifische Interaktion ist somit wichtig für die Funktion von bZIP-Transkriptionsfaktoren in der transkriptionellen Regulation. Dadurch könnten DNA-Bindespezifität, Aktivierungseigenschaften und die Zellphysiologie beeinflusst werden (Naar et al., 2002). Für die Tabak bZIP-Transkriptionsfaktoren BZI-1, BZI-2, BZI-3, und BZI-4 in Hefe (Strathmann et al., 2001), die CPRF-Transkriptionsfaktoren aus Petersilie (Rügner et al., 2001) und die Arabidopsis thaliana Transkriptionsfaktor der Gruppe C und S (Jakoby et $a l .$, 2002) konnte gezeigt werden, dass die Heterodimerisierung zwischen den Mitgliedern der Gruppen vor der Heterodimerisierung in den Gruppen selbst bevorzugt wird.

Es konnten bereits mehrere Proteine identifiziert werden, die mit bZIPTranskriptionsfaktoren interagieren. So konnte Rügner et al., 2001 das CPRF1 (,common plant regulatory factor') interagierende Protein CIP (,CPRF1 interacting protein') in Petersilie identifizieren, das im Zellkern lokalisiert ist. Die Funktion von CIP ist unbekannt.

Eine Interaktion zwischen dem Gruppe C bZIP-Transkriptionsfaktor bZIP10 aus Arabidopsis thaliana und LSD1 (,leasion simulating disease resistance 1') konnte erst kürzlich gefunden werden. LSD1 ist cytosolisch lokalisiert und dient als Retentionsfaktor für bZIP10 im uninduzierten Zustand (Kaminaka et al., 2006).

Um den Einfluss der Lokalisation von ANK1 näher zu untersuchen, wurden transgene Pflanzen hergestellt, in denen ANK1 durch Dexamethason Induktion in den Zellkern gelangt. Die Transgenexpression in diesen Pflanzen war, genauso wie die der ANK1OEX Pflanzen, nur sehr schwach, so dass von einer weiteren Analyse der Dexamethason 
induzierbaren Pflanzen abgesehen wurde. Um über die Funktion von ANK1 im Zellkern genauere Aussagen machen zu können, sind noch weitere Versuche notwendig.

Die eingesetzte Methode der transienten Expression von Fusionsproteinen in Tabak Mesophyllprotoplasten ermöglicht eine schnelle Analyse von Proteininteraktionen und Aktiverungseigenschaften in planta. Dabei ist aber zu beachten, dass die Protoplastierung und die darauf folgende Transformation in den Protoplasten physiologischen Stress hervorrufen können, der die Interaktionen der Fusionsproteine oder die Expression des Reportergens stark beeinflussen kann. Weiterhin ist die Interaktionsanalyse ein stark artifizielles System, in dem die untersuchten Proteine als Fusionsproteine überexprimiert werden. Diese Fusionen können die räumliche Struktur oder auch die Funktion des Proteins beeinflussen. Die Expression der Effektoren wurde in allen verwendeten Plasmiden durch den konstitutiven 35S-Promotor kontrolliert. Dieser Promotor ist allerdings bedingt Auxin induzierbar. Ein Einfluss des Auxins in den Induktionsexperimenten kann daher nicht ausgeschlossen werden. Unterschiedliche Expressionen konnten aber generell durch den Einsatz des konstitutiv exprimierten NANMarkers abgeglichen werden. Die Analysen wurden mit dem künstlichen GAL4-UASGUS-Konstrukt durchgeführt, da für ANK1 und BZI-1 bisher noch kein Zielgen bestätigt werden konnte.

Es wurden bereits weitere Analysen zur Funktion von ANK1 und BZI-1 im Auxin Signaltransduktionsweg durchgeführt. Für BZI-1 $\Delta$ N Pflanzen konnten viele der für eine reduzierte Auxinantwort beschriebenen phänotypischen Veränderungen beobachtet werden (Heinekamp et al., 2003). Bei den ANK1 und BZI-1 Überexpressionspflanzen war allerdings kein Effekt zu erkennen, was aber an der schwachen Überexpression liegen kann. Übereinstimmend zu den Ergebnissen in den BZI-1 $\Delta \mathrm{N}$ Pflanzen konnte auch für BZI-1-RNAi, BZI-2-RNAi und ANK1-RNAi Pflanzen eine reduzierte Auxinantwort beobachtet werden. Dabei muss allerdings jeweils zwischen den beiden Gruppen der BZI1- und ANK1-RNAi Pflanzen unterschieden werden.

Die Expression von ANK1 konnte in keiner der transgenen ANK1-RNAi Pflanzen nachgewiesen werden, da die Menge an ANK1 Protein unterhalb der Nachweisgrenzen der verwendeten Methoden liegt. Deshalb war eine Korrelation der verschiedenen Phänotypen mit der Expression auch nicht möglich. Die phänotypischen Veränderungen in den ANK1RNAi Pflanzen könnten aber an der starken Reduktion von ANK1 liegen. 
Bei den BZI-1-RNAi Pflanzen war in Northern-Blot Experimenten nur eine unspezifische Bande zu erkennen. Diese Bande kann auf den Mechanismus der RNA-Interferenz zurückgeführt werden, der zur Degradation des endogenen BZI-1 und des eingeführten BZI-1-RNAi Konstruktes führt. Auch mit einer BZI-1 3'UTR Sonde und in qRT-PCR Analysen ließ sich die Reduktion von BZI-1 nicht bestimmen. Die Expression des BZI-1 Proteins ist sehr gering, so dass sich auch mit dem vorhandenen BZI-1 Antikörper keine Aussage über die Reduktion von BZI-1 machen lässt.

Da die BZI-1 Expression in den transgenen Pflanzen nicht analysiert werden konnte, konnte sie auch nicht mit den auftretenden Phänotypen korreliert werden. Aus diesem Grund wurden Phänotypklassen gebildet und mehrere unabhängige Transformanden jeder Klasse für die Experimente ausgewählt.

Für die Reduktion von BZI-1 in diesen Pflanzen spricht der ,ledrig/krause Phänotyp', den sowohl die BZI-1- als auch die ANK-1-RNAi Pflanzen zeigen, sowie die abgeschwächte Auxinantwort und die veränderte Läsionsbildung nach TMV-Infektion in beiden Gruppen.

Die Blütengröße der BZI-1 $\Delta \mathrm{N}$ und der BZI-2-RNAi Pflanzen ist im Vergleich zum Wildtyp reduziert. Bei den ,Läsionsphänotypen' der ANK1-RNAi Pflanzen und bei den ,lanzettförmigen Phänotypen' der BZI-1-RNAi Pflanzen sind die Blüten insgesamt etwas kleiner und teilweise sind die Petalen farblich etwas heller, wie es auch bei den BZI-1 $\Delta \mathrm{N}$ Pflanzen schon beobachtet werden konnte. Die ,ledrig/krausen Phänotypen' der ANK1RNAi Pflanzen sind kleiner als der Wildtyp und haben weniger Samen. Bei den ,ledrig/krausen Phänotypen' der BZI-1-RNAi Pflanzen gibt es eine Vielzahl an Blütenphänotypen neben nahezu normal aussehenden Blüten. Sie sind meist kleiner, haben teilweise vier Sepalen anstelle von fünf, manche haben anstelle eines zweiteiligen ein dreioder vierteiliges Stigma. Insgesamt konnte kein einheitlicher Phänotyp festgestellt werden. Wichtig ist, dass eine Veränderung der Blütenmorphologie sowohl bei ANK1-, BZI-1-, BZI-2-RNAi als auch bei BZI-1 $\Delta \mathrm{N}$ Pflanzen zu erkennen ist, was auf eine gemeinsame Funktion bezüglich der Blütenmorphologie hindeutet. Auch Auxin spielt in nahezu allen Bereichen der Blütenentwicklung eine wichtige Rolle (zur Übersicht: Nemhauser et al., 1998). In der Auxin resistenten Mutante axrl aus Arabidopsis thaliana konnten z.B. kleinere Blütenorgane beobachtet werden (Lincoln et al., 1990).

Um die Beteiligung von ANK1, BZI-1 und BZI-2 an der Auxinantwort zu untersuchen, wurden die transgenen ANK1- und BZI-1-RNAi Pflanzen in Experimenten zur Auxin induzierten Organogenese an Blattscheiben und epinastischen Krümmung von Blattstreifen 
näher untersucht. Für BZI-1 $\Delta \mathrm{N}$ Pflanzen konnte bereits eine reduzierte Auxin induzierte Wurzelbildung und Krümmung der Blattstreifen gezeigt werden, wobei die endogene Auxinkonzentration nicht verändert ist (Heinekamp et al., 2004).

Die Auxin induzierte Wurzelbildung und Krümmung der Blattstreifen derANK1- und BZI1-RNAi Pflanzen ist deutlich reduziert. Auch bei den BZI-2-RNAi Linien konnte eine verminderte Auxin induzierte Wurzelbildung und Krümmung der Blattstreifen festgestellt werden (Zwafink, 2005). Bei BZI-1OEX, ANK1OEX und BZI-2OEX Pflanzen zeigte sich hingegen kein Unterschied (Strathmann, 2003).

Zusammenfassend lässt sich sagen, dass die ANK1- und BZI-1-RNAi Pflanzen Phänotypen zeigen, die auf eine reduzierte Auxinantwort hindeuten. Die Reduktion von ANK1, BZI-1 und BZI-2 wirkt sich dabei negativ auf die Auxin induzierten Organogenese an Blattscheiben und epinastischen Krümmung von Blattstreifen aus. Diese Ergebnisse sprechen für eine Kooperation von ANK1, BZI-1 und BZI-2 im Rahmen der Auxinantwort.

Heinekamp et al., 2003 konnte eine leicht reduzierte GH3 Expression nach Auxininduktion in BZI-1 $1 \Delta \mathrm{N}$ Pflanzen feststellen. GH3 ist spezifisch durch aktive Auxine induzierbar (Roux et al., 1997). Die cis-Elemente des Soja (Glycine max) GH3-Promotors ähneln denen des GH3-Promotors aus Nicotiana tabacum und wurden ausführlich untersucht (Liu et al., 1994; Ulmasov et al., 1995; Heinekamp et al., 2004). Die Auxin induzierte Transkription von GH3 wird durch verschiedene ARF-Transkriptionsfaktoren vermittelt, die an AuxREs im Promotorbereich des $G H 3$ binden. Im NtGH3-Promotor befinden sich neben den AuxRE-Elementen zwei ACGT-Motive. Pflanzliche bZIPTranskriptionsfaktoren binden bevorzugt an ACGT-Elemente, wobei die das Element umgebenden Basen die Spezifität der Bindung regulieren (Hagen und Guilfoyle, 2002; Jakoby et al., 2002). Dabei wird die Bindung an eine A-Box (TACGTA), C-Box (GACGTC) und G-Box (CACGTG) bevorzugt (Izawa et al., 1993), aber auch eine Bindung der bZIP-Transkriptionsfaktoren an nicht palindromische Boxen ist bekannt (Chot et al., 2000; Fukazawa et al., 2000, Kuhlmann et al., 2003).

Eine veränderte GH3 Expression konnte in den ANK1- und BZI-1-RNAi Pflanzen allerdings nicht festgestellt werden (Daten nicht gezeigt). Verschiedene Faktoren können dafür verantwortlich sein. So ist die Auxin induzierte Genexpression unter anderem abhängig vom Alter der Pflanze oder von der Stellung des Blattes an der das Blattmaterial geerntet wird. Weitere Experimente sind zur genauen Analyse der GH3 Expression in den 
transgenen ANK1- und BZI-1-RNAi Pflanzen notwendig. Es sollen in diesem Kontext auch weitere Auxin induzierbare Gene in den transgenen Pflanzen auf eine geänderte Expression hin untersucht werden.

Eine mögliche Erklärung für die unterschiedlichen phänotypischen Ausprägungen ist, dass die Reduktion von ANK1 und BZI-1 stark in den Auxin Signaltransduktionsweg eingreift. Möglicherweise gleicht die Pflanze das Fehlen von ANK1 oder BZI-1 aus, indem andere Proteine die Funktionen teilweise übernehmen. Für Nicotiana tabacum könnten das z.B. die zwei ANK1/TIP1 homologen Proteine TIP2 und TIP3 sein (Fridborg et al., 2002), die nicht unbedingt durch den RNAi Effekt betroffen sein müssen.

\subsection{ANK1 und BZI-1 wirken als negative Regulatoren des TMV-induzierten Hypersensitiven Zelltods}

Neben der Analyse der transgenen ANK1 und BZI-1 Pflanzen in Bezug auf ihre Auxin Antwort, wurden diese Pflanzen auch in Bezug auf ihre Pathogen-Antwort nach TMVInfektion untersucht. Die Transkription von ANK1 und BZI-1 ändert sich nur unwesentlich nach Infektion mit TMV und auch die ANK1 Proteinmenge bleibt konstant. Für die ANK1 orthologen Proteine TIP und GBP konnte nach Infektion mit TMV (Wirdnam et al., 2004) und PVX (,potato virus X') (Fridborg et al., 2002), oder nach Induktion mit Ethylen oder BTH (SA-Analogon) (Wirdnam et al., 2004) ebenfalls keine veränderte Expression festgestellt werden.

Die transgenen ANK1 und BZI-1 Pflanzen wurden nach TMV-Infektion auf die Ausbildung der HR-induzierten Läsionen untersucht. Die ANK1 und BZI-1 Überexpressionspflanzen zeigen dabei keinen Unterschied zum Wildtyp. Die RNAi Pflanzen unterscheiden sich jedoch stark. Auch hier muss, wie schon vorher bei der Auxin induzierten Organogenese an Blattscheiben zwischen den einzelnen Gruppen der RNAi Pflanzen unterschieden werden. Die ,Läsionsphänotypen' der ANK1-RNAi Pflanzen und die ,lanzettförmigen Phänotypen' der BZI-1-RNAi Pflanzen zeigen einen normalen TMVinduzierten Zelltod wie der Wildtyp. Auch die TMV-Vermehrung, gemessen durch Northernblot Analysen der Expression des viralen ,movement protein' Gens MP30, und die PRla Expression entsprach generell der des Wildtyps. Die ,ledrig/krausen Phänotypen’ beider RNAi Pflanzen zeigen jedoch einen verstärkten Zelltod nach TMV-Infektion. Die PRla Expression ist in diesen Pflanzen nicht verändert, und auch die TMV-Vermehrung 
ist bei beiden Gruppen und bei der BZI-1 $1 \Delta \mathrm{N}$ Pflanze im Bereich der natürlichen Schwankung. Die deutliche Zunahme des hypersensitiven Zelltods ist damit wahrscheinlich nicht mit einer verstärkten Virus-Replikation oder einer veränderten pflanzlichen Pathogenantwort korreliert. Es handelt sich also möglicherweise um eine spezifische Veränderung im Prozess des hypersensitiven Zelltods. Vielleicht ist auch die Eingrenzung der Zelltods in diesen Pflanzen betroffen. Für die $l s d l$ Mutante aus Arabidopsis thaliana konnte ein ähnlicher Phänotyp beschrieben werden (Dietrich et al., 1997). LSD1 ist ein Zink-Finger Protein, das cytosolisch lokalisiert ist und als negativer Regulator des induzierten Zelltods fungiert. Durch die Interaktion von LSD1 mit bZIP10 kommt es zur Retention von bZIP10 im Cytosol. Diese Retention bewirkt die Inhibierung des positiv regulierenden Effekts von bZIP10 auf die Hypersensitiver Reaktion (Kaminaka et al., 2006). Für die Interaktion von ANK1 und BZI-1 kann eine Funktion, wie sie für die Interaktion von LSD1 mit bZIP10 postuliert wird, ausgeschlossen werden. Für BZI-1 und ANK1 kann aber eine Funktion in der negativen Regulation des HR induzierten Zelltods angenommen werden.

Es konnte für die RNAi Pflanzen gezeigt werden, dass sich die Reduktion von ANK1 oder BZI-1 in diesen Pflanzen auf die TMV induzierte Läsionsbildung und auf die Auxin induzierte Organogenese an Blattscheiben in ähnlicher Weise auswirkt. In transgenen Pflanzen, in denen ein BZI-1 Derivat exprimiert wird, dass noch zusätzlich zu der Aktivierungsdomäne $\mathrm{N}$ die ANK1 interagierende Domäne DI deletiert hat (BZI-1 $\Delta \mathrm{N} \Delta \mathrm{DI})$, ist die Wurzelregeneration und die Läsionsbildung zu vergleichen mit der des Wildtyps. Ein funktioneller Zusammenhang zwischen ANK1 und BZI-1 kann somit angenommen werde.

Doch wie könnten die reduzierte Auxinantwort und die HR induzierte Läsionsbildung zusammenhängen?

Lange Zeit wurde davon ausgegangen, dass nur die nach Pathogen Stimulus induzierten Hormone SA (,salicylic acid'), JA (,jasmonic acid') und Ethylen eine Rolle in der Pflanzenerkrankung und Pathogenabwehr spielen. In den letzten Jahren haben sich die Hinweise darauf verdichtet, dass auch weitere Hormone eine Rolle in der Pathogenantwort spielen können (zur Übersicht: Robert-Seilaniantz et al., 2007).

Navarro et al., 2006 konnte zeigen, dass die RNA der F-box Auxin Rezeptoren TIR1, AFB2 und AFB3 nach Induktion mit flg22 durch miRNA vermittelte Degradation abgebaut wird. Entsprechend konnte Navarro et al., 2006 auch zeigen, dass die 
Verstärkung der Auxinantwort Pflanzen anfälliger und die Reduzierung der Auxinantwort sie resistenter gegenüber dem virulenten Pathogen PstDC3000 (Pseudomonas syringae pv. tomato DC3000) macht. Übereinstimmend konnte O'Donnell et al., 2003 zeigen, dass die Auxinkonzentration nach Infektion mit den virulenten Pathogenen PstDC3000 und Xanthomonas campestris pv. campestris ansteigt. Diese Arbeiten zeigen deutlich, dass die Reduzierung der Auxinantwort ein Teil der induzierten pflanzlichen Immunantwort ist. Arbeiten mit TMV scheinen dies zum Teil zu bestätigen. In Arabidopsis thaliana konnte eine Interaktion zwischen der TMV-Replikase und PAP1/IAA26, IAA18 und IAA27 gezeigt werden (Padmanabhan et al., 2004; Padmanabhan et al., 2006). Pflanzen, die mit einem TMV-Virus mit einer mutierten, nicht mehr mit PAP1/IAA26 interagierenden Replikase infiziert wurden, zeigen abgeschwächte Krankheitssymptome bei gleich bleibender Virusreplikation. Dies deutet auf einen Mechanismus des Virus hin, der aktiv versucht, die pflanzliche Auxinantwort zu beeinflussen, um seine Virulenz zu steigern.

Doch wie sind die pflanzlichen Hormone in die Pathogenabwehr integriert? Oft kann unter Stressbedingungen eine Einstellung des pflanzlichen Wachstums beobachtet werden. Einerseits ist es nicht verwunderlich, wenn transgene Pflanzen, die in einem Signaltransduktionsweg beeinflusst sind der in die Entwicklung involviert ist, auch eine veränderte Pathogenantwort zeigen. Andererseits könnten natürlich Pathogene das komplizierte Netzwerk der Hormon Signaltransduktionswege einfach manipulieren, um einen Nutzen aus dieser Veränderung zu ziehen. Die Interaktion zwischen der TMVReplikase und PAP1 deutet auf jeden Fall auf die aktive Beeinflussung des Auxin Signaltransduktionsweges hin.

In diesem Kontext könnten auch ANK1 und BZI-1 eine Rolle spielen. Für das ANK1 orthologe Protein HBP1 konnte eine Interaktion mit der Replikase des Alfalfa Mosaik Virus (Van der Hejden, 2002) und für TIP1 eine Interaktion mit TGB12K einer Replikase des PVX (Fridborg et al., 2003) gezeigt werden.

Weitere Experimente müssen klären, ob eine direkte Protein-Protein-Interaktion zwischen ANK1 und der viralen Replikase oder ein indirekter Einfluss durch die veränderte Auxin Responsivität der Pflanze den beobachteten Zelltod-Phänotyp verursachen. 


\subsection{Modell der BZI-1/ANK1 vermittelten Zielgenexpression}

Aus den in dieser Arbeit erhaltenen Ergebnissen, lässt sich folgendes Modell aufstellen (Abbildung 6.1). Im uninduzierten Zustand ist ANK1 als Homodimer oder Multimer im Cytosol und BZI-1 im Zellkern lokalisiert (A). Durch eine Induktion kommt es möglicherweise zur Monomerisierung von ANK1 (a). Mehrere Möglichkeiten können dann zu einer Translokation von ANK1 in den Kern führen: ANK1 interagiert schon im Cytosol mit neu translatiertem BZI-1 und bei der Translokation von BZI-1 gelangt ANK1 ebenfalls in den Zellkern (b), ANK1 gelangt aktiv durch die Auxininduktion in den Zellkern(c), oder aber ANK1 diffundiert passiv in den Zellkern (d).

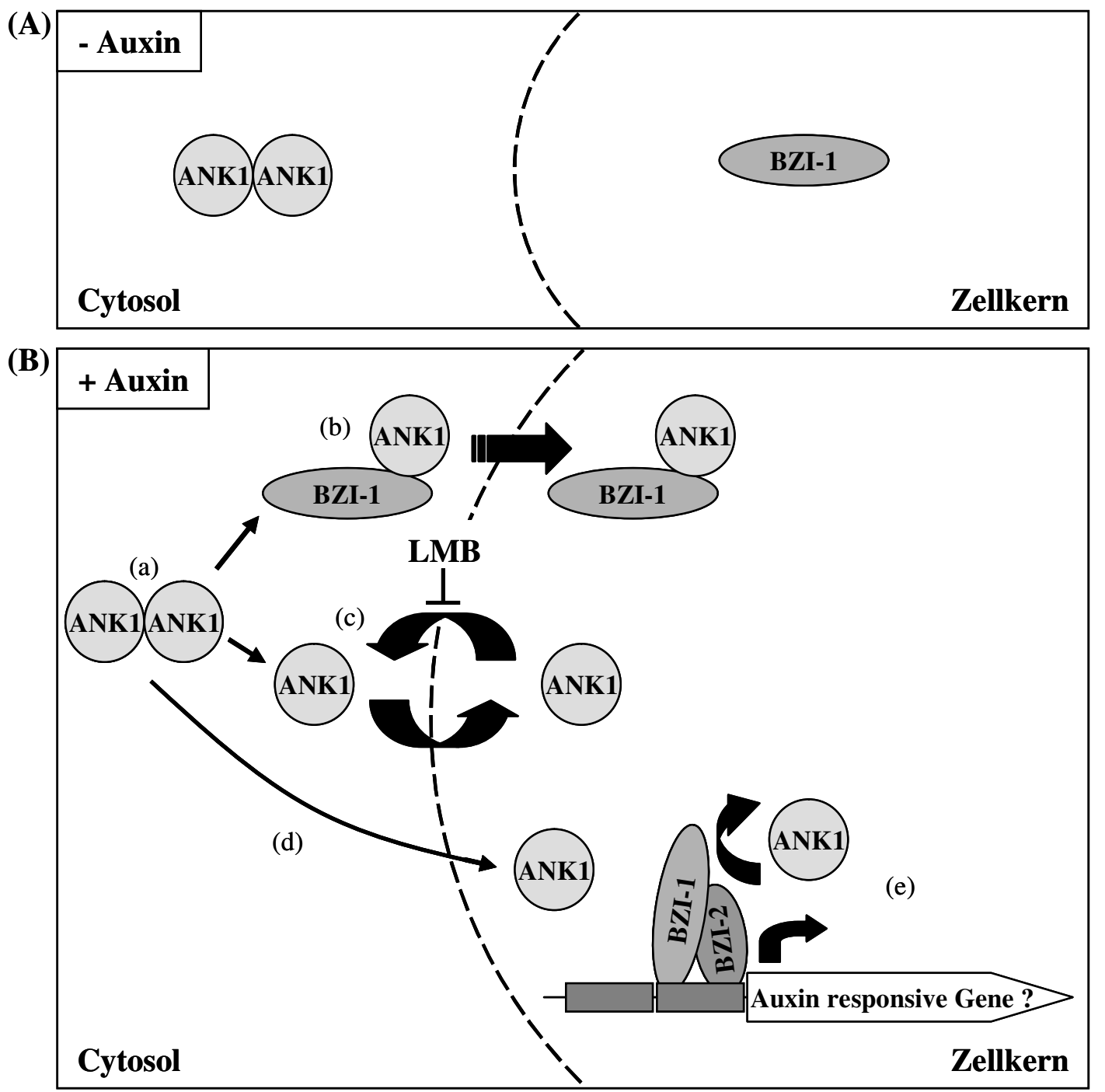

Abbildung 6.1: Modell der Funktion der ANK1 - BZI-1 Interaktion. Erklärung siehe Text. ANK1: Ankyrin-Repeat Protein 1; BZI-1 und BZI-2: bZIP-Transkriptionsfaktoren 1 und 2; LMB: Leptomycin B. 
Wie genau ANK1 in den Kern gelangt, konnte im Rahmen dieser Arbeit nicht ermittelt werden. Möglicherweise interagiert ANK1 mit BZI-1 erst im Zellkern und reguliert dort die Expression von Zielgenen (e). Dabei könnte ANK1 entweder die Heterodimerisierung von BZI-1 mit BZI-2 regulieren, als Co-Aktivator in der Auxin vermittelten Genaktivierung fungieren, oder auch die Bindung von BZI-1 Homodimeren oder BZI1/BZI-2 Heterodimere an die DNA beeinflussen. 


\section{$7 \quad$ Literaturverzeichnis}

Abel S., Oeller P.W. and Theologis A. (1994) Early auxin-induced genes encode short-lived nuclear proteins. Proc. Natl. Acad. Sci. 91(1), 326-30.

Altschul S.F., Madden T.L., Schäffer A.A., Zhang J., Zhang Z., Miller W. and Lipman D.J. (1997) Gapped BLAST and PSI-BLAST: a new generation of protein database search programs. Nucleic Acids Res. 25, 3389-3402.

Ausube F.M, Brent R., Kingston R.E., Moore D.D., Seidmann J.G., Smith J.A. and Struhl K. (1993) Current Protocols in Molecular Biology. John Wiley and Sons, Inc.

Becerra C., Jahrmann T., Puigdomenech P. and Vicient C.M. (2004) Ankyrin repeat-containing proteins in Arabidopsis: characterization of a novel and abundant group of genes coding ankyrin-transmembrane proteins. Gene. 340(1), 111-21.

Bernard P. (1993) Epidemiology and dermatology. Ann. Dermatol Venereol. 120(12), 867-869.

Bhat R.A., Lahaye T. and Panstruga R. (2006) The visible touch: in planta visualization of protein-protein interactions by fluorophore-based methods. Plant Methods. 2, 12.

Bork P. (1993) Hundreds of ankyrin-like repeats in functionally diverse proteins: mobile modules that cross phyla horizontally? Proteins: Structure, Function and Genetics 17, 363-374.

Botha C.E. and Cross R.H. (2000) Towards reconciliation of structure with function in plasmodesmata-who is the gatekeeper? Micron. 31(6), 713-21.

Böttner S. (2003) Funktionelle Charakterisierung des Ankyrin-Domänen-Proteins ANK1 aus Nicotiana tabacum. Diplomarbeit.

Brent R. and Ptashne M. (1985) A eukaryotic transcriptional activator bearing the DNA specificity of a prokaryotic repressor. Cell 43, 729-736.

Bullock W.O., Fernandez J.M. and Short J.M. (1987) XL-1-Blue: A high effiviency plasmid transforming recA-Escherichia coli strain with beta galactosidase selection. Biotechniques 5, 376-379.

Casal J.J. (2002) Environmental cues affecting development. Curr Opin Plant Biol. 5(1), 37-42.

Chapman S., Kavanagh T. and Baulcombe D. (1992) Potato virus X as a vector for gene expression in plants. Plant J. 2(4), 549-57.

Choi H., Hong J., Ha J., Kang J. and Kim S.Y. (2000) ABFs, a family of ABA-responsive element binding factors. J Biol Chem. 275(3), 1723-30.

Chomczynski P. (1993): A reagent for the single-step simultaneous isolation of RNA, DNA and proteins from cell and tissue samples. Biotechniques 15, 532-4, 536-7.

Church G.M. and Gilbert W. (1984) Genomic sequencing. PNAS 81(7), 1991-1995.

Clark J.M. (1988) Novel non-templated nucleotide addition reactions catalyzed by procaryotic and eucaryotic DNA polymerases. Nucleic Acids Res 16, 9677-86.

Cokol M., Nair R. and Rost B. (2000) Finding nuclear localization signals. EMBO Rep. 1(5), 411-5.

Cranz S., Berger C., Baici A., Jelesarov I. and Bosshard H.R. (2004) Monomeric and dimeric bZIP transcription factor GCN4 bind at the same rate to their target DNA site. Biochemistry 43(3), 718-27.

Creighton T.E. (1993) Proteins. W.H. Freeman and Co. New York. 4(2), 327-341. 
Cutt J.R., Dixon D.C., Carr J.P. and Klessig (1988) Isolation and nucleotide sequence of cDNA clones for the pathogenesis-related proteins PR1a, PR1b and PR1c of Nicotiana tabacum cv Xanthi nc by TMV infection. Nucl. Acids Res. 16, 9861.

Després C., Chubak C., Rochon A., Clark R., Bethune T., Desveaux D. and Fobert P.R. (2003) The Arabidopsis NPR1 disease resistance protein is a novel cofactor that confers redox regulation of DNA binding activity to the basic domain/leucine zipper transcription factor TGA1. Plant Cell. 15(9), 2181-91.

Dharmasiri N., Dharmasiri S. and Estelle M. (2005) The F-box protein TIR1 is an Auxin receptor. Nature 435(7041), 441-5.

Dietrich R.A., Riechberg M.H., Schmidt R., Dean C. and Dangl J.L. (1997) Anovel zinc finger protein is encoded by the Arabidopsis LSD1 gene and functions as a negtive regulator of plant cell death. Cell 88, 685694.

Dong X. (2004) NPR1, all things considered. Curr Opin Plant Biol. 7(5), 547-52. Review.

Dower W.J., Miller J.F. and Ragsdale C.W. (1988) High efficiency transformation of E.coli by high voltage electroporation. Nucl. Acid Res. 16(13), 6127-6145.

Dröge-Laser W., Kaiser A., Lindsay W.P., Halkier B.A., Loake G.J., Doerner P., Dixon R.A. and Lamb C. (1997) Rapid stimulation of a soybean protein-serine kinase that phosphorylates a novel bZIP DNA-binding protein, G/HBF-, during the induction of early transcription-dependent defenses. EMBO 16 (4), 726-738.

Ehlert A., Weltmeier F., Wang X., Mayer C.S., Smeekens S., Vicente-Carbajosa J. and Droge-Laser W. (2006) Two-hybrid protein-protein interaction analysis in Arabidopsis protoplasts: establishment of a heterodimerization map of group C and group S bZIP transcription factors. Plant J. 46(5), 890-900.

Ellenberger T.E, Brandl C.J, Struhl K. and Harrison S.C. (1992) The GCN4 basic region leucine zipper binds DNA as a dimer of uninterrupted alpha helices: crystal structure of the protein-DNA complex. Cell. 71(7), 1223-37.

Fedorkin O., Solovyev A, Yelina N., Zamyatnin A. Jr, Zinovkin R., Makinen K., Schiemann J. and Yu Morozov S. (2001) Cell-to-cell movement of potato virus X involves distinct functions of the coat protein. J Gen Virol. 82(2), 449-58.

Feinberg A. P. and Vogelstein B. (1983) A technique for radiolabeling DNA restriction endonuclease fragments to high specific activity. Anal Biochem 132, 6-13.

Feinberg A. P. and Vogelstein B. (1984) A technique for radiolabeling DNA restriction endonuclease fragments to high specific activity. Addendum. Anal Biochem, 137, 266-7.

Feng W., Benko A.L., Lee J.H., Stanford D.R. and Hopper A.K. (1999) Antagonistic effects of NES and NLS motifs determine S. cerevisiae Rna1p subcellular distribution. J Cell Sci. 112 (Pt 3),339-47.

Fischer U., Huber J., Boelens W.C., Mattaj I.W. and Luhrmann R. (1995) The HIV-1 Rev activation domain is a nuclear export signal that accesses an export pathway used by specific cellular RNAs. Cell. $82(3), 475-83$.

Fobert P.R. and Després C. (2005) Redox control of systemic acquired resistance. Curr Opin Plant Biol. $8(4), 378-82$.

Fornerod M., Ohno M., Yoshida M. and Mattaj I.W. (1997) CRM1 is an export receptor for leucine-rich nuclear export signals. Cell. 90, 1051-1060.

Frankel A.D. and Kim P.S. (1991) Modular structure of transcription factors: implications for gene regulation. Cell 65(5), 717-9. 
Fridborg I., Grainger J., Page A., Coleman M., Findlay K. and Angell S. (2003) TIP, a novel host factor linking callose degradation with the cell-to-cell movement of Potato virus X. Mol Plant Microbe Interact. $16(2), 132-40$.

Fukazawa, J., Sakai, T., Ishida, S., Yamaguchi, I., Kamiya, Y. and Takahashi, Y. (2000) Repression of shoot growth, a bZIP transcriptional activator, regulates cell elongation by controlling the level of gibberellins. Plant Cell 12, 901-915.

Gasteiger E., Gattiker A., Hoogland C., Ivanyi I., Appel R.D. and Bairoch A. (2003) ExPASy: the proteomics server for in-depth protein knowledge and analysis. Nucleic Acids Res. 31, 3784-3788.

Gatz C., Frohberg C. and Wendenburg R. (1992) Stringent repression and homogeneous de-repression by tetracycline of a modified CaMV 35S promoter in intact transgenic tobacco plants. Plant J. 2(3), 397-404.

Ginger E., Varnum S.M. and Ptashne M. (1985) Specific DNA binding of GAL4, a positive regulatory protein of yeast. Cell 40, 767-774.

Görlich D. and Kutay U. (1999) Transport between the cell nucleus and the cytoplasm. Annu. Rev. Cell Dev. Biol. 15, 607-660.

Greenberg J.T. and Ausubel F.M. (1993) Arabidopsis mutants compromised for the control of cellular damage during pathogenesis and aging. The Plant Journal 4 (2), 327-341.

Guarente L., Yocum R.R., Gifford P. (1982) A GAL10-CYC1 hybrid yeast promoter identifies the GAL4 regulatory region as an upstream site. Proc.Natl.Acad.Sci. USA 79, 7410-7414.

Guilfoyle T.J., Ulmasov T. and Hagen G. (1998) The ARF family of transcription factors and their role in plant hormone-responsive transcription. Cell Mol Life Sci. 54(7), 619-27.

Haasen D., Köhler C., Neuhaus G. and Merkle T. (1999) Nuclear export of proteins in plants: AtXPO1 is the export receptor for leucine-rich nuclear export signals in Arabidopsis thaliana. Plant J. 20,695-705.

Hagen G. and Guilfoyle T. (2002) Auxin-responsive gene expression: genes, promoters and regulatory factors. Plant Mol Biol. 49(3-4), 373-85.

Haizel T., Merkle T., Pay A., Fejes E. and Nagy F. (1997) Characterization of proteins that interact with the GTP-bound form of the regulatory GTPase Ran in Arabidopsis. Plant J. 11(1), 93-103.

Hanahan D. (1983) Studies on transformation of Escherichia coli with plasmids. J. Mol. Biol. 166, 557-580.

Heinekamp T. (2002) Der bZIP-Transkriptionsfaktor BZI-1 aus Nicotiana tabacum: Analyse der in vivo Funktion durch Modulation der BZI-1-Aktivierungseigenschaften in transgenen Pflanzen. Dissertation, Universität Göttingen.

Heinekamp T., Kuhlmann M., Lenk A., Strathmann A. and Dröge-Laser W. (2002) The tobacco bZIP transcription factor BZI-1 binds to G-box elements in the promoters of phenylpropanoid pathway genes in vitro, but it is not involved in the regulation in vivo. Mol. Gen. Genom. 267(1), 16-26.

Hokema A., HirschP.R., Hooykaas P.J.J. and Schilperoort R.A. (1983) A binary plant vectorstrategy based on separation of vir and T-region of the Agrobacterium tumefaciens Ti-plasmid. Nature 303, 179-180.

Holden M. (1965) Chlorophylls. In: Chemistry and Biochemistry of Plant Pigments (T.W. Goodwin, ed.), Academic Press, New York, 461-488.

Hopp T.P., Prickett K.S., Price V.L., Libby R.T., March C.J., Cerretti D.P., Urdal D.L. and Conlon P.J. (1988) Ashort polypeptide marker sequence useful for recombinant protein identification and purification. Biotechnology 6, 1204- 1210.

Horiguchi G. (2004) RNA silencing in plants: a shortcut to functional analysis. Differentiation. 72(2-3),65. 
Horvay K. (2000) Isolierung und Analyse von Proteininteraktionspartnern des bZIP-Transkriptionsfaktors BZI-1 aus Nicotiana tabacum. Diplomarbeit, Universität Göttingen.

Hu C.D., Chinenov Y. and Kerppola T.K. (2002) Visualization of interactions among bZIP and Rel family proteins in living cells using bimolecular fluorescence complementation. Mol Cell 9(4), 789-98.

Huxford T., Huang D.B., Malek S. and Ghosh G. (1998) The crystal structure of the IkappaBalpha/NFkappB complex reveals mechanisms of NF-kappaB inactivation. Cell 95(6), 729-731.

Inoue H., Nojima H. and Okayama H. (1990) High efficiency transformation of Escherichia coli with plasmids. Gene 96, 23-28.

Ito H. and Gray W.M. (2006) A gain-of-function mutation in the Arabidopsis pleiotropic drug resistance transporter PDR9 confers resistance to auxinic herbicides. Plant Physiol. 142(1), 63-74.

Iven T. (2004) Funktionelle Charakterisierung der bZIP-Transkriptionsfaktoren BZI-2, BZI-3 und BZI-4 aus Nicotiana tabacum mittels RNA-Interferenz. Diplomarbeit.

Izawa T., Foster R. and Chua N.H. (1993) Plant bZIP protein DNA binding specificy. J. Mol. Biol. 230, 1131-1144.

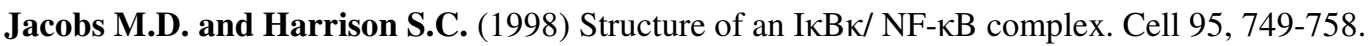

Jakoby M., Parcy F., Vicente-Carbajossa J., Tiedemann J., Kroj T., Dröge-Laser W. and Weisshaar B. (2002) The bZIP Research Group: bZIP transcription factors in Arabidopsis. Trends Plant Sci. 7(3) 106-111.

Jefferson R.A., Kavanagh T.A. and Bevan M.W. (1987) GUS fusions: betaglucuronidase as a sensitive and versatile gene fusion marker in higher plants. Embo J. 6, 3901-7.

Joo J.H., Yoo H.J., Hwang I., Lee J.S., Nam K.H. and Bae Y.S. (2005) Auxin-induced reactive oxygen species production requires the activation of phosphatidylinositol 3-kinase. FEBS Lett. 579(5), 1243-8.

Kaminaka H., Nake C., Epple P., Dittgen J., Schutze K., Chaban C., Holt B.F. 3rd, Merkle T., Schafer E., Harter K. and Dangl J.L. (2006) bZIP10-LSD1 antagonism modulates basal defense and cell death in Arabidopsis following infection. EMBO J. 25(18), 4400-11.

Keegan L., Gill G. and Ptashne M. (1986) Separation of DNA binding from the transcription-activating function of a eukaryotic regulatory protein. Science 231(4739), 699-704.

Keller C.P. and Van Volkenburgh E. (1997) Auxin-Induced Epinasty of Tobacco Leaf Tissues (A Nonethylene-Mediated Response). Plant Phys. 113, 603-610.

Kimura M. (1983) The neutral Theory of Molecular Evolution. Camb.Univ.Press, 1983, p.75.

Kirby J. and Kavanagh T.A. (2002) NAN fusions: a synthetic sialidase reporter gene as a sensitive and versatile partner for GUS. Plant J. 32(3),391-400.

Kondo H. and Ushiki T. (1985) Polyethylene glycol (PEG) embedding and subsequent de-embedding as a method for the correlation of light microscopy, scanning electron microscopy, and transmission electron microscopy. Journal of Electron Microscopy Technique 2, 457-462.

Krylov D., Olive M. and Vinson C. (1995) Extending dimerization interfaces: the bZIP basic region can form a coiled coil. EMBO J. 14(21), 5329-37.

Kudo N., Matsumori N., Taoka H., Fujiwara D., Schreiner E.P., Wolff B., Yoshida M. and Horinouchi S. (1999) Leptomycin B inactivates CRM1/exportin 1 by covalent modification at a cysteine residue in the central conserved region. Proc Natl Acad Sci USA. 96, 9112-9117. 
Kudo N., Wolff B., Sekimoto T., Schreiner E.P., Yoneda Y., Yanagida M., Horinouchi S. and Yoshida M. (1998) Leptomycin B inhibition of signal-mediated nuclear export by direct binding to CRM1. Exp Cell Res. 242, 540-547.

Kuhlmann M. (2002) Charakterisierung der konservierten Domänen des Transkriptionsfaktors N.t.BZI-1. Dissertation Universität Göttingen.

Kuhlmann M., Horvay K., Strathmann A., Heinekamp T., Fischer U., Böttner S. and Dröge-Laser W. (2003) The $\alpha$-helical D1 domain of the tobacco bZIP transcription factor BZI-1 interacts with the ankyrinrepeat protein ANK1, and is important for BZI-1 function, both in auxin signalling and pathogen response. JBC 278(10), 8786-94.

Kyhse-Andersen J. (1984) Electroblotting of multiple gels: A simple apparatus without buffer tank for rapid transfer of proteins from polyacrylamide to nitrocellulose. J. Biochem. Biophys. Meth. 10, 203-209.

la Cour T., Kiemer L., Mølgaard A., Gupta R., Skriver K. and Brunak S. (2004) Analysis and prediction of leucine-rich nuclear export signals. Protein Eng Des Sel. 17(6), 527-36.

Laemmli U.K. (1970) Cleavage of structural proteins during the assembly of the head of bacteriophage T4. Nature 227, 690-685.

Landschulz W.H., Johnson P.F. and McKnight S.L. (1988) The leucin zipper: a hypothetical structure common to a new class of DNA binding proteins. Science 240, 1759-1764.

Lang G. (2006) Einbettungsprozess (Tissue processing). Histotechnik 86-122.

Le Gouill C., Parent J.-L., Rola-Pleszczynski M. and Stankova J. (1994) Analysis of recombinant plasmids by a modified alkaline lysis method. Anal. biochem. 219, 164.

Lee B.J., Cansizoglu A.E., Suel K.E., Louis T.H., Zhang Z. and Chook Y.M. (2006) Rules for nuclear localization sequence recognition by karyopherin beta 2. Cell 126(3), 543-58.

Lin J.H., Makris A., McMahon C., Bear S.E., Patriotis C., Prasad V.R., Brent R., Golemis E.A. and Tsichlis P.N. (1999) The ankyrin repeat-containing adaptor protein Tvl-1 is a novel substrate and regulator of Raf-1. J Biol Chem. 274(21), 14706-15.

Lincoln C., Britton J.H. and Estelle M. (1990) Growth and development of the axr1 mutants of Arabidopsis. Plant Cell 2(11), 1071-80.

Liu Z.-B., Hagen G. and Guilfoyle T.J. (1997) A G-Box-Binding Protein from Soybean Binds to the E1 Auxin-Response Element in the Soybean GH3 Promoter and Contains a Proline-Rich Repression Domain. Plant Physiol. 115, 397-407.

Liu Z.-B., Ulmasov T., Shi X., Hagen G. and Guilfoyle T.J. (1994) Soybean GH3 promotor contains multiple auxin-inducible-elements. Plant Cell \&, 645-657.

Ma J. and Ptashne M. (1987). A new class of yeast transcriptional activators. Cell 51, 13-19.

Maniattis T., Fritsch E.F. and Sambrook J. (1982) Moleclar Cloning. New York: Cold Spring Laboratory Press.

McDonell M.W., Simon M.N. and Studier F.W. (1977) Analysis of restriction fragments of T7 DNA and determination of molecular weights by electrophoresis in neutral and alkaline gels. J Mol Biol 110, 119-46.

Michaely P. and Bennett V. (1992) The ANK repeat: a ubiquitous motif involved in macromolecular recognition. Trends Cell Biol. 2, 127-129.

Mittler R., Feng X. and Cohen M. (1998) Post-transcriptional suppression of cytosolic ascorbate peroxidase expression during pathogen-induced programmed cell death in tobacco. Plant Cell 10, 461-474. 
Mittler R., Herr E.H., Orvar B.L., van Camp W., Willekens H., Inze D. and Ellis B.E. (1999) Transgenic tobacco plants with reduced capability to detoxify reactive oxygen intermediates are hyperresponsive to pathogen infection. Proc Natl Acad Sci USA 96(24), 14165-70.

Mosavi L.K., Minor D.L. Jr and Peng Z.Y. (2002) Consensus-derived structural determinants of the ankyrin repeat motif. Proc Natl Acad Sci USA. 99(25), 16029-34.

Mosavi L.K., Williams S. and Peng Z.Y. (2002) Equilibrium folding and stability of myotrophin: a model ankyrin repeat protein. J Mol Biol. 320(2), 165-70.

Mou Z., Fan W. and Dong X. (2003) Inducers of plant systemic acquired resistance regulate NPR1 function through redox changes. Cell. 113(7), 935-44.

Mulder N.J., Apweiler R., Attwood T.K., Bairoch A., Bateman A., Binns D., Bork P., Buillard V., Cerutti L., Copley R., Courcelle E., Das U., Daugherty L., Dibley M., Finn R., Fleischmann W., Gough J., Haft D., Hulo N., Hunter S., Kahn D., Kanapin A., Kejariwal A., Labarga A., Langendijk-Genevaux P.S., Lonsdale D., Lopez R., Letunic I., Madera M., Maslen J., McAnulla C., McDowall J., Mistry J., Mitchell A., Nikolskaya A.N., Orchard S., Orengo C., Petryszak R., Selengut J.D., Sigrist C.J., Thomas P.D., Valentin F., Wilson D., Wu C.H. and Yeats C. (2007) New developments in the InterPro database. Nucleic Acids Res. 35, D224-8.

Mullis K.B. and Faloona F.A. (1987) Specific synthesis of DNA in vitro via a polymerase-catalyzed chain reaction. Methods Enzymol. 155, 335-350.

Murashige T. and Skoog F. (1962) A revised medium for rapid growth and bioassays with tobacco tissue cultures. Physiol Plant 15, 473-497.

Navarro L., Dunoyer P., Jay F., Arnold B., Dharmasiri N., Estelle M., Voinnet O. and Jones J.D. (2006) A plant miRNA contributes to antibacterial resistance by repressing auxin signaling. Science 312(5772), 436-9.

Nemhauser J.L., Zambryski P.C. and Roe J.L. (1998) Auxin signalling in Arabidopsis flower development. Curr.Opin.Plant.Biol. 1, 531-535.

Niggeweg R. (1999) Salizylsäure- und Auxin-induzierte Genexpression in Nicotiana tabacum: Funktionelle Bedeutung der TGA-Faktoren der Subklasse II. Dissertation, Universität Bielefeld.

O'Shea E.K., Rutkowski R. and Kim P.S. (1989) Evidence that the leucine zipper is a coiled coil. Science $243,538-542$.

Okushima Y., Overvoorde P.J., Arima K., Alonso J.M., Chan A., Chang C., Ecker J.R., Hughes B., Lui A, Nguyen D., Onodera C., Quach H, Smith A., Yu G. and Theologis A. (2005) Functional genomic analysis of the AUXIN RESPONSE FACTOR gene family members in Arabidopsis thaliana: unique and overlapping functions of ARF7 and ARF19. Plant Cell. 17(2), 444-63.

Padmanabhan M.S., Goregaoker S.P., Golem S., Shiferaw H. and Culver J.N. (2005) Interaction of the tobacco mosaic virus replicase protein with the Aux/IAA protein PAP1/IAA26 is associated with disease development. J Virol. 79(4), 2549-58.

Padmanabhan M.S., Shiferaw H. and Culver J.N. (2006) The Tobacco mosaic virus replicase protein disrupts the localization and function of interacting Aux/IAA proteins. Mol Plant Microbe Interact. 19(8), 864-73.

Peck S.C., Nuhse T.S., Hess D., Iglesias A., Meins F. and Boller T. (2001) Directed Proteomics Identifies a Plant-Specific Protein Rapidly Phosphorylated in Response to Bacterial and Fungal Elicitors. Plant Cell 13 $1467-1475$

Ptashne M. (1988) How eukaryotic transcriptional activators work. Nature 335(6192), 683-9.

Ptashne M. (1989) How gene activators work. Sci.Am. 260(1), 40-47. 
Pysh L.D., Aukermann M.J. and Schmidt R.J. (1993) OHP1: a maize basic domain/leucine zipper protein that interacts with Opaque2. Plant Cell 5, 227-236.

Rechsteiner M. and Rogers S.W. (1996) PEST sequences and regulation by proteolysis Trends Biochem. Sci 21, 267-271.

Rhode K. and Bork P. (1993) A fast, sensitive pattern-matching approach for protein sequences. CABIOS 9, 183-189.

Riechmann J.L. and Ratcliffe O.J. (2000) A genomic perspective on plant transcription factors. Cur. Opin. Plant Biol. 3, 423-434.

Riechmann J.L., Heard J., Martin G., Reuber L., Jiang C., Keddie J., Adam L., Pineda O., Ratcliffe O.J., Samaha R.R., Creelman R., Pilgrim M., Broun P., Zhang J.Z., Ghandehari D., Sherman B.K. and Yu G. (2000) Arabidopsis transcription factors: genome-wide comparative analysis among eukaryotes. Science 290(5499), 2105-10.

Robert-Seilaniantz A., Navarro L., Bari R. and Jones J.D. (2007) Pathological hormone imbalances. Curr Opin Plant Biol. 10(4), 372-9.

Rook F., Weisbeck P.P. and Smeekens S. (1998) The light-regulated Arabidopsis bZIP transcription factor ATB2 encodes a protein with an unusually long leucine zipper domain. Plant Mol Biol. 37, 171-178.

Roux C. and Perrot-Rechenmann C. (1997) Isolation by differential display and characerization of a tobacco auxin-responsive cDNA Nt-gh3, related to GH3. FEBS Letter 419, 131-136.

Rügner A., Frohnmeyer H., Näke C., Wellmer F., Kircher S., Schäfer E. and Harter K. (2001) Isolation and characterization of four novel parsley proteins that interact with the transcriptional regulators CPRF1 and CPRF2. Mol Genet Genomics. 265(6), 964-76.

Sambrook J. and Russell D.W. (2001) Molecular cloning: A laboratory manual. $3^{\text {rd }}$ edn. Cold Spring Habor Laboratory Press. Cold Spring Habor, New York.

Sambrook, Fritsch and Maniatis (1989) Molecular cloning: A Laboratory Manual. Cold Spring Habor LaboratoryPress.

Sanger F., Nickler S. and Coulson A.R. (1977) DNA-Sequencing with chain-terminating inhibitors. Proc. Natl. Acad. Sic. USA 74, 5463-5467.

Schäffer A.A., Aravind L., Madden T.L., Shavirin S., Spouge J.L., Wolf Y.I., Koonin E.V. and Altschul S.F. (2001) Improving the accuracy of PSI-BLAST protein database searches with composition-based statistics and other refinements. Nucleic Acids Res. 29, 2994-3005.

Schmid J., Doerner P.W., Clouse S.D., Dixon,R.A. and Lamb C.J. (1990) Developmental and environmental regulation of a bean chalcon synthase promoter in transgenic tobacco. Plant Cell 2, 619-631.

Schmidt R.J., Ketudat M., Aukerman M.J. and Hoschek, G. (1992) Opaque-2 is a transcriptional activator that recognizes a specific target site in 22-kD zein genes. Plant Cell 4, 689-700.

Schopfer P. and Liszkay A. (2006) Plasma membrane-generated reactive oxygen intermediates and their role in cell growth of plants. Biofactors 28(2), 73-81.

Sedgwick S.G. and Smerdon S.J. (1999) The ankyrin repeat: a diversity of interactions on a common strucural framework. Trends Biochem. Sci. 24(8), 311-316.

Smith H. O. and Wilcox K. W. (1970) A restriction enzyme from Hemophilus influenzae. Purification and general properties. J Mol Biol 51, 379-91.

Southern E.M. (1979) Measurement of DNA length by gel electrophoresis. Anal Biochem 100, 319-23. 
Sprenger-Haussels M. and Weisshaar B.: Transactivation properties of parsley proline-rich bZIP transcription factors. Plant J. 22(1) 1-8 (2000)

Strathmann A. (2003) Charakterisierung der Nicotiana tabacum bZIP-Transkriptionsfaktoren BZI-2, BZI-3 und BZI-4 als Heterodimerisierungspartner von BZI-1. Dissertation.

Strathmann A., Kuhlmann M., Heinekamp T. and Dröge-Laser W. (2002) BZI-1 specifically heterodimerises with the tobacco bZIP transcription factors BZI-2, BZI3/TBZF and BZI-4, and is functionally involved in flower development. Plant J. 28(4), 397-408.

Teale W.D., Paponov I.A. and Palme K. (2006) Auxin in action: signalling, transport and the control of plant growth and development. Nat Rev Mol Cell Biol 7(11), 847-59.

Tiwari SB, Hagen G, Guilfoyle T. (2003) The roles of auxin response factor domains in auxin-responsive transcription. Plant Cell. 15(2), 533-43.

Ulmasov T., Liu Z.-B., Hagen G. and Guilfoyle T.J. (1995) Composite structure of Auxin Response Elements. Plant Cell 7, 1611-1623.

Ulmasov T., Murfett J., Hagen G. and Guilfoyle T.J. (1997) Aux/IAA proteins repress expression of reporter genes containing natural and highly active synthetic auxin response elements. Plant Cell. 9(11), 1963-71.

Van der Heijden (2002) Alfalfa Mosaic Virus RNA Polymerase: Analysis of Viral and Host Proteins in the Replication Complex. PhD-thesis.

van der Krol A.R. and Chua N.H. (1991) The basic domain of plant B-ZIP proteins facilitates import of a reporter protein into plant nuclei. Plant Cell. 3(7), 667-75.

Venkataramani S., Yan J., Wang J., Narendra S., Zhang H.: The role of AKR2 in plant disease resistance and in antioxidation. PosterAbstract American Society of Plant Biologists.

Vincentz M., Bandeira-Kobarg C., Gauer L., Schlogl P. and Leite A. (2003) Evolutionary pattern of angiosperm bZIP factors homologous to the maize Opaque2 regulatory protein. J Mol Evol. 56(1), 105-16.

Vinson C.R., Sigler P.B. and McKnight S.L. (1989) Scissors-grip model for DNA recognition by a family of leucine zipper proteins. Science 246, 911-916.

Voinnet O., Rivas S., Mestre P. and Baulcombe D. (2003) An enhanced transient expression system in plants based on suppression of gene silencing by the p19 protein of tomato bushy stunt virus. Plant J. 33(5), 949-56.

Walter M., Chaban C., Schütze K., Batistic O., Weckermann K., Näke C., Blazevic D., Grefen C., Schumacher K., Oecking C., Harter K. and Kudla J. (2004) Visualization of protein interactions in living plant cells using bimolecular fluorescence complementation. Plant J. 40(3), 428-38

Waterhouse P.M., Graham M.W. and Wang M.B. (1998) Virus resistance and gene silencing in plants can be induced by simultaneous expression of sense and antisense RNA. Proc Natl Acad Sci USA. 95(23), $13959-64$

Weisshaar B., Armstrong G.A., Block A., daCosta e Silva O. and Hahlbrock K. (1991) Light-inducible and constitutivley expressed DNA-binding proteins recognizing a plant promotor element with functional relevance in light response. EMBO J. 10(7), 1777-1786.

Weltmeier F., Ehlert A., Mayer C.S., Dietrich K., Wang X., Schutze K., Alonso R., Harter K., VicenteCarbajosa J. and Droge-Laser W. (2006) Combinatorial control of Arabidopsis proline dehydrogenase transcription by specific heterodimerisation of bZIP transcription factors. EMBO J. 25(13), 3133-43.

Wen W., Meinkoth J.L., Tsien R.Y. and Taylor S.S. (1995) Identification of a signal for rapid export of proteins from the nucleus. Cell 82, 463-473. 
Went F. (1926) On growth accelerating substances in the coleoptile of Avena sativa. Proc.K.Akad.Wetensch. Amsterdam 30, 10- 19.

Wiese A., Elzinga N., Wobbes B. and Smeekens S. (2004) A conserved upstream open reading frame mediates sucrose-induced repression of translation. Plant Cell. 16(7), 1717-29.

Wirdnam C., Motoyama A., Arn-Bouldoires E., van Eeden S., Iglesias A. and Meins F. Jr. (2004) Altered expression of an ankyrin-repeat protein results in leaf abnormalities, necrotic lesions, and the elaboration of a systemic signal. Plant Mol Biol. 56(5), 717-30.

Witte C.P., Noël L.D., Gielbert J., Parker J.E. and Romeis T. (2004) Rapid one-step protein purification from plant material using the eight-amino acid StrepII epitope. Plant Mol Biol. 55(1), 135-47.

Wobbes B. (2004) Control of plant carbohydrate partitioning by the Arabidopsis thaliana ATB2 bZIP transcription factor gene. $\mathrm{PhD}$ thesis.

Woodward A.W. and Bartel B. (2005) Auxin: regulation, action, and interaction. Ann Bot (Lond). 95(5), 707-35.

Xia G., Ramachandran S., Hong Y., Chan Y.S., Simanis V. and Chua N.H. (1996) Identification of plant cytoskeletal, cell cycle-related and polarity-related proteins using Schizosaccharomyces pombe. Plant J. 10(4),761-9.

Yalpani N., Silvermann P., Wilson T.M., Kleier D.A. and Raskin I. (1991) Salicylic acid is a systemic signal and an inducer of pathogenesis-related proteins in virus-infected tobacco. Plant Cell 3(8) 809-818.

Yan J., Wang J. and Zhang H. (2002) An ankyrin repeat-containing protein plays a role in both disease resistance and antioxidation metabolism. Plant Journal 29 (2), 193-202.

Yang S.H., Berberich T., Sano H. and Kusano T. (2001) Specific association of transcripts of tbzF and tbz17, tobacco genes encoding basic region leucine zipper-type transcriptional activators, with guard cells of senescing leaves and/or flowers. Plant Physiol. 127(1), 23-32.

Zhang Y., Fan W., Kinkema M., Li X. and Dong X. (1999)Free in PMC Interaction of NPR1 with basic leucine zipper protein transcription factors that bind sequences required for salicylic acid induction of the PR-1 gene. Proc Natl Acad Sci U S A. 96(11), 6523-8.

Zwafink T. (2005) Die BZI-Transkriptionsfaktoren aus Tabak (Nicotiana tabacum): Aktivierungseigenschaften, Heterodimerisierung, Zielgene und Funktion. Diplomarbeit. 


\section{Anhang}

\subsection{Abkürzungsverzeichnis}

\subsubsection{Allgemeine Abkürzungen}

4-MUG 4-Methylumbelferyl- $\beta$-D-Glucuronid

$\mathrm{AD}$

Aktivierungsdomäne (von GAL4)

Amp

ARF

At

Ampicillin (resistent)

ATP , auxin responsive factor'

AuxREs

Arabidopsis thaliana

BD

Adenosintriphosphat

, auxin responsive element'

bidest.

Bindedomäne (von GAL4)

bidestilliert

$\mathrm{bp}$

'Bimolecular Fluorescence Complementation'

$\mathrm{BPB}$

Basenpaare

bZIP

Bromphenolblau

bZIP-TF

basischer Leucin-Zipper

bzw.

ca. basischer Leucinzipper Transkriptionsfaktor beziehungsweise

CaMV

circa

cDNA

'cauliflour mosaic virus'

CE

komplementäre DNA

ChIP

C-terminale Fragment von YFP

d.h. Chromatin Immunopräzipitation

ddNTPs

das heißt

DNA

Didesoxyribonucleotide

dNTP

Desoxyribonukleinsäure

E. coli

Desoxyribonukleotide

ECL

Escherichia coli

EDTA

Enhanced Chemilumineszenz

EMSA

et al.

Ethylendiamintetraessigsäure

Gelretardationsanalyse ('electro mobility shift assay')

etc.

Ethidiumbromid

$\mathrm{EtOH}$

und so weiter (et cetera)

Glycine max

GUS $\quad \beta$-Glucuronidase

GUS $\quad . \beta$-Glucuronidase

$\mathrm{H}_{2} \mathrm{O} \quad$ Wasser

$\mathrm{HCl} \quad$ Salzsäure

HEPES 2-[4-(2-Hydroxyethyl)-1-piperazino]-ethansulfonsäure

HMM ,Hidden Markov Models'

HR

Hypersensitive Reaktion ('hypersensitive response')

IAA Indol-3-Essigsäure 


\begin{tabular}{|c|c|}
\hline IPTG & Isopropylthiogalactosid \\
\hline JA & Jasmonsäure \\
\hline $\mathrm{kb}$ & kilo Basen(paare) \\
\hline $\mathrm{kDa}$ & Kilodalton \\
\hline LB & Luria-Bertani Broth \\
\hline LMB & Leptomycin B \\
\hline $\mathrm{MgCl}_{2}$ & Magnesiumchlorid \\
\hline $\min$ & Minuten \\
\hline MOPS & Morpholinopropansulfonsäure \\
\hline MP30 & 'movement protein 30 ' \\
\hline mRNA & messenger RNA \\
\hline $\mathrm{NaCl}$ & Natriumchlorid \\
\hline NAN & Neuraminidase \\
\hline $\mathrm{NE}$ & N-terminale Fragment von YFP \\
\hline NLS & ,nuclear localisation sequence' \\
\hline NN & ,Artifical Neuronal Network' \\
\hline$N t$ & Nicotiana tabacum \\
\hline o. g. & oben genannten \\
\hline $\mathrm{OD}$ & optische Dichte \\
\hline OEX & überexprimierend \\
\hline ORF & offener Leserahmen (,Open Reading Frame’) \\
\hline $\mathrm{P} 2 \mathrm{H}$ & Protoplasten ,Two-Hybrid' \\
\hline PAGE & Polyacrylamidgelelektrophorese \\
\hline PCR & Polymerasekettenreaktion ('Polymerase Chain Reaction') \\
\hline $\mathrm{pH}$ & negativ dekadischer Logarithmus der Protonenkonzentration \\
\hline PIPES & 1,4-Piperazin-bis-(ethansulfonsäure) \\
\hline PVDF & Polyvinylendifluorid \\
\hline PVX & 'potato virus $\mathrm{X}$ ' \\
\hline RNA & Ribonukleinsäure \\
\hline RNAi & RNA-Interferenz \\
\hline Rnase & Ribonuclease \\
\hline $\mathrm{rpm}$ & Umdrehungen pro Minute (,rounds per minute') \\
\hline RT & Raumtemperatur \\
\hline SDS & Natriumdodecylsulfat (, sodiumdodecylsulfate') \\
\hline Sek. & Sekunden \\
\hline SEL & , sice exclusion limit' \\
\hline ss & einzelsträngig (,single stranded') \\
\hline SSC & Standard Saline Citrat Puffer \\
\hline $\mathrm{t}$ & Reaktionszeit \\
\hline Taq & Thermus aquaticus (DNA-Polymerase aus T. aquaticus) \\
\hline $\mathrm{TBE}$ & Tris-Borat-EDTA-Puffer \\
\hline TBS & Tris buffered saline \\
\hline T-DNA & Transfer-DNA \\
\hline $\mathrm{TE}$ & Tris-EDTA-Puffer \\
\hline $\mathrm{Tm}$ & Schmelztemperatur \\
\hline TMV & Tabak Mosaik Virus \\
\hline TPI & Trypsin Protease Inhibitor \\
\hline Tris & Tris(hydroxymethyl)aminomethan \\
\hline u. a. & unter anderem \\
\hline ü.N. & über Nacht \\
\hline
\end{tabular}




$\begin{array}{ll}\text { uORF } & \text { upstream open reading frame (offenes Leseraster im 5'-UTR) } \\ \text { UTR } & \text { untranslatierte Region } \\ \text { UV } & \text { Ultraviolettes Licht } \\ \text { v/v } & \text { Volumenprozent (, volume per volume') } \\ \text { Vol. } & \text { Volumen } \\ \text { w/v } & \text { Gewichtsprozent (, weight per volume') } \\ \text { WT } & \text { Wildtyp } \\ \text { X-Gal } & \text { 5-Brom-4-chlor-3-indolyl- } \beta \text {-D-galactopyranosid } \\ \text { Y2H } & \text { Yeast 'Two-Hybird' } \\ \text { YFP } & \text {,Yellow Fluorescence Protein' } \\ \text { z. B. } & \text { zum Beispiel } \\ \text { z. T. } & \text { zum Teil } \\ \lambda & \text { Bakteriophage Lambda }\end{array}$

\subsubsection{Einheiten}

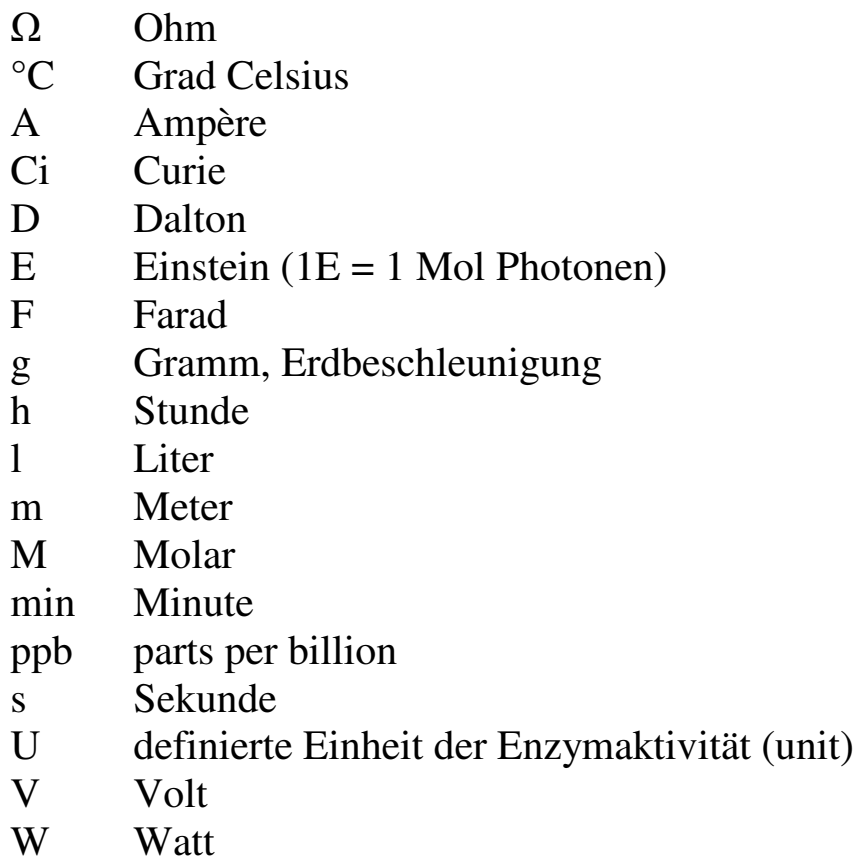

\subsubsection{Aminosäuren}
A Alanin
C Cystein
D Asparaginsäure
E Glutaminsäure
F Phenylalanin
G Glycin
$\mathrm{H} \quad$ Histidin
I Isoleucin
K Lysin
L Leucin
M Methionin
$\mathrm{N}$ Asparagin
$\mathrm{P} \quad$ Prolin 
$\begin{array}{ll}\text { Q } & \text { Glutamin } \\ \text { R } & \text { Arginin } \\ \text { S } & \text { Serin } \\ \text { T } & \text { Threonin } \\ \text { V } & \text { Valin } \\ \text { W } & \text { Tryptophan } \\ \text { Y } & \text { Tyrosin }\end{array}$

\subsubsection{Nukleotide}
A Adenosin
C Cytosin
G Guanosin
$\mathrm{T}$ Thymin
U Uracil

\subsubsection{Präfixe}

$\begin{array}{lll}\mathrm{k} & \text { kilo } & \left(10^{3}\right) \\ \mathrm{m} & \text { milli } & \left(10^{-3}\right) \\ \mu & \text { mikro } & \left(10^{-6}\right) \\ \mathrm{n} & \text { nano } & \left(10^{-9}\right) \\ \mathrm{p} & \text { pico } & \left(10^{-12}\right)\end{array}$




\section{Danksagung}

Und zu guter Letzt möchte ich alle, die mich bei meiner Doktorarbeit unterstützt haben, erwähnen.

Als erstes währe da PD Dr. Wolfgang Dröge-Laser zu nennen, dem ich für die Betreuung und Motivation während der gesamten Zeit danke. Frau Professor Gatz möchte ich für die Aufnahme in die Arbeitsgruppe und für die Begutachtung der Arbeit danken.

Allen Mitarbeitern der Abteilung Gatz gilt natürlich auch ein großes Dankeschön für alles was sie für mich getan oder auch nicht getan haben. Corinna ist zu erwähnen, die immer ein offenes Ohr für eine Frage hat und donnerstags um 19:00 nach Hause muss.

Besonders zu erwähnen sind auch unsere TAs Anna und Ronald die beide für mich die eine oder andere Kleinigkeit erledigt haben und ohne die diese Arbeit nicht zustande gekommen wäre. Auch die Gärtner haben meinen Arbeitsalltag sehr erleichtert, wofür ich ihnen danke.

Die mikroskopischen Arbeiten wurden in den Abteilungen von Herrn Prof. Friedl und Herrn PD. Schu durchgeführt. Die Arbeiten am Mikrotom wurden in der Abteilung von Herrn Prof. Leuschner durchgeführt, wofür ich mich bei ihnen allen bedanke. Hier ist auch Boris zu erwähnen, der mir nicht nur im fremden Labor zur Seite stand, sondern auch regelmäßig beim Altherrensport.

Meine Labormitstreiter Tim, der durch das Feuer ging, Katrin ohne Worte, unseren kleinen Christoph, die Protofrau Andrea, unsere Mutter Caroline C und Inken, unsere jüngste möchte ich hier besonders erwähnen, da sie mich in guten wie in schlechten Zeiten ertragen mussten. Und übrigens: Über Musik lässt sich nicht streiten! Von den Alten möchte ich hier nur den Fridtjof erwähnen, der dies sowieso nicht lesen wird, da er zu viel arbeitet.

Meinen größten Dank möchte ich am Ende an meine Eltern richten, die mich immer unterstützt haben, sowie an meine Freunde, die mir immer zu Seite standen. Und zu guter Letzt natürlich meiner Freundin Katrin, die immer für mich da ist und die all die Sachen, die ich geschrieben habe, korrigiert hat. Ohne sie hätte ich die Arbeit in der kurzen Zeit nie beenden können. 


\section{Lebenslauf:}

\section{Persönliche Daten:}

Name: $\quad$ Stefan Böttner

Geburtsdatum: $\quad 12.01 .1977$

Staatsangehörigkeit: deutsch

08/1983-07/1987: Mittelpunkt Grundschule Abterode

08/1987-07/1993: Brüder-Gimm Realschule Eschwege

08/1993-07/1996: Oberstufengymnasium Eschwege

08/1986-08/1997: Zivildienst im Seniorenzentrum Göttingen

10/1997 Beginn des Diplomstudiengangs Biologie an der Universität Göttingen

06/2002-03/2003: Diplomarbeit ,Funktionelle Charakterisierung des Ankyrin-DomänenProteins ANK1 aus Nicotiana tabacum'

04/2003-10/2003: Wissenschaftlicher Mitarbeiter der Abteilung Allgemeine und Entwicklungsphysiologie der Pflanze

11/2003 Beginn der Dissertation: ,Funktionale Bedeutung der Protein-Protein Interaktion zwischen dem Tabak Ankyrin-Repeat Protein ANK1 und dem bZIP-Transkriptionsfaktor BZI-1 im Rahmen der pflanzlichen Auxin- und Pathogenantwort' 